\title{
A services operations performance measurement framework for multimodal logistics gateways in emerging megaregions
}

\section{Dimitrios Paraskevadakis}

\begin{abstract}
A thesis submitted in partial fulfilment of the requirements of Liverpool John Moores University for the degree of Doctor of Philosophy.
\end{abstract}

July 2015 


\begin{abstract}
Gateways in emerging megaregions have the available transport infrastructure that could support modal shift and sustainable development and more could be made of them. A gateway is not a defined administration area but rather a functional economic area. Typically it has some port, airport, rail hub and logistics clusters and is key to the regional economy. Existing policies try to achieve an optimisation of the performance of multimodal logistic chains and transport infrastructure, including making greater use of inherently more resource efficient modes, where other technological innovations may be insufficient (e.g. long-distance freight). Emerging megaregions rely heavily on global logistics operations to supply their population, the majority of which is living in metropolitan areas with a higher concentration of greenhouse gases and a heavy concentration of multiple-layer logistics and transport operations, and other urban functions.
\end{abstract}

To address these issues, there is a need for more efficient traffic management solutions, a stronger shift away from road transportation towards more environmentally friendly modes both for freight and for passengers but most importantly the adoption of an integrated methodological approach when assessing existing and planned transport infrastructure by the decision makers with respect to sustainable development. This research provides a novel approach to the literature of performance evaluation of modal shift and transport infrastructure service quality by capturing the involved stakeholders' perceptions and expectations. The application and combination of the importanceperformance analysis (IPA) and analytical hierarchical process (AHP) model in an intermodal transport infrastructure regional case study provides a straightforward methodology for the assessment of sustainable development as a result of an industrial survey. In addition added value is provided to the literature for long term scenarios' planning for sustainable transport infrastructure.

Keywords: Logistics gateways, megaregions, modal shift, transport infrastructure, service operations management, sustainable development. 


\section{Acknowledgements}

Firstly, I would like to thank my first supervisor Dr Jun Ren for his valuable suggestions and guidance during all stages of writing this thesis. Many thanks are also given to the director of the Logistics, Offshore and Marine Research Institute (LOOM) Professor Jin Wang and Dr Steve Bonsall for their friendship, patience and encouragement all these years.

I am grateful also to the head of the department of Maritime and Mechanical Engineering at Liverpool John Moores University Professor Ian Jenkinson for supporting my $\mathrm{PhD}$ scholarship. I must also express my appreciation to my colleagues in LOOM, Alan Bury, Andrew John and Dennis Atehnjia who have been of great support.

Lastly, I am indebted to my wife Katerina and to my parents Apostolos and Zografia for their endless love and full support. Their understanding and faith in me have helped me through this difficult and challenging time. 
Table of Contents

Abstract .. $\mathrm{i}$

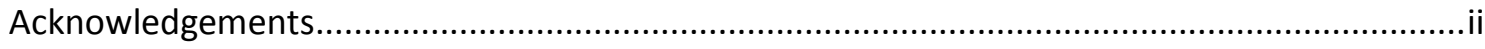

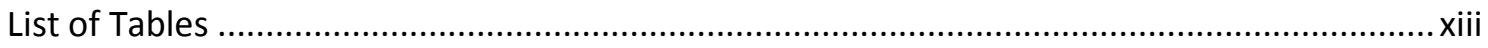

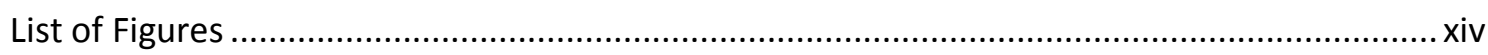

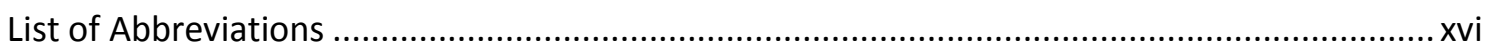

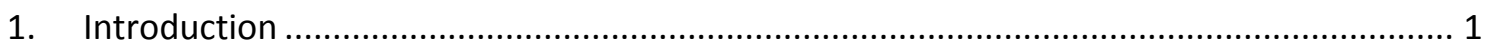

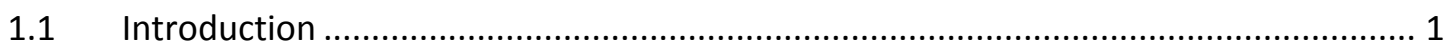

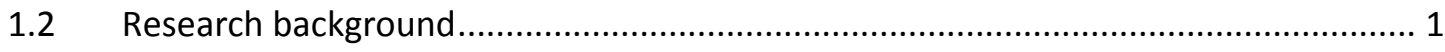

1.3 Scope of this research and statement of the problem .............................................. 2

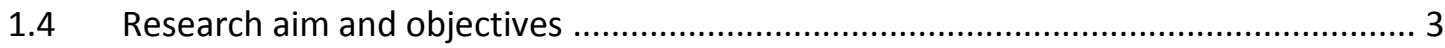

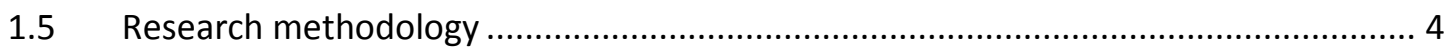

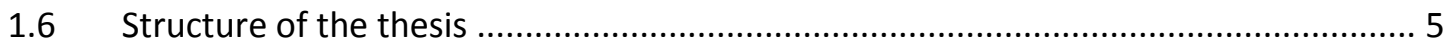

2. Literature review on service quality and transport logistics .......................................... 8

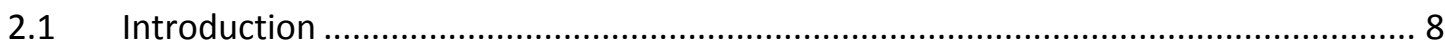

2.2 The service concept and the evolution of the service operations management

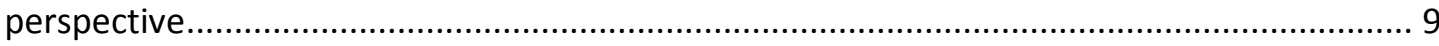

2.2.1 The service encounter and the servicescape concept ...................................... 11

2.2.2 Service quality as a major service encounter competitive component............. 12

2.2.2.1 Differences between goods and services ................................................. 13

2.2.3 Service quality management issues ............................................................ 13

2.2.3.1 Customers' perception of service quality ..................................................... 15

2.2.3.2 Personal factors' influence on perception of service quality ........................ 17

2.2.3.3 Customers' expectations of service quality ................................................ 18

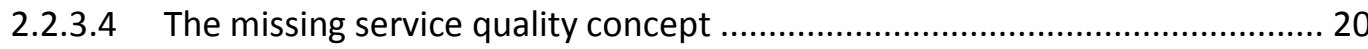

2.3 The need for integrated service management in transport and logistics................... 21

2.4 Emerging megaregions and logistics gateways.................................................... 22

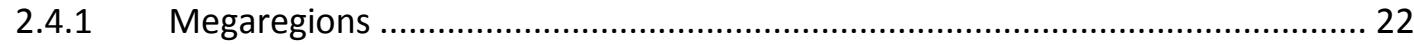

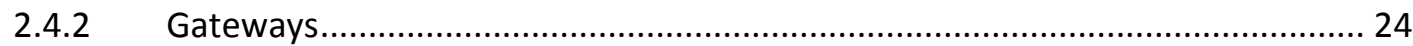

2.5 Challenges of planning for sustainable transport infrastructure............................... 27

2.5.1 Development of sustainable transport infrastructure in regional logistics gateways 30

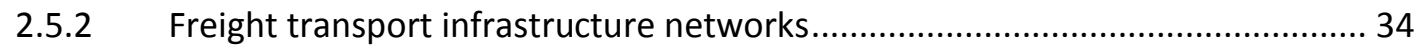

2.5.3 Intermodal transport and the vision of co-modality ........................................... 35 
2.6 Performance evaluation gaps of critical priority transport infrastructure projects in regional logistics gateways .............................................................................. 41

2.7 The need for an integrated evaluation methodology........................................ 42

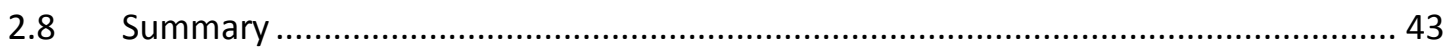

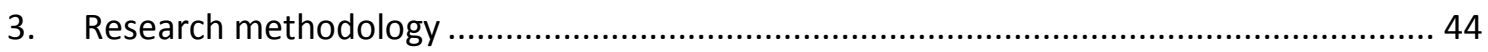

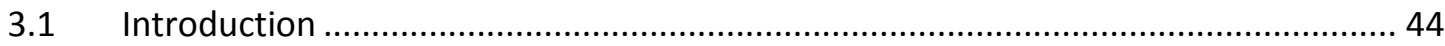

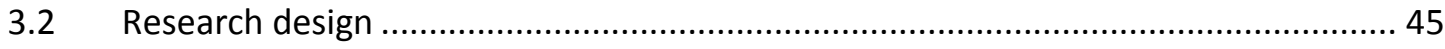

3.3 Research philosophy and research choice ................................................ 46

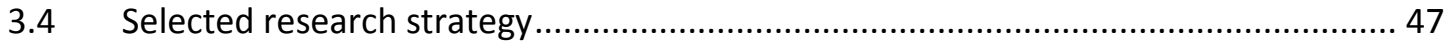

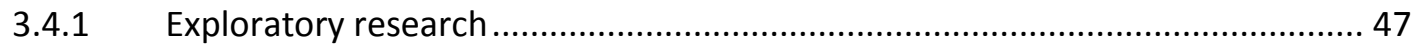

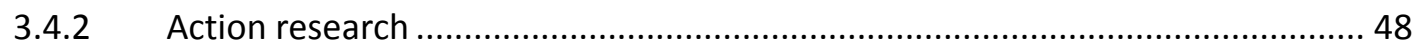

Single case study survey..................................................................... 48

Focus group multi-case survey............................................................. 49

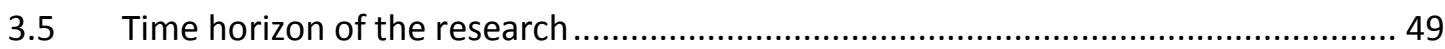

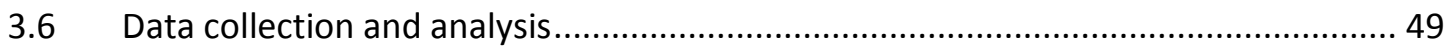

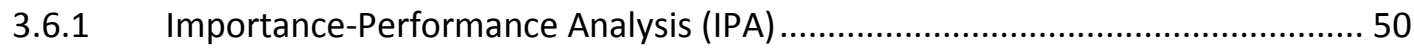

3.6.2 Analytical Hierarchical Process (AHP) analysis....................................... 56

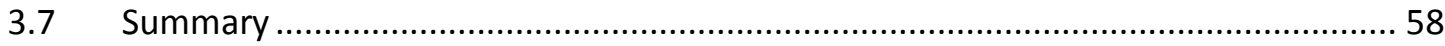

4. Identification of the research setting and methodology for the identification of regional

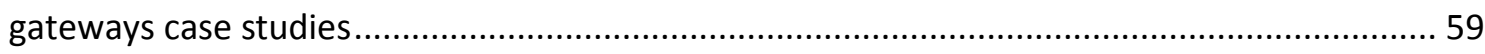

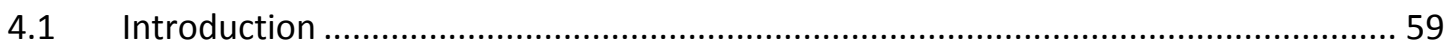

4.2 Overview of emerging megaregions in Europe and other parts of the world.......... 60

4.2.1 Emerging megaregions in Europe ..................................................... 60

4.2.2 Emerging megaregions in other parts of the world .................................... 61

4.3 Selection of a single regional logistics gateway case study in North West Europe .... 62

4.4 Selection of multiple case studies in the greater territory of North West Europe..... 64

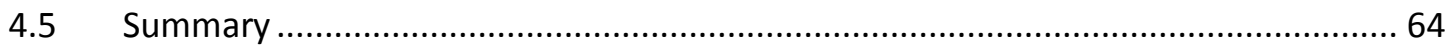

5. Micro-level service performance measurement assessment of a megaregional logistics gateway in North West Europe................................................................................. 66

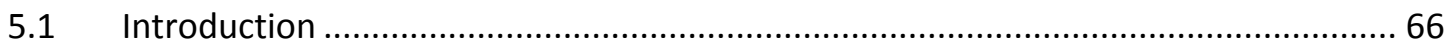

5.2 Strategic decision making with an industrial case study an expert survey on interest groups and stakeholders of regional logistics gateway 
5.3 Selection and application of a case study for the sustainable service delivery assessment of a gateway's transport network within an emerging megaregion

5.4 Employment of a combined IPA and AHP methodology for the measurement of critical service quality attributes of a multimodal logistics gateway's transport infrastructure

5.4.1 Construction of the combined IPA and AHP survey index................................ 72

5.4.2 Importance-performance matrix survey data analysis ...................................... 77

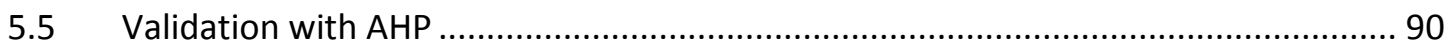

5.5.1 Construction of a pairwise comparison index for the main criteria .................... 90

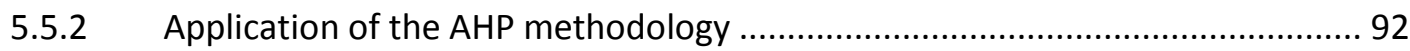

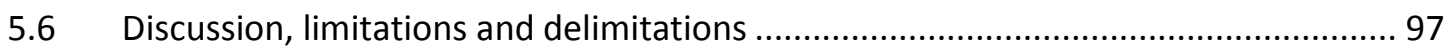

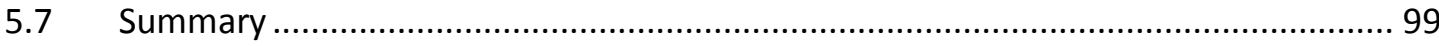

6. Macro-level analysis for transport systems in megaregional logistics gateways in North

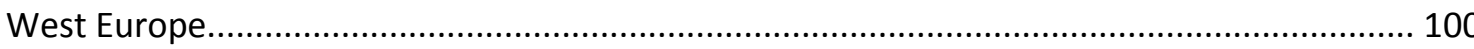

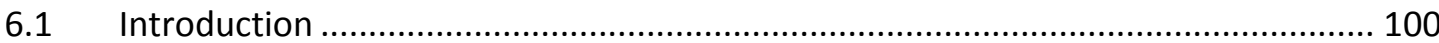

6.2 Environmental considerations for the planning on new transport infrastructure in

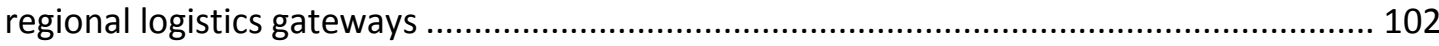

6.3 Scenarios of sustainable development in regional logistics gateways through comodality

6.4 Methodology development for the creation of sustainable transport scenarios .... 104

6.4.1 Focus groups survey instrument design ..................................................... 106

6.4.2 Selection and organisation of the focus group .............................................. 108

6.5 Identification of regional transport infrastructure projects and considerations on the development of future supply and demand scenarios in the emerging megaregion of North West Europe 109

6.5.1 Identification of critical transport priority projects for sustainable development in the Republic of Ireland

6.5.2 Identification of critical transport priority projects for sustainable development in the United Kingdom

6.5.3 Identification of critical transport priority projects for sustainable development in France 112

6.5.4 Identification of critical transport priority projects for sustainable development in Holland

6.5.5 Identification of critical transport priority projects for sustainable development in Germany. 
6.5.6 Identification of critical transport priority projects for sustainable development

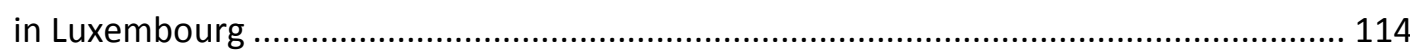

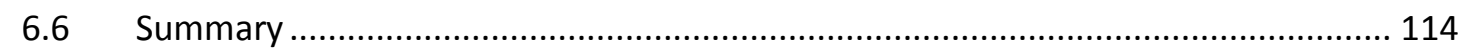

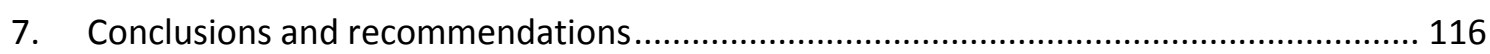

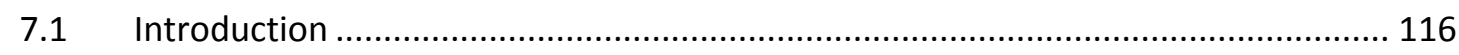

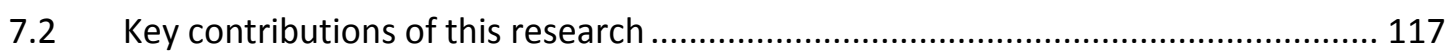

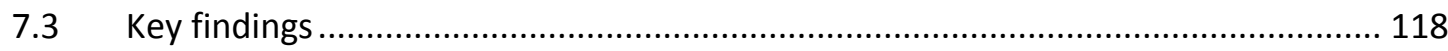

7.4 Summary and recommendations for further research........................................... 120

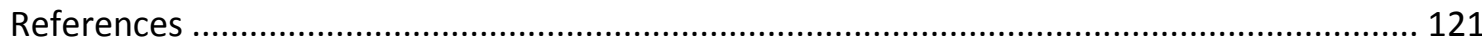

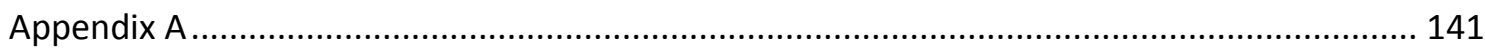

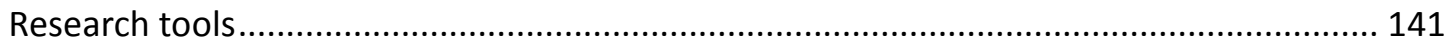

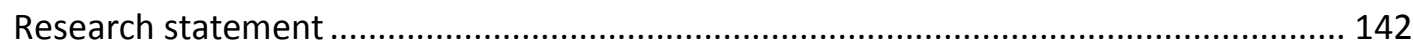

A-1: Questionnaire for the service quality assessment of transport infrastructure systems

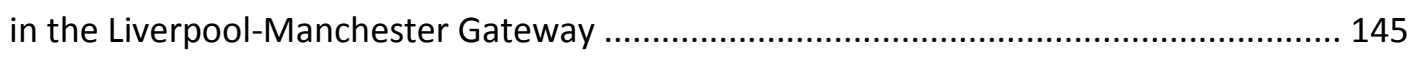

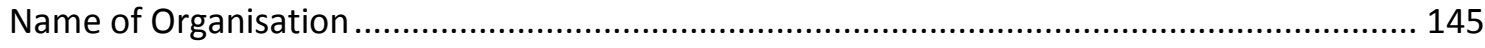

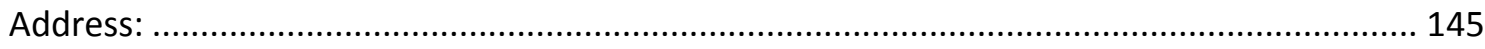

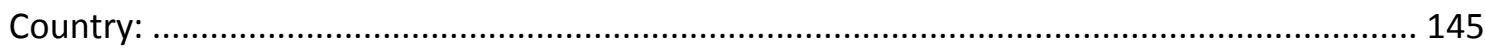

Type of Organisation:

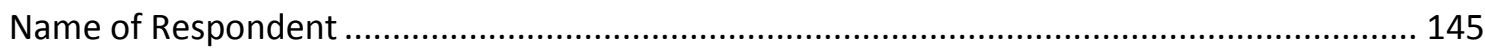

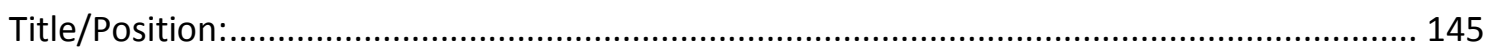

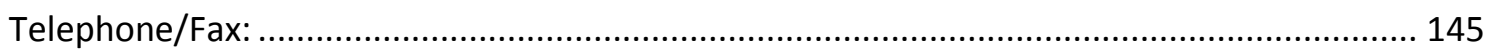

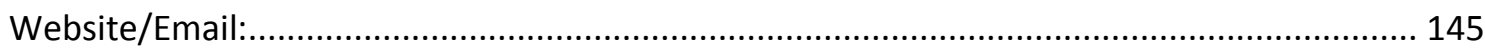

A-2: Questionnaire for identification and sustainability assessment of critical transport infrastructure projects in the emerging mega-region of North West Europe.................. 155

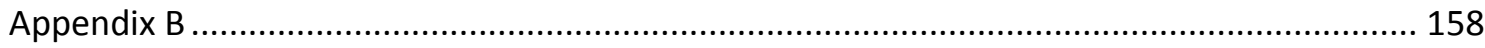

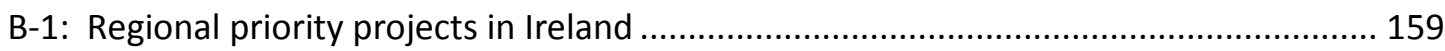

The Air Cargo project in Shannon Airport........................................................................ 160

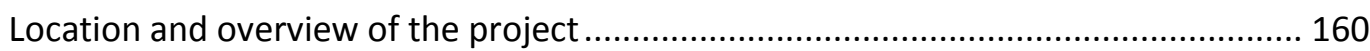

SWOT analysis with emphasis to congestion and modal shift.................................... 160

Bottlenecks that the projects aims to reduce in the region ....................................... 161

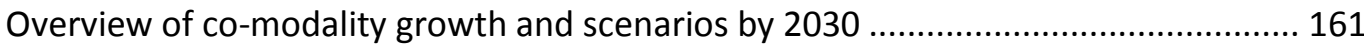

Sustainable development scenarios by 2030 ........................................................... 161

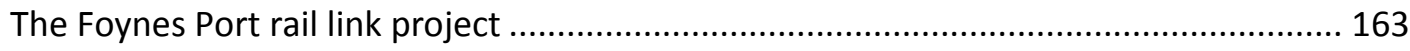

Location and overview of the project ...................................................................... 163 
SWOT analysis with emphasis to congestion and modal shift.

Bottlenecks that the project aims to reduce in the region 164

Overview of co-modality growth and scenarios by 2030 164

Sustainable development scenarios by 2030 164

B-2: Regional priority projects in the United Kingdom 166

The Forth Replacement Crossing (FRC) project 167

Location and overview of the project. 167

SWOT analysis with emphasis to congestion and modal shift. 168

Bottlenecks that the project aims to reduce in the region 169

Overview of co-modality growth and scenarios by 2030 169

Sustainable development scenarios by 2030 169

The Rosyth International Container Terminal project 171

Location and overview of the project. 171

SWOT analysis with emphasis to congestion and modal shift. 172

Bottlenecks that the project aims to reduce in the region 173

Overview of co-modality growth and scenarios by 2030 173

Sustainable development scenarios by 2030 174

Edinburgh - Glascow improvement programme (EGIP)... 175

Location and overview of the project. 175

SWOT analysis with emphasis to congestion and modal shift 177

Bottlenecks that the project aims to reduce in the region 177

Overview of co-modality growth and scenarios by 2030 177

Sustainable development scenarios by 2030 177

The Aberdeen Western Bypass project 179

Location and overview of the project. 179

SWOT analysis with emphasis to congestion and modal shift 180

Bottlenecks that the project aims to reduce in the region 181

Overview of co-modality growth and scenarios by 2030 181

Sustainable development scenarios by 2030 182

The Liverpool 2 container terminal project . 183

Location and overview of the project. 183

SWOT analysis with emphasis to congestion and modal shift. 183

Bottlenecks that the project aims to reduce in the region 184 
Overview of co-modality growth and scenarios by 2030

Sustainable development scenarios by 2030 ........................................................... 185

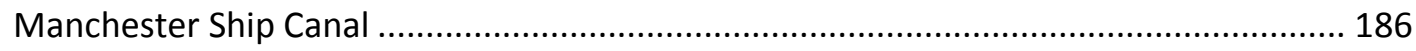

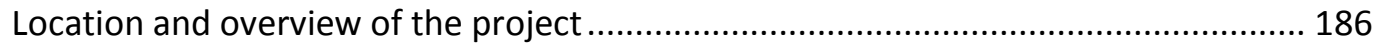

SWOT analysis with emphasis to congestion and modal shift................................... 186

Bottlenecks that the project aims to reduce in the region ............................................ 186

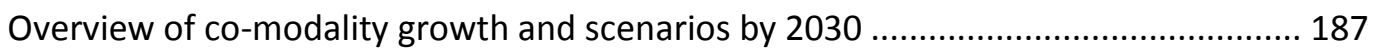

Sustainable development scenarios by 2030 ............................................................. 187

The Mersey Gateway bridge project......................................................................... 188

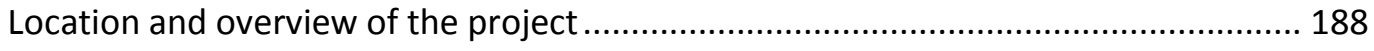

SWOT analysis with emphasis to congestion and modal shift.................................... 190

Bottlenecks that the project aims to reduce in the region ........................................... 190

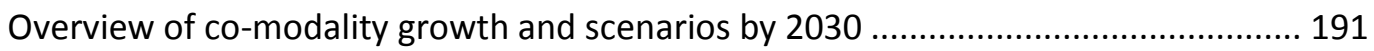

Sustainable development scenarios by 2030 ............................................................. 191

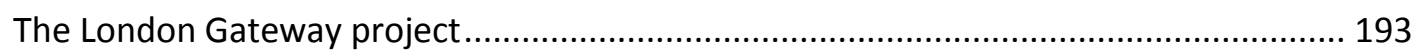

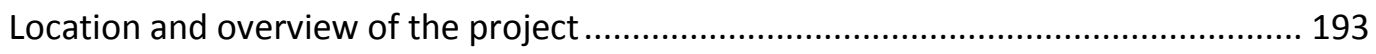

SWOT analysis with emphasis to congestion and modal shift.................................... 194

Bottlenecks that the project aims to reduce in the region......................................... 194

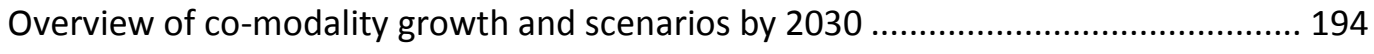

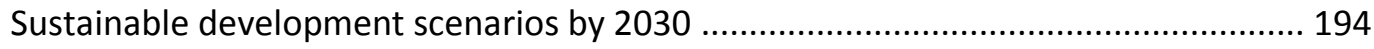

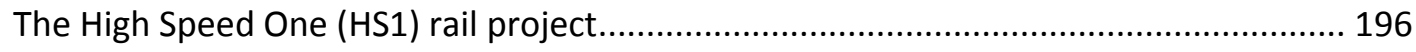

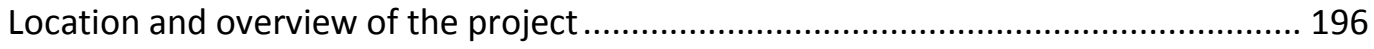

SWOT analysis with emphasis to congestion and modal shift.................................... 197

Bottlenecks that the project aims to reduce in the region ......................................... 197

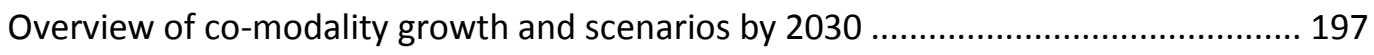

Sustainable development scenarios by 2030 ......................................................... 197

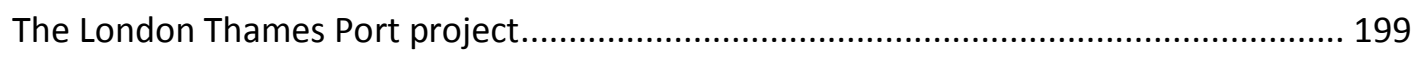

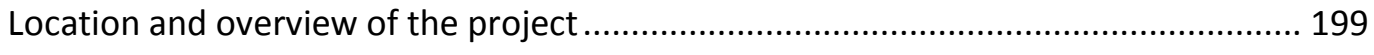

SWOT analysis with emphasis to congestion and modal shift.................................... 199

Bottlenecks that the project aims to reduce in the region........................................... 200

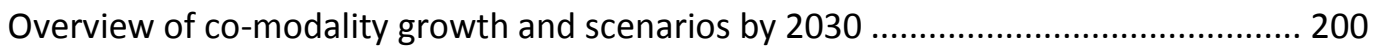

Sustainable development scenarios by 2030 ............................................................. 201

The Daventry International Rail Freight project (DIRFT)............................................... 202 
Location and overview of the project ........................................................ 202

SWOT analysis with emphasis to congestion and modal shift.............................. 202

Bottlenecks that the project aims to reduce in the region.................................. 203

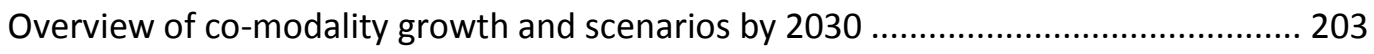

Sustainable development scenarios by 2030 ................................................... 203

B-3: Regional priority projects in France.................................................................. 205

The maritime container shuttle project between Le Havre and Caen ........................... 205

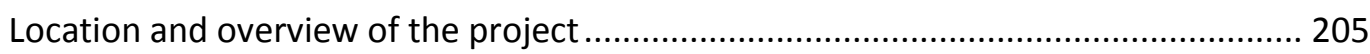

SWOT analysis with emphasis to congestion and modal shift............................... 206

Bottlenecks that the project aims to reduce in the region ................................. 206

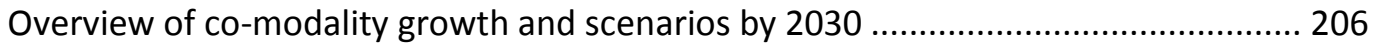

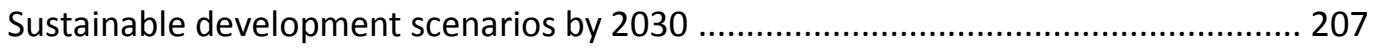

The new railway line project between Paris and Le Havre .................................... 208

Location and overview of the project ............................................................ 208

SWOT analysis with emphasis to congestion and modal shift.................................. 209

Bottlenecks that the project aims to reduce in the region...................................... 209

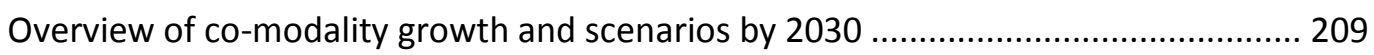

Sustainable development scenarios by 2030 ............................................... 209

The multimodal terminal project in the Port of Le Havre ....................................... 211

Location and overview of the project ..................................................... 211

SWOT analysis with emphasis to congestion and modal shift.............................. 212

Bottlenecks that the project aims to reduce in the region ..................................... 212

Overview of co-modality growth and scenarios by 2030 .................................... 212

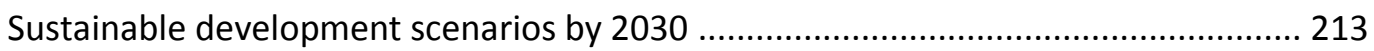

The extension and renovation project of the Tancarville bridge................................ 214

Location and overview of the project ......................................................... 214

SWOT analysis with emphasis to congestion and modal shift................................ 215

Bottlenecks that the project aims to reduce in the region .................................. 215

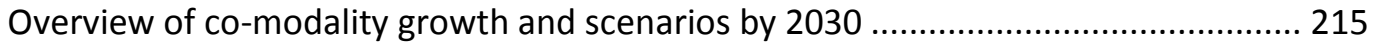

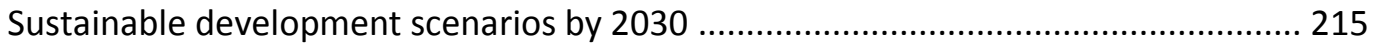

The modernisation of the rail network project from Gisors to Serqueux ..................... 217

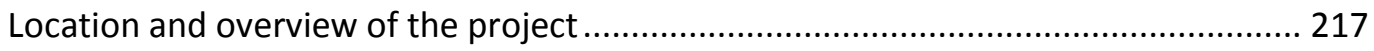

SWOT analysis with emphasis to congestion and modal shift................................ 218 
Bottlenecks that the project aims to reduce in the region

Overview of co-modality growth and scenarios by 2030 219

Sustainable development scenarios by 2030 219

Bypass Rouen 221

Location and overview of the project.....

SWOT analysis with emphasis to congestion and modal shift.

Bottlenecks that the project aims to reduce in the region. 223

Overview of co-modality growth and scenarios by 2030 223

Sustainable development scenarios by 2030

The Laoutebourg platform extension project 225

Location and overview of the project.... 225

SWOT analysis with emphasis to congestion and modal shift\#. 226

Bottlenecks that the project aims to reduce in the region 226

Overview of co-modality growth and scenarios by 2030 226

Sustainable development scenarios by 2030 226

B-4: Regional priority projects in Belgium 228

The Luxembourg Freeport project. 229

Location and overview of the project... 229

SWOT analysis with emphasis to congestion and modal shift. 230

Bottlenecks that the project aims to reduce in the region 230

Overview of co-modality growth and scenarios by 2030 231

Sustainable development scenarios by 2030 231

The new Luxembourg - Bettembourg rail link project 233

Location and overview of the project 233

SWOT analysis with emphasis to congestion and modal shift. 234

Bottlenecks that the project aims to reduce in the region.................................... 234

Overview of co-modality growth and scenarios by 2030 ..................................... 235

Sustainable development scenarios by 2030 ................................................... 236

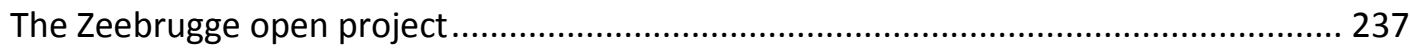

Location and overview of the project........................................................... 237

SWOT analysis with emphasis to congestion and modal shift................................ 238

Bottlenecks that the project aims to reduce in the region .................................... 238

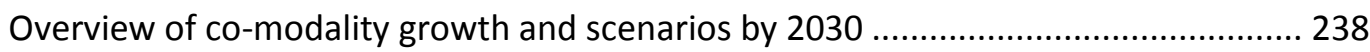




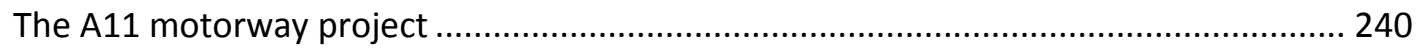

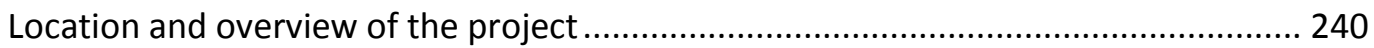

SWOT analysis with emphasis to congestion and modal shift................................... 241

Bottlenecks that the project aims to reduce in the region ......................................... 241

Overview of co-modality growth and scenarios by 2030 ............................................ 241

7.4.1.1 Sustainable development scenarios by 2030............................................. 242

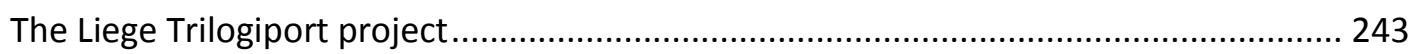

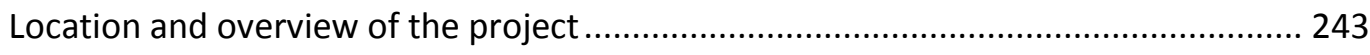

SWOT analysis with emphasis to congestion and modal shift.................................... 244

Bottlenecks that the project aims to reduce in the region ........................................... 245

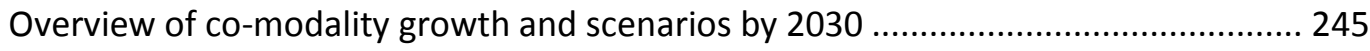

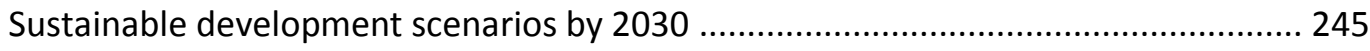

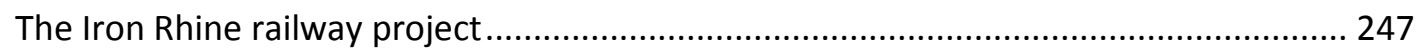

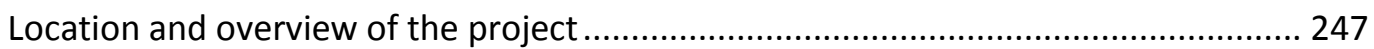

SWOT analysis with emphasis to congestion and modal shift.................................... 248

Bottlenecks that the project aims to reduce in the region .......................................... 248

Overview of co-modality growth and scenarios by 2030 .......................................... 248

7.4.1.2 Sustainable development scenarios by 2030............................................. 249

The Moselle-Saône-Rhône inland water link project......................................................... 250

Location and overview of the project ................................................................... 250

SWOT analysis with emphasis to congestion and modal shift..................................... 251

Bottlenecks that the project aims to reduce in the region ......................................... 251

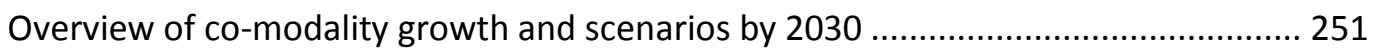

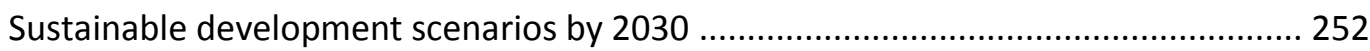

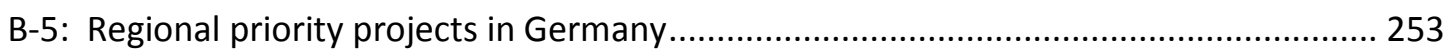

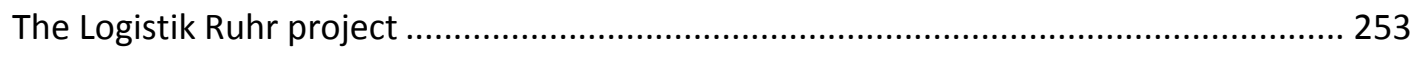

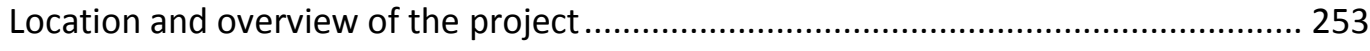

SWOT analysis with emphasis to congestion and modal shift.................................... 253

Bottlenecks that the project aims to reduce in the region.......................................... 254

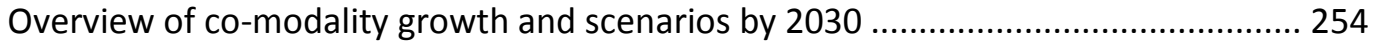

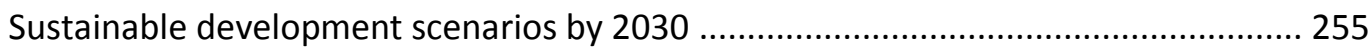

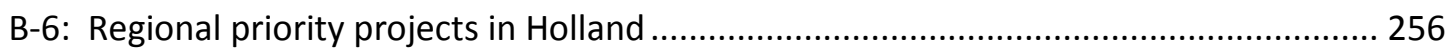


Zuid.

Location and overview of the project. 256

SWOT analysis with emphasis to congestion and modal shift................................... 257

Bottlenecks that the project aims to reduce in the region........................................ 258

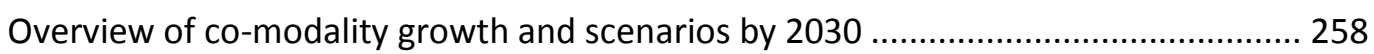

Sustainable development scenarios by 2030 ................................................................ 258 


\section{List of Tables}

Table 2-1: $\quad$ The strengths and weakness of transport modes................... 38

Table 3-1: $\quad$ Recent selected publications showing the applicability of IPA..... 54

Table 5-1: $\quad$ Importance-performance indicators index ....................... 73

Table 5-2: $\quad$ Aggregate performance and importance scores for the road mode...83

Table 5-3: $\quad$ Aggregate performance and importance scores for the rail mode.....85

Table 5-4: $\quad$ Aggregate performance and importance scores for the air mode......87

Table 5-5: $\quad$ Aggregate performance and importance scores for the water mode...89

Table 5-6: $\quad$ Pairwise comparison for main indicators......................... 91

Table 5-7: $\quad$ Result of relative importance of main indicators...................93

Table 5-8: The $n$th root of each criterion.......................................94

Table 5-9: The priority weight of each criterion...............................95

Table 5-10: The calculation of the consistency ratio...........................96

Table 5-11: Value of RI versus Matrix Order..................................96

Table 6-1: $\quad$ Selected critical priority transport projects in Ireland................110

Table 6-2: $\quad$ List of selected critical priority transport projects in the UK.........111

Table 6-3: $\quad$ List of selected critical priority transport projects in France...........112

Table 6-4: $\quad$ List of selected critical priority transport projects in Holland.........113

Table 6-5: $\quad$ List of selected critical priority transport projects in Germany........113

Table 6-6: $\quad$ List of selected critical priority transport projects in Luxembourg...114 


\section{List of Figures}

Figure 1-1: $\quad$ Thesis structure $\quad 7$

Figure 2-1: $\quad$ Main components of the literature review methodology 8

Figure 2-2: The components of Supply Chain Management 22

Figure 2-3: Intermodal Transport 35

Figure 3-1: $\quad$ Research methodology planning and process 45

Figure 3-2: The "Research Onion" approach 46

Figure 3-3: $\quad$ Adapted IPA matrix for the service performance analysis 53

Figure 4-1: Methodology for the identification of the research setting 59

Figure 4-2: The "blue banana" corridor 60

Figure 4-3: GIS representation of the Liverpool - Manchester gateway 63

Figure 5-1: $\quad$ Methodology for the assessment of the service performance $\quad 67$

Figure 5-2: $\quad$ GIS representation of participants in the survey 79

Figure 5-3: $\quad$ Distribution of stakeholders who responded 79

Figure 5-4: Distribution of mode use by respondents 80

Figure 5-5: $\quad$ Screenshot example of a completed section for the road mode $\quad 80$

Figure 5-6: $\quad$ IPA diagram showing the mean values of attributes (road mode) 82

Figure 5-7: IPA diagram showing the mean values of attributes (rail mode) 84

Figure 5-8: $\quad$ IPA diagram showing the mean values of attributes (air mode) 86

Figure 5-9: IPA diagram showing the mean values of attributes (water mode) 88

Figure 5-10: AHP framework 92

Figure 5-11: Weights obtained from AHP as displayed in table 5-7 95

Figure 6-1: $\quad$ Methodology for projects evaluation framework 102

Figure 6-2: Main drivers that influence the transport system 108

Figure B-1: Radar chart representation of growth scenario of sustainable development for the air cargo project in Shannon Airport

162

Figure B-2: $\quad$ Radar chart representation of growth scenario of sustainable development for the Foynes port rail link project

Figure B-3: Radar chart representation of growth scenario of sustainable development for the Forth replacement crossing project

Figure B-4: Radar chart representation of growth scenario of sustainable development for the Forth replacement crossing project

Figure B-5: Radar chart representation of growth scenario of sustainable development for the Edinburgh - Glascow improvement project 178

Figure B-6: Radar chart representation of growth scenario of sustainable development for the Aberdeen Western bypass project

Figure B-7: Radar chart representation of growth scenario of sustainable development for the Liverpool 2 Container Terminal project

Figure B-8: Radar chart representation of growth scenario of sustainable development of the Manchester Ship Canal project

Figure B-9: Radar chart representation of growth scenario of sustainable development for the Mersey Gateway Bridge project 
Figure B-10: Radar chart representation of growth scenario of sustainable development for the London Gateway project

Figure B-11: Radar chart representation of growth scenario of sustainable development for the High Speed One rail project

Figure B-12: Radar chart representation of growth scenario of sustainable development for the London - Thames port project

Figure B-13: Radar chart representation of growth scenario of sustainable development for the Daventry Rail Freight Project

Figure B-14: Radar chart of growth scenario of sustainable development for the Maritime Container Shuttle project between Le Havre and Caen

Figure B-15: Radar chart of growth scenario of sustainable development for the railway line project between Paris and Le Havre

Figure B-16: Radar chart representation of growth scenario of sustainable development for the multimodal project in the port of Le Havre

Figure B-17: Radar chart representation of growth scenario of sustainable development for the Tancarville bridge renovation project

Figure B-18: Radar chart representation of growth scenario of sustainable development of the rail network from Gisors to Serqueux project

Figure B-19: Radar chart representation of growth scenario of sustainable development for the Rouen bypass project

Figure B-20: Radar chart representation of future growth scenario of sustainable development for the Laouterbourg platform extension project

Figure B-21: Radar chart representation of future growth scenario of sustainable development for the Luxembourg Freeport project

Figure B-22: Radar chart representation of future growth scenario of sustainable development for the Luxembourg - Bettembourg rail link project 236

Figure B-23: Radar chart representation of future growth scenario of sustainable development for the Zeebrugge open project

Figure B-24: Radar chart representation of future growth scenario of sustainable development for the A11 motorway project

Figure B-25: Radar chart representation of future growth scenario of sustainable development for the Liege Trilogiport project

Figure B-26: Radar chart representation of future growth scenario of sustainable development for the Iron Rhine railway project

Figure B-27: Radar chart representation of future growth scenario of sustainable development for the Moselle inland water link project

Figure B-28: Radar chart representation of future growth scenario of sustainable development for the Logistik Ruhr project

Figure B-29: Radar chart representation of future growth scenario of sustainable development for the Zuid project 


\section{List of Abbreviations}

\begin{tabular}{ll} 
AHP & Analytical Hierarchical Process \\
CLM & Council of Logistics Management \\
EU & European Union \\
FDI & Foreign Direct Investment \\
GDP & Gross Domestics Product \\
GIS & Geographical Information System \\
HGV & Heavy Goods Vehicle \\
MCDM & Multi Criteria Decision Making \\
NUTS & Nomenclature of Territorial Units for Statistics \\
OECD & Organisation for Economic Co-operation and Development \\
SCM & Supply Chain Management \\
SME & Small and Medium Enterprise \\
SWOT & Strengths, Weaknesses, Opportunities, Threats analysis \\
TEN-T & Trans-European Transport Networks \\
WCED & World Commission on Environment and Development \\
\hline
\end{tabular}




\section{Introduction}

\subsection{Introduction}

The need to reduce greenhouse gas emissions across the transport logistics service industry is a global necessity. It is a common belief that modal shift is a necessity by engaging supported by logistics businesses to make their operations and premises more efficient and thirdly by formalising the delivery of a more sustainable gateway by improving the service quality of the transport infrastructure (Kohn 2012). Regions are growing and they rely heavily on global logistics operations to supply their population, the majority of which is living in metropolitan areas with a higher concentration of greenhouse gases and a heavy concentration of a multiple layer of logistics and transport operations and other urban functions (Todorovich 2009). Reducing emissions of the transport sector needs a better modal mix, more synergies between the private and public sectors and a coordinated transnational approach.

\subsection{Research background}

Megaregions are a new scale of urban agglomerations which are emerging across the world and have the available transport infrastructure that could support modal shift and sustainable development and more could be made of them (Scott 2001; Hall and Pain 2006; McGee and Robinson 1995; Berube et al 2006; Lang and Dhavale 2005). Megaregions also have gateways which may contain tens of millions of people and extend for hundreds of miles (Teitz and Barbour 2007). A gateway is not a defined administration area but rather a functional economic area (Pain 2011). Typically, it has some port, airport, rail hub and logistics clusters and is key to the regional economy. Existing policies try to achieve an optimisation of the performance of multimodal logistic chains and transport infrastructure, including making greater use of inherently more resource efficient modes, where other technological innovations in long distance freight may be insufficient. The existing situation is that individual public authorities as infrastructure providers have little influence over how logistics work in their jurisdiction and there are limited initiatives well-coordinated between different jurisdictions therefore creating the need for stronger governance (Gorka and Szyja 2015). 
Competition regulation and the competiveness of companies prevent them from coordinating or sharing available transport infrastructure. The key objective for a gateway's supply chain clusters is the creation of intermodal solutions and the development of sustainable transport infrastructure. A modal shift approach is an environmentally friendly alternative to the traditional door to door road transport supply chains. Modal shift also supports the competitiveness of the industry and improves the competitiveness of those gateway ports as important hubs and logistic nodes. Actions supporting modal shift can lead to an increased capacity of transport management authorities (public or private) enabling them to better plan for and manage the transportation of goods and people across growing regions, such as more efficient use of existing infrastructure. In order to support modal shift, there is a need for more efficient traffic management solutions, a stronger shift away from road transportation towards more environmentally friendly modes both for freight and for passengers but most importantly the adoption of an integrated methodological approach when assessing existing and planned transport infrastructure by the decision makers with respect to sustainable development.

\subsection{Scope of this research and statement of the problem}

The research presented in this thesis was carried out within the context of the EU Interreg IVB Weastflows and is concerned with the assessment of service performance of the intermodal transport network with a regional logistics gateway and also with the impact that existing and planned transport infrastructure could have in the future to a megaregion's sustainable development in the long term. Currently the majority of the existing methodologies are primarily focusing on the performance measurement that a project is having or will have within the economic, social and environmental dimensions only, without taking much into consideration on how the project will provide a sustainable balance between them. From a decision making perspective the evaluation and analysis of investment proposals both during and after the planning phase of a project may prove to be quite complex for the targeted geographical areas that are planned to change or to be re-developed. 


\subsection{Research aim and objectives}

The challenge of sustainable development in growing regions (also known as megaregions) calls for the adoption of novel approaches to the performance assessment of transport infrastructure in regional logistics gateways. Decision makers need to be aware that enhanced global competitiveness can be achieved through enabling sustainable and environmentally friendly transport infrastructure that would facilitate modal shift and consequently the provision of service quality for all stakeholders involved. This research aims to provide decision makers with a research framework that can support the better use of gateway opportunities by identifying service performance gaps in the use of different modes of transport and also by producing future scenarios for existing and planned transport infrastructures impact that will have in sustainable development. In this research a research framework is regarded as a set of basic assumptions or fundamental principles of intellectual origin in which discussions and actions can proceed (Popper, 1994). The aim of this research is primarily driven by the need for better coordination that is required between all key stakeholders both in the private and in the public sector in order to investigate gateways' opportunities (i.e. the interface structure between regional and global transport systems) (Van Klink and Van den Berg 1998). Also another aim is to encourage better synergies with different kinds of transport operators, supply chain clusters and infrastructure providers across emerging megaregions aiming to affect large-scale behavioural change with respect to the use of low carbon transportation and the implementation of modal shift. Following the aims the objectives set out in this research look into the specific and measurable outputs with respect to service performance measurement of logistics gateways.

More specifically this research's objectives are the following:

- To specify the vision for sustainable development and to draw upon a literature that clearly defines sustainable transport, logistics gateways and emerging megaregions;

- To select and adapt a number of services operations performance management models into a new research context (i.e. logistics gateways); 
- To identify and select the suitable research settings for the collection and analysis of primary data through the conduction of industrial and focus group surveys;

- To provide a novel approach to the literature of performance evaluation of modal shift and transport infrastructure service quality by capturing the involved stakeholders perceptions and expectations;

- To propose a framework for the application and combination of the IPA and AHP models over alternative methodologies in an intermodal transport infrastructure regional case study which will provide a straightforward methodology for the assessment of sustainable development as a result of an industrial survey;

- To produce significant supply and demand of available and planned transport infrastructure scenarios based on the likely impact that existing and planned transport infrastructure are expected to have in sustainable development.

\subsection{Research methodology}

Transport facilitates the movement of billions of people and associated freight all around the globe. In some parts of the developed world (for example in Western Europe) emerging megaregions are divided into sovereign countries with their own logistics gateways (Taylor and Pain 2007). The research problem addressed here deals with the lack of an analytical framework for the assessment of the service performance of the intermodal transport network within regional logistics gateways in the megaregion of North West Europe. For this to be achieved a selection of an appropriate list of indicators is required in order to carry out surveys that capture both the perceptions and expectations of the stakeholders that operate within and beyond a logistics gateway. The methodology followed in this research provides a novel approach to the service performance assessment of the transport network of a regional logistics gateway of North West England by examining the service attributes of different service performance indicators for every mode of transport as a micro-level analysis of the megaregional space of North West Europe (Harrison and Holyer 2015). The selected case study of North West England allowed also the employment and application of a proposed combined IPA and AHP model for decision making based on primary data collected with multiple participants from the industry. 
Additionally a focus group survey has been carried out with selected participants from different areas of the megaregional space of North West Europe (Hall and Pain 2006) in order to produce future scenarios analysis at a macro-level of the impact that a number of transport priority infrastructure projects are expected to have in sustainable development through graphical representation.

\subsection{Structure of the thesis}

This thesis consists of seven chapters as shown in figure 1-1. Chapter one introduces the research as a whole. Background information on the research topic, the research gap, aim and objectives, and a brief explanation of the methodology are given. This is followed by a literature review in chapter two. Chapter two reviews the literature on services operations management and the importance of transport infrastructure for sustainable development through the provision of service quality in logistics gateways. It also provides an extensive review on service quality, service encounter and the various service quality measurement tools developed in the literature. Finally it elaborates how these concepts are relevant and important to the measurement of service performance of transport infrastructure and the promotion of modal shift for sustainable development through perceived and expected service quality.

Chapter three describes how the research was designed and conducted. After a brief review of the research structure, the research philosophy of social enquiry and management and the researcher's personal philosophical stance on the current research are set out. This is followed by a discussion of the research methods based on the "research onion" approach. The survey strategy adopted is explained, and a justification is given for using questionnaire surveys as the main methods for data collection. Importance - Performance Analysis (IPA) and Analytical Hierarchical Process (AHP) are addressed in detail. This chapter ends by presenting the tools employed for data analysis and data interpretation. Chapter four identifies the research setting and provides an overview of the megaregions, logistics gateways and sustainable development in more detail. 
Then it provides an overview of emerging megaregions in the world, in Europe and more specifically in its North West part which is also known as the "blue banana"(Brunet 1989). This chapter concludes by selecting the case study for the scientific application of the methodological tools and techniques for the assessment of service quality in the transport infrastructure in a regional logistics gateway. With these in mind chapter five offers an in depth view of the selected gateway case study by providing a performance assessment of the existing transport infrastructure system with respect to service performance and modal shift.

For this purpose an industrial action research survey was conducted in order to capture the views of the industrial stakeholders. More specifically the survey used a model consisting of universal performance indicators for every mode of transport based on the IPA methodology which also receives validation by an AHP methodology. Chapter six adopts a multi-case action research approach by examining various existing and planned transport infrastructure projects in the emerging megaregion of North West Europe which aim to enhance sustainable development. This scenarios' development methodology for the long term is based on a modified sustainable transport systems evaluation model with data collected from participants of a focus group consisting of experts from different areas of interest in North West Europe. Finally chapter seven concludes this research by discussing the key findings. Also the realisation of the research objectives is discussed and the originality and contributions of the research. The chapter also concludes with limitations of this research and suggestions for future research. 


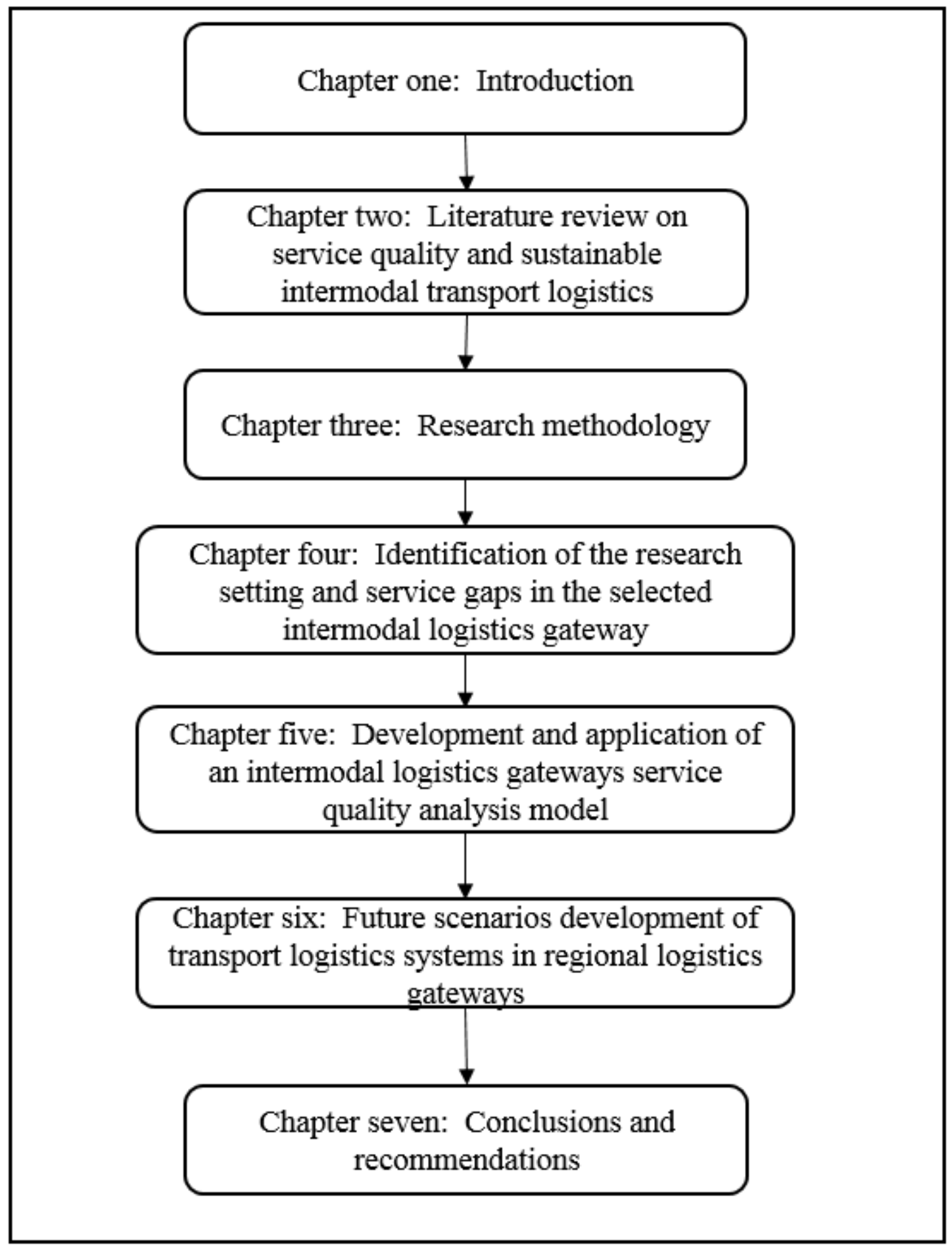

Figure 1-1: Thesis structure 


\section{Literature review on service quality and transport logistics}

\subsection{Introduction}

Operations management is an area of management concerned with designing, organising and controlling existing and new processes for the production of goods and services (Corrêa et al 2007). In supply chain and transport logistics, improved service quality can be achieved by balancing the perceptions and expectations on the service levels experienced by the involved stakeholders. The literature review methodology that was followed for this chapter consists of many interrelated components. As shown in figure 2-1 the literature review from the fields of services operations management, service quality, transport logistics and sustainable development served as main inputs to the collection and reviewing process regarding the management science behind the analysis to be conducted in subsequent chapters. Literature review was also carried out with relevance to the modern developments of megaregions and sustainable logistics gateways in order to explore further the research setting in the subsequent chapters of the research analysis.

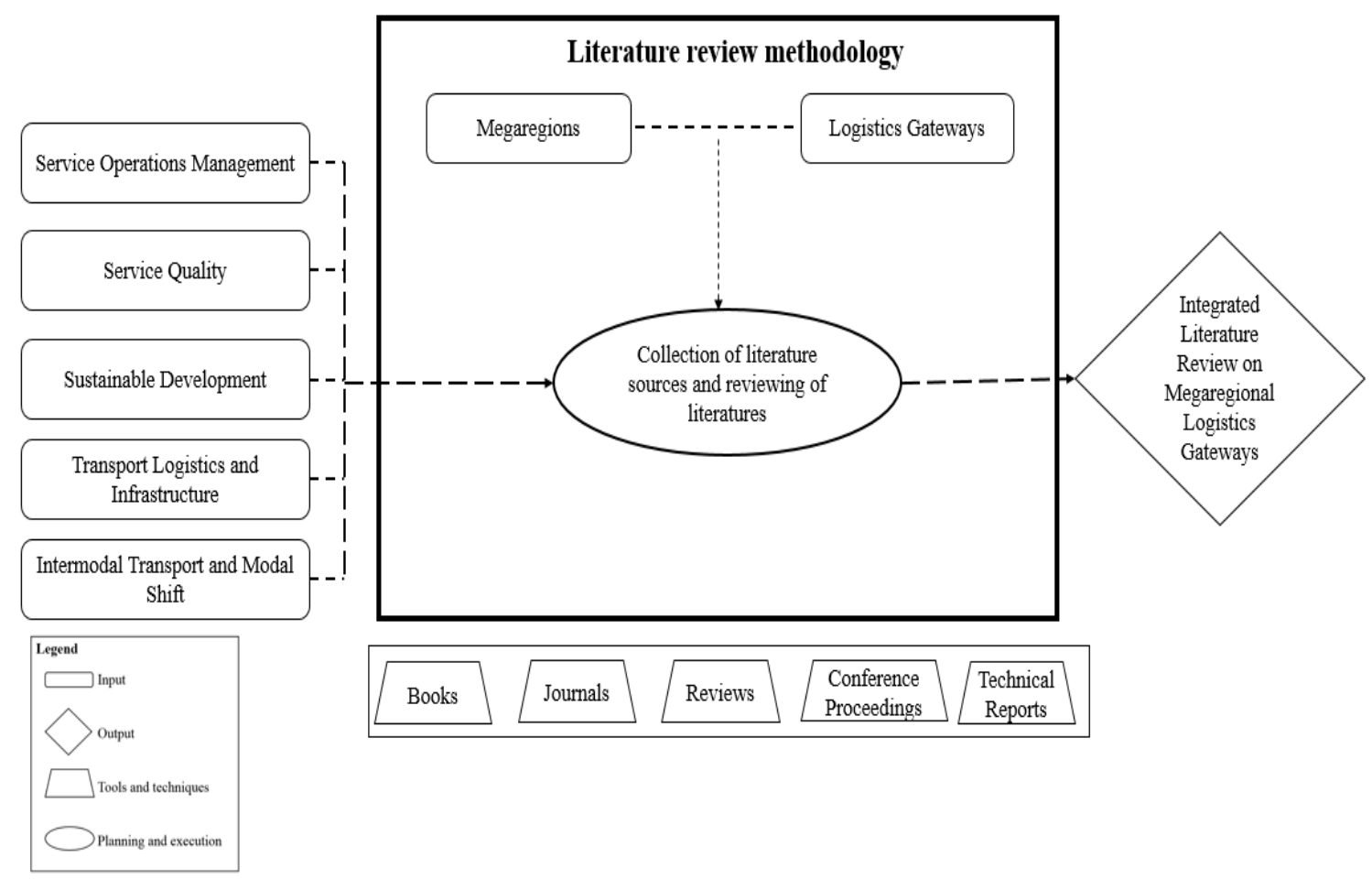

Figure 2-1: Main components of the literature review methodology 


\subsection{The service concept and the evolution of the service operations management perspective}

Service management is considered to be a perspective rather than a discipline, which aims to equip firms with the understanding that service elements have to be managed in such a way that the development of successful customer relationships will enhance the achievement of a competitive advantage. The principle of service management requires that service should become an "organisational imperative" that will lead to the creation of a set of guidelines with a purpose to develop the separate areas of management, marketing, operations, organisational theory and human resources management as well as quality management including service quality and total quality management. On the other hand, there is the notion of service as a process. Operations management theorists have included "service" as one of the four principal functions of operating systems for at least three decades. This body of theory regards the other three functions as "manufacture", "transport" and "supply", leading to a potential confusion since the latter two are clearly "service" components in terms of their output. Through metaphor, "process" acquires connotations of manufacturing and systems theory, its dominant paradigm. Many authors have used manufacturing as a model for service, for example in the "servuction" (service-production) approach of Eiglier and Langeard (1987).

In order to express service processes as systems it is necessary to define their inputs, outputs and the platform upon which they act. Slack et al (2001) mentioned that service operations depends on the customer to provide the information that is the raw material to be transformed into the service output. Shostack (1982) subjected service processes to detailed design just as it is commonly done with manufacturing processes. However, there is interplay between manufacturing and service paradigms. Economic batch quantities, line balancing and stock control are a just few topics that had little relation to the key issues faced by managers running service operations. That is not to say that these tools and techniques are of no value, but customer service, service quality and service design are central issues facing many service operations managers, yet there are no tools or techniques to help them in these matters. Levitt (1976) applied a manufacturing view of productivity to the service sector. 
This perspective stimulated the adoption of systems thinking and mechanised techniques in several service industries, including the modern fast-food industry, computerised banking and airline central reservations. In terms of productivity though, there was a problem when attempting to define the value of an intangible offering and the appropriateness of applying the productivity concept in the service sector. The basic management principles that are available today have derived from a perspective that grew during the industrial revolution. Traces of this revolution can be found to Adam Smith's analysis of the pin factory and more specifically in The Wealth of Nations where he stressed the issues of specialisation and the division of labour. Similarly Taylor (1998) went through the concepts of mass production and economies of scale and these issues were the cornerstones of the management philosophy that existed at that period of time. Taylor's (1998) Scientific Management movement seems to have created a series of problems for today's management principles that are based on this notion. Nowadays, the working force has become more demanding due to its advanced educational levels along with consumers as well. International competition due to globalisation has increased and firms face pressure due to the fact that their excellent core products can only now qualify for winning, technology has become an effective tool for customers in their quest for more demands and in general the traditional management principles are under question.

The development of new models, concepts and tools based on the issues of services and their production and delivery processes started during the 1970s. A number of researchers went through the nature of services and of specific problems in services marketing and operations. The nature of customer relationships, operations and delivery processes were considered different for services and the quality of services was found to be formed and perceived in such a way that traditional models from manufacturing did not apply. From these early beginnings, a large-scale, worldwide movement gained pace and membership. Over the last ten to twenty years this had a profound effect on research and teaching. The service operations movement, like the service marketing movement, has been characterised by a number of stages from the initial realisation of the difference between goods and service to the development of conceptual frameworks in services operations management and the empirical testing of these frameworks (Brown 1996). 


\subsubsection{The service encounter and the servicescape concept}

The concept of a service encounter is critical to the understanding of the service management movement presented here, and the literature in this area will be briefly reviewed. Service encounters are "face-to-face" interactions between a buyer and a seller in a service setting" (Solomon et al 1985). Solomon et al (1985) continued that "Any encounter is assumed to contain learned and consistent behaviour patterns; each participant should enact certain behaviours in order for the transaction to proceed smoothly". Shostack's (1985) view of the service encounter expanded the definition to include "a period of time during which the consumer directly interacts with a service". This broader definition recognises that human interaction, either face-to-face or decoupled by a contact technology such as a telephone line, is not required to complete a service encounter. This view includes interaction the customer has with buildings, equipment, employee's uniforms, advertisements, etc. Service encounters are important for several reasons. The service encounter level is where the customer judges the value of the service. Service providers at the service encounter level require service management skills such as technical expertise, cross-selling other products and services, and good human interaction skills. Considerable resources include facility, process, job, and equipment design, network architecture and the location of the service facilities.

The physical setting, or infrastructure, where service encounters take place is termed as the servicescape (Bitner, 1992). The servicescape accounts for both who is performing actions during service delivery and the physical complexity of the service setting. Service delivery actions can be performed by the customer alone, the employees alone, or comibination of the two. Bitner (1992) defined physical complexity as follows: "Some service environments are very simple, with few elements, few spaces and few forms. They are termed as lean environments. Servicescapes do more than set the physical operating environment for acting out service encounters. Servicescapes also help define the customer's route through the service delivery system. The servicescape plays a variety of roles with respect to both the customers and the employees of the service firm. For example, the servicescape serves as a package for the service offering in a way not unlike that of a product's package. 
Product packages are designed to portray a particular image to the consumer as well as evoke a particular sensory or emotional reaction. In a service setting, the servicescape does the same thing through the interaction of many complex stimuli.

\subsubsection{Service quality as a major service encounter competitive component}

Product and service quality as defined by Feingenbaum (1983), is "the total composite of product or service characteristics of marketing, engineering, manufacturing, and maintenance through which the product and service in use will meet the expectations of the customer". The significance of product and service quality as a major competitive success factor is unquestionable. It is also argued that there is no alternative to hardfought buyers' markets made up of critical, demanding customers to consistent quality orientation. In recent times, though, the design of product and service quality has come to be seen not simply as the task of a single functional unit, but as a central challenge for every company. Furthermore, marketers realized that in order to retain customers, and to survive and grow, they must provide a high quality of service (Dabholkar 2000). According to many authors (Crosby 1984; Zeithaml et al 1993; Edvardsson 1998), quality development can lead to the increase of profits because of increased customer satisfaction, increased productivity, and increased cost savings. A service firm may win by delivering consistently higher-quality service than its competitors and exceeding its customers' expectations, which are formed by their past experiences, word-of-mouth, and advertising. After receiving the service, customers compare the perceived service with expected service.

If the perceived service falls below the expected service, customers lose interest in the provider, on the other hand, if the perceived service meets or exceeds their expectations, they will use the particular product/service again (Kotler 1992). However, Hansen and Bush's (1999) principle has been that "competitive advantage can be gained through quality, even in mature commodity industries, but a quality based competitive strategy will be successful only if managers understand both how quality is perceived by their customers and their company's level of quality performance." Furthermore, they also supported that achieving competitive advantage through quality requires not only the understanding of the quality customer requirements, but also a method of measuring 
efforts to provide quality under these requirements. Developing an effective quality strategy for a business is one of the most important challenges faced by top management (Cravens et al 1988). According to O'Neal and LaFief (1992), “... quality is increasingly cited as a primary strategic variable for effectively competing in the global marketplace." Moreover, some experts believe that quality improvements are essential merely to maintain competitive position; whereas others claim that quality competition has replaced price competition (Whiting and Walsh 1986).

\subsubsection{Differences between goods and services}

Services, due to their very nature, are more difficult to provide than traditional manufactured products. Berry et al (1980) have indicated that to a large extent, the difficulty lies in the fact that services can be considered as performances carried out by humans. Furthermore, service quality has different meanings to various consumers as individuals or groups. Additionally, the dynamic of the service delivery and the experiential perspectives vary across different sectors. The implications of these are that firstly, the service delivery personnel play a critical role, and secondly, each customer individual or groups has different needs, which must be met or exceeded. The quality of each of the product areas and the manner in which they are delivered contribute to the customers' perceptions, enjoyment, and satisfaction with the overall service experience (Teye and Leclere 2003). More precisely, services have four characteristics, which distinguish them from products, and affect the design of marketing programs, such as intangibility, inseparability, variability and perishability (Kotler 2006).

\subsubsection{Service quality management issues}

The term customer satisfaction represents a modern approach for quality in all kinds of organisations and serves the development of a truly customer-focused management and culture. Kotler (2006) suggested that “customer satisfaction is a person's feelings of pleasure or disappointment resulting from comparing a product's perceived performance (or outcome) in relation to his or her expectations". Measuring customer satisfaction offers an immediate, meaningful and objective feedback about the clients' preferences and expectations. Thus, the company's performance may be evaluated in relation to a set 
of satisfaction dimensions, which indicate the strengths and weaknesses of a business organisation (Mihelis et al 2001). It is also generally accepted that customer satisfaction is positively related to loyalty, which in turn leads to increased profitability, market share, and growth (Naumann 2001). This can be achieved because of the general assumption that customer satisfaction is a significant determinant of repeat sales, positive word-ofmouth and customer loyalty (Bearden and Teel 1983; Homburg and Rudolph 2001).

However, the challenge to achieve and maintain the customer satisfaction is faced not only by the business leaders, but also by the academics and policy makers (Parasuraman 1985). According to Mihelis (2001), customer satisfaction is a dynamic parameter of the business organisation and the changes in the current market can affect customers' preferences and expectations. The provision of poor service quality is a familiar experience for most of us and the need to improve its measurement and control is a common theme of the service management literature. According to Koepp (1987), "Personal service has become a maddeningly rare commodity". His article in Time provides several examples of poor service, concluding that there was a lack of understanding of service quality. Many authors, for example Voss (1985), and Edvardsson (1988), highlighted the problems in service quality which emanate from the nature of service itself. Service is usually the result of the interaction between the customer and the service system, including the contact staff, equipment, service environment and facilities. It is this interaction that results in the characteristics of service which make the provision, measurement and control of quality so difficult. There has been wide spread agreement in the service management literature that the provision of service quality is concerned with generating customer satisfaction. Gronroos (1984), Parasuraman et al (1985) and Johnston and Morris (1985) defined service quality in terms of customer satisfaction, which is the degree of fit between customers' expectation and perception of service. Many researchers attempt to deal more specifically with the issue of service quality measurement. Smith (1987), in his paper "How to Quantify Quality", provided evidence to support the proposition that service quality is difficult to quantify yet, whilst identifying measures used in manufacturing firms, finds no measures of service for service organisations. 
Voss (1985), proposed that it is the intangible aspects of the service package that are most difficult to measure and concludes that as a result service quality tends not to be measured. Johnston and Morris (1985) argued that service organisations tend to measure only what is easy to measure and quantify and are reluctant to use soft, qualitative measures. Smith (1987), also argued similarly but for manufacturing businesses, that there is a tendency to measure only what is easily quantifiable (such as financial performance and productivity) even though other aspects such as quality, innovation and flexibility may be crucial to a company's competitive success. Several authors agree that measures of service quality may either be hard or soft. Hard measures are those, which are quantifiable or objective; for example, computer downtime or the proportion of telephone calls answered. Soft measures are those that are qualitative, judgmental, and subjective and based on perceptual data, for example, customers' satisfaction with speed of service or managers' assessment of staff attitude towards customers. Soft measures of service quality are particularly relevant to the measurement of the quality of intangible aspects of service.

Information on service quality can be gathered from internal and/or external data sources. Internal data are those generated by the staff or management inside an organisation, enabling the organisation to ensure that it is meeting its own internal specification of service quality. However, internal measurement of service quality alone may be of little value if an organisation has no means of assessing whether or not the service levels set internally are generating customer satisfaction. Customers also inevitably assess the quality of the service during and after its provision. Their assessments result in a level of customer satisfaction. Thus service organisations may measure service quality not only on the basis of their own internal data but also by using external data, by monitoring customer satisfaction.

\subsubsection{Customers' perception of service quality}

Perception is the mental function of giving significance to stimuli such as shape, colour, movement, taste, sound, touch, smell, pain, stress and feelings. Perception can be described as "how we see the world around us" (Sureshchandar et al 2002). For example two individuals may be subjected to the same stimuli under the same conditions, but how they recognise them, select them, and interpret them is a high individual process based 
on each person's own needs, values and expectations. Sureshchandar et al (2002) stated that customers often judge the quality of a product on the basis of a variety of informational cues that they associate with it. Some of these cues are intrinsic to the product; others are extrinsic, such as price, storage image, service environment, brand image, and promotional message. Either singly or in composite, such cues provide the basis for perceptions of product and service quality.

Consumers base their product quality evaluations on intrinsic cues, because they can justify resulting product selection decisions (either positive or negative) on the basis of rational or objective product choice. Zeithaml et al (1990) stated that in services, perceptions are what the customer thinks he gets, and are not necessarily the same as the objective quality. According to Peter et al (1993), "the customers perceive service in his/her own unique, idiosyncratic, end-of-the-day, emotional, irrational and totally human terms....there is no such thing as fact and reality". There is only what the customer thinks as reality. The customer's perception in his/her overall feeling about a product or service, e.g. physical tangibles, the intangibles such as politeness of the service provider, are all considered when he/she perceives the service. However, some aspects of the intangibles may be deemed more important, and will be given more weight than others, by the customers. Services cannot be compared side-by-side, as physical products, and service quality relies on extrinsic cues to evaluate. Unlike products which are first produced, inventoried, then sold, then consumed, most services are first sold, then produced and consumed simultaneously. If a product is defective, it is likely that factory quality control will spot it before it leaves the factory; however, since a defective service is consumed as it is being produced, there is very little opportunity to effect corrections to defects; thus laying even stronger credence to the TQM maxim of "getting it right the first time, always" (Crosby 1984).

Perceptions of service quality are influenced by a number of factors, and the two main groups of factors are:

- Personal factors, which relate to characteristics of the individual; and

- Stimulus factors, which are any physical stimuli which influence the customer. 


\subsubsection{Personal factors' influence on perception of service quality}

Humans differ in personalities, needs and preferences, and therefore tend to interpret stimuli and judge quality by different sets of criteria. A customer will judge the quality of the overall service on attributes, which are important to his/her own personality. Learning and past experience also generate expected events or results from stimuli, dictating future perceptions. Similarly, memory and retention also come into play, with the customer's personal characteristics filtering and influencing his/her decision making process. The relative importance of the various characteristics may however change over time, according to experience. Sureshchandar et al (2002) also stated that, the behavioural dispositions discussed above notwithstanding, individuals tend to be subjected to a number of influences that distort their perceptions, and some of these are as follows:

- Stereotypes: individuals tend to carry 'pictures' fixed in their minds, of the meanings of various types of stimuli. These stereotypes serve as expectations of what specific situations or people or events will be like, and are important determinants of how such stimuli are perceived.

- Irrelevant cues: when required to form a difficult perceptual judgement, customers often respond to irrelevant stimuli, e.g. many expensive cars are purchased because of their colour, or luxury options like leather upholstery, rather than on the basis of mechanical and technical superiority.

- First impression: first impressions are often lasting, and introducing a new product before it has been perfected may prove fatal to its ultimate success, because subsequent information about its advantages, even if true, will often be negated by memory of its early failure.

- Jumping to conclusions: many people tend to jump to conclusions before examining the relevant evidence e.g. the customer may hear just the beginning of a commercial message, and draw conclusions regarding the product or service being advertised on the basis of such limited information.

- Halo effect: the halo effect has been used to describe situations in which the evaluation of a single object or person on a multitude of dimensions is based on the 
evaluation of just one or a few dimensions (e.g. a man is trustworthy, fine and noble because he/she looks you in the eye when speaking).

\subsubsection{Customers' expectations of service quality}

The customers' expectations are the standards of reference points for performance, against which service experiences are compared, and are often formulated in terms of what a customer believes should or will happen (Zeithaml \& Bitner 1996). The importance of expectations is showed in literature on service marketing and measurement of service quality. Expectations represent the threshold that sets the required standards with which subsequent experiences are compared, resulting in evaluations of satisfaction or quality (Zeithaml et al 1993). A customer's judgement and perception about the service will be influenced by his/her expectations of the quality level, therefore, a customer with high expectations of quality will perceive the quality of the service as poorer, compared to another with lower expectations. Similarly, a customer can be satisfied because he/she has low expectations about the performance level. Marketing management literature has used expectations to convey a variety of conceptualisations, including the ideal (can be), normative (should be), and predictive (will be) expectations (Hubbert et al 1995). By general usage, predictive "will be" expectations represent the customer's expectations about what will happen in his/her next interaction with the firm; however in service quality literature, expectations are viewed as customers' desire or wants, referring to what they feel a service provider should offer, rather than what they would offer (Parasuraman et al 1988).

Research by Zeithaml et al (1993), suggested that expectations are characterised by different levels, rather than a single level attribute:

- Desired service is defined as the level of service the customer hopes to receive, and is a blend of what they believe "can be" and "should be". However, the customers realise that achieving the desired level of service is not always possible, and they also hold a lower threshold of acceptable service.

- Adequate service, is the level of service the customer will accept, and is lowest level of performance acceptable to the customer. 
- Predicted service, which is defined as the level of service customers believe is likely to occur, and corresponds to definitions of expectation in customer satisfaction literature.

Also Zeithaml et al (1990) stated that there are several key factors that might shape customers' expectations, with all the following factors influencing customers when comparing perceived performance against expectations, which are preconceived and often subconscious:

- First, what customers hear from other customers by word of mouth communication is a potential determinant of expectations.

- Second, according to the survey, respondents' expectations appear to vary depending on their individual characteristics and circumstances.

- Third, the extent of past experience with using a service could also influence customers' expectations levels. More experienced participants seemed to have different levels of expectations compared to inexperienced customers, with the more experienced group appearing to be more demanding.

- Fourth, external communications from service providers play a key role in shaping customers' expectations. The external communications include a variety of direct and indirect messages conveyed by service firms to their customers.

Problems are encountered when trying to measure performance expectations of service. Due to the fact that expectations and perceptions are measured at the same point in time, during/following product consumption, with the expectation data being based on recall, therefore there is a limit on different factors that influence the customers. The data are further influenced by the likelihood that expectations are assessed after product exposure has been influenced by the perceived level performance (Oliver 1993). Informative data can however be obtained when expectations are measured prior to product exposure; however this constraint also limits the accessibility to a meaningful measure of customer expectations in most service encounters. 


\subsubsection{The missing service quality concept}

Gronroos (1982) argued that the customer expectations are affected by how they view the particular company, i.e. the company's image. Therefore, this model is based mainly on the construction of an 'image', which represents the gap between the perceived quality and the perceived service. In addition to that, Gronroos (1982) claimed that two primary dimensions, technical quality and functional quality can describe service quality. Technical quality refers to what the customer of the service actually receives; whereas, functional quality refers to how the customer receives that service. Holmlund and Kock (1995) expanded the ideas of Gronroos by adding a third dimension, economic service quality, which incorporates the idea that business must be profitable. Gronroos (1982) suggested that in order a company to achieve customer satisfaction, it should try to manage the perceived service quality means so that it would match with the customers' expected service.

Therefore, the company should try to keep the gap between the expected and perceived services at the minimum level in two ways:

- $\quad$ Try to keep its promises about how the services will perform by using traditional marketing activities, and as far as the word-of-mouth communication is concerned, it must be realistic with the actual service quality.

- Also, managers have to understand how the different elements of quality are influenced, and, the most important, how these quality dimensions are perceived by the customers.

Brogowicz et al (1990) wrote of core service (what is being offered) and facilitating services (necessary for core service consumption), recalling Kotler's (1992) core, formal and augmented service elements, but little attention to the performance aspect. Various lists of service quality elements or "determinants", take account of the delivery/performance issue, but emphasise intangibles at the expense of tangibles. 
Martin (1986) asserted that restaurant service consists of a procedural and a convivial element, ignoring the core food offering, and effectively defining two sub-components of the "facilitating/functional/process" element of service. These ideas enrich, but also confuse the concept of service quality. The question is on whether it is the quality of a whole service offering, or a part of it. If it is a part the question is which part and of what elements it consists. In this context, Gilmore and Carson (1993) identified a mix of marketing management dimensions of service quality, which include "instrumental" and "psychological qualitative standards". These authors included tangible elements among the former but in fact, from the customer's point of view, all service quality elements have a psychological dimension. Thus the convivial/intangible/psychological aspect of service reflects a softer view of what is being provided, but still regards the provider as "doing something" to the customer.

\subsection{The need for integrated service management in transport and logistics}

Service management and transport and logistics are very interrelated as functions of the supply chain. Generally transport and logistics management are the subsets of supply chain management. The Council of Logistics Management (CLM) in 1998 have defined logistics as "That part of supply chain process that plans, implements, and controls the efficient, effective flow and storage of goods, services, and related information from the point of origin to the point of consumption in order to meet customers' requirements". Lambert (1998), defined supply chain management as "the integration of key business processes from end user through original suppliers that provide products, services, and information that add value for customers and other stakeholders."

The diagram in figure 2-2 shows an overview of supply chain management how closely the transport logistics management is with interrelated that of services management within the context of supply chain management. This is a very important interrelationship for all stakeholders involved in the supply chain process and located within the different geographical regions to which the transport chain is extended. Global supply chain management can only be supported by global transport chains in which both the private and public sector work together. 
For quality to be achieved both in the goods and the services produced and provided these transport chains should be supported by quality transport infrastructure that is interoperable and synchronised though the different modes of transport.

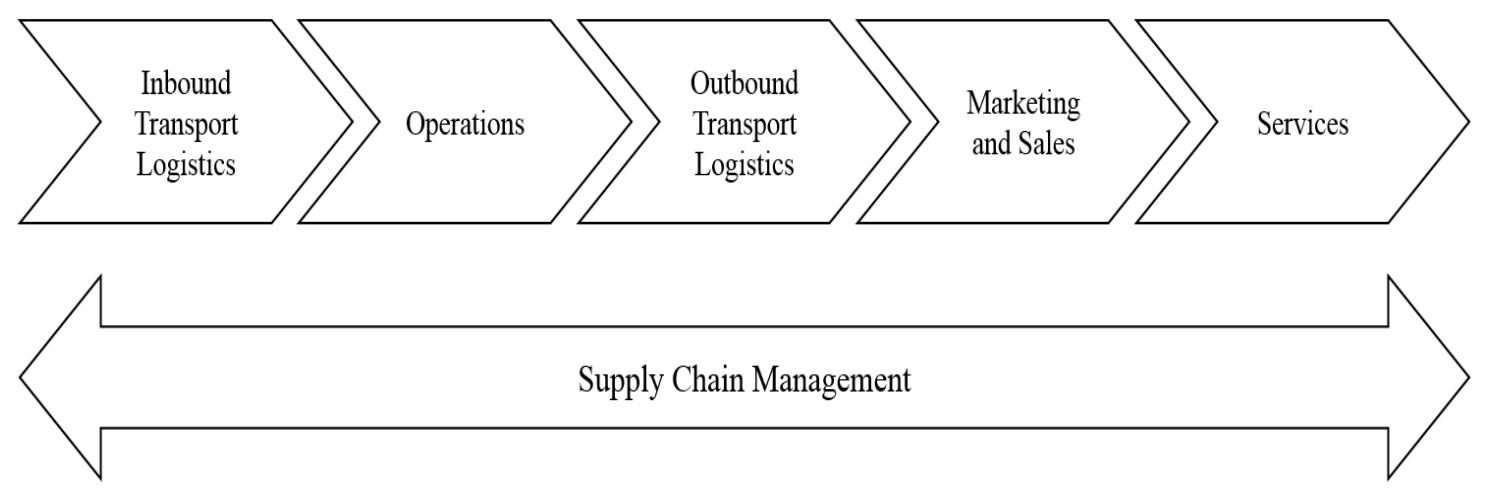

Figure 2-2: Overview of the components of Supply Chain Management Source: Biz - Development 2011

\subsection{Emerging megaregions and logistics gateways}

\subsubsection{Megaregions}

The term megaregion is currently defined in a variety of ways, most emphasizing some aspect of economies of scale and success in social and economic relationships, such as a "network of metropolitan centres and their surrounding areas, connected by existing environmental, economic, cultural, and infrastructure relationships" (Ross et al 2008). Megaregions are very large interconnected urbanized areas in which populations are concentrated and bound together by transportation networks and job markets (Sassen 2007). Other authors have defined megaregional areas using integrating forces such as passenger commute patterns or intercity travel, goods movement, business linkages, cultural commonality (e.g., race), physical and geographical environments, population density, population growth, economic outputs, and projected estimates of national GDP (Lang and Dhavale 2005; Florida et al 2007). The authors further state that megaregional areas should possess two qualities "concentrated populations and the corridor form" to make them excellent geographic units for transportation system organization (Lang et al 2005). Megaregions, as defined by the US Regional Planning Association (2007), are "large networks of metropolitan regions linked by environmental systems and geography, 
infrastructure systems, economic linkages, settlement patterns and shared culture and history."

According to America 2050 (2009) the five major categories of relationships that define megaregions are:

- Environmental systems and topography

- Infrastructure systems

- Economic linkages

- Settlement patterns and land use

- Shared culture and history

While every megaregion may not share every one of these characteristics, the possession of several indicates a stronger and more cohesive megaregion. This means that, within the national economic development framework, each community engaged in recruiting and retaining high-impact companies must learn how to compete on the global stage. For years, economic development organizations, consultants, and investors have advocated a "regional approach" to economic development as the ideal approach to compete effectively on a global scale. In most cases, that "regional approach" simply meant cooperation and collaboration between central cities and their suburban counterparts.

The megaregions of today perform functions that are somewhat similar to those of the great cities of the past massing together talent, productive capability, innovation and markets (Ross 2008). They do this on a far larger scale. Furthermore, while cities in the past were part of national systems, globalization has exposed them to world-wide competition. As the distribution of economic activity has gone global, the city-system has also become global meaning that cities compete now on a global terrain. Urban megaregions are coming to relate to the global economy in much the same way that metropolitan regions relate to national economies. Cities, and now megaregions, are the central engines of economic growth and development (Jacobs 1961, 1969, 1984). A dynamic city, according to Jacobs, integrates its hinterland and becomes a "city region" as national borders no longer define economies. Instead, the mega-region has emerged as the new "natural" economic unit. The megaregion is not an artefact of artificial political 
boundaries, like the nation state or even its provinces, but the product of concentrations of centres of innovation, production and consumer markets.

Today's megaregions extend far beyond individual cities and their hinterlands. Megaregions are more than just a bigger version of a city or a metropolitan region (Florida 2007). As a city is composed of separate neighbourhoods, and as a metropolitan region is made up of a central city and its suburbs, a megaregion is a polycentric agglomeration of citIes and their lower density hinterlands. It represents the new, natural economic unit that emerges as metropolitan regions not only grow upward and become denser but grow outward and into one another. Just as a city is not simply a large neighbourhood, a megaregion is not simply a large city but also is an "emergent" entity with characteristics that are qualitatively different from those of its constituent cities.

\subsubsection{Gateways}

A functional and efficient freight logistics system which provides the ability to move goods is an essential element of modern economic activity (Caris et al 2013). However, the dependence of many freight logistics systems on the movement of goods by road is viewed as being inefficient and unsustainable when compared with rail or waterborne modes (inland \& maritime) which benefit from higher capacity for the equivalent or lower fuel usage (Daamen 2007). This view of sustainability is heavily influenced by the environmental effects that road based freight logistics have (such as air pollution and the impacts of building and maintaining infrastructure). However, this view of sustainability often disregards the potential to enhance the sustainability of this vital mode of transport and reduce or mitigate its negative impacts. The three pillars on which the concept of sustainable freight logistics rests are similar to those associated with the general concept and understanding of sustainability, specifically the environmental, economic and societal pillars (European Commission 2007). It is imperative that all measures aimed at enhancing sustainability seek to strike a balance between these three pillars.

A sustainable freight logistics gateway is best understood as being a city or region which features an efficient freight logistics system, the operation of which contributes both to 
the economic and social wellbeing of the region while having a limited and well understood impact on the environment (IFS 2014). Measures intended to enhance the sustainability of freight logistics should look to increase utilisation rates, reduce the occurrence of empty loading and minimise the environmental impact of freight movements, while facilitating a positive or neutral impact on employment and the socioeconomic make-up of the gateway (Lieb and Lieb 2010). While widespread modal shift is desirable, it is not always possible due to our continuing economic reliance on the ability to move goods quickly and with the inherent flexibility that can be offered by road based freight logistics operations (Larsson and Kohn 2012). Therefore it is being accepted that there will always be a high proportion of goods which will have to travel by road, for part or all of this journey, and therefore, the objective is to reduce the environmental impact of this dominant mode wherever possible and to introduce intermodal transport as an alternative where feasible (D'Este 1996). By reducing the negative impacts of the least sustainable mode there will be benefits for the overall sustainability of specific regions and cities, as well as the countries within which they occur.

Freight logistics operations make a substantial contribution to the socio-economic composition of cities and regions through the provision of employment and the facilitation of economic activity through the movement of goods (Botekoning et al 2004). However, the economic role and importance of freight logistics is constantly evolving as operators move away from the traditional function of simply moving goods between points of origin and destination, instead developing their services to include innovative value added services which enhance the efficiency of the supply chain (Lau 2000). Socioeconomic policy contributes to this process, such as in the provision of funding for education and training and the promotion of increased innovation in the sector. The freight logistics functionality of a city or region can also have negative socio-economic impacts in a variety of ways. With this in mind, it is of great importance that there is a thorough understanding of both the positive and negative impacts that freight logistics have within a city or region (Katayama 1999). 
This understanding is used to introduce suitable policies which encourage the positive implications and limit the negative aspects of the freight logistics operations of the area or region. Improving the sustainability of freight logistics adds significant added value to the overall supply chain, such as through enhancing the marketability of goods produced within the region which can demonstrate such sustainability according to MesaArango and Ukkusuri (2013). For example increasing the corporate social responsibility of companies, in particular multi nationals who may have operations in the city or region, or who are looking to invest. Improved functionality is also attractive to Foreign Direct Investment (FDI) investment as the region demonstrates a capacity to get goods to market faster. An integrated transnational governance structure has an important role to play in enhancing the sustainability of freight logistics within cities and regions. Through the use of such a holistic approach to governance, comprehensive policies and actions have been developed and implemented through transnational consultation, development and collaboration to reduce the negative implications of freight logistics operations. The potential for bias is often viewed as being an issue for the way in which sustainability initiatives are developed and implemented (Schmitter 2010).

Opposite sides of the sustainability debate require incidences of bias to the advantage of their opposition. Transparency within the decision making process, through the use of a sound and verifiable evidence base upon which to frame decision making is the only effective method of removing the possibility of bias from governance. Given the vital contribution which freight logistics makes in facilitating economic activity, governance structures need to be cognisant of the necessity to support the entire sector (Anderson 2005). This normally is at the expense of developing methods which are capable of producing positive benefits for its sustainability (such as promoting technologies which can reduce its environmental impact), and which do not negatively impact upon its ability to support the overall economy. Improved cooperation, partnership and collaboration across the public and private sectors allows for greater oversight, commitment, information and data exchange and the creation of management systems that integrate the needs of all stakeholders into day-to-day decision-making. Improved governance structures have the ability to mobilise the sector towards collective lobbying on policy change, to better position the city or region towards future freight opportunities, to react 
quickly to change and global trends, to support and secure capital investment and EU funding opportunities and to be more attractive for FDI investment into the city or region.

As with governance, an integrated approach to the composition of policies regarding the provision of infrastructure is an integral element in enhancing the sustainability of the freight logistics sector within specific regions and cities. In many countries throughout Europe, the control of infrastructure has become somewhat fragmented, as private enterprise becomes more involved in its provision and maintenance. Congestion is a significant issue for many of the most populated regions of Europe, and places substantial pressures and costs on the available infrastructure. The development and implementation of innovative approaches to minimising congestion is used to incentivise behavioural change amongst all infrastructure users, such as has occurred within London through the congestion charging initiative. It is crucial that decision making regarding the development and provision of infrastructure and the expansion of capacity is founded upon a robust evidence base to allow for well-informed strategic decision making and planning.

\subsection{Challenges of planning for sustainable transport infrastructure}

The term (and concept) of sustainability has become one of ever increasing importance in recent years (Dey et al 2011). The pace at which energy usage grew during much of the Twentieth Century (and continues to grow today) has meant that a sizeable proportion of the known global reserves of fossil fuels are now rapidly depleting. Coupled with this is the vast quantity of $\mathrm{CO}_{2}$ which has been produced as a result of fossil fuel consumption, and which has been widely linked to 'Global Warming' and the associated issues regarding climate change (Tegart and Jolley 2001). It is within the context of the ongoing push for enhancements to sustainability, reducing global dependence on fossil fuels and increasing the efficiency of the way in which we both produce and use energy, that the need to address the level of energy consumption should be seen. Transport has long been accepted as one of the biggest consumers of energy, a huge proportion of which is derived from the burning of fossil fuels. The transport of goods and people is an essential part of modern life and, as such, until such time as alternative reliable fuel sources can be 
developed to take the place of fossil fuels, the transportation needs of society will continue to be met through the use of $\mathrm{CO}_{2}$ producing fossil fuels (Velazquez et al 2015).

Investing in transport infrastructure is a complex process that requires the stakeholders to have a clear idea of how available funds are allocated in order to realise the long term sustainable development of a region's economy (Newman 2015). The evaluation of such projects requires the creation of a simple tool that can be used to provide a projection of long term scenarios. The existing transport infrastructure of a number of key megaregions in many parts of the world is crucially important in serving a number of significant gateways and trade routes that are vital to the movement of goods and resources. It is also likely that the importance will continue to grow in the foreseeable future. However, the recent economic downturn has brought about sluggish trade activity and resulted in a reduced short term outlook for growth. In the long term the forecast for 2050 is quite promising especially for the countries of the developed world. For this to happen capacity needs to be expanded in order to accommodate freight flows which in some cases are expected to double or even triple in size (Barthel and Woxenius 2004).

The design of new container ships, aircraft and rail traction equipment will dictate in the long term how new transport infrastructure such as ports, airports and multimodal terminals will be financed and developed (Feng et al 2012). Currently the existing infrastructure in key locations of emerging mega-regions will face extreme difficulties if they are required to cope with an increase in traffic. The period from 2014 to 2050 is perceived by many experts as being likely to witness a rapid increase in freight flows. As a result there is increasing demand for infrastructure that will be capable of handling this upsurge in an environmentally friendly manner.

Both international and national policies need to be formulated in order to manage this rising trend. Planning and developing major transport infrastructure projects can take years while their lifecycle is expected to be decades or more (Caris et al 2008). There are a number of key ingredients required for the successful planning and development of significant infrastructure in key locations of an existing transport network. Availability of funding and a robust sustainable strategy must be very high on the agenda of any project that hopes to be approved. Moreover quality issues are of vital importance as 
transport infrastructure plays a major role in economic growth, competition and sustainable development. There is little doubt that modern economies rely heavily on infrastructure that is safe, reliable, resilient and able to respond to unexpected events (Yang et al 2010). Improved access to infrastructure and the resultant smooth movement of goods and people through the transport network is essential. This can be more reliably provided by the employment of intelligent and low carbon technologies that are vital for future prosperity. In emerging mega-regions there are a number of international gateways and trade corridors (Todorovich 2009). These physical structures are of enormous economic significance to the regions in which they are found. They provide connectivity, productivity, quality of life and a sustainable environment. It is important though, to take into account the volatility of the economic market. The recent economic crisis that has hit the global economy has made national governments and other key stakeholders keen to re-examine the funding mechanisms and evaluation processes involved in approving the development of new infrastructure (Sason and Reve 2015).

In this turbulent environment and under the new and stricter financial regulations the achievement of economic growth is a challenge. Long waiting times and the complicated application processes are posing a threat to the evaluation and approval of applications for future projects. The current economic environment necessitates the design and application of a framework that will ensure the provision of timely funding for the infrastructure projects with the most likelihood of meeting with success. Infrastructure such as roads, ports, airports, multimodal terminals and others are significant investments that aim to serve their regions in the long term (Kelleher et al 2003). Therefore it is vital that the private and public bodies involved have a good understanding of what will ultimately be expected of a project before they offer their approval to it. When evaluating transport infrastructure projects it is often assumed that a project will deliver economic development, either at a national or regional level (Preston 2001). A methodical understanding of the system is required to determine which transport infrastructure is of regional significance. This approach also aims to strengthen economic and social cohesion throughout an emerging mega-region, by promoting the balanced development of the continent through cross-border, transnational and interregional cooperation. One of the primary objectives is also to minimise the role played by national borders in order to realise equal economic, social and cultural development. 


\subsubsection{Development of sustainable transport infrastructure in regional logistics gateways}

As regions expand and continue to attract significant amounts of the country's population, economic activity, and global connections, they struggle with intense traffic congestion, pressures on the natural environment, resource constraints, and other negative externalities associated with rapid urban growth. Given continued growth, the emerging question is how planners, elected officials, and policy makers should structure transportation and infrastructure investment in order to address the particular challenges and opportunities presented by growing regions. Large cities have always challenged planners but arguably the industrial revolution focused attention on how they might be managed and served by a variety of transportation modes. Also not captured is how the private sector is arguably already working at effectively planning freight movement systems that address issues within metropolitan areas, with the focus on integrating all the metropolitan areas and mega-regional conglomerations served by their networks. Transport planners in the public sector generally view highways as ways of serving the population. Private sector entities, in contrast, see highways as freight arteries where problems in other metropolitan areas can reduce the effectiveness in their own area. Successful transport infrastructure is utterly dependent on efficient freight movement that, while competitive, must in the long term mitigate all the social costs presently associated with goods flows.

Although some planners are sceptical as to how this concept might enhance traditional planning, it does merit examination in the freight transportation sector, which tends to get less emphasis in community and regional planning. Succinctly, transport logistics and freight planning need to integrate transportation plans in a manner that acknowledges the dependence on neighbouring cities, particularly in respect to freight movement modal systems. It seeks also simultaneous goals that address efficiency, competitiveness, modal choice, and sustainability. In addition to the above, transport logistics planning should present "a new perspective on defining regionalism that captures the economic, political and spatial level at which planning should be conducted in order to respond to the challenges of agglomerations of economic activity and population" (Ross et al 2009). 
Transport and logistics planning should also present a new way of approaching largescale transportation systems, green infrastructure, and economic development (Zhang 2011). It is evident that over the last few years many countries in the developed world have invested heavily in developing their transport infrastructure in order to boost their economies and help their local markets to grow at a faster pace (Bartherl and Woxenius 2004). However, during this development phase connectivity and interoperability issues between borders were given low priority. The circumstances have now dramatically changed and the need for planning for improved intermodal transport connections has become of vital importance. This is also evident from the global dimension that proposed and finished transport infrastructure projects have adopted recently. Typical examples are the Pan-European transport corridor projects which aim to minimise the connectivity gaps between the member states of the European Union (Caris et al 2008). Other projects' purpose may be serving only at a local or regional level but consequently could also add value to the national or international transport network due to the location of the infrastructure.

The transnational nature of a project is also of great importance when planning and developing transport infrastructure. What could also prove to be beneficial is the contribution that a project can make to the sustainable development of a geographical area. The term "sustainable development" refers not only to the environmental aspects related to the development of transport infrastructure but also to the social and economic sides that need to be improved. However, for sustainable development to be realised there needs to be proper planning and development for the transport infrastructure. According to Kessides (2004) investment on the development of infrastructure has a direct positive impact on GDP. He also pointed out that the economic growth which results from the creation of infrastructure projects affects both the supply and demand streams of the market as it helps to facilitate trade and the movement of goods and labour. Consequently geographical areas that enjoy new or improved infrastructure provision are also experiencing improvements in the levels of quality of life and reduction in unemployment and poverty. More specifically the increase in quality of life is achieved by creating a balance between the industry and the ecosystem while improved access to transport infrastructure helps the population to move from their home to the workplace, market 
places and others. The most influential and commonly used definition relating to sustainability was actually compiled to describe sustainable development. Popularised by the landmark publication 'Our Common Future' (also known as the Brundtland Report 1987), this definition has been influential on much of the work to define other elements of sustainability which followed. It defined sustainable development as "Development which meets the needs of the present without compromising the ability of future generations to meet their own needs". As a result of this document, it is generally recognised that sustainable development calls for a convergence between the three pillars of economic development, social equity, and environmental protection. However, while this definition of sustainable development was formulated to encompass these three pillars, it is often considered as predominantly an environmental issue.

Utilising sustainable development and the wider sustainability concept necessitates an understanding of the complex interconnections and interdependencies that exist between the environment, economy, and society. Rather than seeking to impose a balance between these three pillars, efforts to promote sustainability must recognise the interdependent nature of these pillars, and implement solutions which best suit these interdependencies. Indeed defining and implementing sustainable solutions has often proved to be problematic due to the inherent tensions between the three pillars, and the prevailing 'influences' at different points in time. This is an issue which is particularly true in the area of freight logistics, where the cost of service provision is frequently the deciding factor for operators and customers alike. Although the definition of sustainability which emerged from the Brundtland Report remains the most important definition to date, it does not suit all applications. Sustainability, as a definition, has now grown beyond being only relevant to physical development. Other areas and disciplines are now also embracing the ideal that sustainability, as a concept, can bring about real benefits. One such area is that of economics, with the formulation of policies which have as their core aim the achievement of sustainable economic growth.

According to the European Commission 'sustainable growth' means:

- Building a more competitive low-carbon economy that makes efficient, sustainable use of resources; 
- Protecting the environment, reducing emissions and preventing biodiversity loss;

- Capitalising on Europe's leadership in developing new green technologies and production methods;

- Introducing efficient smart electricity grids;

- Harnessing EU-scale networks to give our businesses (especially small manufacturing firms) an additional competitive advantage;

- Improving the business environment, in particular for SMEs; and

- Helping consumers make well-informed choices.

The promotion of, and adherence to, the ideals of sustainable growth, has the potential to enhance the viability of small companies and small economies alike within the overall European and wider Global economic contexts. In addition to sustainable growth, another area which is now coming under the influence of the concept of sustainability is that of competition. The World Economic Forum defines sustainable competitiveness as "The set of institutions, policies, and factors that make a nation remain productive over the longer term while ensuring social and environmental sustainability" (2012). Both of these concepts can be seen to have drawn on the three pillars identified as being the foundations of sustainable development as defined within the Brundtland Report. As can be seen in its application within an economic context, the three pillars which are a key element within the Brundtland Report's definition of sustainable development are equally applicable within other contexts. It can be shown that, through adaptation, the concept of sustainability can also produce real benefits in the formulation of policies and strategies, producing economic, environmental and societal benefits. It is with this in mind that a number of organisations have sought to develop definitions for sustainability in transportation. The World Business Council for Sustainable Development has transferred Brundtland's definition of sustainable development to transport systems and defines sustainable mobility as the "ability to meet the needs of society to move freely, gain access, communicate, trade, and establish relationships without sacrificing other essential human or ecological values today or in the future" (WCED, 1987). 
The European Commission (2005) has also sought to provide a clear and detailed interpretation of sustainability within the area of transportation. Also drawing heavily on the work of the Brundtland Report, it defines a sustainable transport system as one that:

- Allows the basic access and development of individuals, companies and societies to be met safely and in a manner consistent with human and ecosystem health, and promotes equity within and between successive generations;

- Is affordable, operates fairly and efficiently, offers choice of transport mode, and supports a competitive economy as well as balanced regional development;

- Limits emissions and waste within the planet's ability to absorb them, uses renewable resources at or below their rates of regeneration, and uses non-renewable resources at or below the rates of development of renewable substitutes while minimizing the impact on the use of land and the generation of noise.

This definition can be seen to encompass a wide range of areas and issues which can be influenced by or exert influence on transport. In this way, this definition is intended to be a starting point for the formulation of policies at EU and National levels which can enhance the sustainability of all forms of transport throughout Europe.

\subsubsection{Freight transport infrastructure networks}

Most countries in the North West region of Europe have experienced a rapid growth in their foreign trade in recent years. The preservation of these healthy trade figures in to the future will depend on the availability of adequate transport infrastructure and on the adoption of modern, systematic approaches to infrastructure management (Heddebaut 1999). Freight transport networks are primarily composed of links (sections of road, rail, and inland waterway) accompanied by nodes (freight handling rail terminals, seaports, airports, inland ports). Road networks of significance to the regional transportation of freight are typically made up of motorways and a small number of major supporting roads of less than motorway standard. The relevant rail network consists of both high speed 
and conventional lines which are typically used for the transportation of both passengers and freight. In terms of sustainability, electrified sections of the rail network provide advantages over sections where locomotives are diesel powered. Inland waterway networks include navigable rivers, canals and inland ports. Inland ports often play a major role in the local distribution network. In comparison, sea ports are seen as facilitators of regional growth and development. All ports provide connections to other modes of transport, typically road and/or rail.

In the freight industry airports represent the specialist niche of long distance, high speed and often high value freight movements. The focus of an airport (passenger, freight, combined) influences the volume of freight handled and the subsequent level of involvement of that airport in the freight industry. The airport's focus will also influence its level and type of connectivity with other modes of transport.

\subsubsection{Intermodal transport and the vision of co-modality}

The OECD (2002) as shown in figure 2-3 defines Intermodal Transport as the:

"Movement of goods (in one and the same loading unit or a vehicle) by successive modes of transport without handling of the goods themselves when changing modes."

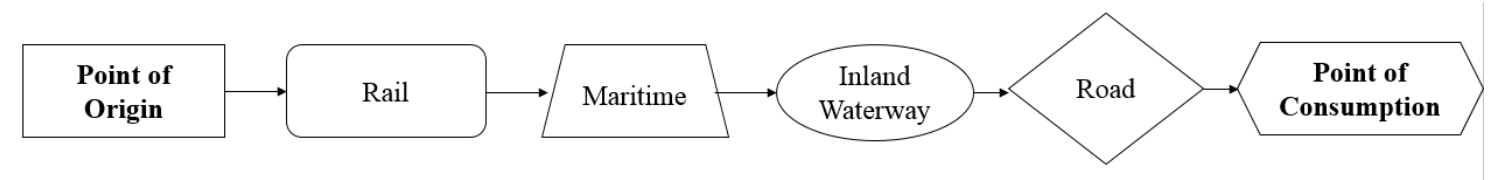

Figure 2-3: Intermodal Transport

Source: Own

The term "loading unit" refers to intermodal transport units such as containers, swap bodies, road or rail vehicles, and waterborne vessels. Through intermodal transport advanced transport chains can be created where goods are transported efficiently from origin to destination. Such transport chains meet the needs of producers, suppliers and consumers whilst also addressing environmental concerns by avoiding unnecessary vehicle movements (Trip and Bontekoning 2002). Key to this development is the implementation of modern logistics management systems which address factors such as 
waiting times, route selection, and cost reduction. These systems are essential in providing the level of performance and synchronisation necessary in modern supply chains where it is essential that the seamless transportation of goods is achieved from origin to destination through different modes of transport. The seamless operation of a transport network is a complicated task requiring a wide array of systems to interact effectively (D'Este 1996). An essential part of these systems is the use of standardised documents. Increasingly this is in an electronic format geared towards allowing both private and public sector organisations to interact effectively through a transparent, supply chain management platform that also offers accurate cargo condition, traffic, tracking, timing and safety data.

The benefits of intermodal freight transport include:

- Utilizing the "best" mode for a given leg of a journey.

- The combination of different modes of transport with the benefits of one being used to negate the shortcomings of another. In combining a variety of modes a competitive advantage can be produced.

- $\quad$ Making use of otherwise unused capacity, such as is the case with long distance railway services.

- Improved security. Individual units don't need to be opened in transit.

- $\quad$ Reduction of traffic and congestion on highways.

Increasing congestion on the road network has made intermodal transport a hot topic in the transport industry. As a result, National governments are aiming to stimulate intermodal transport in order to achieve a modal shift away from road, towards rail and waterborne transport (Weisbrod et al 2001). The new vision of co-modality was introduced by the European Commission in 2006 and called for the combination of different modes of transport with a view to optimising in a more sustainable manner the different resources available (Wassalo 2008). This concept also emphasized the need to adopt a set of wider objectives such as commercial, monetary and sustainable growth. Infrastructure planning was accordingly shaped at both national and international levels to provide a combined approach to future infrastructure provision. However nowadays for the provision of transport infrastructure to be adequate in the long term good planning, 
project selection and the evaluation of selected factors needs to be performed. Some of these factors will relate to reducing levels of $\mathrm{CO}_{2}$ emissions and protecting communities from the environmental impacts of the already substantial amounts of $\mathrm{CO}_{2}$ that are being emitted. The notion of co-modality supports initiatives associated with enhancing "greener transport" as they are both aimed at achieving optimal sustainable scenarios in freight movement.

\subsubsection{Modal shift and intermodal transport network development}

The development of a more sustainable intermodal transport network requires the identification of the "level of use" of existing infrastructure as an indicator for determining which links and nodes are the most heavily used. For the integration of different modes of transport to take place infrastructure usage should be assessed both quantitatively and qualitatively (Kengpol et al 2011). This will give an indication as to which parts of the network are essential to the movement of freight and therefore must be included in any plans for the development of a more sustainable intermodal freight transport network (Klibi et al 2010). This will also indicate which sections are currently underutilised and could absorb more freight movements. From an economic perspective it is often stated that the development of a more sustainable intermodal freight transport network would require substantial investments in infrastructure, equipment and technology. In comparison, from an operational perspective it is believed that new infrastructure is not required but the more efficient use of existing infrastructure would be a better way to deliver an improved network (Profir 2011).

Regardless of this, to ensure the most efficient use of the existing infrastructure it is essential to understand the strengths and weaknesses of each transport mode. These are commonly agreed to be as shown in table $2-1$. 
Table 2-1: The strengths and weakness of transport modes

\begin{tabular}{|c|c|c|}
\hline $\begin{array}{l}\text { Transport } \\
\text { Mode }\end{array}$ & Strengths & Weaknesses \\
\hline Road & $\begin{array}{l}\text { Door to door service, many } \\
\text { alternative routes, suited to ad } \\
\text { hoc flows, low unit operating cost } \\
\text { for small volumes. }\end{array}$ & $\begin{array}{l}\text { High perceived environmental and } \\
\text { social impacts, high unit operating } \\
\text { costs for large volumes, open } \\
\text { access to infrastructure leads to } \\
\text { network congestion. }\end{array}$ \\
\hline Rail & $\begin{array}{l}\text { Hauls large volumes in a single } \\
\text { train load, low unit operating } \\
\text { costs for large volumes, } \\
\text { timetabling to avoid congestion, } \\
\text { suited to regular flows, low } \\
\text { perceived environmental and } \\
\text { social impacts. }\end{array}$ & $\begin{array}{l}\text { Limited network coverage, route } \\
\text { capacity and capability } \\
\text { constraints, transhipment costs } \\
\text { and risk, road use is often required } \\
\text { at one or both ends of a leg. }\end{array}$ \\
\hline Water & $\begin{array}{l}\text { Moves a large volume in a single } \\
\text { vessel, low unit operating costs } \\
\text { for large volumes, uses natural } \\
\text { transport corridors, low perceived } \\
\text { environmental and social impacts. } \\
\text { Weaknesses: }\end{array}$ & $\begin{array}{l}\text { Limited network coverage, low } \\
\text { operating speeds, road use is often } \\
\text { required at one or both ends of a } \\
\text { leg, tidal constraints, susceptible } \\
\text { to weather conditions. }\end{array}$ \\
\hline Air & $\begin{array}{l}\text { Uses natural transport corridors, } \\
\text { low perceived environmental and } \\
\text { social impacts, high operating } \\
\text { speeds, timetabling to avoid } \\
\text { congestion. }\end{array}$ & $\begin{array}{l}\text { Aircraft capability constraints, } \\
\text { limited network coverage, moves a } \\
\text { small volume in a single aircraft, } \\
\text { high unit operating costs for large } \\
\text { volumes, road use is often required } \\
\text { at one or both ends of a leg. }\end{array}$ \\
\hline
\end{tabular}


The modal choice decision making process undertaken before a shipment is dispatched requires a complex evaluation analysis of the advantages and disadvantages of each mode. This comparative analysis, typically undertaken in the head of a company's operations manager, has been modelled by academics in what has become known as multiple criteria decision making (Moghadam et al 2009). It is interesting to note that in some cases regardless of its strengths and weaknesses a particular mode will dominate the transport chains of a region. This could be due to the characteristics of the region promoting the use of a particular transport mode ahead of others e.g. an island nation. Alternatively, the carriage of particular cargo types can also be dominated by a certain mode as it best meets the most desired transport requirements e.g. fruit, jewellery. The currently high levels of road based traffic and the resultant congestion are also high on the agenda of the European Commission.

There is a need for measures to be taken to improve the situation. Modal shift is seen as the solution to the problem. However, for modal shift to be achieved competitive services must be made available to all stakeholders operating at various points along a supply chain allowing everyone involved to benefit from improvements to the system that they are part of (Tsamboulas et al 2006). For a modal shift policy to be successful a number of other managerial, technical and economic issues must also be resolved.

These issues include:

- The synchronisation of different transport modes.

- The consolidation of traffic in modernised intermodal transport terminals capable of handling smart intermodal loading units.

- The application of efficient handling practises for both standardised and nonstandardised loading units in order to accomplish interoperability.

- Reduction of overheads in relation to transits.

- Improvement of transport reliability.

- The improvement of the existing regulatory framework with new laws and regulations complemented by relevant policies, standards, directives and guidelines. 
The decision making process that a shipper goes through when choosing which mode of transport will carry a shipment is complex. Moreover this process is market driven with a number of criteria such as reliability, time, cost, safety, and security all playing a role in the selection process. With this in mind, influencing the modal choice selection process to bring about a change in freight transport modal share is a difficult task. Globalisation is one of the main drivers behind the development of integrated transport systems. Within this context the enlarged European Union has to keep pace with new trends and to adjust its policies and strategies accordingly. In turn the requirements of global production and distribution have also made it necessary for the transport sector to modernise its operations and evolve.

One outcome of this is that the documentation of shipments on both the upstream and downstream sides of supply chains has improved significantly. Another outcome is that the equipment required for the transport of goods (such as vehicles and loading units) has been adapted and configured to comply with new international standards and specialised product categories. However, the transport sector is experiencing major challenges and changes as a result of geographical restructuring and the resultant new market forces. The emerging markets that have been created require the redesign of existing supply chains and their conformance with a new set of performance indicators. Despite ongoing infrastructure development and technological advancements a transport system cannot achieve the same levels of efficiency in all regions (Vickerman 1996). This is because enormous inconsistencies exist between different parts of the world. Such discrepancies are evident in Europe between the southern (Portugal, Greece, Spain) and northern (Germany, France, United Kingdom) regions.

This is not a new occurrence, throughout the various stages of the freight transportation industry's evolution various gaps exist which have at first needed to be identified and then subsequently resolved for the benefit of all. These solutions have often required substantial investments to be made in terms of both time and cost. The last most significant improvement to the freight transportation system came when the shipping industry introduced intermodal containers (Thill and Lim 2010). 
Containerised freight transport is now a central part of global integrated intermodal transport systems. Containerisation has provided:

- An uninterrupted flow of cargo through the links and suitably equipped nodes of all transport modes.

- The ability to easily move cargo between different modes of transport.

- Reduction of risk and hazard to cargo during the journey.

- Reduction of costs associated with loading and unloading operations.

- Simplified tracking and tracing of consignments to a geographical location.

- Reduction of unnecessary administrative barriers through the simplification of the documentation process.

International trade has been revolutionised over the last few decades as a result of the containerisation of goods. Estimates state that $90 \%$ of the world's non-bulk freight is now carried in intermodal containers. These move through container facilities that also offer increased connectivity, security and "door to door" traceability.

\subsection{Performance evaluation gaps of critical priority transport infrastructure projects in regional logistics gateways}

There is an agreement between industrial stakeholders and academics that improper planning and implementation of an infrastructure project may have adverse effects on a society's economy and environment. GIS has the ability to capture and to map the distribution patterns of the trends related to the demographics of a geographical area. A better appreciation of these dynamics is needed in order to plan and develop a transport infrastructure that will achieve sustainable development.

In some cases an infrastructure investment can pose a threat to the communities that are directly affected. Therefore it is imperative that a performance assessment is carried out before, during and after the planning phase in order to measure the positive or negative impact that a transport infrastructure project may have against a set of different socio economic and environmental future scenarios (Day and Zou 1994). There are a number of different methodologies for the evaluation of the impact that a project may have in the 
short and long term from an economic, social and environmental perspective. The majority of these methodologies are primarily focusing on the performance measurement that a project is having or will have within the economic, social and environmental dimensions only, without taking much into consideration on how the project will provide a sustainable balance between them.

This lack of focus has led in the last few years to the need for the adoption of an integrated methodology with emphasis on the creation of balance between these different dimensions and also on sustainable development when an infrastructure project is planned. Another downside of the conventional modelling and evaluation methodologies is that there is no consideration of the relationships that exist between the performance dynamics of an infrastructure project. This is one of the primary reasons that an understanding of these performance parameters should have a high priority in all stages of a project's implementation particularly for those that require increased funding and long periods of implementation time.

\subsection{The need for an integrated evaluation methodology}

Investments in transport infrastructure and regional economic development are closely interrelated and as a result they can also be quite complicated. This belief is also justified by the findings of recent research studies which explored the linkage between transport infrastructure investments and economic growth. The benefits of these investments are usually expected to be evident both in the national and international level of a megaregion. However, in some cases, one geographical area may not have received the same level of investment compared to another. Therefore there has been a growing interest over the last few years for the stakeholders involved regarding the level of local, regional or national impact that an investment in transport infrastructure may have.

From a decision making perspective the evaluation and analysis of investment proposals both during and after the planning phase of a project may prove to be quite complex for the targeted geographical areas that are planned to change or to be re-developed. In most cases the ongoing interventions have long term objectives to achieve and the developed transport infrastructure aims to serve the public for many years. Consequently, 
the evaluation stage of the preliminary investment proposals necessitates the consideration and employment of a number of different parameters and criteria. The selected criteria also need to reflect the different socioeconomic and environmental dimensions on which the proposed transport infrastructure is looking to make a positive impact. A scientifically sound methodology is proposed in this research in order to create and to assess the scenarios that a transport infrastructure investment is looking to generate and to fulfil in the future. This also heavily depends on the quantity, quality and also the availability of data that can help to create significant supply and demand scenarios.

\subsection{Summary}

Decision makers need to have a good understanding of how service is being perceived and is expected to perform within the transport sector by the stakeholders that operate within an emerging megaregion's logistics gateway. For quality products and services to be provided it is critical that the quality and service of the transport infrastructure is also of high standards. Supply chains that operate at a global level have their transport chains of products and services which depend on quality transport infrastructure that is expected to be interoperable, co-modal and sustainable. In this chapter an integrated literature review was produced covering important and relevant topics to the research topic under investigation that of service performance of transport infrastructure in logistics gateways of emerging megaregions. The management science behind the creation and provision of service quality in transport and logistics has been extensively covered in combination with the transport geographical issues as the new trends of global supply chains management. These are the concepts of logistics gateways and emerging megaregions which have been also extensively covered in this literature review.

The next chapter explains the methodology of this research. It is important to have a clear understanding of which research tools and techniques are particularly important to the research topic and also how they relate to service performance measurement and decision making with respect to creating a sustainable transport infrastructure system based on stakeholders' perception and expectations. 


\section{Research methodology}

\subsection{Introduction}

Currently in the existing service operations management literature there is a lack of service performance evaluation methodologies that could provide a reliable assessment of the performance of existing and planned transport infrastructure with respect to service quality, modal shift and sustainable development. The literature covered in the previous chapter is applicable to traditional business models but there is a need for service operations performance evaluation models and decision making techniques to be adapted in the modern context as there is a need for the development of sustainable transport infrastructure systems in regional logistics gateways located in emerging megaregions. The following diagram in figure 3-1 shows the research structure of this thesis and the links that exist between the different chapters. This research methodology chapter takes over from the literature chapter and serves chapters four, five and six which are at the core of this thesis.

In order for the research methodology to be developed many interrelated concepts had to be grouped and organised as main inputs in combination with various research tools and techniques. As shown in the diagram in figure 3-2 the methodology clarifies the philosophical stance of this research and what is the research strategy and choice based on the "research onion approach" as explained in more detail in the following section. Different research approaches also serve as inputs to the construction of the research methodology such as the exploratory research, action research and the balanced approach which will be explained in more detail in this chapter. Another important input is the selection of case studies for the analysis of the service performance of the transport infrastructure and the generation of future sustainable development scenarios in selected gateways of the emerging megaregion on North West Europe. The diagram in figure 32 also demonstrates how the multicriteria decision making methods (MCDM) are employed for the collection and analysis of data with the objective of producing two main research outputs which are the service performance analysis and the development of future scenarios for regional logistics gateways. 


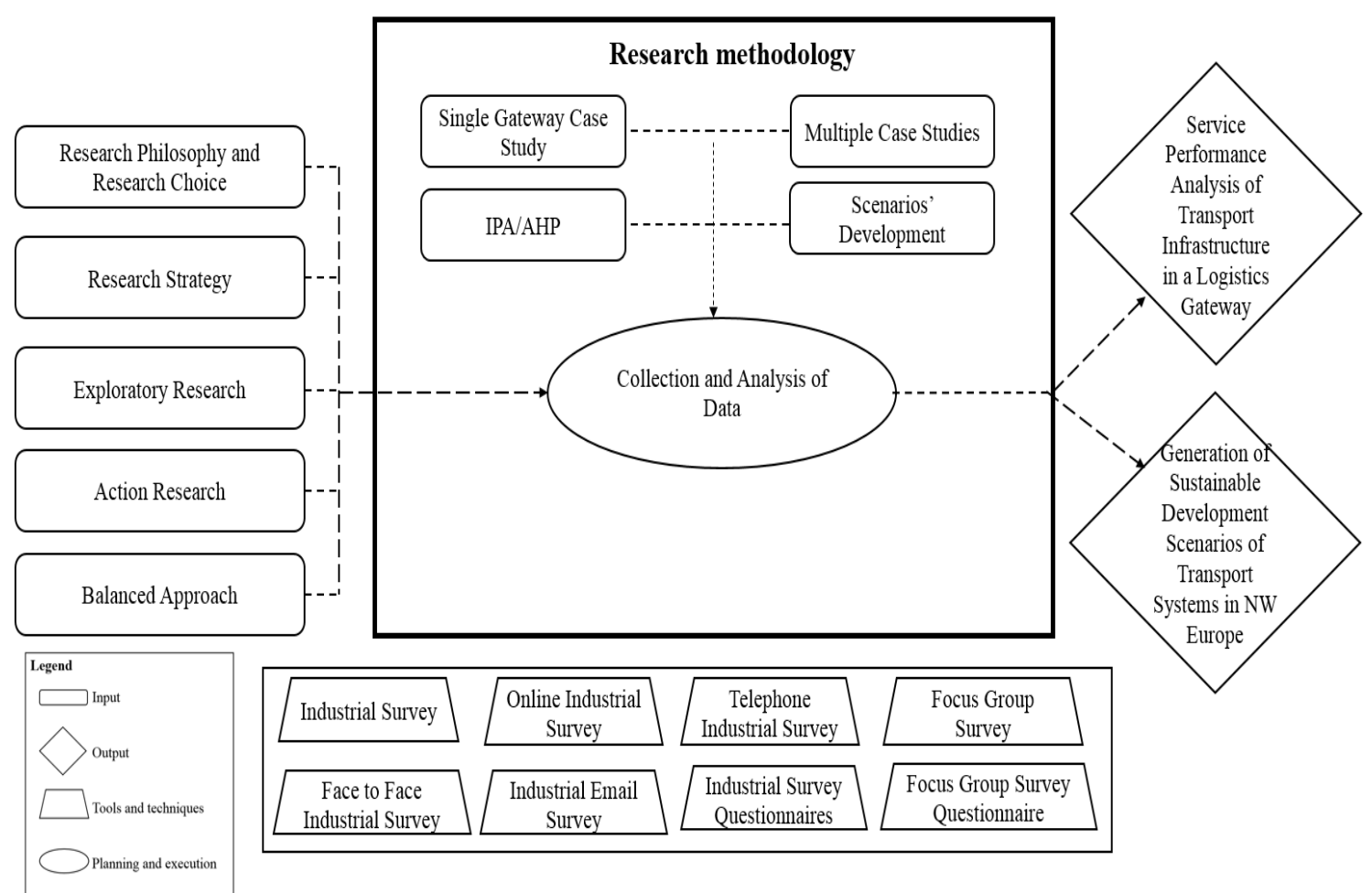

Figure 3-1: Research methodology planning and process

\subsection{Research design}

For the research design this thesis uses the categorization which has been suggested by Saunders et al (2009). The following categorization in figure 3-3, which has the distinctive title "research onion", illustrates the various components of a research project using the layers of an onion.

The top layer represents the choice of the research philosophy while the next layer is the choice of the research approach (i.e. deductive or inductive). These layers are followed by the layers of the research strategy and the research choice respectively. These are where the research chooses how the data will be collected and what type of data. The fifth layer represents the time horizon of the research conducted and final layer represents the data collection and analysis process. The "research onion" framework provides a structure to this research in order to follow a more specific and less general format. This is simply because researchers must first choose the philosophy of their research before their research approach and the method of research is chosen. Another reason is because the outer layers determine and limit to a large extent the kind of choices of internal layers. 


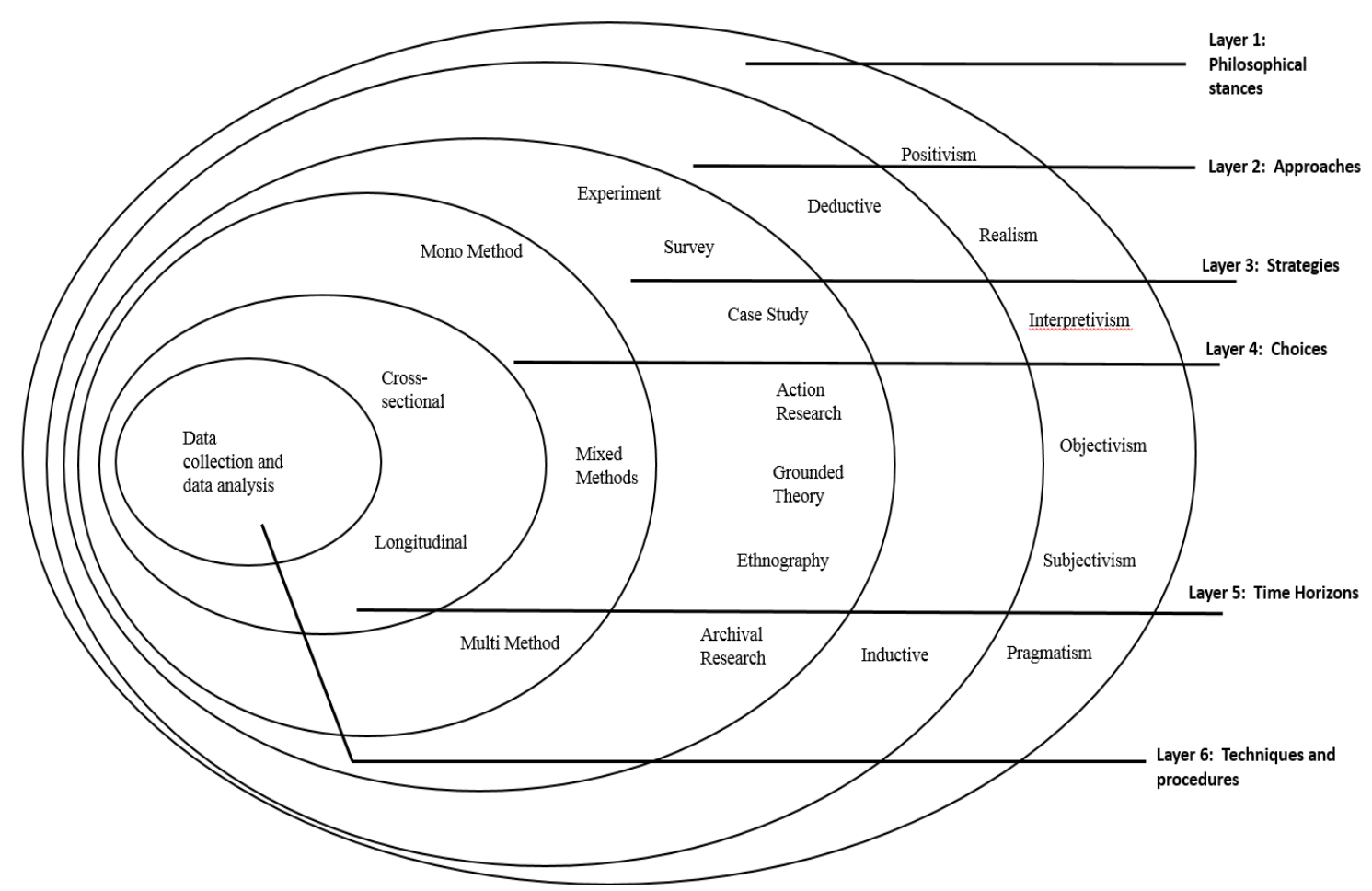

Figure 3-2: The "Research Onion" approach

\subsection{Research philosophy and research choice}

The researcher is affiliated to positivism, as a philosophy of research. Although the fact that modern theories of social sciences deviate from positivism because as a philosophy it is in favour of unobservable constructs (Godfrey and Hill 1995), the researcher takes the view that, in the disciplines of strategy and performance evaluation, that positivism as a philosophy is more appropriate in relation to the alternative research philosophies. Other reasons also for the selected research philosophy, are specific and therefore can be subject to research and study on the basis of the reasonable documentation. Therefore, the subject of strategic management is compatible with the axiomatic assumptions of positivism, namely, that knowledge is objective - independent of the observer - and is based in logic, in perception and positive verification (Wicks and Freeman 1998).

A researcher can determine the research approach beforehand, which can be either deductive or inductive. The type of this research is both exploratory and causative as the objective is the collection of data related to the general nature of the research problem (Saunders et al 2009), as relational observation cases and to investigate differences in the 
characteristics of population groups. On the other hand, the objective of the research is to discover the relations between cause and effect governing elements of the phenomenon under examination (Trochim 2000). At the heart of logistics and supply chain research it is the researcher's idea about a particular phenomenon. Once the phenomenon is identified (i.e. the level of use on different modes of transport), the researcher sharpens the focus of the proposed study by developing research questions.

\subsection{Selected research strategy}

The main objective of the proposed research strategy is the investigation and explanation of the reasons that some factors have highest performance in relationships with others in the field of intermodal freight transport and sustainable development (Amit and Zott 2001; Ceccagnoli 2009). As this research focuses on the collection of observations from the business environment, the research strategy, or method of research used in accordance with the Saunders et al (2009) "research onion" framework, is a combination of a preliminary exploratory research followed by a single case study with a field industrial survey and a multi-case focus group survey.

The field research, as a method of investigation, was chosen because it is the most common method in studies (Saunders et al 2009) and also because this research strategy largely determines the research method followed. Moreover, this research is aimed at capturing spontaneous answers and information without the biased effect of the researcher. For this reason as part of the overall research strategy has been to participate without the interference of the researcher, in the natural environment of the interviewee, not constructed, or technical environment.

\subsubsection{Exploratory research}

Exploratory research is a form of research based on available secondary data when examining a research problem that is not clearly defined and requires the research to understand more about it before conducting a primary research analysis. A preliminary exploratory research analysis also seeks to lay the basis that will prompt additional and more in depth analysis based on primary data. Likewise in this research chapter four 
provides a preliminary exploratory analysis for the identification of the research setting in order to facilitate a research methodology in chapters six and seven where original primary data were have been collected.

\subsubsection{Action research}

Action research is a research method used to tackle an existing problem in a dynamic critical thinking manner and it is often initiated and carried out by a number of people working with others in groups or as a feature of a "group of practice" to enhance the way they address issues and take care of issues. Action research includes effectively participating in a change process activity, frequently by means of a current association, by carefully monitoring progress and the achievement of agreed objectives by the research group. Elements of action research can be found in this research as the researcher participated in the action research group of the European project Weastflows which carried out activities aiming at the efficient and sustainable freight transport in order to help deliver economic, social and environmental benefits to communities and businesses from 2011 to 2015 . This has helped the researcher to engage in an action research process which allowed access to data collection, experts' opinions and the observation of industrial case studies.

\subsubsection{Single case study survey}

A case study is an in depth study of a particular situation and also is a method used to narrow down a very broad field of research into one easily researchable topic. The case study research design is also useful for testing whether scientific theories and models actually work in the real world. The case study is the most flexible of all research designs, allowing the researcher to retain the holistic characteristics of real-life events while investigating empirical events. Case studies are only one of many ways of doing social science research, with experimentation, observation, surveys and archival information (as mentioned above) each suited to a certain type of research problem, degree of experimenter control over events and historical/contemporary perspective and focus. 
In chapter five of this research a single gateway study was selected for an industrial primary survey analysis by combining quantitative and qualitative data as well as observations.

\subsubsection{Focus group multi-case survey}

A focus group is a form of qualitative research in which a group of people are asked about their perceptions, opinions, beliefs, and attitudes towards a product, service, concept, advertisement, idea, or packaging. Questions are asked in an interactive group setting where participants are free to talk with other group members. For the needs of chapter seven a multi-case survey methodology was selected in order to identify critical transport priority infrastructure projects in the emerging megaregion of North West Europe. Participants in the focus group were pre-selected experts from the transport industry who were asked to provide their views on existing and planned transport priority infrastructure projects by using a research tool which allowed the researcher to produce long term scenarios with respect to sustainable development.

\subsection{Time horizon of the research}

This research was undertaken primarily to answer a question or address a problem at a particular time; this 'snapshot' is considered to be cross-sectional and it has made use of a single case study survey in chapter six. However chapter seven conversely, attempts to answer a question or address the problem by collecting data for an extended period of time, and therefore the research in that case is considered to be longitudinal as it is forecasting long term scenarios for sustainable development in different regional logistics gateways located within the emerging megaregion of North West Europe.

\subsection{Data collection and analysis}

Data collection is the process of gathering and measuring information on variables of interest, in an established systematic fashion that enables one to answer stated research questions, test hypotheses, and evaluate outcomes. The data collection component of research is common to all fields of study including physical and social sciences, humanities, business, etc. While methods vary by discipline, the emphasis on ensuring 
accurate and honest collection remains the same. The goal for all data collection is to capture quality evidence that then translates to rich data analysis and allows the building of a convincing and credible answer to questions that have been posed. Secondary qualitative data were collected by carrying out a desktop survey in chapter four by using the geographical information systems (GIS) in order to identify the research setting. This process allowed the researcher to gain an understanding of the Liverpool - Manchester regional logistics gateway's dynamics with respect to its service performance, levels of modals shift and sustainable development. In order for data to be collected and analysed in chapter five an industrial survey was carried out aiming to gauge the views of stakeholders involved in the specific regional logistics gateway regarding their perceptions on the performance of the existing transport network. An array of universal indicators were used in order to develop the data collection and analysis model against a number of determinants of service quality.

A crucial stage in the formulation of operations strategy is the derivation of a ranked (or rated) list of competitive factors such as quality, flexibility, cost, etc. This list is used either to infer an appropriate set of strategic operations decisions or, in conjunction with an independently derived list of the organisation's performance to prioritise each of the competitive factors (Slack, 1994). In chapter five the importance-performance analysis (IPA) was employed in order to map stakeholder's perceptions and to position the scores within a service performance matrix for each mode of transport. Analytical hierarchical process (AHP) was then applied in order to validate the findings of the IPA analysis with pairwise comparisons of the selected indicators.

\subsubsection{Importance-Performance Analysis (IPA)}

In this framework the manufacturing competitive priorities are determined in respect of both their importance for customers and the current performance of the company against its competitors. The IPA framework was first introduced by Martilla and James (1977) and since then has been widely used mainly in marketing research, quality and service operations management, usually focusing on customer satisfaction issues. Numerous practitioners and researchers have applied importance-performance analysis (IPA) to identify the critical performance attributes in customer satisfaction survey data for 
products and services. The technique, based on the conceptual foundations of multiattribute choice models, is designed to identify the strengths and weaknesses of an object (e.g. a hospital) in terms of two dimensions which consumers employ in evaluating that object. The first is the relative importance of the attributes to consumers. The second is consumers' assessment of the performance of the object in terms of these attributes (Yavas and Shemwell 2001).

An alternative technique to IPA which was considered for this research has been the SERVQUAL methodology which was proposed by Parasuraman et al in 1988 based on the five dimensions of service quality, namely, Tangibles, Responsiveness, Reliability, Assurance, and Empathy. They also developed and proposed a 22 item instrument for assessing the quality of any service and this is referred to as the SERVQUAL instrument (Aigbedo and Parameswaran 2004). SERVQUAL's similarity to the IPA is that the construct measures the difference between a respondent's perception of a given service and his or her expectation regarding that service. The SERVQUAL's applicability however could not be possible in this research as the five dimensions of service quality are not relevant in a transport research setting.

Slack in 1994, proposed a modified importance-performance matrix in order to prioritise improvement programs related to different manufacturing competitive factors. Slack's (1994) importance performance matrix uses a more detailed approach to service competence, defining four different zones in chapter six for the fit/misfit between importance and performance of competitive criteria between the different modes of transport. The different zones of Slack's importance performance matrix are described as follows:

- "Urgent action" zone refers to the competitive factors that are very important for customers (i.e. order winners) but the mode's performance on these factors is lagging behind other modes of transport, therefore extremely less sustainable;

- In the "Improve" zone the misfit between importance and performance is still smaller but still exists; 
- The "Appropriate" zone is the ideal place, where the performance of one of mode of transport against other modes of transport exceeds importance therefore it is sustainable;

- Finally, in the "Excess" zone the particular mode of transport under investigation provides an even higher service performance required by the users of the transport infrastructure network, therefore the focus should be shifted on improving other criteria.

Figure 3-4 shows the adapted importance-performance matrix for this research, where the two variables importance and performance perceived by the users of the transport network, are measured on the horizontal and vertical axis respectively. In chapter five of this research for measures of the service performance of different modes of transport a five point scale was used in order to be consistent with the measurement used in the questionnaire applied for the industrial survey (the original nine point scales of Slack were converted to five point scales, and the same approach was used to determine the boundaries of the zones). The importance-performance matrix offers a more refined operationalization of the notion of fit between importance and performance competitive factors for sustainable development of every transport made within the regional logistics gateway under examination. Therefore, the proposed research framework aims to empirically test the usefulness of the importance-performance matrix in strategic service operations transport management decisions by linking it to sustainable development performance indicators as shown in figure 3-4. Over the last few years the IPA technique and tool has been used by many researchers in many different sub-fields of operations management. Some examples are provided in table 3-1.

In this research a novel approach is provided for a proposed framework for the service performance and sustainable development of intermodal transport infrastructure in regional logistics gateways within emerging megaregions. The IPA technique has never been used or adapted in order to investigate a research problem in intermodal freight transport. Moreover the performance analysis framework is proposing the combination of IPA with AHP in order to validate the main indicators of the framework. 
The proposed technique allows the stakeholders involved in the freight industry both from the private and the public sector to perform an assessment of the transport network in which they operate by providing their comparative views on how modes of transport perform separately against a number of universal indicators which are directly related to sustainable development.

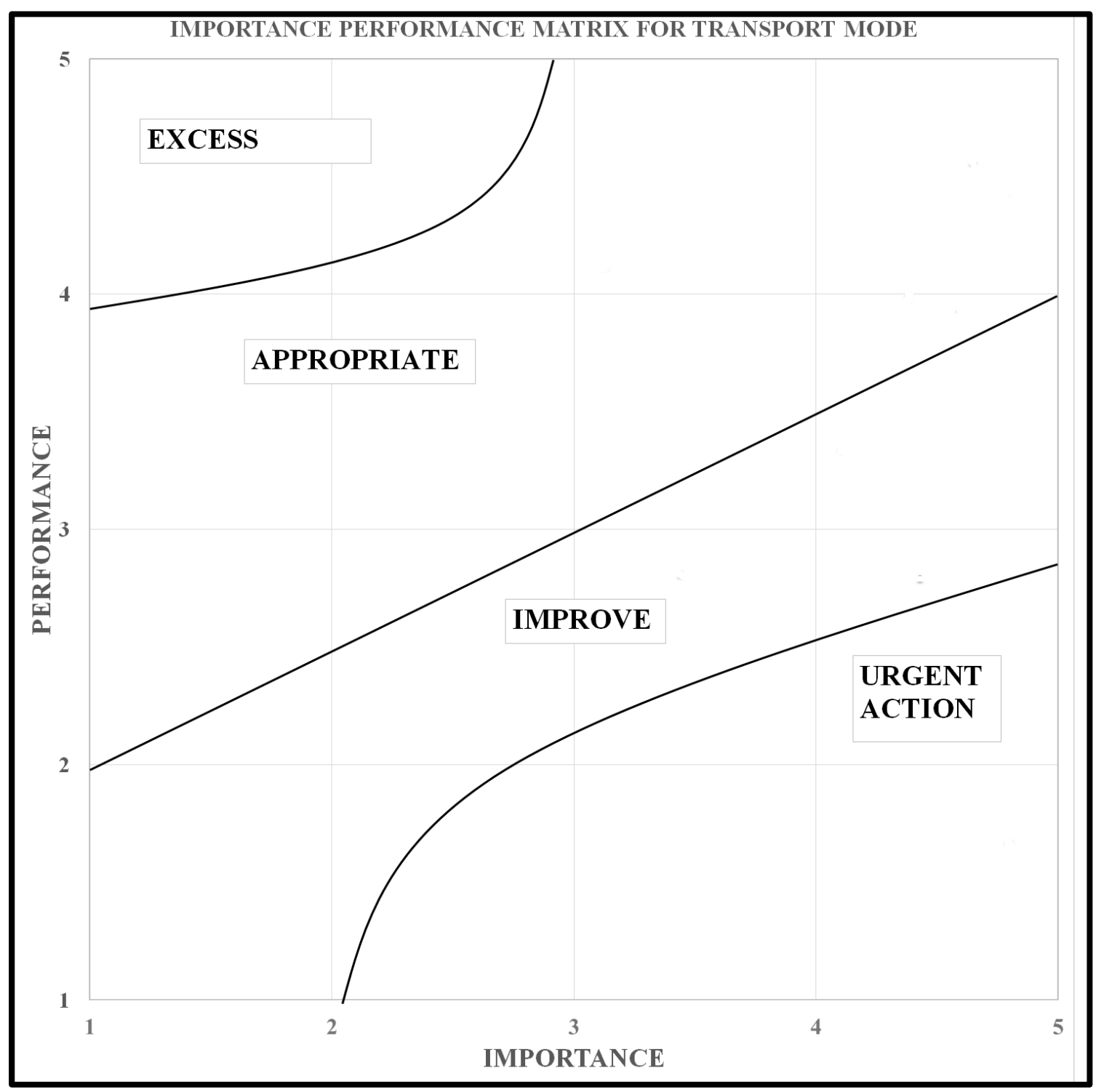

Figure 3-3: Adapted importance-performance matrix for the service performance analysis of intermodal freight transport in a regional logistics gateway of an emerging megaregion. 
Table 3-1: Recent selected publications showing the applicability of the IPA methodology for the examination of different academic topics

\begin{tabular}{|c|c|c|}
\hline $\begin{array}{l}\text { Authors (Year) } \\
\text { Source }\end{array}$ & Title & Applicability \\
\hline $\begin{array}{l}\text { Chu (2002) } \\
\text { Journal of Services Marketing }\end{array}$ & $\begin{array}{l}\text { Stated importance versus derived } \\
\text { importance customer satisfaction } \\
\text { measurement. }\end{array}$ & $\begin{array}{l}\text { Measurement } \\
\text { of travellers } \\
\text { overall } \\
\text { satisfaction } \\
\text { towards hotel } \\
\text { stay in Hong } \\
\text { Kong. }\end{array}$ \\
\hline $\begin{array}{l}\text { Abalo et al (2007) } \\
\text { Journal of Business Research }\end{array}$ & $\begin{array}{l}\text { Importance values for importance- } \\
\text { performance Analysis: A formula for } \\
\text { spreading values derived from } \\
\text { preference rankings. }\end{array}$ & $\begin{array}{l}\text { Measurement } \\
\text { of patients } \\
\text { overall } \\
\text { satisfaction } \\
\text { towards health } \\
\text { care service in } \\
\text { Galicia. }\end{array}$ \\
\hline $\begin{array}{l}\text { Ainin and Hisham (2008) } \\
\text { Journal of Information, Information } \\
\text { Technology and Organisations }\end{array}$ & $\begin{array}{l}\text { Applying importance-performance } \\
\text { analysis to information systems: An } \\
\text { exploratory case study. }\end{array}$ & $\begin{array}{l}\text { Evaluation of } \\
\text { Information } \\
\text { Systems by } \\
\text { end users. }\end{array}$ \\
\hline $\begin{array}{l}\text { Szasz and Demeter (2009) } \\
\text { Babes-Bolyai University, } \\
\text { Romania }\end{array}$ & $\begin{array}{l}\text { Importance-performance fit within } \\
\text { manufacturing strategy and its impact } \\
\text { on business performance. }\end{array}$ & $\begin{array}{l}\text { Assessment of } \\
\text { decision } \\
\text { makers' } \\
\text { strategies for } \\
\text { improvement } \\
\text { of } \\
\text { manufacturing } \\
\text { strategy. }\end{array}$ \\
\hline $\begin{array}{l}\text { Wu and Shieh (2009) } \\
\text { Journal of Expert Systems with } \\
\text { Applications }\end{array}$ & $\begin{array}{l}\text { The development of a confidence } \\
\text { interval-based importance- } \\
\text { performance analysis by considering } \\
\text { variability in analysing service } \\
\text { quality. }\end{array}$ & $\begin{array}{l}\text { Analysis of } \\
\text { satisfaction } \\
\text { and } \\
\text { importance for } \\
\text { service items } \\
\text { of the } \\
\text { dormitory } \\
\text { located in Asia } \\
\text { University. }\end{array}$ \\
\hline
\end{tabular}




\begin{tabular}{|c|c|c|}
\hline $\begin{array}{l}\text { Rahman and Selen (2010) } \\
\text { International Conference on } \\
\text { Industrial Engineering and } \\
\text { Operations Management }\end{array}$ & $\begin{array}{l}\text { Shippers-providers perception of } \\
\text { third-party logistics services - An } \\
\text { importance - performance matrix } \\
\text { analysis. }\end{array}$ & $\begin{array}{l}\text { Evaluation of } \\
\text { shippers and } \\
\text { logistics } \\
\text { service } \\
\text { providers to } \\
\text { various } \\
\text { elements of } \\
\text { third party } \\
\text { logistics } \\
\text { services in } \\
\text { Australia. }\end{array}$ \\
\hline $\begin{array}{l}\text { Sezhian et al (2011) } \\
\text { Journal of Theoretical and } \\
\text { Empirical Researches in Urban } \\
\text { Management }\end{array}$ & $\begin{array}{l}\text { Developing a performance } \\
\text { importance matrix for a public sector } \\
\text { bus transport company: A case study. }\end{array}$ & $\begin{array}{l}\text { Analysis of } \\
\text { service } \\
\text { characteristics } \\
\text { towards the } \\
\text { public } \\
\text { transportation } \\
\text { services } \\
\text { provided by a } \\
\text { bus company. }\end{array}$ \\
\hline $\begin{array}{l}\text { Wang, Hideki and George (2011) } \\
\text { Journal of Theoretical and Applied } \\
\text { Electronic Commerce Research }\end{array}$ & $\begin{array}{l}\text { The use of importance - performance } \\
\text { analysis (IPA) in evaluating Japan's } \\
\text { E-government services. }\end{array}$ & $\begin{array}{l}\text { Measurement } \\
\text { of the e- } \\
\text { government } \\
\text { benefits from } \\
\text { the users' } \\
\text { perspective in } \\
\text { Japan. }\end{array}$ \\
\hline $\begin{array}{l}\text { Yang, Chou and Ding (2011) } \\
\text { African Journal of Business } \\
\text { Management }\end{array}$ & $\begin{array}{l}\text { Using the importance - performance } \\
\text { analysis (IPA) approach to measure } \\
\text { the service quality of mobile } \\
\text { application stores in Taiwan. }\end{array}$ & $\begin{array}{l}\text { Empirical } \\
\text { study of the } \\
\text { service quality } \\
\text { of mobile } \\
\text { application } \\
\text { stores in } \\
\text { Taiwan based } \\
\text { upon the } \\
\text { customers' } \\
\text { perspective. }\end{array}$ \\
\hline
\end{tabular}




\subsubsection{Analytical Hierarchical Process (AHP) analysis}

AHP which was developed by Saaty (1977) is a methodology that incorporates both quantitative and qualitative criteria and is also used as a decision support system to evaluate various alternatives for achieving a goal, through comparing them (Saaty 1980). Ever since its inception AHP has been a tool in the hands of decision makers and researchers and is one of the most widely used multicriteria decision making (MCDM) tools (Vaidya and Kumar 2006). AHP was also developed to analyse a variety of decisions involving complex technological, economic and socio-political problems and has been accepted by the international scientific community as a very useful tool for advanced troubleshooting decision. AHP has been implemented successfully in many cases that required complex analysis and decision making (Caliskan 2006) and several companies and Governments use AHP for making important political decisions (Golden et al 1989).

Generally, AHP is used either by applying a questionnaire or with group decision-making processes. The combination of both, with questionnaires from each team member and then carrying out collective decision-making procedures, provides additional value. This practice enables integration of all experience and all the views, with a view to examining the problem with a holistic approach. According to Ho (2008) AHP consists of various steps that include the construction of a hierarchical model, the analysis of priorities and consistency checking. Firstly the decision makers must break the complex problem facing the main ingredients and to structure them in a hierarchical model of the problem. The problem under examination or object of decision-making is at the top level of the hierarchical model. The criteria on the basis of which the decision and their sub-criteria (if any) are located in the middle level of the hierarchical model. The alternatives being considered then are placed in the lower level of the hierarchical model. In the next steps of AHP, decision makers create pairs comparisons in order to measure the impact of items in a level of hierarchy to the next higher level. This activity compares the criteria under the goal of the problem, the sub-criteria of each of the criteria and alternatives in relation to each sub-criterion. The questionnaire is completed either by the decision makers (especially in research carried out within the framework of an organisation) or, usually, 
by industry experts. In order to achieve the above, based on the hierarchical model, questionnaires are administered which include all the comparisons at all levels. A comparison of the criteria usually takes place on a scale of 1-9, although some researchers use a scale of 1-5 (Kuo et al 2002), while there is the possibility instead of a quantitative scale to the corresponding lexical terms used. Finally, researchers such as Millet and Schoner (2005) consider that negative values should be used, in order to indicate the opposition against some criterion. As mentioned in chapter five, the comparison is primarily based on the importance of the criteria. It allows pair-wise comparison to assess the criteria for service management of different modes of transport (Forman and Selly 2002). Thus, respondents were invited to appreciate how much more important, or more importantly, how many times is a criterion against each other at the same level.

Similarly with the IPA methodology, AHP is a highly versatile tool that can be applied to any performance measures hierarchy and also can be combined with the IPA tool. The AHP has been successfully applied to decisions concerning the choice of the product/service and process project (Tang and Nam 1993) and also in the field of logistics and transport with tangible results (Vreeker et al 2002). The advantage of AHP is its flexibility, which allows it to integrate with IPA in chapter five over alternative methodologies such as ANP and DEMATEL as the causal relationship and the influential degree among each quality attribute is an additional objective that can be achieved in further research beyond this work. This allowed the researcher to utilize the benefits that each of the combined methods gives, and hence, to validate the results of the industrial survey in chapter six in a better way (Vaidya and Kumar 2006). Another important advantage of AHP is that it allows the existence of inconsistency in judgment (Liberatore and Nydick 2008; Hummel et al 2000). Therefore AHP is proven to be a useful tool for addressing multiple factors in areas where the quality criteria are of particular importance (Hummel et al 2000) in order to make a decision on what particular actions are required within the transport infrastructure system in order to make it more sustainable. The analysis of focus group data in chapter seven presents both challenges and opportunities when compared to other types of qualitative data as these provide the opportunity to analyze the strength with which an expert holds an opinion regarding sustainable development at the megaregional level. 


\subsection{Summary}

In this chapter the methodology of this research has been outlined by covering the various research tools and techniques available in the literature for the service performance measurement and decision making. Also the philosophical stance and research strategy have been discussed by following the "research onion" categorization which serves as a very useful approach for organising the different layers of the research in a strategic manner. Moreover it has been described in this chapter how the research setting is identified through the use of GIS and how the case study for chapter five and multiple case studies in chapter six selected for the use of an industrial survey and a focus group survey respectively. The technique for the collection and analysis of the data of the industrial survey is heavily based on the employment of a combined IPA and AHP research tool for the assessment of the perceptions of stakeholders with respect to the importance and performance of the selected criteria for sustainable development of the transport network in the regional logistics gateway selected for examination in chapter five. This novel approach to the service performance assessment of each mode of transport of the transport network is facilitated by customising and adapting the combined IPA and AHP tool to be used in order to analyse an intermodal freight transport case study. A list of previous applications of the IPA methodology in the academic literature has also been provided demonstrating therefore the novelty of the combined IPA and AHP methodology in the intermodal freight transport and logistics research literature.

Moreover in chapter six the research methodology is based on the use of a focus group survey specifically designed to analyse the impact that different transport infrastructure priority projects will have on the sustainable development of different logistics gateways in the emerging megaregion of North West Europe. The main research output of this transnational activity is the generation of future scenarios for sustainable development based on the responses given by participants of the focus group. 


\section{Identification of the research setting and methodology for the identification of regional gateways case studies}

\subsection{Introduction}

A research setting can be defined as the physical, social and cultural site in which a researcher is conducting a study (Poitras 2012). As shown in the diagram in figure 4-1 this chapter provides an overview of megaregions in different parts of the world and in Europe by examining the transport geography of this research.

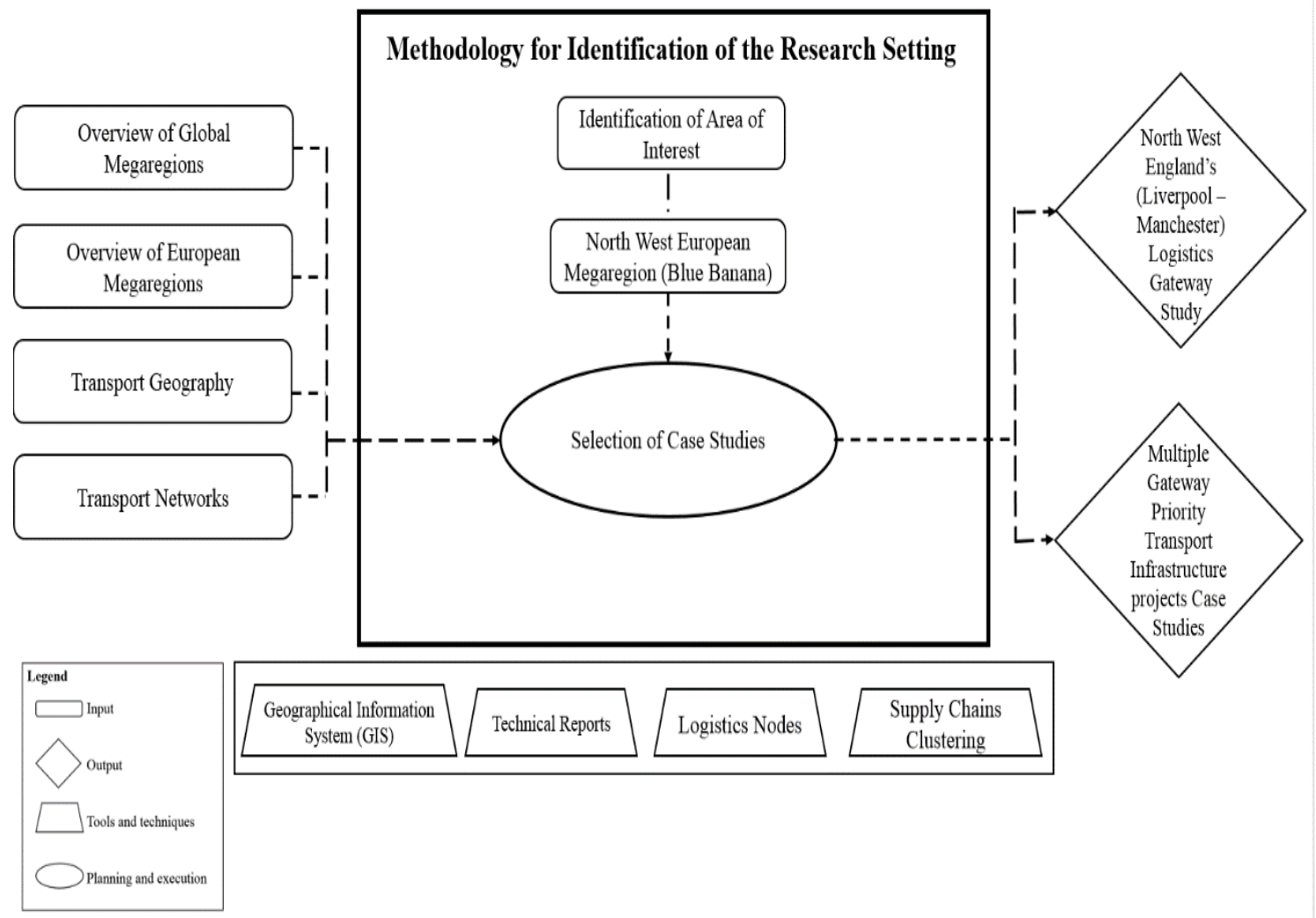

Figure 4-1: Methodology for the identification of the research setting

Figure 4-1 also shows that in this research the main research setting is the emerging megaregion of North West Europe. Within this main research setting a logistics gateway case study has been selected with the use of an online GIS software. The selection of a single logistics gateway study in this chapter serves the subsequent chapter five as a service performance analysis of its transport network is carried out through the administration of an industrial survey to the supply chain clusters that are positioned within its geographical boundaries. 
Also within the same main research setting, that of North West Europe, different transport infrastructure priority projects are identified and will be analysed in chapter six with the use of a focus group survey with participants from different areas of interest in North West Europe. The main aim of this transnational research activity has been to generate future sustainable development scenarios based on the assessment of the impact that each single transport infrastructure project is likely to have in the logistics gateway in which it is located.

\subsection{Overview of emerging megaregions in Europe and other parts of the world}

\subsubsection{Emerging megaregions in Europe}

The phenomenon of the so called "endless city" could be one of the most significant developments and problems in the way people live and economies grow in the next 50 years, and is also observed in Europe and more specifically in the Liverpool to Milan axis-corridor also known as the "blue banana" as shown in figure 4-2.

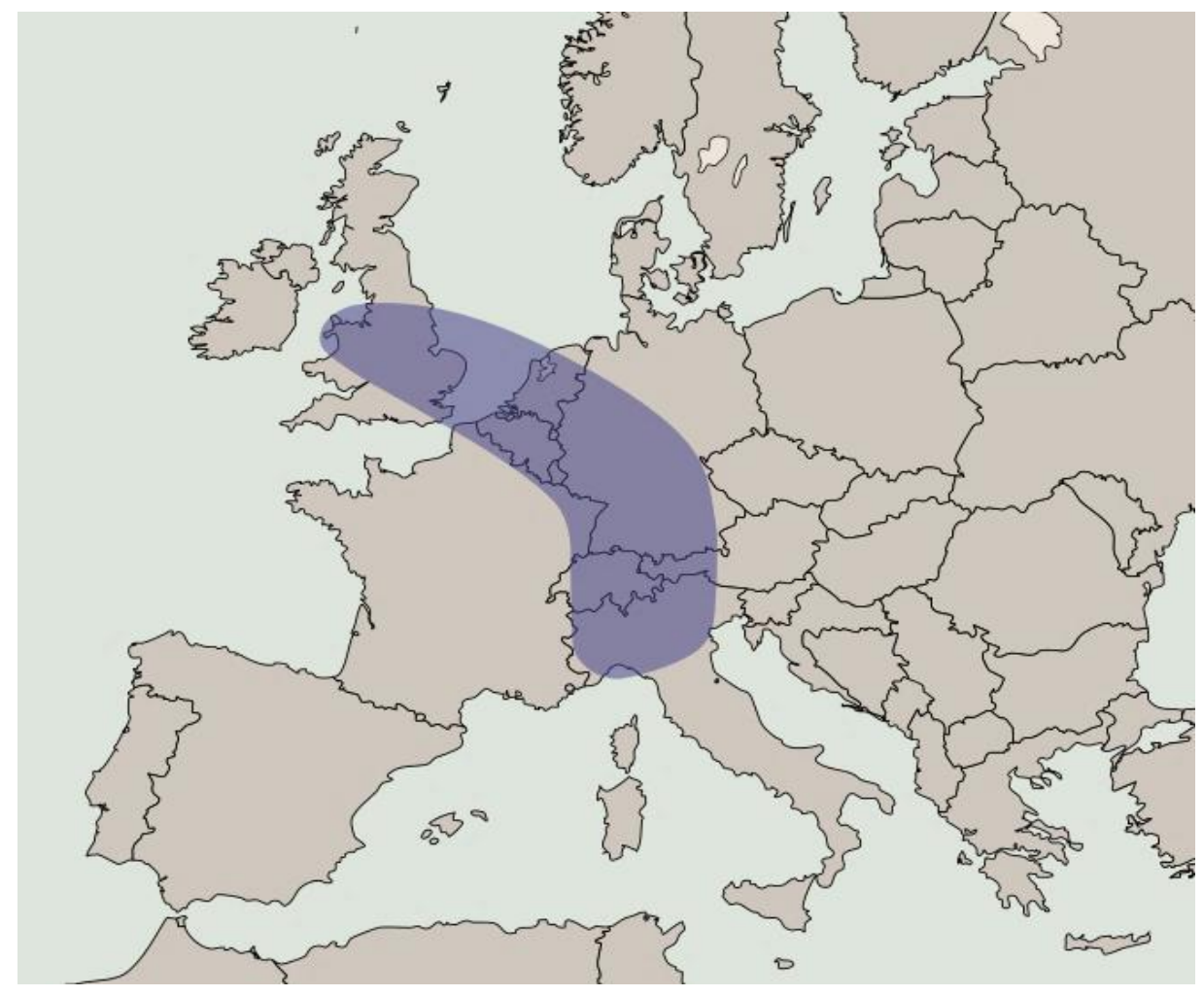

Figure 4-2: The "blue banana" corridor of the emerging megaregion of North West Europe

Source: Brunet (1989) "Les villes europeénnes: Rapport pour la DATAR", Montpellier, RECLUS 


\subsubsection{Emerging megaregions in other parts of the world}

In the twenty-first century the emergence of globalization made national boundaries mean a lot less. Capital can now be allocated freely around the globe seeking maximum returns wherever they may be. Megaregions are integrated sets of cities and their surrounding suburban hinterlands across which labour and capital can be reallocated at very low cost. Examining megaregions in terms of population can be highly misleading (Ziegler 2009). Megacities are generally conceived in terms of population (often as metropolitan areas of 10 million or more). In many cases these megacities seem to have arisen with a price, especially in the underdeveloped parts of the world. Looking at economic growth and the creation of wealth solely through national data is also misleading. Globalization renders national political borders less relevant in economic terms. Firms locate where skill, capabilities and markets cluster; capital flows to where the returns are greatest; and highly skilled people move where opportunity lies. This also results in a more fully integrated global economy and it also means that both capital and talent concentrate where opportunities for productivity and returns are highest, hence every nation experiences massive concentrations of population and productivity in its largest urban regions. This is true in the advanced economies of the United States, Europe and Japan, and even more so for the emerging economies like China and India (Wilson and Purushothaman 2003).

Accelerated processes of global economic integration alongside rapid urbanisation are producing a new metropolitan landscape. The challenges of providing adequate basic services in many major global cities are substantial; many urban centers have failed to meet the growing demand of their communities. Megacities, as they are popularly known, are said to be "playing catch-up". Megacities in less developed and developing countries (e.g., Lagos, Nigeria; Mexico City; and São Paulo) deal with basic issues of survival, such as access to sanitation and clean drinking water, and those in developed countries (e.g., Los Angeles, New York, and Tokyo) have the task of managing growth to continue advancing the quality of life of their communities (Amekudzi et al 2007).

Recently a great deal of attention has been focused on the emergence of the European Union and on European spatial planning, which has boosted the region's competitiveness. The measurement of current and future national economic performance typically begins 
with calculating a variety of gross domestic product (GDP) measures. GDP measures are key elements in the current rankings of groups such as the G8 and lie behind future moves up the rankings by the economies of Brazil, Russia, India, and China. GDP be the key variable in predicting future national growth. Florida (2007) reported that from all the nations in the world, just 40 mega-regions power the world economy, accounting for twothirds of global output and over $85 \%$ of all global innovation.

The biggest mega-regions, which are at the forefront of the rapid urbanization sweeping the world, are:

- Hong Kong-Shenhzen-Guangzhou, China, home to about 120 million people.

- Nagoya-Osaka-Kyoto-Kobe, Japan, expected to grow to 60 million people by 2015.

- Rio de Janeiro-São Paulo region with 43 million people in Brazil.

- West Africa: $600 \mathrm{~km}$ of urbanization linking Nigeria, Benin, Togo and Ghana, and driving the entire region's economy.

- India: From Mumbai to Delhi.

- East Asia: Four connected megalopolises and 77 separate cities of over 200,000 people each occur from Beijing to Tokyo via Pyongyang and Seoul.

\subsection{Selection of a single regional logistics gateway case study in North West Europe}

The megaregion of North West Europe is characterized by functional divisions of labour between city units in a highly networked region and by intensive development along transportation corridors (Ipenburg et al, 2001). The North West of Europe has been selected for this research as it forms a mass of no less than 72 million people, and while not contiguous they are sufficiently close and highly linked. Intra-regional functional linkages vary accordingly in the global and European logistics network. The North West of England occupies a unique global role in the North West European mega region, and this appears to spawn complex interdependencies between this geographical area's central 
business district and its regional periphery. This micro-level analysis also seeks to lay the basis that will prompt additional and more in depth analysis based on primary data. Likewise in this research chapter four provides an exploratory analysis of a selected gateway study in order to facilitate an explanatory research methodology in chapters five and six where original primary data were collected. The Liverpool - Manchester gateway as shown in figure 4-3 through the use of an online GIS platform is located on the NorthWest coast of England and, as the name suggests, consists of the two cities of Liverpool and Manchester as well as the interconnected hinterlands which surround both cities. This gateway, which has a heavy emphasis on private sector leadership, has been conceived to enhance integration and connectivity, advancing the concept of a 'bi-polar urban region' focused upon what is the most heavily populated area within this part of the emerging mega-region of North West Europe. The gateway is home to approximately seven million people, representing just over $13 \%$ of the English population.

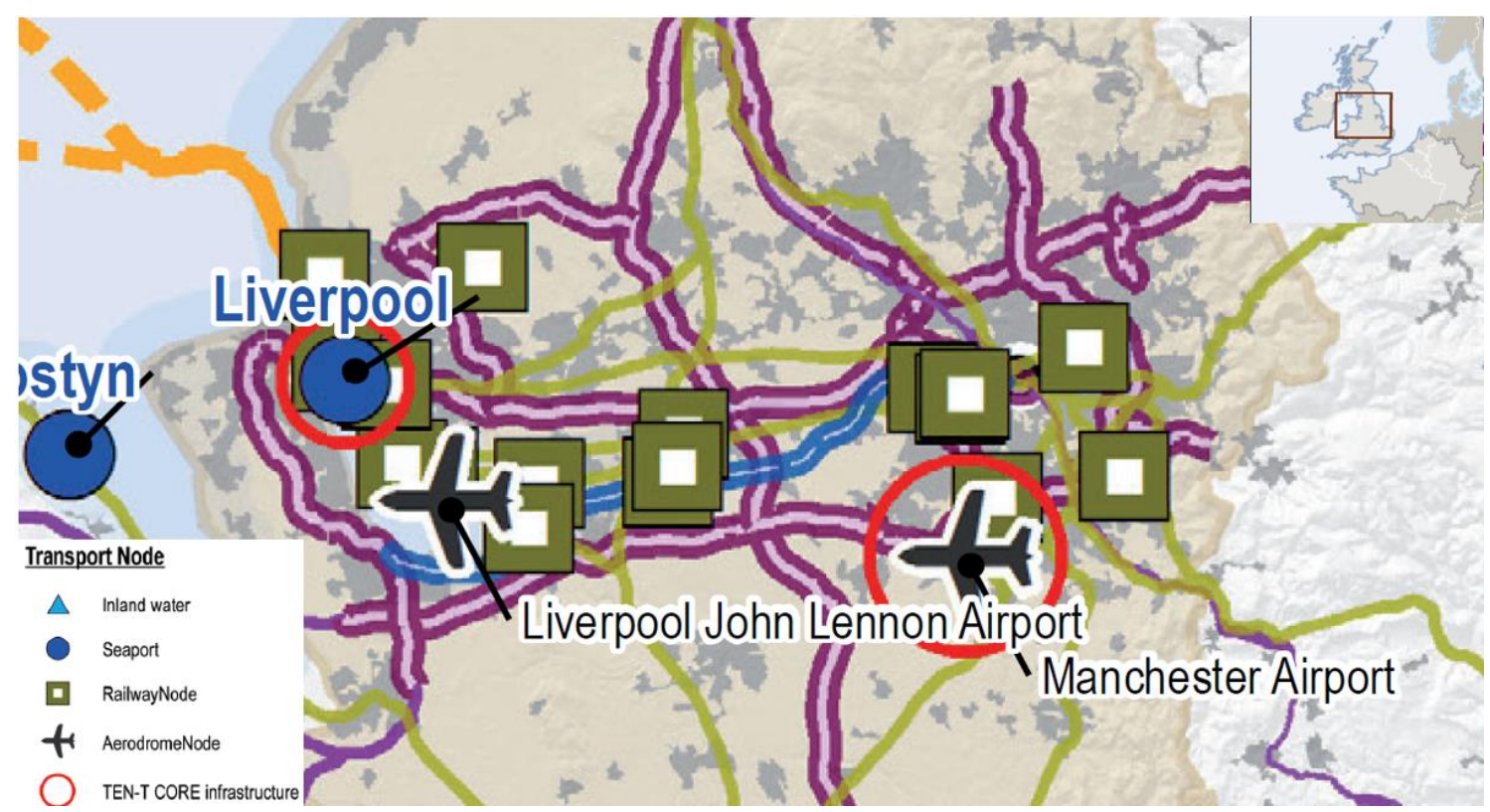

Figure 4-3: GIS representation of the Liverpool - Manchester gateway

Source: ESRI Online ArcGIS

The designation of the cities as a single gateway has also assisted in broadening the economic areas of Liverpool and Manchester, enhancing their collective roles as the economic engines of North-West England. An integral part of the connectivity of the gateway and a major influence in its designation relates to the presence of the Port of Liverpool and the Manchester Ship Canal, which links the two cities. The close proximity 
of a number of the traditional industrial hubs of the English Midlands and North, including Leeds and Sheffield, the international shipping potential of the gateway represents a viable alternative to the heavily congested ports of the South and South East. The movement of goods through the gateway to and from international markets, reducing the proportion of goods travelling by road from the south, and increasing the utilisation of the canal has the potential to yield substantial enhancements in the sustainability of this part of the UK.

\subsection{Selection of multiple case studies in the greater territory of North West Europe}

In order to assess the impact that similar transport infrastructure systems have, like the one in the Liverpool - Manchester regional logistics gateway, in the sustainable development of other parts of the emerging megaregion of North West Europe a different geographical approach at macro-level is required. As shown in figure 4-2 the "blue banana" corridor extends from Liverpool and beyond all the way through the central Europe down to the South. Due to limited available resources for this research it was only possible to identify some key transport infrastructure priority projects in North West Europe based on experts' judgements and their willingness to participate in the focus group survey that was conducted for the needs of chapter six. The various transport priority infrastructure projects identified for the sustainable development analysis and generation of future scenarios are in the countries of Ireland, the UK, France, Holland, Germany and Belgium.

\subsection{Summary}

This chapter has dealt with the identification of the main research setting, that of the emerging megaregion of North West Europe. Within the main research setting a single case study is also identified, that of the Liverpool - Manchester logistics gateway in North West England, in the United Kingdom. The identification of this regional logistics gateway case study facilitates the examination of how its transport network performs in terms of sustainable development through modal shift within a regional logistics gateway by analysing every mode of transport based on the perceptions of stakeholders within the freight industry in the next chapter, chapter five. The use of an online web GIS platform 
has also enabled the identification of the logistics gateway study within the main research setting. GIS is a valuable tool in the science of transport logistics that allows researchers to represent graphically the location of their research setting. However logistics gateways and their transport networks are not only important for their local regions but also have a crucial role to play at a megaregional level. This is because megaregions in some cases are transnational (such as in Europe). This necessitates a common approach into the development of a strategy for sustainable development.

As discussed earlier the "blue banana" transport logistics corridor that spans from Liverpool to Milan is such an example. This is also the reason why this research is proposing an additional research framework for the examination of the likely impact that existing and planned transport infrastructure priority projects are expected to have on the sustainable development of the megaregion of North West Europe in chapter six. The added value of this research activity is that it provides a novel approach to the generation of future supply and demand scenarios with respect to elimination of congestion bottlenecks in the regions and sustainable development based on experts' judgement from different areas of interest of the megaregion through a focus group survey. 


\section{Micro-level service performance measurement assessment of a megaregional logistics gateway in North West Europe}

\subsection{Introduction}

Following chapter four which dealt with the identification of the research setting, the aim of this chapter is to evaluate the transport infrastructure network in the Liverpool Manchester gateway in the emerging megaregion of North West Europe by examining its service performance. This research approach facilitates also the analysis of strategies for removing the barriers that restrict the intermodal flow of freight. A key policy objective of the EU is to decrease the amount of freight moved by road in favour of alternative transport modes such as rail, inland waterways and aviation. Such an objective can be achieved by helping to identify ways to increase the diversity of modes commonly used for freight transportation between the different gateways of a mega region. One of the major setbacks to this process is quality, or perhaps more accurately the assessment of quality in terms of infrastructure performance (Kreutzberger 2008). Quality is a key factor in today's freight transport market (Korinek 2011). Intermodal transport can sometimes be slower, less reliable and more expensive than unimodal transport. Determining why this is the case is key to promoting intermodal transport and service quality is central to that process.

It is difficult to determine the spatial and non-spatial relationships that exist between transport infrastructure and regional growth. The non-spatial aspects can be provided through measures of economic performance, productivity and competitiveness (Wichser and Nash 2007). On the other hand the spatial aspects of infrastructure distribution can provide insight into the discrepancies between different locations in the network. Publicly available infrastructure can maximise the economic potential of both the public and private sector provided that spare capacity is available. When this is not the case and a regional network is working at maximum capacity congestion is very likely to occur and the effects of bottlenecks will become more important. Bottlenecks are obstacles to the economic growth of a gateway and can also be a contributing factor to regional inconsistencies (when the lack of infrastructure is not a constraint). In order to examine the performance dynamics of a regional transport infrastructure network within a regional 
logistics gateway a number of indicators must be weighed within the context of a wider conceptual research framework through which it is possible to compare the different modes of transport. The importance attached to this micro level of analysis is the need to better understand how processes impact different spaces, places and people unevenly across the megaregional space of North West Europe. The diagram in figure 5-1 shows the methodology was followed for the assessment of the service performance of the transport network within the selected regional gateway case study. The identification of the research setting in chapter four serves as a major input to this process at this stage. Also other important inputs are the identification of the transport network and its service performance dynamics. These need to be taken into consideration from a system's point of view in order to be linked with the sustainability of the logistics gateway (Perrels 2004). Central to the methodology of this chapter is the design of an industrial survey which uses universal criteria in order to capture the views of the stakeholders of the gateway's freight industry. Also central to this process is a novel approach to the sustainable service performance of a logistics gateways transport network by proposing a service performance measurement methodology which combines the benefits of IPA and AHP during the collection and analysis of data.

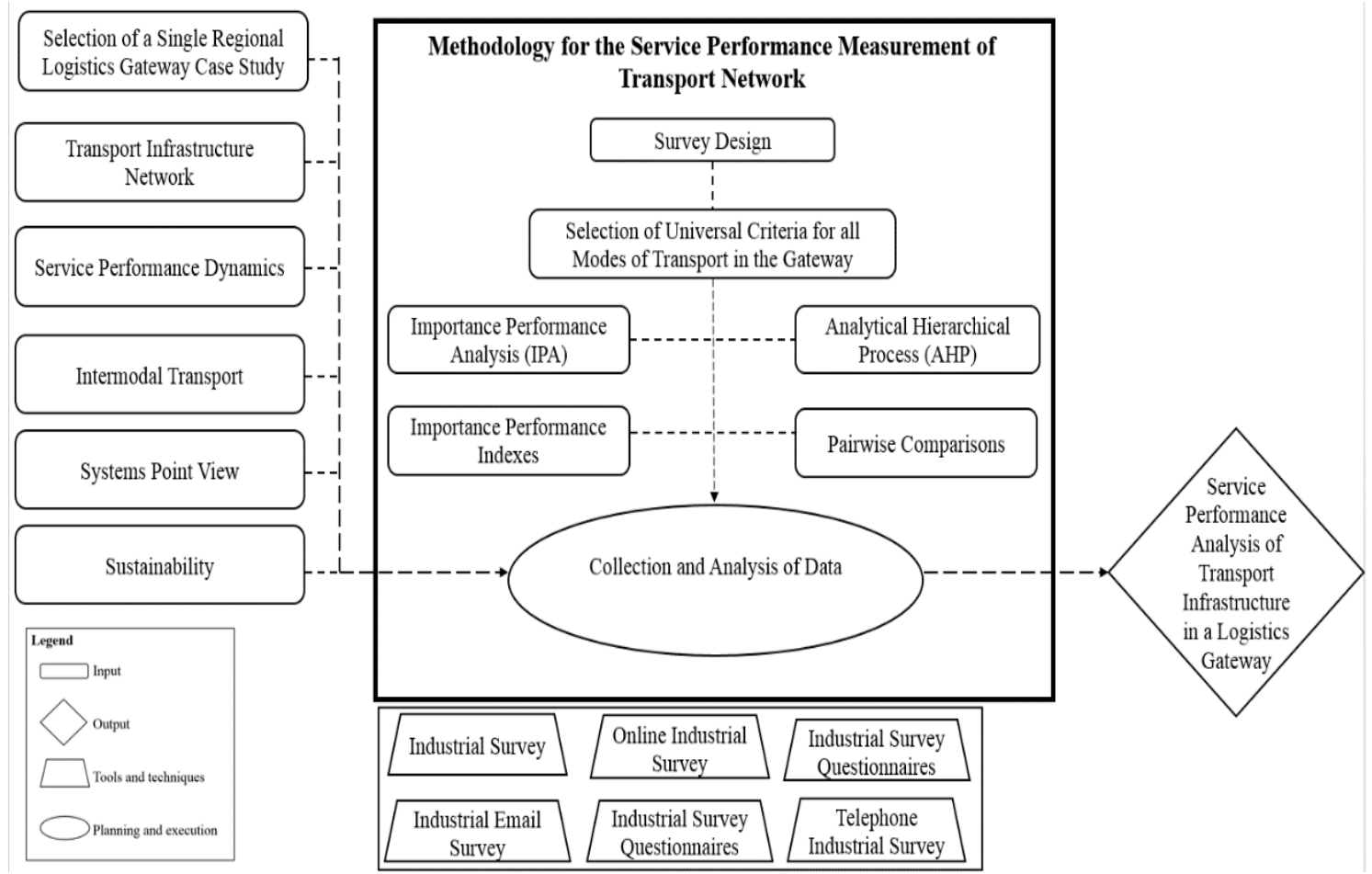

Figure 5-1: Methodology for the assessment of the service performance of a megaregional logistics gateways transport network at a micro level 


\subsection{Strategic decision making with an industrial case study an expert survey on interest groups and stakeholders of regional logistics gateway}

Underused transport infrastructure, due to lack of proper planning, can be an enormous obstacle to business growth and competitiveness, but it is a factor over which stakeholders have little control. To address this a performance measurement tool is needed. Developing a performance measurement methodology for use in intermodal transportation systems is not possible by simply combining criteria of relevance to each mode. It is instead done by carefully defining the network from a system viewpoint (Perrels 2004). Also by determining the performance indicators of a transportation system come in the form of adopting a top down approach to identify and measure common service attributes for each transport mode.

The organisations operating within the intermodal freight transport industry are considered its stakeholders. These are trading entities, which include the entire group of private, non-profit, or governmental organisations that are involved in import/export activities. When taken as individuals these entities can be either small or midsize companies or large corporations. However, taken as a group their freight logistics operations are a major part of a region's economy. As users of the infrastructure system, freight community members provide a unique perspective on the problems they confront on a daily basis. Capturing their experiences provides information that, when combined with quantitative data, helps to establish the inherent costs of current infrastructure conditions and the benefits of future improvements to them. A carefully designed survey can be useful in assessing a number of transportation development goals as well as rating the importance and performance of their related measures (Eskildsen and Kristensen 2006). Making contact with the freight community in a gateway to gauge their views requires sensitivity to the industry and an appreciation of what it is actually possible for members of the that community to contribute to our understanding of the freight operations in the area under investigation (Ipsos MORI 2008). Key to understanding a business's perception of the transport network surrounding it is to identify the factors that are most important to them when they evaluate and compare transport options. The objective of this research chapter has been to develop a usable survey instrument for gathering information from members of the freight community across the Liverpool - 
Manchester gateway on their perceptions of the importance of infrastructure to their operations and the performance that the existing transport infrastructure provides. The case study selected was based around a corridor joining two major urban areas with welldeveloped road, rail and inland waterway networks.

\subsection{Selection and application of a case study for the sustainable service delivery assessment of a gateway's transport network within an emerging megaregion}

It is commonly accepted that transport and logistics are vital to the growth and development of megaregions. However there are a number of unexpected side effects to the transport industry that have increasingly emerged over the last few years, predominantly with regard to road transport. Some of the most important include:

- Congestion has increased as roads have become busier, especially during peak hours.

- There has been a damaging impact on the environment resulting from increased $\mathrm{CO} 2$ emissions.

- The number of accidents that have caused serious injuries, single and multiple fatalities has increased.

- The transport industry's heavy dependence on oil which makes it susceptible to fluctuations in oil prices resulting in increased costs.

In order to tackle these issues policy makers have taken a number of actions including:

- Legislative acts such as regulations, directives, decisions and non-binding recommendations.

- Economic measures, proposals and policies.

- Regional and industrial growth funding schemes aimed at supporting the development and improvement of new or existing transport infrastructure.

- Trial projects that have as an objective the promotion of technological breakthroughs and state of the art applications.

- Research and knowledge transfer funding for the creation of new ideas, methodologies and practices at a transnational level. 
The key challenge for these initiatives is not only to realize growth but also to maintain social and economic balance emphasising the need for corrective action taking in order to prevent the side effects from escalating and also to raise awareness of sustainable development (Rees 2005). Increased road traffic is a result of the rising number of privately owned vehicles and the increasing number of HGV trips in the border free market. However, investment for the creation or improvement of infrastructure capacity has not kept pace with the increase in the level of use over the last few decades resulting in the high levels of congestion currently observed and the development of bottlenecks.

Although there have been many proposals in the past for investment in the development of new infrastructure, in recent years the lack of focus on existing infrastructure has become increasingly evident. The lack of financial resources as a result of the economic crisis that the world has experienced over the last few years and also the need for an environmentally friendly approach in infrastructure capability improvement necessitates the identification of unused capacity (which does not require heavy investment) so that existing infrastructure can be better utilised. In most cases spare capacity can be identified in rail, sea and inland waterway networks. Although these alternative modes of transport can also be friendlier to the environment the road mode still remains dominant.

In Europe the European Commission established the Trans-European Transport Networks (TEN-T) and issued the first guidelines in the early 1990s (Gutierrez and Urbano 1996). The European Union's Maastricht Treaty (1995) calls for development of a TransEuropean Network (TEN). This network is designed to link the major cities and economic areas throughout Europe (both inside and outside the EU). It consists of ten multimodal (e.g. road, rail and waterway) corridors. The idea is to concentrate international traffic in to these corridors. As part of the EU's development strategy, a large number of infrastructure improvement projects have been identified for the TEN corridors. These high profile projects are intended to better coordinate national and international network development and to improve trans-border transportation. The projects include improvements to the infrastructure of Central, Eastern and South Eastern European countries. Progress on implementing the TEN corridors and their related infrastructure projects differs significantly between regions and countries. 
The infrastructure projects that are currently under development in the emerging megaregion of North West Europe have the potential to improve the future accessibility of transport networks and therefore to contribute significantly to regional economic growth. Such plans are high on the Commission's agenda and the Trans European Transport - Networks (TEN-Ts) scheme is considered to be a key tool in achieving the EU's transport targets. These infrastructure development projects will require extensive planning, evaluation and appraisal prior to commencing. Discrepancies between regions will also need to be carefully assessed in the proposal phase in order to identify future inconsistencies on the enlarged transport network. This requires a sophisticated risk analysis and decision making analysis to be undertaken to provide a spatial cost benefit analysis between the different modes of transport.

Inland waterways, either rivers or canals, are increasingly being seen as providing new opportunities for development as a complementary, or even as an alternative, mode of transport to the existing road and rail networks. Depending upon their dimensions inland waterways can accommodate a wide range of ship sizes. The main source of restrictions is that a navigable channel must be deep enough to accommodate the draft of a ship, wide enough to allow the passage of a ship's beam width and free of other physical barriers such as low bridges. In a geographical area with a high population density, but with welldeveloped river or inland waterway infrastructure, inland navigation provides real economic development potential where other transport systems are so congested that economic development is becoming threatened. The key elements in the promotion of inland waterway transport are flexibility, low cost of transport, energy efficiency and low adverse environmental impact (Radmilovic, Zobenica and Maras 2011). When utilized efficiently, inland waterways can be categorised as one of the major components of intermodal freight transport systems.

Due to their nature, inland waterways can be used to carry dry bulk, liquid bulk, containers, break bulk and roll on - roll off cargoes in an economically viable fashion. They can serve not only as an environmentally friendly mode of transport, but also provide the cheapest transport cost per tonne-kilometre of freight movement for high load factors (Kader 1997). The use of inland waterways to carry freight to inland locations 
reduces the distance a shipment needs to travel on road or rail. This can result in reduced operation costs and the possible alleviation of local congestion problems. However, investment in channel improvements and new developments are necessary if many of the existing European inland waterways are to be able to meet the requirements necessary to accommodate the currently projected levels of future freight movements.

The Liverpool-Manchester canal is an example of a custom made inland waterway, which has a significant role in the flow of freight in a dynamic environment. It is has also been recognised as a TEN-T priority project. Information was collected by administering the questionnaire to infrastructure providers and companies which were listed in the local freight and maritime membership directories as being located within the Liverpool to Manchester corridor.

\subsection{Employment of a combined IPA and AHP methodology for the measurement of critical service quality attributes of a multimodal logistics gateway's transport infrastructure}

As discussed in chapter three the importance-performance matrix offers a more refined operationalization of the notion of fit between importance and performance competitive factors for sustainable development of every transport mode within the regional logistics gateway under examination. Therefore, the proposed research methodology aims to empirically test the usefulness of the importance-performance matrix in strategic service operations transport management decisions by linking it to sustainable development' performance indicators.

\subsubsection{Construction of the combined IPA and AHP survey index}

For each transport mode, an importance-performance index has been constructed (Abalo et al 2007). The indices used are based on a variety of dimensions that describe the broad characteristics of performance (Jin et al 2004). The dimension indices shown in table 51 are constructed from universal indicators that describe particular elements of the importance and performance attributes of the different transportation modes. 
The amount of literature concerning transport infrastructure service performance variables and respective influencing factors is substantial. With this in mind six key attributes have been identified on the underlying criteria and constraints in the use of intermodal transport: mobility, reliability, cost efficiency, safety and security, infrastructure condition and environment.

Table 5-1: Importance-performance indicators index

\begin{tabular}{|c|c|c|c|c|c|c|c|c|c|c|}
\hline \multirow{2}{*}{$\begin{array}{l}\text { TRANSPORT } \\
\text { MODE } \\
\text { Indicators }\end{array}$} & \multirow[b]{2}{*}{ Sub-indicators } & \multicolumn{5}{|c|}{ Importance } & \multicolumn{4}{|c|}{ Performance } \\
\hline & & $\mathbf{1}$ & 2 & 3 & 4 & 5 & 1 & 2 & 3 & \begin{tabular}{l|l}
4 & 5
\end{tabular} \\
\hline \multirow[t]{2}{*}{ Mobility (M) } & $\begin{array}{l}\text { (M1) Accessibility to } \\
\text { Transport Network }\end{array}$ & & & & & & & & & \\
\hline & $\begin{array}{l}\text { (M2) Capacity of Transport } \\
\text { Network }\end{array}$ & & & & & & & & & \\
\hline \multirow[t]{2}{*}{ Reliability (R) } & $\begin{array}{l}\text { (R1) Travel Time from } \\
\text { Origin to Destination }\end{array}$ & & & & & & & & & \\
\hline & (R2) Congestion & & & & & & & & & \\
\hline \multirow[t]{2}{*}{$\begin{array}{l}\text { Cost Efficiency } \\
\text { (C) }\end{array}$} & $\begin{array}{l}\text { (C1) Operating Costs of Moving } \\
\text { Freight }\end{array}$ & & & & & & & & & \\
\hline & (C2) Competitiveness & & & & & & & & & \\
\hline \multirow{2}{*}{$\begin{array}{l}\text { Safety \& } \\
\text { Security (S) }\end{array}$} & (S1) Traffic Safety & & & & & & & & & \\
\hline & (S2) Traffic Security & & & & & & & & & \\
\hline \multirow[t]{2}{*}{$\begin{array}{l}\text { Infrastructure } \\
\text { Condition (I) }\end{array}$} & $\begin{array}{l}\text { (I1) Transport Network } \\
\text { Conditions }\end{array}$ & & & & & & & & & \\
\hline & (I2) Intermodal Links & & & & & & & & & \\
\hline \multirow{2}{*}{$\begin{array}{l}\text { Environment } \\
\text { (E) }\end{array}$} & (E1) Energy Consumption & & & & & & & & & \\
\hline & $\begin{array}{l}\text { (E2) Amount of Pollutants } \\
\text { released }\end{array}$ & & & & & & & & & \\
\hline & & \multicolumn{5}{|c|}{$\begin{array}{l}\text { How important is } \\
\text { this factor to you? } \\
\text { (1) Not usually } \\
\text { important } \\
\text { (2) Only an issue if } \\
\text { it falls below a } \\
\text { minimum standard } \\
\text { (3) It is useful but } \\
\text { not vital } \\
\text { (4) It is very } \\
\text { important to our } \\
\text { satisfaction } \\
\text { (5) It is crucial to } \\
\text { our satisfaction }\end{array}$} & \multicolumn{4}{|c|}{$\begin{array}{l}\text { What is the } \\
\text { network's } \\
\text { performance at } \\
\text { delivering this } \\
\text { factor to you? } \\
\text { (1) They fall below } \\
\text { your minimum } \\
\text { standard } \\
\text { (2) They meet the } \\
\text { minimum standard } \\
\text { which you could } \\
\text { tolerate } \\
\text { (3) They just meet } \\
\text { your expectations } \\
\text { (4) They meet you } \\
\text { best expectations } \\
\text { (5) They exceed } \\
\text { your best } \\
\text { expectations }\end{array}$} \\
\hline
\end{tabular}




\section{Mobility (M)}

The service performance attribute Mobility $(M)$ relates to the ease of movement of people, goods and services. Since the main purpose of transportation is to move things from their origin to their destination, mobility is an important indicator of how well a transportation system functions. Mobility can be defined as the ability to transport goods, and people efficiently. Under the main indicator Mobility $(M)$ a sub-indicator is Accessibility to transport network and it is designated in the service performance measurement template shown in table 5-1 as M1. Gateways are inherently dependent on the quality of the infrastructure which occurs within them and level of accessibility which such infrastructure can provide to support the functional efficiency of such gateways. The accessibility of any given gateway city or area will be an important factor within the decision making process for a logistics company seeking to relocate or to establish themselves within a new location. Accessibility issues can arise when transport users must compete for limited transport system capacity. Another also important sub-indicator under the main indicator mobility $(M)$ as shown in table 5-1 is Capacity of the transport network (M2). This is most easily summarised as congestion, and can have substantial operational and economic implications, which most commonly manifest themselves in longer journey times, poor fuel consumption and lost productivity.

\section{$\underline{\text { Reliability (R) }}$}

For a transportation system, throughout the majority of Europe, the movement of freight by road is the primary means of goods distribution. This offers benefits to customers in terms of Reliability $(R)$, but large scale use can be described as unsustainable due to the amount of fossil fuels required in the movement of goods by this mode when compared with other modes. Amongst the modes which are generally accepted as being more sustainable are rail and waterborne transport modes, which allow for larger quantities of goods to be transported in a more fuel efficient, and therefore, in a more sustainable manner. The sub-indicator Travel time from origin to destination (RI) is usually represented by the delays produced by unusual events, such as: accidents, intersection congestion, operational problems at intermodal terminals, or other lost time incidents. 
Sub-indicator Congestion $(R 2)$ is used to denote one aspect of the reliability of transportation systems. The types of infrastructure which form the main basis of the transportation system within each gateway have an important influence on its sustainability, as well as how this is defined.

\section{$\underline{\text { Cost Efficiency (C) }}$}

The main indicator Cost efficiency $(C)$ as shown in table 5-1 relates to the various way that the transport network enables its users to reduce the costs of running their business. Goods are generally transported by five basic modes - road, rail, air, waterborne and pipeline. However these modes vary in economic service characteristics (e.g., speed, availability, and flexibility), capacity and cost structure, and each mode is the predominant option for a certain type of transport flow (Stock and Lambert 2001). These modes also differ in the impacts they have on a region. An understanding of these differences is critical in analysing the sustainability of any gateway. The sub-indicator Operating Costs of Moving Freight (C1) explores the ability of the transport network in a gateway to offer to its users cost reduction benefits. That could be for example lower fuel prices along the network or special schemes. Similarly the sub-indicator Competitiveness ( $C 2$ ) is concerned with how the users perceive the transport network and how the different modes of transport within it enable them to compete more effectively.

\section{$\underline{\text { Safety and Security (S) }}$}

Safety and security $(S)$ are inherent performance measures for transportation. A transportation system without high safety and security is simply unreliable and inefficient. The sub-indicators Traffic Safety (S1) and Traffic Security (S2) provides the ability to the users of the transport network to indicate whether they feel that the transport network is safe and secure. Expected and unexpected events can cause serious disruptions to the flows of goods, services and people. Safety and security are also important indicators for the sustainable development of a transport network. Also they play a crucial role in the coordination and harmonisation of the intermodal transport as a whole from a system's view point. 


\section{$\underline{\text { Infrastructure Conditions (I) }}$}

The Infrastructure Conditions (I) of a transportation infrastructure system is a key indicator. Whether the infrastructure is in good condition or not will directly influence its users in a range of ways. The average travel time and the reliability of a transportation system will deteriorate as the infrastructure does. Transport network conditions (II) is a critical sub-indicator in any assessment of the characteristics of a sustainable gateway. Assessments under this sub-theme seek to define where improvements have been made to the freight transportation capabilities of a gateway, how this has impacted upon the sustainability of freight transport to, through and from the gateway. Also the subindicator Intermodal links (I2) is a useful dimension which shows the development of intermodal links. In such cases where it can be proven that improvements to the sustainable transport network resulted from such decisions, then it can be shown that governance within a particular gateway has enhanced the sustainability of that gateway, and this can be used as an example to other gateways regarding how to enhance their own sustainability.

\section{$\underline{\text { Environment (E) }}$}

The main indicator $E$ is concerned with the preservation of the existing state of the environment of the transport network and its surroundings. One major trade off associated with a transportation system is its impact on both the human and natural environment. Users may enjoy the service from transportation, but at the expense of the environment as the sub-indicator Energy Consumption (E1) denotes. In the long run, the sustainability of a transportation system is affected by its impact on the environment. A sustainable freight logistics system contributes to social and economic welfare without damaging the environment or depleting environmental resources. The impacts of freight logistics which can be described as unsustainable are numerous and include a wide spectrum of issues. The sub-indicator Amount of pollutants released (E2) is concerned with such issues which range from the emission of $\mathrm{CO}_{2}$ and other pollutants, the use of non-renewable resources such as fossil fuels, the loss or fragmentation of wildlife habitats and the associated threats to wildlife species. 
When assessing the sustainability of gateways, consideration must be given to environmental performance in these key areas. Environmental quality is often overlooked in the types of heavily industrialised environments within which freight logistics facilities are frequently located. The term sustainability is often heavily linked with environmental protection, but the environmental element of sustainability is just one of three interrelated elements (the other two being social and economic). The protection and enhancement of environmental quality must be seen as being a priority within the context of a sustainable transport gateway, but should not be pursued in isolation from economic and social development.

\subsubsection{Importance-performance matrix survey data analysis}

The main questionnaire used in this research can be found in appendix A-1. The questionnaire was designed after brainstorming sessions with a group of five experts based in the UK in the fields of multimodal transport, maritime logistics, marine engineering and supply chain management. The experts were asked openly to express and share their views regarding the design of the questionnaire in frequent monthly meetings over a period of three months. Also in the meetings the selection of measurable service attributes was discussed and their applicability into the identified research setting (case study). These measurable service attributes were used to construct the combined IPA and AHP survey index as it was discussed in section 5.4.1. With these in mind also the main approaches for the collection of the primary data was discussed. In accordance with Lawson and Stratham (U.S Department for Transportation 2002) the suggested approaches to gather information included:

- $\quad$ Face to face interviews

- $\quad$ Email survey with the questionnaire attached

- Online survey

- $\quad$ Telephone survey

The completed first draft of the survey questionnaire was then administered to a small sample of respondents by the experts who participated in the brainstorming sessions. The results of the completed questionnaires were analysed and presented in a workshop 
for European logistics and transport research in Ireland on May 2012. Feedbacks were received regarding the use of the survey tool within the selected regional case study by another group of experts who were based in other parts of North West Europe and they were asked to comment on the methodology. Presenting the survey tool and the pilot survey results in this transnational workshop provided valuable advices on how to improve the survey tool and how to administer it. The survey tool then was completed and the final version was used in order to collect primary data within the Liverpool Manchester regional logistics gateway.

The next stage of the process involved asking for the assistance of the group of experts to distribute the questionnaires to high level contacts within the industry and the public sector by email. Also by email the questionnaire was sent to members of professional membership directories such the Liverpool Enterprise Partnership (LEP) and Mersey Maritime. Also in order to collect primary data from companies based within the outer limits of the gateway, such as Greater Manchester and Lancashire, telephone surveys were contacted with the assistance of two colleagues in the Logistics, Offshore and Marine Research Institute. Also questionnaires were handed in person to high level contacts of the Chartered Institute of Logistics and Transport in an event organised in Manchester on the topic of the new Liverpool container terminal's master plan. The collected primary data were then analysed and presented in another transnational research workshop which took place in Germany on December 2012 at the same group of external experts from other European countries. It was then suggested that the survey tool and methodology could be applicable also in similar case studies in their regions of interest.

In this research a total of 142 surveys were conducted to various stakeholders of the freight industry in the gateway coming both from the private and the public sector. In figure 5-2 a GIS representation is provided as part of the methodology for the identification of stakeholders of the freight industry. Some examples of the organisations that have been contacted were warehouse and distribution centres, manufacturing companies, retailers, third party logistics companies and others such as infrastructure providers and independent consultants. 


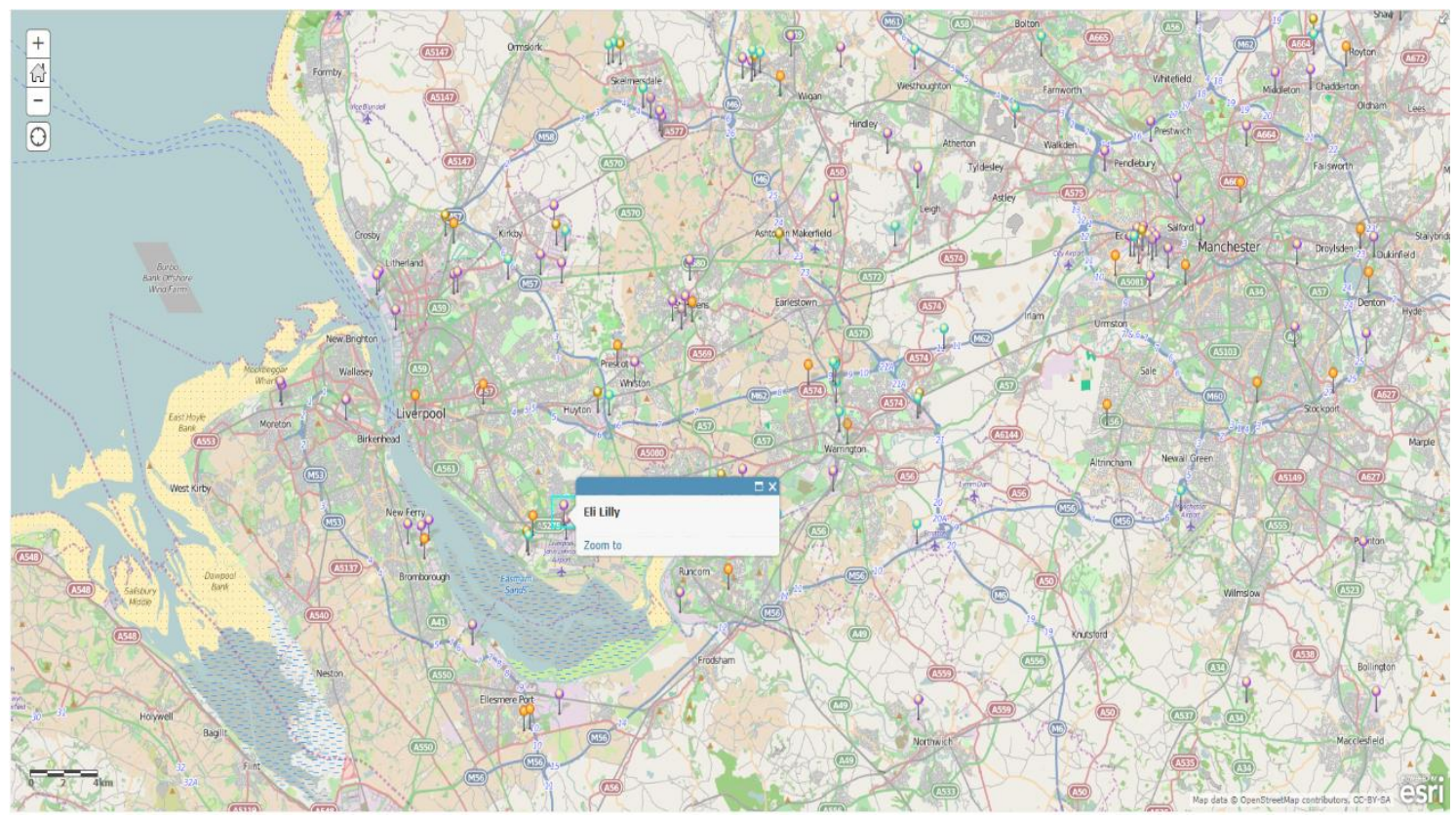

Figure 5-2: GIS representation of participants in the survey (example given from the private sector)

The survey yielded a $16 \%$ response rate. Figure 5-3 shows that the majority of respondents to the survey were service providers by $50 \%, 18 \%$ were goods providers, $6 \%$ infrastructure providers and $26 \%$ involved in other types of businesses.

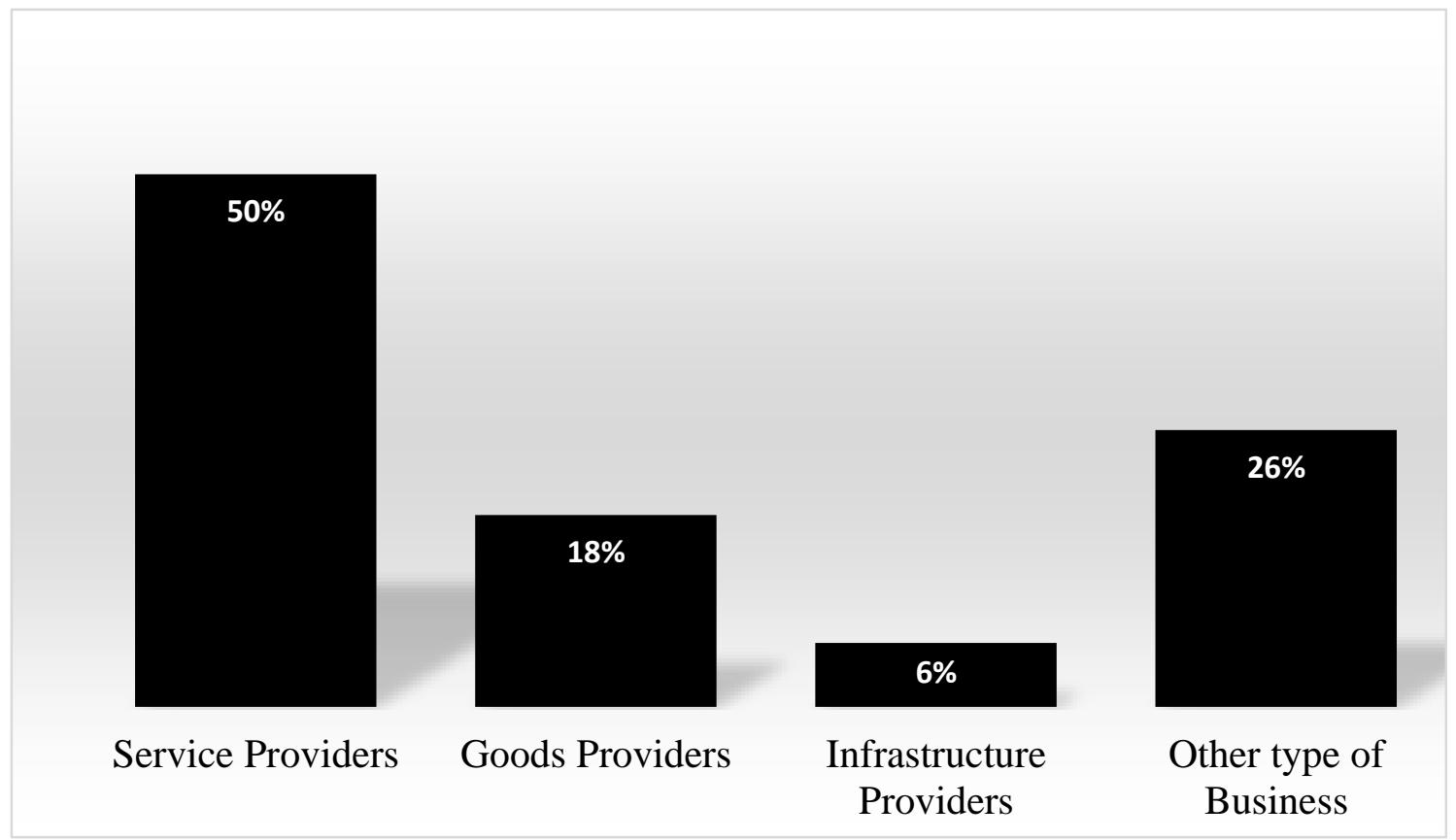

Figure 5-3: Distribution of stakeholders who responded 
Figure 5-4 shows that $45 \%$ of all respondents reporting using road in order to move freight whereas $22.5 \%$ and $16.3 \%$ used rail and water modes respectively.

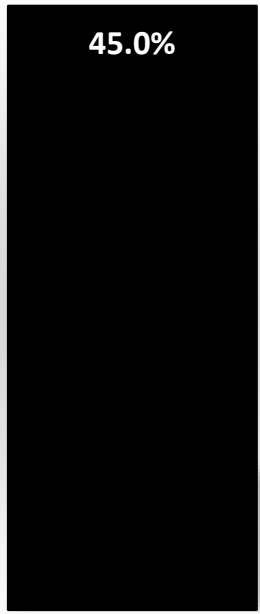

Road

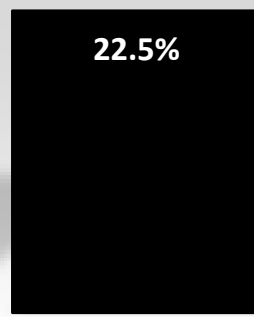

Rail

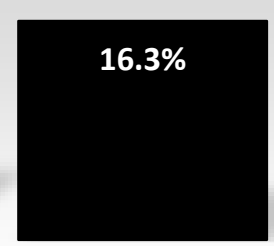

Water

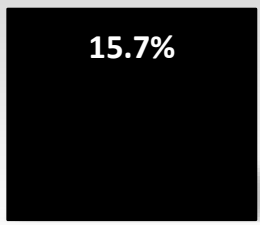

Air

Figure 5-4: Distribution of mode use by respondents

\begin{tabular}{|c|c|c|c|c|c|c|c|c|c|c|c|}
\hline \multirow{2}{*}{$\begin{array}{l}\text { ROAD } \\
\text { Indicators }\end{array}$} & \multirow[b]{2}{*}{ Sub-indicators } & \multicolumn{5}{|c|}{ Importance } & \multicolumn{5}{|c|}{ Performance } \\
\hline & & 1 & 2 & 3 & 4 & 5 & 1 & 2 & 3 & 4 & 5 \\
\hline \multirow[t]{2}{*}{ Mobility } & Accessibility to Road Network & $\mathrm{X}$ & & & & & & $\mathrm{X}$ & & & \\
\hline & Capacity of Road Network & $\mathrm{X}$ & & & & & & & $\mathrm{X}$ & & \\
\hline \multirow[t]{2}{*}{ Reliability } & Travel Time from Origin to Destination & & $\mathrm{X}$ & & & & & $\mathrm{X}$ & & & \\
\hline & Congestion & & $\mathrm{X}$ & & & & & $\mathrm{X}$ & & & \\
\hline \multirow[t]{2}{*}{ Cost Efficiency } & Operating Costs of Moving Freight & & $\mathrm{X}$ & & & & & $\mathrm{X}$ & & & \\
\hline & Competitiveness & & $\mathrm{X}$ & & & & & & $\mathrm{x}$ & & \\
\hline \multirow[t]{2}{*}{ Safety \& Security } & Traffic Safety & & $\mathrm{X}$ & & & & & $\mathrm{X}$ & & & \\
\hline & Traffic Security & $\mathrm{X}$ & & & & & & $\mathrm{X}$ & & & \\
\hline \multirow{2}{*}{$\begin{array}{l}\text { Infrastructure } \\
\text { Condition }\end{array}$} & Road Conditions & & $\mathrm{X}$ & & & & & & $\mathrm{X}$ & & \\
\hline & Intermodal Links & & & $\mathrm{X}$ & & & & $\mathrm{X}$ & & & \\
\hline \multirow[t]{2}{*}{ Environment } & Energy Consumption & & $\mathrm{X}$ & & & & & $\mathrm{X}$ & & & \\
\hline & Amount of Pollutants released & & $\mathrm{X}$ & & & & & $\mathrm{X}$ & & & \\
\hline \multirow[t]{2}{*}{ Comments: } & & \multicolumn{5}{|c|}{$\begin{array}{l}\text { How important is this factor to } \\
\text { you? }\end{array}$} & \multicolumn{5}{|c|}{$\begin{array}{l}\text { What is the network's } \\
\text { performance at delivering this } \\
\text { factor to you? }\end{array}$} \\
\hline & & \multicolumn{5}{|c|}{$\begin{array}{l}\text { (1) Not usually important } \\
\text { (2) Only an issue if it falls } \\
\text { below a minimum standard } \\
\text { (3) It is useful but not vital } \\
\text { (4) It is very important to our } \\
\text { satisfaction } \\
\text { (5) It is crucial to our } \\
\text { satisfaction }\end{array}$} & \multicolumn{5}{|c|}{$\begin{array}{l}\text { (1) They fall below your } \\
\text { minimum standard } \\
\text { (2) They meet the minimum } \\
\text { standard which you could } \\
\text { tolerate } \\
\text { (3) They just meet your } \\
\text { expectations } \\
\text { (4) They meet your best } \\
\text { expectations } \\
\text { (5) They exceed your best } \\
\text { expectations }\end{array}$} \\
\hline
\end{tabular}

Figure 5-5: Screenshot example of a completed section for the road mode of the service performance of the transport network by a respondent 
For the majority of stakeholders that responded to the survey road is their most dominant mode of transport as shown in the example of a completed template for the road mode as shown in figure 5-5. This emphasizes the validity of the modal shift that the EU is hoping to achieve whereby each leg of a given journey should be undertaken using the most sustainable mode of freight transport for that leg. A modified importance performance matrix allowed in order to explore improvement priorities in for each mode of freight transport utilised in the region. As it was discussed earlier it is a method of identifying the most important aspects of infrastructure so that they can be altered to improve the users' satisfaction and the performance of infrastructure against perceived expectations. The importance performance matrix positions each factor of the operation in accordance with its related survey score. The matrix is an aid for identifying which factors are currently perceived as being satisfactory and which are in need of improvement (Slack 1994). As can be seen in figures 5-6, 5-7, 5-8 and 5-9 there are four zones within every matrix.

Determinants of service performance are plotted in the matrixes and fall into one of the four categories:

- The 'appropriate' zone is the level into which a stakeholder would not wish performance to fall and would aim to improve performance for it to reach the upper limits of this zone.

- The 'improve' zone indicates that there is room for improvement. The positioning within this zone will dictate the priority for improvement.

- The 'urgent action' zone is a more critical position to be in. The short term aim would be to at least move the factor into the improve zone before making plans to Improve further.

- $\quad$ The 'excess' zone is the level that indicates that the provider may be using too many resources to achieve an appropriate level. 
Figures 5-6, 5-7, 5-8 and 5-9 illustrate the results for the survey for every mode of transport on the different importance and performance matrices. IPA provides a gapbased methodology and lies in its capacity to represent both importance and performance perspectives with regards to the relative improvement priorities required for the sustainable development of a transport infrastructure system. The analysis was applied separately for every mode of transport and it is crucial to acknowledge that IPA is more superior to other service quality management tools such as the SERVQUAL as discussed in chapter three because it has the importance attribution to the items and moreover, IPA can be plotted graphically using the mean values of importance and performance of every criterion.

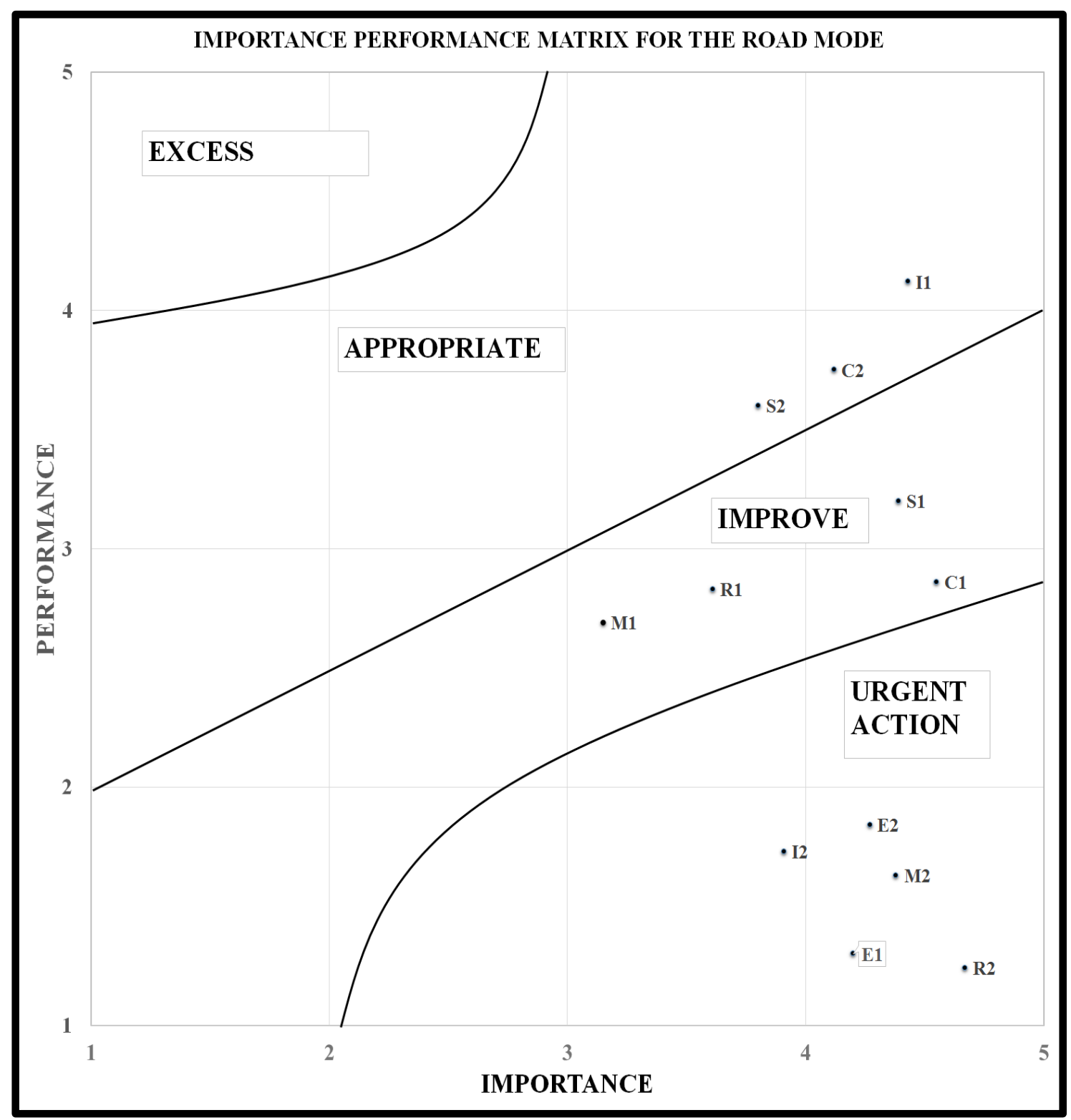

Figure 5-6: IPA diagram showing the mean values of attributes for the road mode 
Table 5-2: Aggregate performance and importance scores for the road mode

\begin{tabular}{|c|c|c|c|}
\hline Attributes' scores for the road mode & Performance & Importance & Discrepancy \\
\hline \multicolumn{4}{|l|}{ Mobility } \\
\hline Accessibility to Road Network (M1) & 2.69 & 3.15 & -0.46 \\
\hline Capacity of Road Network (M2) & 1.63 & 4.38 & -2.75 \\
\hline \multicolumn{4}{|l|}{ Reliability } \\
\hline Travel time from Origin to Destination (R1) & 2.83 & 3.61 & -0.78 \\
\hline Congestion (R2) & 1.24 & 4.67 & -3.43 \\
\hline \multicolumn{4}{|l|}{ Cost Efficiency } \\
\hline Operating costs of moving freight $(\mathrm{C} 1)$ & 2.86 & 4.55 & -1.69 \\
\hline Competitiveness (C2) & 3.75 & 4.12 & -0.37 \\
\hline \multicolumn{4}{|l|}{ Safety and Security } \\
\hline Traffic Safety (S1) & 3.2 & 4.39 & -1.19 \\
\hline Traffic Security (S2) & 3.6 & 3.8 & -0.2 \\
\hline \multicolumn{4}{|l|}{ Infrastructure condition } \\
\hline Infrastructure conditions (I1) & 4.12 & 4.43 & -0.31 \\
\hline Intermodal links (I2) & 1.73 & 3.91 & -2.18 \\
\hline \multicolumn{4}{|l|}{ Environment } \\
\hline Energy consumption (E1) & 1.3 & 4.2 & -3.07 \\
\hline Amount of pollutants released (E2) & 1.84 & 4.27 & -2.43 \\
\hline
\end{tabular}

Mean scores for both importance and performance data were plotted as coordinates on the IPA graph as depicted in figure 5-6 for the road mode. It is apparent from the analysis as shown in table 5-2 that the sub-indicators I1, C2 and S2 fall within the appropriate zone of the IPA matrix while no indicators fall at all within the excess zone. The findings of the service performance analysis for the road mode also indicate that quite a few indicators fall within the urgent action zone. These sub-indicators are E1, E2, I2, M2 and $\mathrm{R} 2$ and it is evident that users of the road mode within the selected regional logistics gateway are concerned with the impact that the road mode has on the environment. Moreover this is a clear indication of the necessity for the intermodal links of the transport network to be improved in order to tackle capacity and congestion problems. The analysis shows that sub- indicators M1, R1, S1 and C1 have the potential and need to be improved. 


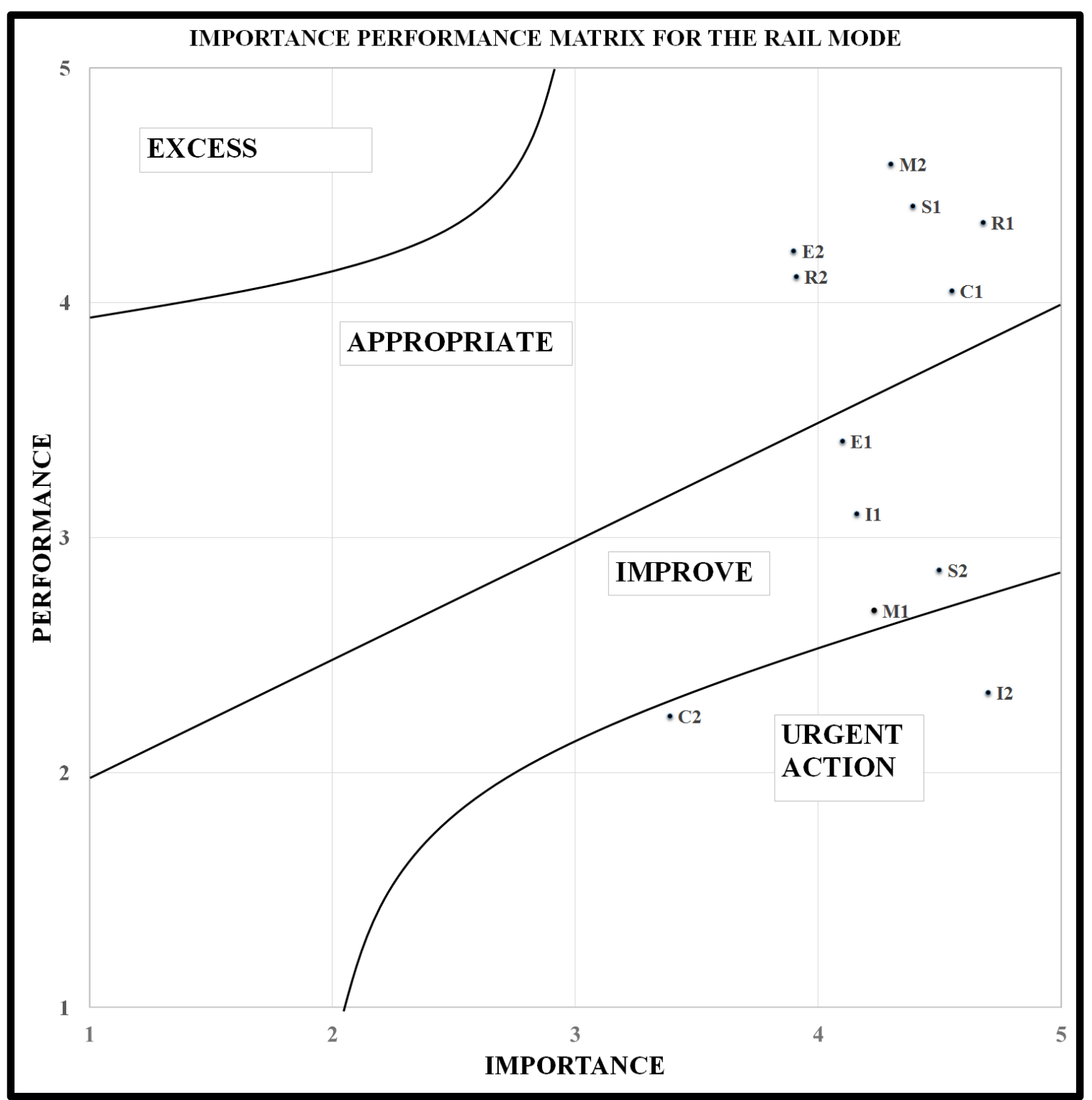

Figure 5-7: IPA diagram showing the mean values of attributes for the rail mode

Figure 5-7 presents the aggregate performance values for the rail mode (see table 5-3) obtained in the present study plotted against the corresponding aggregate performance values on an IPA grid. The analysis shows that the respondents are extremely concerned with how the rail mode could give them a competitive advantage in their daily operations within their regional logistics gateway and also at a global level. This observation derives from the position of the sub-indicator $\mathrm{C} 2$ within the urgent action zone. Also within the urgent action zone the sub-indicator I 2 falls very close within the boundaries of the improvement zone and this is a clear indication of the need for modal shift and the need for better intermodal links within the transport network under examination. 
Table 5-3: Aggregate performance and importance scores for the rail mode

\begin{tabular}{|c|c|c|c|}
\hline Attributes' scores for the rail mode & Performance & Importance & Discrepancy \\
\hline \multicolumn{4}{|l|}{ Mobility } \\
\hline Accessibility to Rail Network (M1) & 2.69 & 4.23 & -1.54 \\
\hline Capacity of Rail Network (M2) & 4.59 & 4.3 & 0.29 \\
\hline \multicolumn{4}{|l|}{ Reliability } \\
\hline Travel time from Origin to Destination (R1) & 4.34 & 4.68 & -0.34 \\
\hline Congestion (R2) & 4.11 & 3.91 & 0.2 \\
\hline \multicolumn{4}{|l|}{ Cost Efficiency } \\
\hline Operating costs of moving freight $(\mathrm{C} 1)$ & 4.05 & 4.55 & -0.5 \\
\hline Competitiveness (C2) & 2.24 & 3.39 & -1.15 \\
\hline \multicolumn{4}{|l|}{ Safety and Security } \\
\hline Traffic Safety (S1) & 4.41 & 4.39 & -0.02 \\
\hline Traffic Security (S2) & 2.86 & 4.5 & -1.64 \\
\hline \multicolumn{4}{|l|}{ Infrastructure condition } \\
\hline Infrastructure conditions (I1) & 3.1 & 4.16 & -1.06 \\
\hline Intemodal links (I2) & 2.34 & 4.7 & -2.36 \\
\hline \multicolumn{4}{|l|}{ Environment } \\
\hline Energy consumption (E1) & 3.41 & 4.1 & -0.69 \\
\hline Amount of pollutants released (E2) & 4.22 & 3.9 & 0.32 \\
\hline
\end{tabular}

Also shown in figure 5-7 the sub-indicators M1, S2, I1 and E1 for the rail mode based on the given scores by the respondents in table 5-3 of the industrial survey that was carried out in this study, fall within the improvement zone. This finding is suggesting that the stakeholders perceive that the accessibility to the rail network needs to be improved and that more could be done for the rail network's infrastructure conditions and security and energy consumption. In the comments section of the questionnaire, the respondents of the survey justified this by stating that improvements can be made for the electrification of the network for longer journeys and that also better synergies can be developed with the road mode in order to enhance the intermodality of the transport network. 


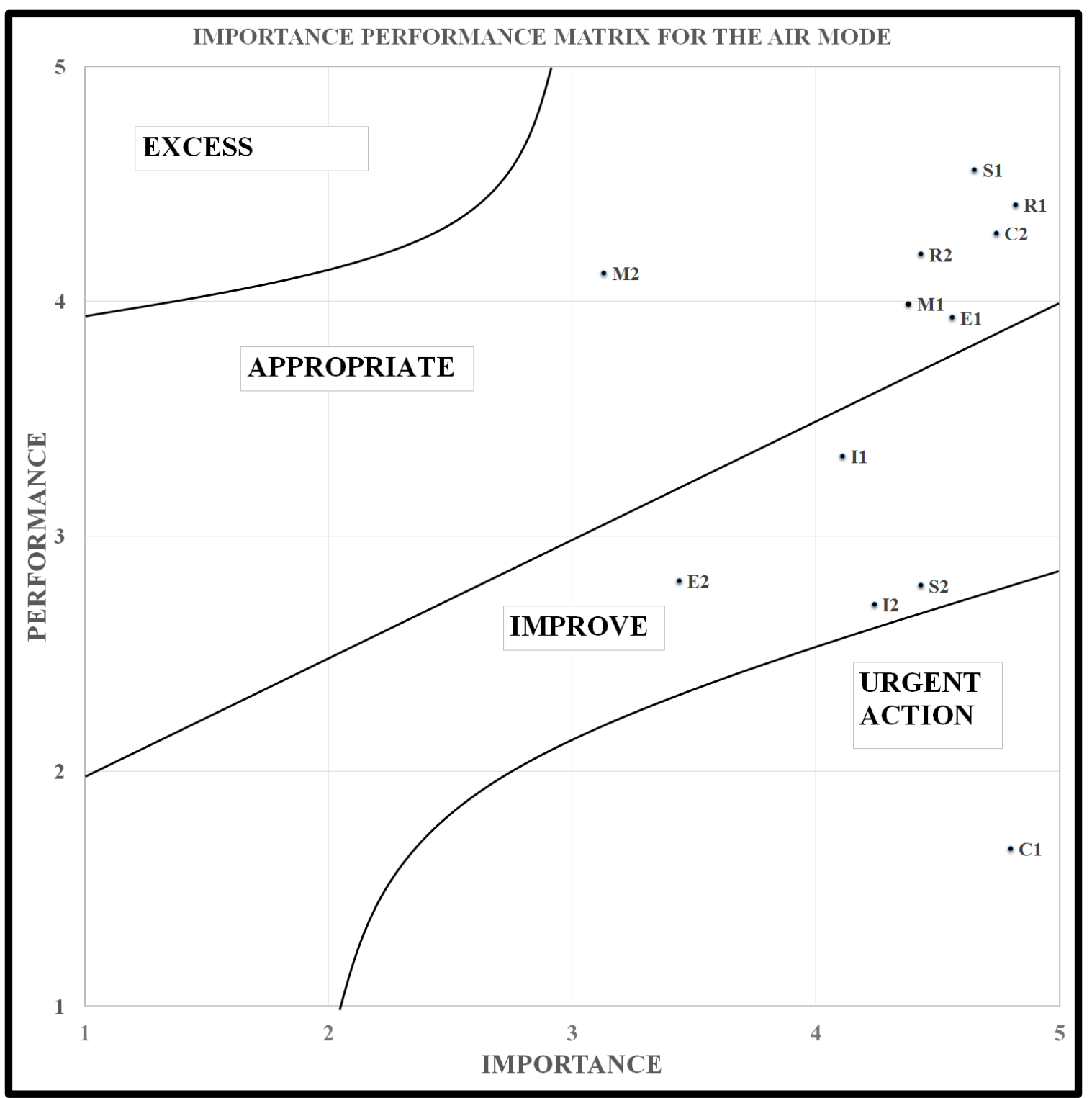

Figure 5-8: IPA diagram showing the mean values of attributes for the air mode

The IPA grid analysis for the air mode shows that the respondents view this mode of transport as a very expensive. Sub-indicator $\mathrm{C} 1$ is the only indicator that falls within the urgent action zone. However the sub-indicators M1, M2, R1, R2, C2, S1 and E1 fall within the appropriate zone of the IPA matrix suggesting that despite the high costs of moving freight the air mode within the regional logistics network is accessible, reliable, safe and also can make a positive contribution to competiveness of their business. No weights have been given for the air mode indicators but as with the other modes of transport the survey revealed that a number of important sub-indicators related to the service performance measurement and sustainable development of the logistics gateway. 
Table 5-4: Aggregate performance and importance scores for the air mode

\begin{tabular}{|c|c|c|c|}
\hline Attributes' scores for the Air mode & Performance & Importance & Discrepancy \\
\hline \multicolumn{4}{|l|}{ Mobility } \\
\hline Accessibility to Airborne Network (M1) & 3.99 & 4.38 & -0.39 \\
\hline Capacity of the Airborne Network (M2) & 4.12 & 3.13 & 0.99 \\
\hline \multicolumn{4}{|l|}{ Reliability } \\
\hline Travel time from Origin to Destination (R1) & 4.41 & 4.82 & -0.41 \\
\hline Congestion (R2) & 4.2 & 4.43 & -0.23 \\
\hline \multicolumn{4}{|l|}{ Cost Efficiency } \\
\hline Operating costs of moving freight $(\mathrm{C} 1)$ & 1.67 & 4.8 & -3.13 \\
\hline Competitiveness (C2) & 4.29 & 4.74 & -0.45 \\
\hline \multicolumn{4}{|l|}{ Safety and Security } \\
\hline Traffic Safety (S1) & 4.56 & 4.65 & -0.09 \\
\hline Traffic Security (S2) & 2.79 & 4.43 & -1.64 \\
\hline \multicolumn{4}{|l|}{ Infrastructure condition } \\
\hline Infrastructure conditions (I1) & 3.34 & 4.11 & -0.77 \\
\hline Intemodal links (I2) & 2.71 & 4.24 & -1.53 \\
\hline \multicolumn{4}{|l|}{ Environment } \\
\hline Energy consumption (E1) & 3.93 & 4.56 & -0.63 \\
\hline Amount of pollutants released (E2) & 2.81 & 3.44 & -0.63 \\
\hline
\end{tabular}

The sub-indicators that recommend improvement actions to be taken for the air mode as part of the gateways' transport network is also shown in figure 5-8 based on the values given in this study by the respondents in table 5-4. These are the sub-indicators S2, I1, I2 and E2. In this particular analysis it is suggested according to the stakeholders' perception who participated in the industrial survey that security, infrastructure conditions and intermodal links can be improved. In the comments section of the industrial survey's questionnaire it has been made clear that this is because increased security measures in some cases do cause delays in the daily operations of their businesses. Also from the infrastructure providers' point of view the sub-indicator E2 is of great importance and requires improvement as it plays a crucial role in sustainability. 


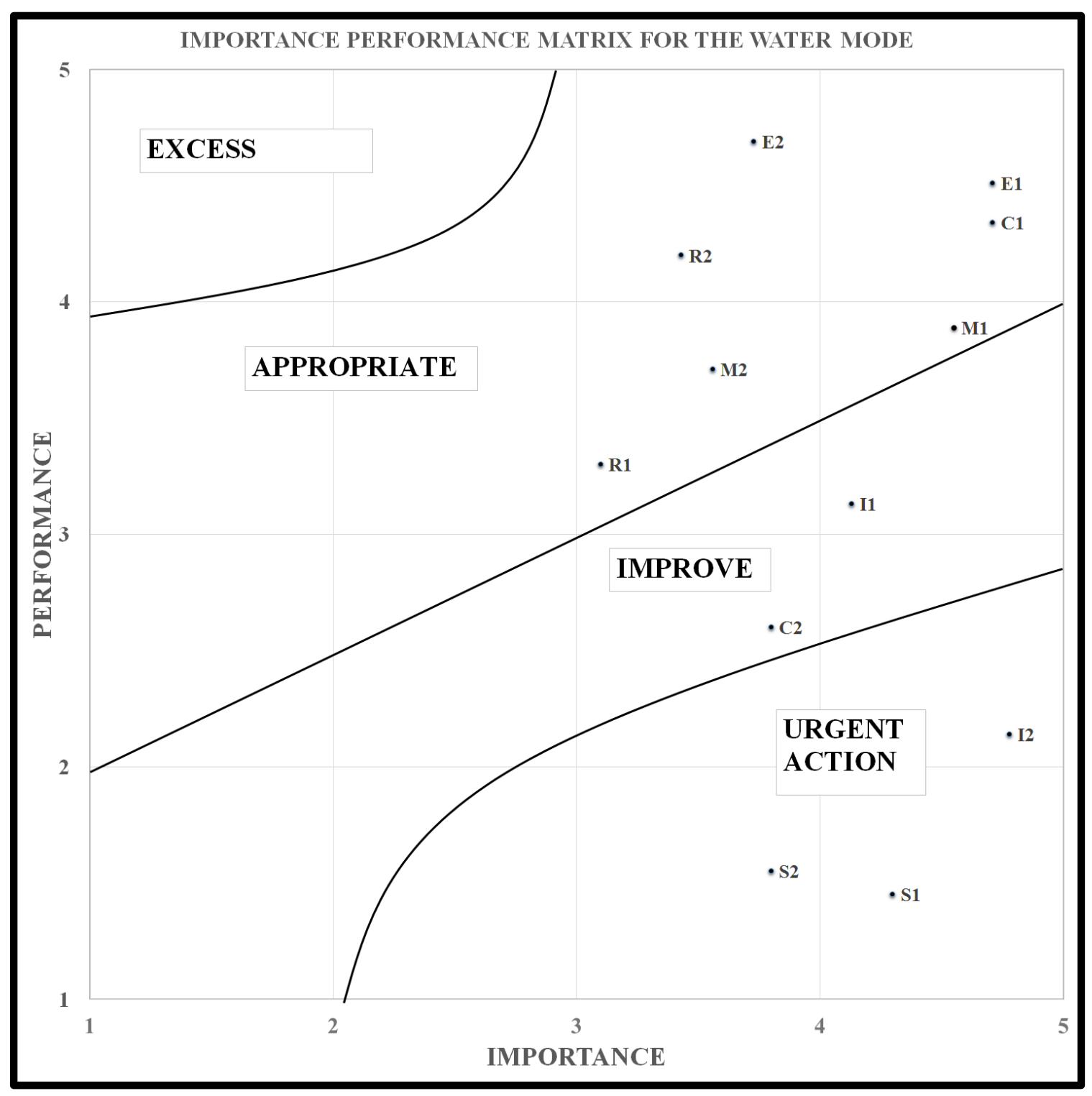

Figure 5-9: IPA diagram showing the mean values of attributes for the water mode

In the IPA matrix for the water mode as shown in figure 5-9 it has been found that the respondents were quite satisfied with the performance of the mean scores of the subindicators M1, M2, R1, R2, C1, E1 and E2 given in table 5-5. It can be also suggested that their performance closely matches their expectations especially in terms of capacity and congestion where there is a positive relationship between the two dimensions (performance and importance). These findings also encourage the consideration that the water mode is an environmentally friendly mode that can support modal shift through the use of the existing inland waterways within the gateway (for example the Manchester ship canal) as supported by the mean values of the sub-indicators E1 and E2. 
Table 5-5: Aggregate performance and importance scores for the water mode

\begin{tabular}{|c|c|c|c|}
\hline Attributes' scores for the water mode & Performance & Importance & Discrepancy \\
\hline \multicolumn{4}{|l|}{ Mobility } \\
\hline Accessibility to Waterborne Network (M1) & 3.89 & 4.55 & -0.66 \\
\hline Capacity of Waterborne Network (M2) & 3.71 & 3.56 & 0.15 \\
\hline \multicolumn{4}{|l|}{ Reliability } \\
\hline Travel time from Origin to Destination (R1) & 3.3 & 3.1 & 0.2 \\
\hline Congestion (R2) & 4.2 & 3.43 & 0.77 \\
\hline \multicolumn{4}{|l|}{ Cost Efficiency } \\
\hline Operating costs of moving freight $(\mathrm{C} 1)$ & 4.34 & 4.71 & -0.37 \\
\hline Competitiveness (C2) & 2.6 & 3.8 & -1.2 \\
\hline \multicolumn{4}{|l|}{ Safety and Security } \\
\hline Traffic Safety (S1) & 1.45 & 4.3 & -2.85 \\
\hline Traffic Security (S2) & 1.55 & 3.8 & -2.25 \\
\hline \multicolumn{4}{|l|}{ Infrastructure condition } \\
\hline Infrastructure conditions (I1) & 3.13 & 4.13 & -1 \\
\hline Intermodal links (I2) & 2.14 & 4.78 & -2.64 \\
\hline \multicolumn{4}{|l|}{ Environment } \\
\hline Energy consumption (E1) & 4.51 & 4.71 & -0.2 \\
\hline Amount of pollutants released (E2) & 4.69 & 3.73 & 0.96 \\
\hline
\end{tabular}

Table 5-5 and the IPA graph provide a gap analysis for the water mode which also indicates that only two sub-indicators are within the improvement zone, $\mathrm{C} 2$ and I1. These should be considered as important attributes, as from a service quality perspective they are particularly important, as the stakeholders involved in the supply chain industry (both from the public and the private sector) have considerations on how the water mode could enhance competitiveness and quality of the infrastructure. However, there are serious considerations expressed through the completion of the survey questionnaire by the respondents, as three sub-indicators do not exceed their expectations (importance) such as I2, S1 and S2. The development of intermodal links of the water mode with other modes of transport such as road and rail for example is crucial to sustainable development. Also concerns are raised for safety and security as the use of inland waterways as an alternative mode of transport is not yet fully developed and operable. 


\subsection{Validation with AHP}

The importance placed on each performance main indicator can be also modelled statistically by means of rank order algorithms, rating scales, pair-wise comparisons or magnitude estimates. This study adapted the pair-wise comparisons approach due to its simplicity and the ease by which it can be understood by experts. The AHP method involves one-by-one comparisons between each of the main performance indicators for all modes of transport. Ultimately, this analysis employs the subjective judgements of experts in the field on the relative importance of each pair of performance main indicators based upon their position in an established hierarchy. Evidence has shown that these pairwise comparisons provide an additional analysis of the responses provided for the IPA's sub-indicators.

The results provided by the pair-wise comparison method can also be analysed to reveal the consistency or the reliability of the responses obtained from experts. An average rating score indicates when there is an unacceptable level of inconsistency within the responses and also highlights where the inconsistency may originate from. This ensures that the main indicators are transparent and allows decision makers to have a sound understanding of them.

\subsubsection{Construction of a pairwise comparison index for the main criteria}

In light of the above, it is important to mention that such an analysis aids decision makers in targeting areas that need more attention for investment strategies. The detailed pairwise comparison that is presented in table 5-2 is based on the IPA's main attributes that were selected for the assessment of the respondents' values. The AHP analysis carried out in this study concentrates on the main indicators only of service performance of the transport network in the selected gateway's case study. The limitations of the proposed service performance measurement methodology is that although it allows for a thorough pairwise comparisons analysis to be carried out for the sub-indicators as well, as shown in figure 5-10, in this case study it was concluded that a pairwise analysis for the main indicators only would be sufficient due to the lack of resources (for example additional time during telephone surveys) as the main objective was to validate the IPA findings. 
Table 5-6: Pairwise comparison for main indicators

\begin{tabular}{|l|l|l|l|l|l|l|l|l|l|l|l|l|l|l|l|l|l|l|}
\hline $\begin{array}{l}\text { Transport } \\
\text { Mode Main } \\
\text { Indicators }\end{array}$ & $\mathbf{9}$ & $\mathbf{8}$ & $\mathbf{7}$ & $\mathbf{6}$ & $\mathbf{5}$ & $\mathbf{4}$ & $\mathbf{3}$ & $\mathbf{2}$ & $\mathbf{1}$ & $\mathbf{2}$ & $\mathbf{3}$ & $\mathbf{4}$ & $\mathbf{5}$ & $\mathbf{6}$ & $\mathbf{7}$ & $\mathbf{8}$ & $\mathbf{9}$ & $\begin{array}{l}\text { Transport } \\
\text { Mode Main } \\
\text { Indicators }\end{array}$ \\
\hline M & & & & & & & & & & & & & & & & & & R \\
\hline M & & & & & & & & & & & & & & & & & C \\
\hline M & & & & & & & & & & & & & & & & & & I \\
\hline M & & & & & & & & & & & & & & & & & E \\
\hline M & & & & & & & & & & & & & & & & & C \\
\hline R & & & & & & & & & & & & & & & & & S \\
\hline R & & & & & & & & & & & & & & & & I \\
\hline R & & & & & & & & & & & & & & & E \\
\hline R & & & & & & & & & & & & & & & & & & I \\
\hline C & & & & & & & & & & & & & & & & & & E \\
\hline C & & & & & & & & & & & & & & & & & & \\
\hline C I
\end{tabular}

Example:

If Mobility is more important than Reliability and this is absolutely the case then please tick 9 on the right hand side

If Mobility is less important than Reliability and this is very strongly the case then please tick 7 on the left hand side. 


\subsubsection{Application of the AHP methodology}

The basic Analytic Hierarchy Process (AHP) procedure for calculating the weights of the six main indicators can be realized by (Kunz, 2010):

- $\quad$ Developing a single pair-wise comparison matrix for the main indicators.

- Multiplying the values of the main indicators' pairs in each row of the matrix in order to estimate the $n^{\text {th }}$ root

- $\quad$ Normalizing the $n^{\text {th }}$ root of the pairwise comparison outputs to obtain the weights of the main indicators.

- $\quad$ Calculating and validating the consistency ratio (CR).

The process of performing pair-wise comparisons can greatly assist policy and decision makers to compare the different pairs of indicators and judge which need urgent action for improvement. This pairwise comparison activity is part of the analytical hierarchical process as shown below in figure 5-10.

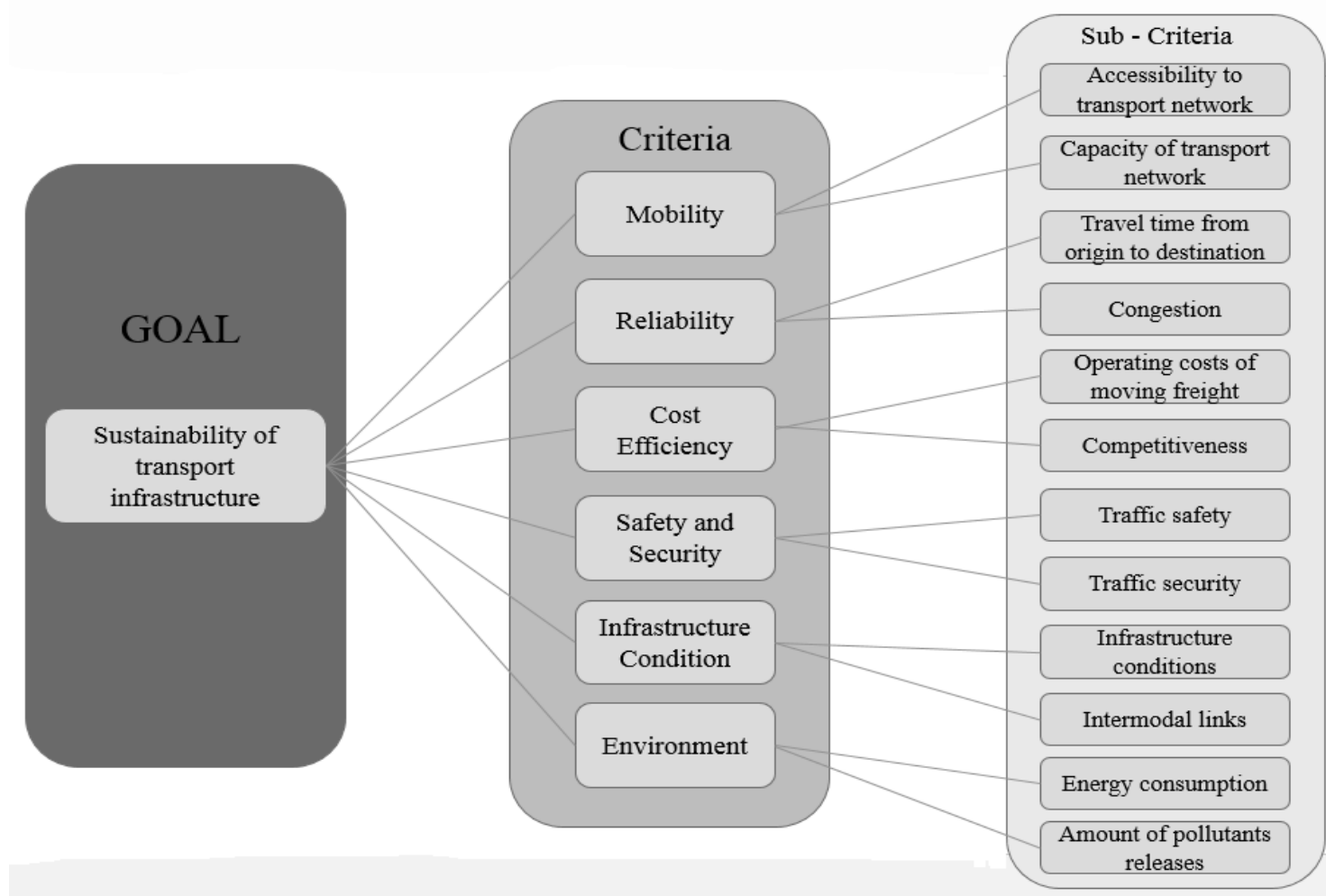

Figure 5-10: AHP for modelling the decision making for the sustainability of a transport infrastructure 
In more detail, the four step process consists of:

\section{Step 1: Develop a single pair-wise comparison matrix for the main indicators}

The computation relied on the responses given in the survey questionnaire. Within this context the eigenvalue-method of the AHP was employed as shown in the algebraic $6 \times 6$ matrix of table 5-7 to facilitate the calculation process.

Table 5-7: Result of relative importance of main indicators

\begin{tabular}{|l|l|l|l|l|l|l|}
\hline & M & R & C & S & I & E \\
\hline M & 1 & 1.129 & 2.229 & 2.651 & 1.868 & 1.072 \\
\hline R & 0.886 & 1 & 3.067 & 3.869 & 3.240 & 0.675 \\
\hline C & 0.448 & 0.326 & 1 & 2.262 & 1.457 & 0.857 \\
\hline S & 0.377 & 0.258 & 0.441 & 1 & 4.022 & 1.622 \\
\hline E & 0.535 & 0.309 & 0.686 & 0.248 & 1 & 0.822 \\
\hline I & 0.932 & 1.481 & 1.166 & 0.616 & 1.216 & 1 \\
\hline SUM & 4.179 & 4.503 & 8.590 & 10.646 & 12.804 & 6.048 \\
\hline
\end{tabular}

The initials M, R, C, S, I and E represent the main indicators for Mobility, Reliability, Cost effectiveness, Safety and Security, Infrastructure condition and the Environment respectively. Moreover the process of performing pair-wise comparisons can greatly assist policy and decision makers to compare the different indicators in pairs and to judge which of each entity needs urgent action for improvement. In this research the use of pair-wise comparisons gives added value to assessment of the service performance of the selected gateway case study as it focuses on the main service attributes only for all the modes of transport. Although during the IPA process the service attributes that fall within the main categories were assessed, in this exercise the main service attributes have only taken into consideration in order to identify which one is perceived and expected by both the private and the public sector to be of significant importance. 
Step 2: Multiply the value of each row and calculate the $n^{\text {th }}$ root of the main indicators.

For such a weight to be obtained it is important first to compute the $6^{\text {th }}$ root of the pair wise comparison output in a row of the matrix.

An example is given below:

$R=\left((0.886 \times 1 \times 3.067 \times 3.869 \times 3.240 \times 0.675)^{\frac{1}{6}}\right)=1.686$

Likewise, the $6^{\text {th }}$ roots of every indicator individually can be calculated in a similar manner as represented in table 5-8 below and the aggregated result of the $6^{\text {th }}$ roots in total has a given value of 6.465 .

Table 5-8: The $\mathrm{n}^{\text {th }}$ root of each criterion and the aggregated result of the $6^{\text {th }}$ roots

\begin{tabular}{|l|l|l|l|l|l|l|l|}
\hline & M & R & C & S & I & E & $\boldsymbol{n}^{\text {th }}$ root of indicators \\
\hline M & 1 & 1.129 & 2.229 & 2.651 & 1.868 & 1.072 & 1.540 \\
\hline R & 0.886 & 1 & 3.067 & 3.869 & 3.240 & 0.675 & 1.686 \\
\hline C & 0.448 & 0.326 & 1 & 2.262 & 1.457 & 0.857 & 0.863 \\
\hline S & 0.377 & 0.258 & 0.441 & 1 & 4.022 & 1.622 & 0.809 \\
\hline E & 0.535 & 0.309 & 0.686 & 0.248 & 1 & 0.822 & 0.533 \\
\hline I & 0.932 & 1.481 & 1.166 & 0.616 & 1.216 & 1 & 1.032 \\
\hline SUM & 4.179 & 4.503 & 8.590 & 10.646 & 12.804 & 6.048 & 6.465 \\
\hline
\end{tabular}

Step 3: Normalise the aforementioned $6^{\text {th }}$ roots of the obtained weights of the indicators.

The normalised weight for Reliability $(\mathrm{R})$ is calculated as follows $(1.686 / 6.465)=$ 0.261 and in a similar way, the weights of the other indicators have been calculated and presented in table 5-9. 
Table 5-9: The Priority Weight (PW) of each criterion and the aggregated result of the $6^{\text {th }}$ roots

\begin{tabular}{|l|l|l|l|l|l|l|l|l|}
\hline & M & R & C & S & I & E & $\begin{array}{l}\boldsymbol{n}^{\text {th }} \text { root of } \\
\text { indicators }\end{array}$ & $\begin{array}{l}\text { Priority } \\
\text { Weight } \\
(\text { PW) }\end{array}$ \\
\hline M & 1 & 1.129 & 2.229 & 2.651 & 1.868 & 1.072 & 1.540 & 0.239 \\
\hline R & 0.886 & 1 & 3.067 & 3.869 & 3.240 & 0.675 & 1.686 & 0.261 \\
\hline C & 0.448 & 0.326 & 1 & 2.262 & 1.457 & 0.857 & 0.863 & 0.134 \\
\hline S & 0.377 & 0.258 & 0.441 & 1 & 4.022 & 1.622 & 0.809 & 0.125 \\
\hline E & 0.535 & 0.309 & 0.686 & 0.248 & 1 & 0.822 & 0.533 & 0.082 \\
\hline I & 0.932 & 1.481 & 1.166 & 0.616 & 1.216 & 1 & 1.032 & 0.159 \\
\hline SUM & 4.179 & 4.503 & 8.590 & 10.646 & 12.804 & 6.048 & 6.465 & \\
\hline
\end{tabular}

The AHP analysis revealed that Reliability (R) scored the highest weight $(0.261)$ and Infrastructures' Conditions (I) scored the lowest (0.082) as shown in figure 5-11.

0.3

0.25

0.2
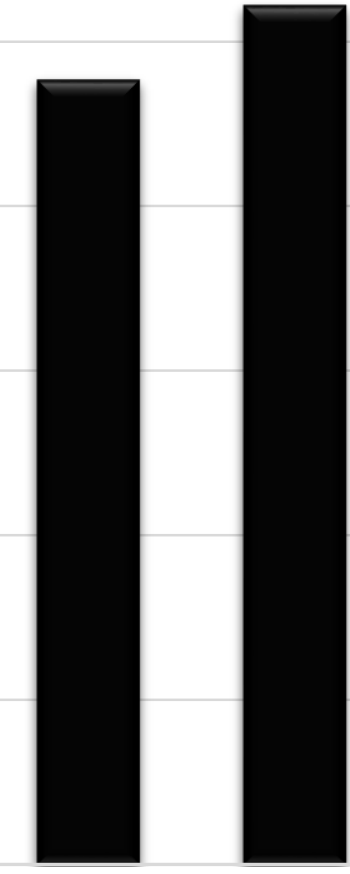

M

$\mathrm{R}$

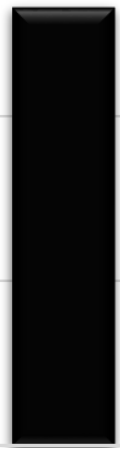

C

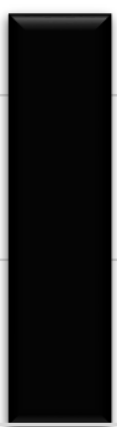

$\mathrm{S}$

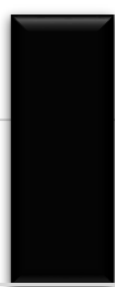

$E$

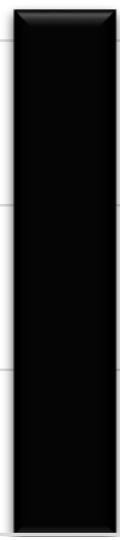

I Indicators

Figure 5-11: AHP for modelling the decision making for the sustainability 


\section{Step 4: Calculate and validate the consistency ratio.}

Each value in the row (SUM $\times \mathrm{PW}$ ) in Table 5-10 is the result of multiplying the individual SUM by the respective weight for that criterion shown in the column priority weight (PW).

$\lambda_{\text {max }}$ is the sum of the overall (SUM $\left.\times \mathrm{PW}\right)$ as demonstrated below:

$\lambda_{\max }=(0.995+1.175+1.147+1.332+1.058+0.965)=6.672$

$\lambda_{\max }=6.672$

$C I=\left(\lambda_{\max }-n\right) /(n-1)$, where $n$ is the number of indicators compared.

$C I=\frac{6.672-6}{6-1}=0.134$

Table 5-10: The calculation of the consistency ratios

\begin{tabular}{|l|l|l|l|l|l|l|l|l|}
\hline & $\mathrm{M}$ & $\mathrm{R}$ & $\mathrm{C}$ & $\mathrm{S}$ & $\mathrm{I}$ & $\mathrm{E}$ & $\begin{array}{l}\boldsymbol{n}^{\text {th }} \text { root of } \\
\text { indicators }\end{array}$ & $\begin{array}{l}\text { Priority } \\
\text { Weight } \\
(\mathrm{PW})\end{array}$ \\
\hline $\mathrm{M}$ & 1 & 1.129 & 2.229 & 2.651 & 1.868 & 1.072 & 1.540 & 0.239 \\
\hline $\mathrm{R}$ & 0.886 & 1 & 3.067 & 3.869 & 3.240 & 0.675 & 1.686 & 0.261 \\
\hline $\mathrm{C}$ & 0.448 & 0.326 & 1 & 2.262 & 1.457 & 0.857 & 0.863 & 0.134 \\
\hline $\mathrm{S}$ & 0.377 & 0.258 & 0.441 & 1 & 4.022 & 1.622 & 0.809 & 0.125 \\
\hline $\mathrm{E}$ & 0.535 & 0.309 & 0.686 & 0.248 & 1 & 0.822 & 0.533 & 0.082 \\
\hline $\mathrm{I}$ & 0.932 & 1.481 & 1.166 & 0.616 & 1.216 & 1 & 1.032 & 0.159 \\
\hline $\mathrm{SUM}$ & 4.179 & 4.503 & 8.590 & 10.646 & 12.804 & 6.048 & 6.465 & \\
\hline $\begin{array}{l}\text { SUM } \times \\
(\mathrm{PW})\end{array}$ & 0.995 & 1.174 & 1.146 & 1.332 & 1.057 & 0.965 & & \\
\hline
\end{tabular}

The random index (RI) is determined from a lookup table (Table 5-11) and is a direct function of the number of indicators being considered.

Table 5-11: Value of RI versus Matrix Order

\begin{tabular}{|l|l|l|l|l|l|l|l|l|l|l|l|}
\hline $\mathrm{n}$ & 1 & 2 & 3 & 4 & 5 & 6 & 7 & 8 & 9 & 10 \\
\hline $\mathrm{RI}$ & 0 & 0 & 0.58 & 0.9 & 1.12 & 1.24 & 1.32 & 1.41 & 1.45 & 1.49 \\
\hline
\end{tabular}


The consistency ratio (CR) emphasizes to the decision maker how consistent the responses have been throughout the pair-wise comparisons. Consistency ratio (CR) is calculated through dividing the consistency index $(\mathrm{CI})$ by a random index (RI).

$C R=\frac{C I}{R I}=\frac{0.134}{1.24}=0.109$

The CR value of 0.109 is slightly higher than the usually acceptable level (i.e. 0.1) (Kauko, 2002). However, given that there are six indicators and also that the respondent stakeholders are from a diverse business environment, 0.109 for $\mathrm{CR}$ is considered reasonably acceptable in this case study.

\subsection{Discussion, limitations and delimitations}

All surveys have their limitations and so does every method of conducting a survey. The research limitations of this research indicate the situations and circumstances that restricted the analysis of research data. Although the questionnaire used in this survey (as shown in appendix A-1) allowed for the performance of pair-wise comparisons not only for the main service attributes but also for the sub-indicators in some cases it was not possible to collect sufficient data for this category. This lack of data was a result was a result of the telephone survey that was conducted where at the last section of the questionnaire some of respondents felt that that the fifteen minutes threshold was exceeded and therefore decided to drop out half way through the completion of this section.

However it was decided that since a thorough collection of data and analysis of data was performed from the IPA process where the respondents stated their perceived and expected service performance of the transport network for every service attribute within the main categories analysed with AHP the findings give clear indication of the respondents preferences. More specifically AHP revealed that the reliability factor is of great importance to the stakeholders of the transport network of the regional logistics gateway under examination whereas IPA demonstrated that it is the water mode that performs well and can support further modal shift and sustainable development. 
The main service attribute reliability from the AHP analysis as shown in figure 5-11 has been regarded by respondents as a key quality aspect. Intermodal freight transport services are not perceived as reliable especially for long distances and this is the primary reason for the stakeholders that have placed greater emphasis on this service attribute. This finding in combination with the weights given to rest of the main service quality indicators such as mobility for example necessitates the need to gain a deeper insight into how to promote and to market intermodal freight transport services within the logistics gateway under examination. The findings of the AHP analysis also indicate that greater emphasis should be placed on reliability during the design and the improvement of the transport network which should be maintained at the existing good service levels as the IPA revealed.

Another main finding has also revealed that decision makers need to take into consideration into designing the network and the services it provides the environmental factor. This is a key requirement to the achievement of sustainable development and it also validates the findings revealed from the IPA of this survey. This can be facilitated through the use of environmentally friendlier modes of transport such as rail, inland waterways and coastal maritime transport. In the light of the above the results of both the IPA and AHP exercise also suggest for the dissemination and communication of these findings both at a local and regional level in the form of a marketing plan that could help to promote the benefits of modal shift to the stakeholders involved and also to create better synergies.

The need to reduce greenhouse gas emissions across the transport logistics service industry is a global necessity. This can be achieved by firstly encouraging further modal shift, secondly by engaging with logistics businesses to make their operations and premises more efficient and thirdly by formalising the delivery of a more sustainable gateway by improving the service quality of the transport infrastructure. 


\subsection{Summary}

An industrial survey was carried out in chapter five in order to gauge the perceptions and expectations of the stakeholders in the freight industry based along the Liverpool Manchester axes regarding the service performance of its transport network. The methodology in this research study used a proposed service performance measurement methodology which combined the IPA and AHP techniques by constructing an index of universal indicators for the road, rail, air and water modes. The analysis of the findings of the combined IPA and AHP methodology revealed that there is a need for decision makers to shift their focus on to more environmentally friendly modes of transport and especially in this case study, towards the water mode (i.e. the Manchester Ship Canal) in order to enhance sustainable development in the region. Emphasis should be placed also on the reliability factor of service performance as indicated from the AHP pairwise comparison analysis of the main service quality attributes of the proposed service performance measurement methodology.

IPA and AHP are existing techniques which have been re-contextualised and applied in a new research setting in this study. The application and the combination of these two techniques in a new context demonstrates the applicability of the proposed research methodology in the academic field of intermodal freight transport and sustainable development. The applicability of the combined IPA and AHP service performance methodology in a new situation such as in a regional logistics gateway of an emerging megaregion shows that a novel approach for the service performance measurement of its transport network by conducting an industrial survey is feasible and can generate tangible research outputs. The added value also of this approach is that it allows for every mode of the transport network in the gateway to be examined separately during the IPA stage of the research and to validate the findings with AHP from a systems' point of view. The next chapter (chapter six) looks into the wider context of the emerging megaregion of North West Europe, by assessing the likely impact that existing and planned transport infrastructure projects will have in the long term future on the sustainable development of different areas of interest. 


\section{Macro-level analysis for transport systems in megaregional logistics gateways in North West Europe}

\subsection{Introduction}

Nations have long been considered the fundamental economic units of the world, but that distinction no longer holds true. Today, the natural units and engines of the global economy are megaregions, cities and suburbs in powerful conurbations, at times spanning national borders, forming vast swaths of trade, transport, innovation, and talent. The trend towards "endless cities" could significantly affect population and wealth in the next 50 years (Florida 2008). The world's mega-cities are merging to form vast megaregions which stretch hundreds of kilometers across countries and are home to more than 100 million people. Interlocking economic systems, shared natural resources and ecosystems, and common transportation systems link these population centres together. As continued population growth and low density settlement patterns place increasing pressure on these systems, there is greater impetus to coordinate policy at this expanded scale (Florida 2008). The new scale for considering economic strength and growth opportunities is the megaregion, a network of metropolitan centres and their surrounding areas that are spatially and functionally linked through environmental, economic, and infrastructure interactions. Experts warn that vast megaregions will be characterized by overcrowding, poverty and pollution. The continuing growth of urban areas is likely to be one of the most significant factors affecting society over the next 50 years, the United Nations warns. However, an explosion of megaregions will not necessarily be a bad thing despite warning of "further patterns of social and economic exclusion" (Moreno 2010). The world economy is organized around a few dozen mega-regions like the Boston-New YorkWashington corridor, or the Shanghai-Nanjing-Hangzhou triangle, or the span stretching from London through Leeds, Manchester, Liverpool, and into Birmingham which account for the bulk of the globe's economic activity and innovation.

The emergence of megaregions in many parts of the planet necessitates the development of new transport infrastructure that will enhance modal shift and will also contribute to the development of sustainable logistics gateways. Congestion in road transport networks in the primary cause of increased greenhouse gas emissions which eventually have a 
negative impact on the quality of life for local communities and also an adverse effect on the daily operations of supply chain clusters. Given the fact that that many regions are now merging into megaregions there is a need to examine how services operations management can relate to the improvement of quality for all the stakeholders involved and what processes can be adopted in order to coordinate different modes of transport and assess the level of use of existing transport infrastructure in an environmentally friendly manner. Long term planning requires the adoption of a scenario based approach in order to gain a good perspective of possible futures. Another advantage of this approach is that the parties involved in the decision making process can obtain a better understanding of the interrelationships that exist in today's fast moving business environment (Haddad et al 2012). Decision makers can also carry out an analysis on whether their strategy can be stress tested against worst case scenarios. According to the opinion of many experts in the field, the quantitative assessment of the transport infrastructure performance in a region's logistics gateway is a difficult task.

This chapter looks into the identification and creation of a catalogue of significant scenarios within different regional logistics gateways and provides a macro level analysis of North West Europe's megaregional space. The development of this methodology is based on a number of existing case studies within the megaregion of North West Europe. The identification and selection of critical transport infrastructure priority projects was achieved by coordinating a transnational focus group where participants were asked about their perceptions, opinions, beliefs, and attitudes towards a project of their choice from their different areas of interest. As shown in figure 6-1 the identification of the main research setting, the identification of multiple logistics gateways studies and the importance of sustainable development have served as inputs to the methodology process of the evaluation of the transport infrastructure in this study. Also the selection of drivers of future change for transport systems with the objective to adopt a scenarios' based approach within the context of co-modal and greener freight transport has made a significant contribution to the methodology of this chapter. The main inputs into the process have been the design of a focus survey to participants from different areas of interest from the megaregion of North West Europe and also the selection of universal criteria for the examination of the identified transport infrastructure projects. Finally as 
shown in the diagram of figure 6-1 the main output is the generation of scenarios for the sustainable development of the transport systems in North West Europe.

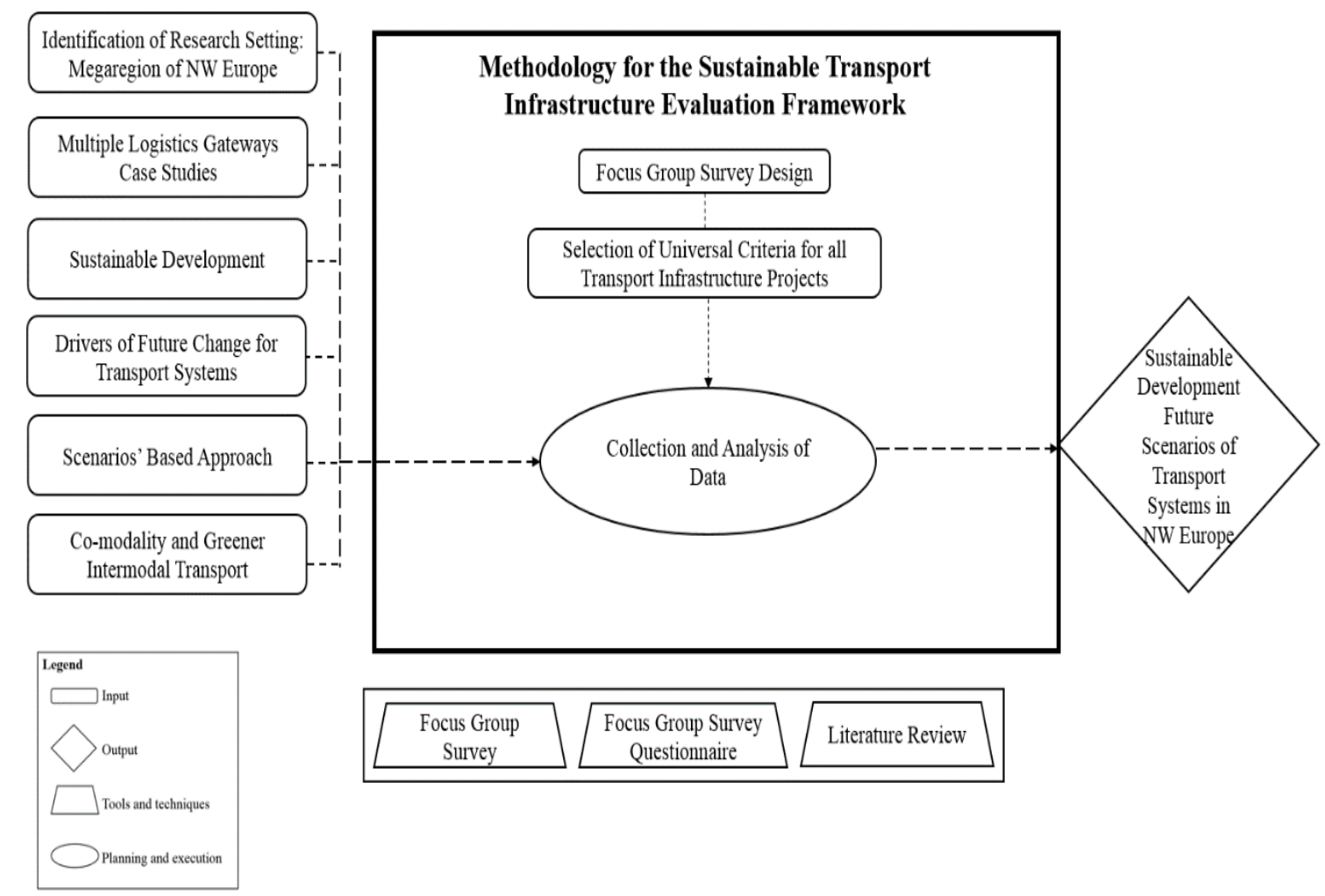

Figure 6-1: Methodology for the sustainable transport infrastructure projects evaluation framework

\subsection{Environmental considerations for the planning on new transport infrastructure in regional logistics gateways}

Quite often the issue of the "infrastructure gap" has been debated amongst experts. Enlarged megaregions require investments to be made in the development of transport infrastructure in regional logistics gateways. Different funding tools have been set up to address the challenge provided by the imbalance in development that exists between different regions. For the megaregion of North West Europe the outlook is promising though. The availability of modern transport infrastructure, although already adequate in the region, looks set to improve. However, the argument exists that the development of new transport infrastructure will negatively affect the environment in both direct and indirect ways. As a result it is critical that planning for the creation of new transport 
infrastructure, or the upgrading of that which already exists, takes into account the impacts upon the environment that these developments will generate.

\subsection{Scenarios of sustainable development in regional logistics gateways through co-modality}

For the provision of transport infrastructure to be adequate in the long term, good planning, selection of priority projects and the evaluation of selected factors needs to be performed. Some of these factors will relate to reducing levels of $\mathrm{CO}_{2}$ emissions and protecting communities within the gateways from the environmental impacts of the already substantial amounts of $\mathrm{CO}_{2}$ that are being emitted. The notion of co-modality supports initiatives associated with enhancing "greener transport" as they are both aimed at achieving optimal sustainable scenarios in freight movement within regional logistics gateways. The vision of co-modality calls for the combination of different modes of transport with a view to optimising in a more sustainable manner the different resources available (Wassalo 2008). This concept also emphasizes the need to adopt a set of wider objectives such as commercial, monetary and sustainable growth. Based on this concept infrastructure planning should accordingly be shaped at both national and international levels to provide a combined approach to future service quality provision.

The use of alternative modes of transport is very high on the agenda of the freight transport industry. Congestion is continuously rising and different stakeholders are struggling to come up with greener solutions. Modal shift needs to be realised by promoting intermodal transport at all levels of public and private governance. Intermodal freight transport is perceived as being the best solution for the integration of the regional transportation systems. Such integration can only take place in conjunction with the needs and demands of the transport and supply chains industry (Zografo and Regan 2004). Awareness of the benefits of intermodal transport and the availability of suitable infrastructure is critical for modal shift to be achieved. The national borders that exist between megaregions provide restrictions to the provision of an interoperable and seamless transportation service of superior quality and limited environmental impact. 


\subsection{Methodology development for the creation of sustainable transport scenarios}

This chapter provides a descriptive scenario based analysis of selected critical infrastructure projects in the megaregion of North West Europe. The practicality of the survey tool that was used during the survey phase of the transnational activity enabled the participants from different countries of North West Europe in a focus group to identify critical infrastructure projects in their areas of interest and to provide valuable information regarding the current status of an infrastructure project. Although investigations of this nature usually lack adequate indicators that can provide an effective assessment of the sustainability of a transport infrastructure project, in this study a list of universal indicators was constructed that would also enable the assessment of future change scenarios for the transportation systems within different regional logistics gateways.

More specifically the methodology used consists of the following five steps:

Step 1:Description of the project, time frame, current status, funding scheme, level of modal interoperability, synergies within a mega region and level of usefulness.

Step 2: SWOT analysis.

Step 3: Identification of bottlenecks, areas of pressure and levels of congestion.

Step 4: Overview of co-modality based scenarios for a specific priority project for the 2030 Horizon.

Step 5: Modelling of scenarios in the form of radar charts based on a multi criteria analysis impact model which originated from the main drivers of change for future transport systems.

It should be noted that the fifth step of the research methodology supports the sustainability scenarios' analysis by providing a comprehensive list of indicators (drivers of change) and sub-indicators in the areas of policy, demography and society, energy and environment, technology and transport chain, economics and finance and risk management. The objective of the transnational research activity is not only to identify some of the critical infrastructure projects in the participants' areas of interest but also to perform a sustainability assessment by using an integrated model which takes into consideration the performance dynamics of an infrastructure project on the various 
economic, social and environmental dimensions. The use of the indicators' based model in this chapter introduces a novel approach for the assessment of future scenarios for sustainable development.

The proposed scenarios' analysis aims to provide some insights into the evaluation of selected critical transport infrastructure projects in the participants' area of interest within the examined mega-region of North West Europe. The selection of performance indicators also supports the analysis by providing an assessment of the impact on the sustainable development of a region that an infrastructure project will have in the future. The approach also employs a universal assessment of the vigorous interrelationships between the numerous parameters on a project's sustainability performance. This allows gaining a better understanding on how sustainable development scenarios are likely to be realised. Also a better insight allows for corrective action to be taken when the likely performance of a project is expected not to be satisfactory.

A consensus was reached with participants of the focus group as to how the indicators' based methodology would best serve the transnational activity on selected priority projects both geographically and modally. A central requirement for the selection of the critical infrastructure projects under investigation has been their contribution to the sustainable development of the transportation systems. Also the transnational and international elements were taken into consideration during the selection process as regional integration into the North West Europe's mega region's transport network. How the projects were or are currently being funded has been another important selection factor since the return on the investment ratio needs to be above average not only in financial terms but also against all dimensions of sustainable development. Within this context the introduced methodology also allows the use of a GIS Geodatabase in order to explore further the selected projects' territorial cohesion and interrelationships.

For logistics services to be competitive the infrastructure on which they operate must be sufficient to allow the services provided to be of high quality (Bowersox et al 2006). In addition to the theoretical dimensions of quality the technical principles of interoperability between different modes of transport must be maintained. Whether consignments are transported by sea or road, they should be able to be loaded onto other modes of transport such as rail, inland waterways and vice versa. Some of the available 
literature has raised the issues of quality and interoperability, and has also looked into providing solutions that facilitate greener transport through modal shift. This is very important as the quality and efficiency of the whole intermodal transport chain relies on the ability of every mode to individually perform to a high standard when required. Another area of concern is the availability of accessible data. In some cases there is a complete absence of data whereas in others there is a mass of data which is all but unintelligible to anyone but an expert in the field. The availability of accessible data is very important as research findings will often contribute towards policy formulation and will therefore need to be validated through the original source data. Predicting the requirements for future transport infrastructure and measuring the level of usefulness that developments will have in the long term becomes a problem when no universal indicators are available for measurement.

\subsubsection{Focus groups survey instrument design}

For the needs of this activity the survey template was designed and produced after carrying out a desktop literature review on the available methodologies of scenario creation and the sustainable development of transport which can be found in appendix A2. It was concluded that a comprehensive but user friendly template would enable the participants of the focus group to identify regional priority projects in their regions and make an assessment against a set list of criteria. It should be noted that the template was designed to assist the respondents in gathering and organizing the available information for the schemes that they believe to be of high importance to both their areas of interest and the mega region they belong to. This universal methodology allows for the transnational application of the data collection tool across different regions and with no restrictions.

The focus group questionnaire used (see appendix A-2) consists of five parts that are designed to allow detailed information about selected regional transport infrastructure projects to be recorded by the participants of the focus group. The first part of the template was used to provide information regarding a project's nature and character, its description and geographical location (NUTS codes), the projected time frame of the development, current status, economic background of the scheme (including who is 
financing the project and its estimated budget), modes of transport which interact with the specific infrastructure, any synergies for the mega region of North West Europe, environmental impacts and likely benefits that the project will bring to its area. The second part of the template provides a strengths, weaknesses, opportunities and threats (SWOT) analysis. This is very useful as it can uncover vital facts regarding the core competencies of the scheme with respect to modal shift and greener transport solutions. Also it allows the detection of any possible weaknesses and threats that could prevent the project from achieving its objectives. The third part of the template looks into the existing bottlenecks that each project is looking to remove or reduce. This analysis complements the analytical framework as it enables the participants to provide details of the existing areas of pressure and levels of congestion that are affecting the proper functioning of the existing transport network.

Part four and five of the template complete the transport infrastructure evaluation framework by providing a scenario planning context for the year 2030. In part four, participants are asked to justify (based on the available information) the decision that they took to include their projects in the investigation process and establish their potential to improve performance. In part five a six point scoring system is used to determine the likely impact that each project is expected to have. The impact is measured against a number of sub criteria that are linked to the established six main categories of drivers of change for future transport (Day and Zou 1994) in the form of radar charts.

For the specific needs of this survey the following categories of drivers and sub-drivers were considered:

- Policy: Governance, Sustainable development, Regulation and Taxation.

- Demography \& Society: Population growth, Employment, Retirement, Urbanisation and Changing work patterns.

- Energy \& Environment: Carbon emissions, Air quality, Natural Environment, Heritage, Landscape and Noise. 
- Technology \& Transport chain: Information technologies, Congestion, Traffic Management, Capacity, Connectivity, Interoperability and Modal Shift.

- Economics \& Finance: Economic growth, Global trade, Regional Development and Transportation Costs.

- Risk Management: Reliability and Resilience.

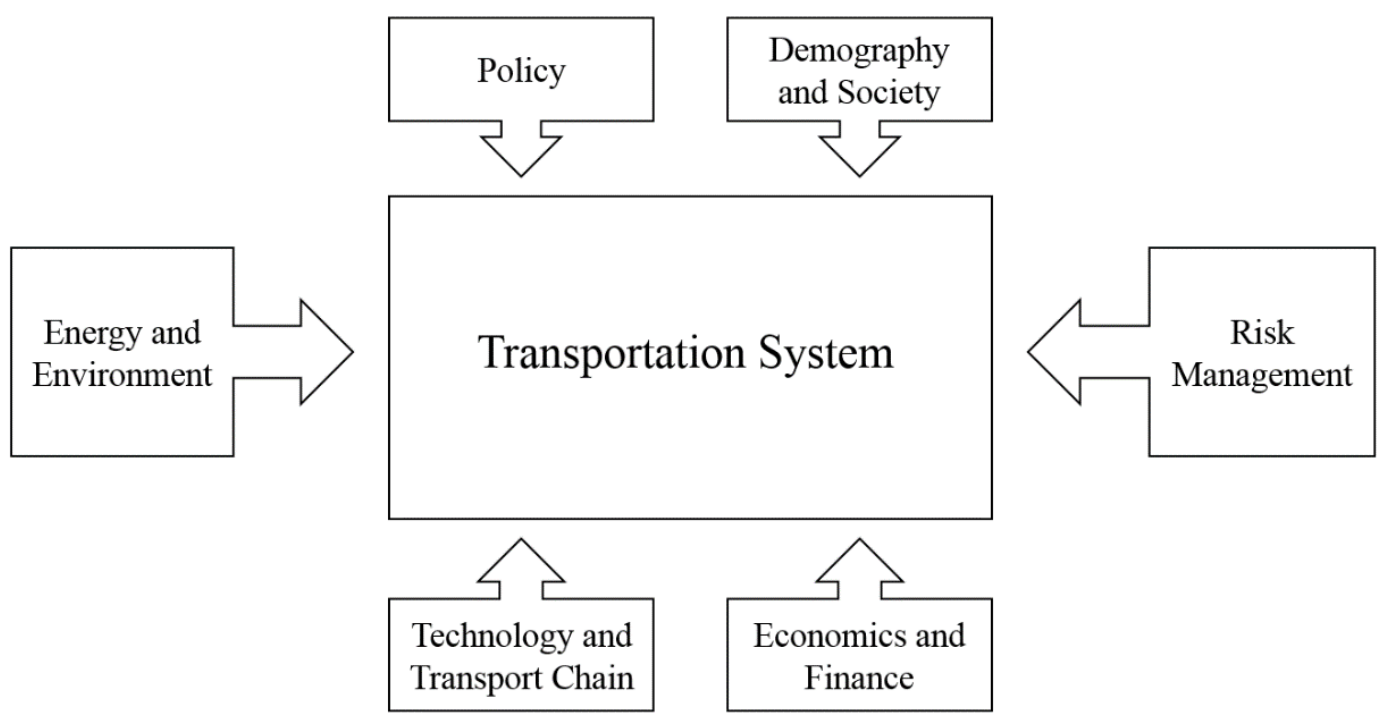

Figure 6-2: Main drivers that influence the transport system

Source: Rodrigue, J.P.(2010) Maritime Transportation: Drivers for the shipping and port industries, International Transport Forum

As shown in figure 6-2 all of these factors play a role both individually and collectively. They interconnect and it is this interrelation that enables the analysis to be performed to look at the impact of a given development and consequently determine a possible future state for the wider regional transportation system.

\subsubsection{Selection and organisation of the focus group}

A focus group was organised in order to form an important part of the research methodology process and also in order to reveal a wealth of detailed information and deep insight. In this research one focus group was selected with participants from different demographic areas of the emerging megarergion of North West Europe. This approach facilitated the identification of the different "hot spots" under examination, meaning the 
selection of existing and planned transport infrastructure priority projects. The size of the selected group was of nine participants where one was from Ireland, three for the UK, two from France, one from Belgium, one from Holland and one from Germany. The selection of the participants was not random as the participants were familiar with each other as members of a European research project in transport and logistics. The focus group met in Germany on March 2014 and the survey template was presented to them and they were encouraged to express their views and to complete one questionnaire during the session. More completed questionnaires were sent via email on May 2014.

\subsection{Identification of regional transport infrastructure projects and considerations on the development of future supply and demand scenarios in the emerging megaregion of North West Europe}

Intermodal transport is not just a concept or business practise it is also a service. Moreover, it is a very complex service that requires the different modes of transport to be operating in close conjunction with each other. The future will be very challenging as the demand for transport and logistics services is set to increase (Stock and Lambert 1987). Also, the expectations of the users of these services will be even higher. Sustainable intermodal freight transport needs to be developed further as its infrastructure is still underutilised or in the worst cases not capable of handling the expected increase in demand.

Energy costs are on the rise and increasing $\mathrm{CO}_{2}$ emissions are making the evaluation and prediction of future scenarios based on supply and demand a necessity. With this in mind this chapter provides the final research stage of this research. More specifically its main objective is to take a closer look at supply and demand based scenarios. This will include the data provided by participants of the focus group for the different development projects within the emerging mega-region of North West Europe. Although at a first glance the findings were very encouraging for the regions that may benefit from the selected schemes, it is accepted that a thorough analysis of the data provided was required in order to validate these scenarios. 
Participants of the focus group were asked to identify, according to the best of their knowledge, a limited number of transport infrastructure projects in their area of interest. This transnational activity was fruitful and it covered the large geographical area of the emerging megaregion of North West Europe. More specifically, high profile projects were identified in key regions such as Ireland, the United Kingdom, France, Belgium, Holland and Germany. The unique features of the various regions were well managed by the partners as they selected development schemes and projects to reflect the needs of their specific areas.

\subsubsection{Identification of critical transport priority projects for sustainable development in the Republic of Ireland}

Respondents of the focus group have identified the following priority transport infrastructure projects as shown in table 6-1 in the area of the Republic of Ireland. The in depth analysis of the data provided can be found in appendix B for this particular area of interest indicates that there is a high sustainable growth future scenario for the region as a result of these development projects.

Table 6-1: Selected critical priority transport projects in the Republic of Ireland

\begin{tabular}{|l|l|l|}
\hline $\begin{array}{l}\text { Identified } \\
\text { project }\end{array}$ & Overview & Future outlook scenario \\
\hline $\begin{array}{l}\text { Lynx Cargo } \\
\text { (Shannon } \\
\text { Airport) }\end{array}$ & $\begin{array}{l}\text { Optimisation of airfreight } \\
\text { transport potential at Shannon } \\
\text { International Airport. }\end{array}$ & $\begin{array}{l}\text { High growth scenariofor the region as } \\
\text { the project is designed to serve the } \\
\text { high tech industry. }\end{array}$ \\
\hline $\begin{array}{l}\text { Limerick } \\
\text { Rail Line } \\
\text { (Foynes } \\
\text { Port) }\end{array}$ & $\begin{array}{l}\text { Stimulation of Bulk Traffic } \\
\text { through the Port and reduction of } \\
\text { road miles. }\end{array}$ & $\begin{array}{l}\text { High growth scenario as the project } \\
\text { is designed to increase infrastructure } \\
\text { capacity. }\end{array}$ \\
\hline
\end{tabular}

\subsubsection{Identification of critical transport priority projects for sustainable development in the United Kingdom}

Respondents of the focus group have identified the following priority transport infrastructure projects as shown in table 6-2 in the area of the United Kingdom. The analysis of the data provided in appendix B produced sustainable development scenarios for the long term future as a result of the development projects under examination. 
Table 6-2: List of selected critical priority transport projects in the United Kingdom

\begin{tabular}{|c|c|c|}
\hline $\begin{array}{l}\text { Identified } \\
\text { project }\end{array}$ & Overview & Future outlook scenario \\
\hline Liverpool 2 & $\begin{array}{l}\text { The project will increase capacity } \\
\text { and it will increase freight flows. }\end{array}$ & $\begin{array}{l}\text { High growth scenario as the } \\
\text { project is expected to increase } \\
\text { infrastructure capacity. }\end{array}$ \\
\hline $\begin{array}{l}\text { Manchester } \\
\text { Ship Canal }\end{array}$ & $\begin{array}{l}\text { The project offers an alternative to } \\
\text { the road sector and also serves the } \\
\text { local port through inland waterways. }\end{array}$ & $\begin{array}{l}\text { High growth scenario as the } \\
\text { project is expected to increase } \\
\text { connectivity and modal shift. }\end{array}$ \\
\hline $\begin{array}{l}\text { 3MG Logistics } \\
\text { Park }\end{array}$ & $\begin{array}{l}\text { The project offers one stop } \\
\text { multimodal services and links. }\end{array}$ & $\begin{array}{l}\text { High growth scenario as the } \\
\text { project is expected to increase } \\
\text { connectivity and modal shift. }\end{array}$ \\
\hline $\begin{array}{l}\text { The Mersey } \\
\text { Gateway } \\
\text { Bridge }\end{array}$ & $\begin{array}{l}\text { The project will increase capacity } \\
\text { and it will increase freight flows. }\end{array}$ & $\begin{array}{l}\text { High growth scenario for the } \\
\text { region as the project is } \\
\text { expected to decrease } \\
\text { congestion and to improve } \\
\text { accessibility. }\end{array}$ \\
\hline $\begin{array}{l}\text { Forth } \\
\text { Replacement } \\
\text { Crossing }\end{array}$ & $\begin{array}{l}\text { The project will increase capacity } \\
\text { and will increase freight flows. }\end{array}$ & $\begin{array}{l}\text { High growth scenario for the } \\
\text { region as the project is } \\
\text { expected to decrease } \\
\text { congestion and to improve } \\
\text { accessibility. }\end{array}$ \\
\hline $\begin{array}{l}\text { Babcock } \\
\text { Container } \\
\text { Terminal } \\
\end{array}$ & $\begin{array}{l}\text { The project will increase capacity, } \\
\text { facilitate containerised freight flows } \\
\text { and improve freight distribution. }\end{array}$ & $\begin{array}{l}\text { High growth scenario as the } \\
\text { project is expected to increase } \\
\text { infrastructure capacity. }\end{array}$ \\
\hline $\begin{array}{l}\text { Aberdeen } \\
\text { Western } \\
\text { Bypass }\end{array}$ & $\begin{array}{l}\text { The project will increase freight } \\
\text { movement in North East Scotland }\end{array}$ & $\begin{array}{l}\text { High growth scenario as the } \\
\text { project is expected to increase } \\
\text { infrastructure capacity. }\end{array}$ \\
\hline $\begin{array}{l}\text { London } \\
\text { Gateway }\end{array}$ & $\begin{array}{l}\text { The project will enable shippers } \\
\text { across the UK to make substantial } \\
\text { savings by reducing delivery times, } \\
\text { haulage costs, fuel consumption and } \\
\text { carbon emissions. }\end{array}$ & $\begin{array}{l}\text { High growth scenario as the } \\
\text { project is expected to increase } \\
\text { infrastructure capacity, } \\
\text { accessibility and promote } \\
\text { modal shift. }\end{array}$ \\
\hline High Speed 1 & $\begin{array}{l}\text { The project links railfreight services } \\
\text { on the high speed line to the } \\
\text { continent. }\end{array}$ & $\begin{array}{l}\text { High growth scenario as the } \\
\text { project is expected to increase } \\
\text { infrastructure capacity, } \\
\text { accessibility and promote } \\
\text { modal shift. }\end{array}$ \\
\hline $\begin{array}{l}\text { London } \\
\text { Thames Port }\end{array}$ & $\begin{array}{l}\text { The project is one of the three UK } \\
\text { deep-water ports capable of handling } \\
\text { super post-panamax container } \\
\text { vessels. }\end{array}$ & $\begin{array}{l}\text { High growth scenario as the } \\
\text { project is expected to increase } \\
\text { infrastructure capacity, } \\
\text { accessibility and promote } \\
\text { modal shift. }\end{array}$ \\
\hline
\end{tabular}




\subsubsection{Identification of critical transport priority projects for sustainable development in France}

Respondents of the focus group have identified the following priority transport infrastructure projects as shown in table 6-3 in the area of France.

Table 6-3: List of selected critical priority transport projects in France

\begin{tabular}{|c|c|c|}
\hline Identified project & Overview & Future outlook scenario \\
\hline $\begin{array}{l}\text { Multimodal } \\
\text { Terminal in Port of } \\
\text { Le Havre }\end{array}$ & $\begin{array}{l}\text { This project will facilitate freight } \\
\text { flows, relieve congestion in port } \\
\text { areas and enhance multimodal } \\
\text { transport. }\end{array}$ & $\begin{array}{l}\text { High growth scenario as } \\
\text { the project is expected to } \\
\text { increase infrastructure } \\
\text { capacity. }\end{array}$ \\
\hline $\begin{array}{l}\text { Extension and } \\
\text { renovation of the } \\
\text { Tancarville bridge }\end{array}$ & $\begin{array}{l}\text { This project will facilitate access and } \\
\text { circulation on the bridge to allow } \\
\text { dealing with the increasing number } \\
\text { of trucks. }\end{array}$ & $\begin{array}{l}\text { High growth scenario as } \\
\text { the project is expected to } \\
\text { improve accessibility and } \\
\text { increase capacity. }\end{array}$ \\
\hline $\begin{array}{l}\text { Modernisation of } \\
\text { the Rail Network } \\
\text { from Gisors }\end{array}$ & $\begin{array}{l}\text { This project will help to relieve } \\
\text { congestion on the rail network and to } \\
\text { offer more multimodal capacity. }\end{array}$ & $\begin{array}{l}\text { High growth scenario as } \\
\text { the project is expected to } \\
\text { provide relief to the heavily } \\
\text { congested line from Paris- } \\
\text { Rouen-Le Havre. }\end{array}$ \\
\hline $\begin{array}{l}\text { East bypass in } \\
\text { Rouen Area }\end{array}$ & $\begin{array}{l}\text { This project will facilitate freight } \\
\text { flows between North West Europe } \\
\text { (UK via Euro Tunnel), Normandy } \\
\text { and the area South of Paris. }\end{array}$ & $\begin{array}{l}\text { High growth scenario as } \\
\text { the project is expected to } \\
\text { improve accessibility and } \\
\text { increase capacity. }\end{array}$ \\
\hline $\begin{array}{l}\mathrm{g} \\
\text { xtension }\end{array}$ & $\begin{array}{l}\text { The project will help to increase the } \\
\text { modal share of Inland Waterways } \\
\text { and shift traffic from roads. }\end{array}$ & $\begin{array}{l}\text { High growth scenario as } \\
\text { the project is expected to } \\
\text { provide modal shift to the } \\
\text { region. }\end{array}$ \\
\hline Eur & $\begin{array}{l}\text { The project will lead to an increased } \\
\text { level of traffic on the inland } \\
\text { waterways and the development of } \\
\text { containerised transport in the } \\
\text { Moselle region. }\end{array}$ & $\begin{array}{l}\text { High growth scenario as } \\
\text { the project is expected to } \\
\text { increase connectivity and } \\
\text { modal shift. }\end{array}$ \\
\hline \begin{tabular}{l}
\multicolumn{2}{l}{ Moselle-Saone- } \\
Rhone inland \\
water link
\end{tabular} & $\begin{array}{l}\text { This project will increase the modal } \\
\text { share of the inland waterways and } \\
\text { lead to the removal of traffic from the } \\
\text { road network. }\end{array}$ & $\begin{array}{l}\text { High growth scenario as } \\
\text { the project is expected to } \\
\text { increase connectivity and } \\
\text { modal shift. }\end{array}$ \\
\hline $\begin{array}{l}\text { New Railway Line } \\
\text { between Paris and } \\
\text { Le Havre }\end{array}$ & $\begin{array}{l}\text { This project will help to relieve } \\
\text { congestion on the rail network and to } \\
\text { offer more multimodal capacity for } \\
\text { freight. It is linked to the project of } \\
\text { modernization of the rail network } \\
\text { from Gisors to Serqueux. }\end{array}$ & $\begin{array}{l}\text { High growth scenario as } \\
\text { the project is expected to } \\
\text { increase connectivity, } \\
\text { capacity and modal shift. }\end{array}$ \\
\hline $\begin{array}{l}\text { Maritime container } \\
\text { Shuttle between Le } \\
\text { Havre and Caen }\end{array}$ & $\begin{array}{l}\text { This project will help to relieve } \\
\text { congestion on the road network } \\
\text { between Le Havre and Caen. }\end{array}$ & $\begin{array}{l}\text { High growth scenario as the } \\
\text { project is expected to } \\
\text { increaser connectivity, } \\
\text { capacity and modal shift. }\end{array}$ \\
\hline
\end{tabular}


The in depth analysis of the data provided can be found in appendix B for this particular area of interest indicates that there are high sustainable growth future scenarios for the region as a result of these development projects.

\subsubsection{Identification of critical transport priority projects for sustainable development in Holland}

Respondents of the focus group have identified the following priority transport infrastructure projects as shown in table 6-4 in the area of Holland. The in depth analysis of the data provided can be found in appendix $b$ for this particular area of interest indicates that there is a medium sustainable growth future scenario for the region as a result of these development projects.

Table 6-4: List of selected critical priority transport projects in Holland

\begin{tabular}{|c|c|c|}
\hline Identified project & Overview & \begin{tabular}{|l} 
Future outlook scenario \\
\end{tabular} \\
\hline $\begin{array}{l}\text { Measure for the } \\
\text { better utilisation of } \\
\text { the Zuid- } \\
\text { Willemsvaart }\end{array}$ & $\begin{array}{l}\text { The overall objective of the project } \\
\text { is to improve accessibility of the } \\
\text { South East Bradant region and } \\
\text { stimulate intermodal freight } \\
\text { transport over water. }\end{array}$ & $\begin{array}{l}\text { Medium growth scenario, } \\
\text { the project is expected to } \\
\text { increase connectivity, } \\
\text { capacity and modal shift. }\end{array}$ \\
\hline
\end{tabular}

\subsubsection{Identification of critical transport priority projects for sustainable development in Germany}

Respondents of the focus group have identified the following priority transport infrastructure projects as shown in table 6-5 in the area of Germany. The in depth analysis of the data provided can be found in appendix B for this particular area of interest indicates that there are medium sustainable growth future scenarios for the region as a result of these development projects.

Table 6-5: List of selected critical priority transport projects in Germany

\begin{tabular}{|l|l|l|}
\hline $\begin{array}{l}\text { Identified } \\
\text { project }\end{array}$ & Overview & $\begin{array}{l}\text { Future outlook } \\
\text { scenario }\end{array}$ \\
\hline $\begin{array}{l}\text { Logistik: } \\
\text { Wissen,wie's } \\
\text { lauft }\end{array}$ & $\begin{array}{l}\text { The project brings together members of the } \\
\text { logistics sector in the Ruhr metropolis. The } \\
\text { main aim of this project is to increase } \\
\text { capacity and facilitate freight flows. Work } \\
\text { will also be carried out to develop the } \\
\text { concept for greener logistic in the region. }\end{array}$ & $\begin{array}{l}\text { Medium growth } \\
\text { scenario, the project is } \\
\text { expected to increase } \\
\text { connectivity, capacity } \\
\text { and modal shift. }\end{array}$ \\
\hline
\end{tabular}




\subsubsection{Identification of critical transport priority projects for sustainable development in Luxembourg}

Respondents of the focus group have identified the following priority transport infrastructure projects as shown in table 6-6 in the area of Germany. The in depth analysis of the data provided can be found in appendix B for this particular area of interest indicates that there is a mixture of medium and high sustainable growth future scenarios for the region as a result of these development projects.

Table 6-6: List of selected critical priority transport projects in Luxembourg

\begin{tabular}{|l|l|l|}
\hline $\begin{array}{l}\text { Identified } \\
\text { project }\end{array}$ & Overview & Future outlook scenario \\
\hline $\begin{array}{l}\text { The Luxembourg } \\
\text { Freeport }\end{array}$ & $\begin{array}{l}\text { The project will offer additional } \\
\text { warehousing facilities in the region. }\end{array}$ & $\begin{array}{l}\text { High growth scenario as } \\
\text { the project is expected to } \\
\text { increase connectivity, } \\
\text { capacity and modal shift. }\end{array}$ \\
\hline $\begin{array}{l}\text { New } \\
\text { Bettembourg rail } \\
\text { link }\end{array}$ & $\begin{array}{l}\text { The project will help increasing the modal } \\
\text { share of rail transport, and shift traffic from } \\
\text { congested existing rail and road } \\
\text { infrastructure. }\end{array}$ & $\begin{array}{l}\text { High growth scenario as } \\
\text { the project is expected to } \\
\text { increase connectivity, } \\
\text { capacity and modal shift. }\end{array}$ \\
\hline Zeebrugge Open & $\begin{array}{l}\text { The project will enhance the maritime } \\
\text { access and connectivity between four } \\
\text { different modes in Zeebrugge port area. }\end{array}$ & $\begin{array}{l}\text { High growth scenario as } \\
\text { the project is expected to } \\
\text { increase connectivity, } \\
\text { capacity and modal shift. }\end{array}$ \\
\hline A11 Motorway & $\begin{array}{l}\text { The project will decongest the road } \\
\text { infrastructure surrounding the port of } \\
\text { Zeebrugge and enhance its accessibility. }\end{array}$ & $\begin{array}{l}\text { High growth scenario as } \\
\text { the project is expected to } \\
\text { increase connectivity, } \\
\text { increase capacity and } \\
\text { reduce congestion. }\end{array}$ \\
\hline The Iron Rhine & $\begin{array}{l}\text { This project refers to a major link between } \\
\text { the port of Antwerp and the industrialised } \\
\text { region of the Ruhr. It will help to increase } \\
\text { rail modal share and shift traffic from roads } \\
\text { within the area of North West Europe. }\end{array}$ & $\begin{array}{l}\text { Medium growth scenario as } \\
\text { the project is expected to } \\
\text { increase connectivity, } \\
\text { capacity and modal shift. }\end{array}$ \\
\hline
\end{tabular}

\subsection{Summary}

The focus group survey that was carried out identified twenty nine transport infrastructure priority projects in total from different areas of interest in the emerging megaregion of North West Europe. The list of these projects is not exhaustive as the projects identified in this study were based on experts' judgement who participated who in a transnational focus group exercise from the countries of the Republic of Ireland, the UK, Holland, 
France, Belgium and Germany. The results in appendix B provide a detailed analysis for every transport priority project under examination. It can be suggested from the findings that the majority of the transport infrastructure priority projects are expected to have a medium to high growth impact on the sustainable development of the megaregion as almost every project (existing or planned) has an objective to eliminate bottlenecks in the transport network, to enhance modal shift with a positive contribution to sustainability. In this chapter also a detailed description of the methodology that was followed for the identification of selected critical transport priority projects and their evaluation with respect to sustainable development has been provided. The analysis of the findings that were collected by using the focus group survey questionnaire (see appendix A-2) is presented in appendix B. The methodology that was followed allowed the collection of useful qualitative data regarding the project's background, location and main objectives. It also allowed for the collection and analysis of quantitative data that facilitated the creation of future long-term growth scenarios that every project is expected to have. The main objective of this chapter has been to examine the performance that a number of identified existing and planned transport infrastructure priority projects are likely to have in the future. The adopted approach was based on the production of supply and demand scenarios which were projected graphically in order to present and predict the discrepancies that the selected indicators are likely to have compared to the best case scenario of sustainable development. Another objective of this chapter has been to examine the sustainable development of transport infrastructure with a selection of multiple case studies at a megaregional level, compared to the analysis of a single gateway case study carried out in chapter five at a regional level. The added value of this research activity is also that it takes into consideration the dynamic interrelationships that exist between the different geographical areas of the megaregion. Furthermore the selected methodology involved collecting experts' judgement from different countries therefore demonstrating a novel approach to gathering and analysing a megaregion's transport infrastructure systems at a megaregional level. This approach also facilitated the assessment of sustainable development at a transnational level as in certain cases megaregions are consisted of different countries, with different transport infrastructure networks and different policies for their gateways' development. 


\section{Conclusions and recommendations}

\subsection{Introduction}

In this research study it has been discussed that regional logistics gateways, which are located in emerging megaregions, have the available transport infrastructure that could support modal shift and sustainable development. Emerging mega-regions rely heavily on global logistics operations to supply their population, the majority of which is living in metropolitan areas with a higher concentration of greenhouse gases and a heavy concentration of a multiple layer of logistics and transport operations and other urban functions. Existing policies try to achieve an optimisation of the performance of multimodal logistic chains and transport infrastructure, including making greater use of inherently more resource efficient modes, and also through better planning.

In accordance with various treaties, the fundamental purposes of common EU transport policy are to enhance sustainable development and at the same time to facilitate maximum level of economic activities, a high level of employment and social protection by raising the standard of living, economic and social cohesion and solidarity among Member States. The development of common EU transport policy must respond to broader issues of depletion of natural resources and environmental degradation at a broader level. Under this perspective the transport sector has been of particular importance. For example, the greenhouse effect connected directly with the use of energy, while emissions carbon dioxide is undoubtedly of significant importance.

Transport policies are seeking to reduce disparities between regions and empowerment of less favoured. The development of the transport infrastructure should be of immediate priority with the application programme that highlight the regions and promoting transEuropean projects, which improve the access to certain areas. Therefore, in the transport sector these objectives require implementation of policies to ensure direct communication in the single market and to create conditions of economic progress in different geographical regions of the emerging megaregion of North West Europe, through the showcasing the best possible environmental and community treaties within the framework of the existing environmental policy. 


\subsection{Key contributions of this research}

This research addressed the importance of service performance of transport infrastructure networks in regional logistics gateways for the sustainable development of an emerging megaregion. The fact that there is a need for more efficient traffic management solutions, a stronger shift away from road transportation towards more environmentally friendly modes both for freight and for passengers, but most importantly the adoption of an integrated methodological approach when assessing existing and planned transport infrastructure by the decision makers with respect to sustainable development, has also been acknowledged. A preliminary exploratory research analysis that was carried out in chapter four which identified the main research setting of the emerging megaregion of North West Europe. In this activity a single regional logistics gateway case study was also identified through the use of GIS in order to collect primary data for the analysis of the service performance of its transport infrastructure. The use of GIS in identifying a regional logistics gateway has been of added value as it enabled the graphical representation of the gateway's geographical boundaries and also the geographical position of the participants selected for the research surveys.

A novel approach has been provided by chapter five to the literature of service operations management, performance evaluation of modal shift and transport infrastructure service quality by capturing the involved stakeholders perceptions and expectations in the emerging megaregion of North West Europe at a micro level. The application and combination of the IPA and AHP model in an intermodal transport infrastructure regional case study provided a straightforward methodology for the micro level assessment of sustainable development as a result of an industrial survey. In addition added value is provided to the literature for long term scenarios' planning for sustainable transport infrastructure in chapter six. This has been achieved by developing an integrated methodology for macro level analysis based on an existing model of drivers for change for transport infrastructure systems. The survey questionnaire that was developed for this purpose was administered by organising a transnational focus group with participants from different areas of interest within the emerging megaregion of North West Europe. 
Transport activity implies that, on the basis of a pure functioning of the internal market, the development of trans-European transport networks and the possibilities for the best available technology to give citizens and businesses can access these technologies with the most appropriate way possible so as to meet the their needs and their aspirations. Access to these facilities should be done with the lowest possible cost for long-term use. At the same time services transport should be safe and to cover both users and those who take the risk. Eventually transport systems should contribute to protection of the environment and in particular to the solution of major environmental threats, such as global warming and the problem of sustainable development. The realization of all these objectives means as a general rule that all users of transport will pay their costs. In particular, the internalisation of external costs could be element of transport policy thus completing the protection of the environment. At the same time access to these facilities will be achieved at the lowest possible cost and for large time of support and development.

\subsection{Key findings}

It is evident from this research that both the concepts of the regional logistics gateway and that of the megaregion have been achieving increased awareness both in Europe and other parts of the planet. Different megaregions share many things in common but most importantly they all have logistics gateways in their different areas. In some cases and especially in Europe the trans-national element is very strong and also very challenging. Different policies, approaches and governance issues require a coordinated approach to making the most of the available and planned transport infrastructure in order to achieve sustainable development. For this to be achieved it is important to ensure that there is a consensus between stakeholders, both from the private and the public sector, that will eventually lead to a co-modal approach for freight transport with the minimum negative impact on the environment and the maximum positive impact on a region's economy.

The analysis of data provided by the surveys carried out in this research has shown that at a megaregional level the development of new infrastructure and also the improvements that have been planned for the existing ones will have a positive impact on the sustainable development of the local area of interest and at a trans-national and/or mega-regional level eventually. However there is lack of a novel performance evaluation process which 
would capture the experts' opinions and produce future sustainable growth scenarios in a systematic way. This research produced such scenarios for selected key priority infrastructure projects which demonstrate the variations of the dynamics that are needed in order to plan and develop a transport infrastructure that will achieve sustainable development. The findings of the single gateway case study also highlight to place greater emphasis on the utilisation of other modes of transport for the achievement of modal shift. For example the use of inland waterways has been found to be of greater importance to the road mode based on the IPA analysis. However, this main finding should not be taken into consideration only on its own. The employment of the AHP analysis revealed that it is also the reliability factor that should be consistent with the use of an alternative mode of transport and in correlation with the sustainable development of the regional logistics gateway under examination.

The trends indicate that under normal conditions, the demand for transport, passengers and goods, are likely to continue to grow at a rate at least as quick is the total growth rate of the economy. This suggests that in the near future probably the demand will be around one third higher than it is today. If action is not taken a large part of this demand will be concentrated on road transport, which is already saturated. Road traffic is expected to rise in the future and an increase of public investment in transport infrastructure is a necessity. The current lack of infrastructure level needs to meet the demand, especially in the road sector. A solution, at least partially, is to explore ways to raise the necessary resources for investments. The approach adopted to meet the European networks sets corresponding objectives. However, new investments in transport infrastructure should be only part of the solution. Also important should be the effort to eliminate technical restrictions on provision of services transport, which impede the adoption of longer effective solutions. In addition it is essential to consider how the underused capacity in the transport system, especially in modes other than the road, could be used. The current unused capacity of the transport network has potential for future development. This can be in favour of the railway, on inland transport and coastal waters transport. Policy measures and advanced technology can be formulated in order to increase both and attractiveness of each individual mode of transport and to promote combined use of different modes. Combined transport should include wider possibilities offered from different combinations, especially railways-sea, road-rail and rail-air. 
These transport solutions by using multiple modes of transport can give the best combination of different systems in order to meet the needs of carriers and users. In order to understand why, over the past thirty years there has been a shift to road transport, it is necessary to look at the determinants of choice among means of transport. Ultimately the increase of the use of roads in all areas plays an important role as the road mode is more manageable than other modes of transport, restricting the competition between modes, especially for small transfers. In the competitive transport market where all modes compete, many attributes are considered when choosing the right mix of transport modes.

\subsection{Summary and recommendations for further research}

It is strongly suggested and encouraged that more future research should be carried out in the transport infrastructure with respect to services operations management. In this research for the first time services operations management has been employed in order to explore the current service levels of regional logistics gateways and transport infrastructure projects. Future research should also be aiming not only to assess future sustainable development growth but also the impact that transport infrastructure has in the short term from a user's importance-performance perspective.

Moreover decision makers should be aware of the impact that the research will have at a megaregional level. This is particularly important for emerging mega-regions in Europe where the transnational element plays a significant role as important issues such as modal shift, interoperability and service quality need to be dealt with promptly. It should also be considered in the new planning process in the field of transport that a distinction should be made between those matters for which the decision makers have exclusive powers. More specifically in planning for infrastructure transport, the first priority should be the need for urgent action as suggested by IPA and AHP for example. Overall adopted approaches for improvement should act as a result of continuous sustainable development programme which will include continuous reinforcement and proper functioning of the internal market, thus facilitating the free movement of goods and persons within the community. 


\section{References}

Abalo, J., Varela J. and Manzano, V. (2007) Importance values for importanceperformance analysis: A formula for spreading values derived from preference rankings. Journal of Business Research, Vol.60, pp.115-121.

Albrecht, K. and Zemke, R. (1985) Service America. Homewood, Ill: Dow Jones- Irwin.

America 2050: Megaregions (2009), available at: www.america2050.org/megaregions.html accessed January 11, 2009).

Amit, R. and Zott, C. (2001) Value creation in e-business. Strategic Management Journal, Vol.22, pp.493-520.

Andersson, T.D. (1992) Another model of service quality: A model of causes and effects of service quality tested on a case within the restaurant industry. In: Kunst, P., Lemmink, J. (Eds.), Quality Management in Services. Van Gorcum, Assen, pp. 41-58.

Anderson, S., Allen, J., Browne, M., 2005. Urban logistics-how can it meet policy makers’ sustainability objectives? J. Transport Geogr. 13 (1), 71-81.

Amekudzi, A.A., Thomas-Mobley, L. and Ross, C.L. (2007) Transportation planning and infrastructure delivery in major cities and megacities. Transportation Research Record 1997, pp. 17-23.

Aigbedo H and Parameswaran R, (2004),"Importance-performance analysis for improving quality of campus food service", International Journal of Quality \& Reliability Management, Vol. 21 Iss 8 pp. $876-896$.

Aubry, C.A. and Zimbler, D.A. (1983) The banking industry: quality costs and improvement, Quality Progress, December, pp. 16-20. 
Babakus, E. and Boller, G.W. (1992) An empirical assessment of the SERVQUAL scale, Journal of Business Research, Vol 24, pp. 253-268.

Bärthel, F. and Woxenius, J. (2004) Developing intermodal transport for small flows over short distances. Transportation Planning and Technology, Vol 27, pp. 403-424.

Bearden, W. Teel, J. (1983) Selected determinants of consumer satisfaction and complaint reports, Journal of Marketing Research Issue 20, pp. 21-28.

Berry, Leonard L. (1980) Services marketing is different, Business, 30 (May-June), 2428.

Berube, Alan, Bruce Katz, and Robert E. Lang (2006). Redefining Urban and Suburban America: Evidence from Census 2000. Washington, DC: Brookings Institution Press.

Bitner, M.J. (1992) Servicescapes: The impact of physical surroundings on customers and employees, Journal of Marketing Vol. 56, April, pp. 57-71.

Brogowicz, A.A., Delene, L.M. and Lyth, D.M. (1990) A synthesized service quality model with managerial implications, International Journal of Service Industry Management Vol. 1, pp. 27-46.

Brown, S. (1996) Strategic Manufacturing for Competitive Advantage, Prentice-Hall, Hemel Hempstead.

Brunet, R. (1989) “Les villes europeénnes: Rapport pour la DATAR”, Montpellier, RECLUS.

Bontekoning, Y., Macharis, C. and Trip, J. (2004), "Is a new applied transportation research field emerging? A review of intermodal rail-truck freight transport literature”, Transportation Research Part A: Policy and Practice, Vol. 38, pp. 1-34. 
Bowen, D.E. and Brown, S.W. (Eds.), Advances in services marketing and management, Vol. 3. JAI Press, Greenwich, CT, pp. 1- 67.

Bowersox, D.J., Closs, D.J. and Cooper, M.B. (2006) Supply Chain Logistics Management, second ed. McGraw-Hill Publishing, New York.

Buffa, E.S. (1976) Operations Management: The Management of Productive Systems, Wiley, New York, NY.

Caliskan, N. (2006) A decision support approach for the evaluation of transport investment alternatives, European Journal of Operational Research Vol. 175, pp. 1696704.

Carbonell, A. and Yaro, R. (2005) American spatial development and the new megalopolis, Land Lines Vol. 17, No. 2, pp. 1-4.

Caris, C. Macharis, G. and Janssens, K. (2008) Planning problems in intermodal freight transport: Accomplishments and prospects. Transportation Planning and Technology, Vol. 31, pp. 277-302.

Caris, A., Macharis, C., Janssens, G.K., (2013). Decision support in intermodal transport: a new research agenda. Comput. Ind. 64 (2), 105-112.

Carman, J.M. (1990) Consumer perceptions of service quality: an assessment of the SERVQUAL dimensions, Journal of Retailing Vol. 66, pp. 33-55.

Ceccagnoli, M. (2009) Appropriability, Pre-emption, and firm performance, Strategic Management Journal Vol. 30, pp. 81-98.

Chase, R.B. (1987) Where does the customer fit in a service operation, Harvard Business Review Vol. 56 No. 4, pp. 137-42. 
Chase, R.B. (1980) A classification and evaluation of research in operations management, Journal of Operations Management Vol. 1 No. 1, pp. 9-14.

Chase, R.B. and Aquilano, N.J. (1992) Production and operations management: A Life Cycle Approach, R.D. Irwin, Homewood, IL.

Chase, R. and Stewart, D. (1994) Make your service failsafe, Sloan Management Review Vol.35, pp. 35-44.

Churchill, G. A. and Surprenant, C. (1982) An investigation into the determinants of customer Satisfaction, Journal of Marketing Research, Vol.19, pp. 491-504.

Collier, D.A. (1987) Service Management - Operating Decisions, Prentice-Hall, Englewood Cliffs, NJ.

Cravens, D. Holland, C. Lamb, W. and Moncrief, C. (1988) Marketing's Role in Product and Service Quality, Industrial Marketing Management Vol.17, pp. 285-304.

Crosby, P.B. (1984) Quality without tears: The art of hassle-free management, New York: McGraw Hill.

Crosby, L. (1991) CSM: the wave of the future, Managing Service Quality: An International Journal Vol. 1, pp. 137 - 140.

Cronin, J. (2003) Looking back to see forward in services marketing: some ideas to consider. Managing Service Quality, Vol.13, pp. 332-337.

Collier, D. A. and Meyer, S. M. (1998) A service positioning matrix. International Journal of Operations and Production Management Vol. 18, pp. 1223 - 1244.

Cowell, W. (1984) The Marketing of Services, Oxford: Butterworth- Heinemann Ltd. 
Daamen T. (2007). Sustainable Development of the European Port-City Interface. Paper ENHR Conference 2007 June 25-28, Rotterdam.

Dabholkar, P.A. (2000), Technology in service delivery: implication for self-service and service support, in Swartz, T.A. and Iacobucci, D. (Eds), Hanbook of Services Marketing and Management, Sage Publications, New York, NY, pp. 103-10.

Day, R.H. and Zou, G. (1994) Infrastructure, restricted factor substitution and economic growth. Journal of Economic Behaviour and Organization Vol.23, pp. 149-166.

Deng W, (2008),"Fuzzy importance-performance analysis for determining critical service attributes", International Journal of Service Industry Management, Vol. 19 Iss 2 pp. 252 -270 .

Dey A, LaGuardia P, Srinivasan M, (2011),"Building sustainability in logistics operations: a research agenda", Management Research Review, Vol. 34 Iss 11 pp. 1237 - 1259.

D’Este, G. (1996) An event-based approach to modelling intermodal freight systems, International Journal of Physical Distribution \& Logistics Vol.26, pp.4-15.

Edvardsson, B., (1998), Service quality improvement, Managing Service Quality: An International Journal Vol. 8 Issue 2, pp. 142 - 149.

Edward H. Ziegler, (2009),"The case for megapolitan growth management in the twentyfirst century", International Journal of Law in the Built Environment, Vol. 1 Iss 2 pp. 105 -129 .

Eskildsen, J. Kristensen, K. (2006) Enhancing importance performance analysis. International Journal of Productivity and Performance Management Vol.55, pp. 40-60

Eiglier, P. and Langeard, E. (1987) Servuction: Le marketing des services, McGraw-Hill, Paris 
Faludi, A. (2002) European spatial planning, The Lincoln Institute of Land Policy, Cambridge, MA.

Feigenbaum, A.V. (1983) Total quality control, 3rd edn. McGraw-Hill, New York.

Fitzsimmons, J.A. and Sullivan, R.S. (1982) Service Operations Management, McGraw Hill, New York, NY.

Florida, R. (2008), Megaregions: The importance of place, Harvard Business Review [Online]. Available at: https://hbr.org/2008/03/megaregions-the-importance-of-place [Accessed 31 March 2013]

Florida, R., Gulden, T. and Mellander, C. (2007) The rise of the mega region. J.L. Rotman School of Management, University of Toronto, The Martin Prosperity Institute.

Florida, R. (2008) Who's Your City? Basic Books, New York.

Fredrik Eng-Larsson Christofer Kohn, (2012),"Modal shift for greener logistics - the shipper's perspective", International Journal of Physical Distribution \& Logistics Management, Vol. 42 Iss 1 pp. 36 - 59.

Forman, E. and Selly M. (2002) Decision by Objectives. World Scientific Publishing, Singapore.

Gilmore, A. and Carson, D. (1993) Quality improvement in a service marketing context, The Journal of Services Marketing Vol 7. No3, pp. 59-68.

Ghobadian, A., Speller, S. and Jones, M. (1994) Service quality concepts and models. International Journal of Quality \& Reliability Management Vol. 11 No. 10, pp. 43-66.

Godfrey, P. C. and Hill, C. W. (1995) The problem of unobservables in strategic management research. Strategic Management Journal Vol. 16, No. 7, pp. 519 - 533. 
Gottman, J. (1961) Megalopolis: The Urbanized Northeastern Seaboard of the United States, The MIT Press, Cambridge, MA.

Górka K and Szyja P, (2015),"Cooperation of local governments and enterprises to support the provision of sustainable transport infrastructure", Management of Environmental Quality: An International Journal, Vol. 26 Iss 5 pp. 739 - 751.

Golden, B., Wasil, E. and Harker, P. (1989) The Analytic Hierarchy Process: Applications and Studies. Heidelberg, Germany: Springer-Verlag.

Grönroos, C. (1984) A service quality model and its marketing implications, European Journal of Marketing, Vol. 18 No. 4, pp. 36-45.

Grönroos, C. (1994) From marketing mix to relationship marketing: towards a paradigm shift in marketing. Management Decision, Vol.32 No.2, pp. 4 - 20.

GH, B. and Development, W. C. o. E. a. (1987). Our common future: Report of the World Commission on Environment and Development. Oxford University.

Gutierez, J. Urbano, P. (1996) Accessibility in the European Union: the impact of the trans-European network". Journal of Transport Geography, Vol.4 No.1, pp.15-25.

Haddad, S., Ren, J. Wang, J. and Wall A. (2012) A study on the implementation of relationship marketing approach in supply chain performance: an analytical literature review, Proceeding of the 17th Annual Logistics Research Network (LRN) Conference, Cranfield University, UK.

Hayes, R. H. and Wheelwright, S.C. (1979) Link manufacturing and product life cycles. Harvard Business Review, January - February, pp. 133 - 140.

Hansen, E. and Bush, R.J. (1999) Understanding customer quality requirements: Model and Application. Industrial Marketing Management, Vol. 28, 119-130. 
Hall, and Pain K., (2006). The Polycentric Metropolis: Learning from Mega-City Regions in Europe. London: Earthscan.

Heddebaut, O. (1999) The cross-Channel support strategy in Kent and the Nord- Pas-deCalais region : Between specific institutional contexts and timing differences, Paper for the Western Regional Association, Ojai, California, February, pp. 17.

Henrique L, Corrêa L, Ellram A, José S, Cooper M, (2007), "An operations management view of the services and goods offering mix", International Journal of Operations \& Production Management, Vol. 27 Iss 5 pp. $444-463$.

Heskett, J.L., Sasser, W.E. and Hart, C.W.L. (1990) Service breakthroughs: Changing the rules of the game, Free Press, New York, NY.

Heung, V.C.S., Wong, M.Y. and Hailin Qu. (2000). “Airport-restaurant service quality in Hong Kong: An Application of SERVQUAL." Cornell Hotel and Restaurant Administration Quarterly Vol 41, Issue 3, pp. 86-97.

Hidisyan, P. and Leiter, B. (2005), The Southern California Mega-Region: A Case Study of Global Gateway Regions: America's Third Century Strategy, Kern County Council of Governments, San Diego Association of Governments, Southern California Association of Governments.

Homburg, C. and Rudolph, B. (2001) Customer satisfaction in industrial markets:

Dimensional and multiple role issues', Journal of Business Research, Vol. 52, pp. 15-33. Holmlund, M. and Kock, S. (1995) Buyer Perceived Service Quality in Industrial Networks. Industrial Marketing Management Vol. 24, pp 109-121.

Hubbert, A.R. (1995) Customer co-creation of service outcomes: effects of locus of causality attributions, unpublished doctoral dissertation, Arizona State University.

Hummel, J.M., Van Rossum, W. Verkerke, G.J. Rakhorst, G. (2000) Assessing medical technologies in development: A new paradigm of medical technology assessment. 
International Journal of Technology Assessment in Health Care Vol.16 No.4, pp.12141219.

Iacobucci, D., Grayson,K.A. and Ostrom, A.L. (1994) The calculus of service quality and customer satisfaction: Theoretical and empirical differentiation and integration.

Jacobs, J. (1961) The Death and Life of Great American Cities, New York: Random House.

Jacobs, J. (1969) The Economies of Cities, New York: Random House

Jacobs, J. (1984) Cities and the Wealth of Nations, New York: Random House

Jean Poitras, (2012),"Meta-analysis of the impact of the research setting on conflict studies", International Journal of Conflict Management, Vol. 23 Iss 2 pp. 116 - 132.

Johnson, R.A. Newell, W.T. and Vergin R.C. (1972) Operations Management, Houghton Mifflin, Boston, MA.

Johnston, R. and Morris, B. (1985) Monitoring and control in service operations", International Journal of Operations \& Production Management, Vol. 5 No. 1, pp. 332-8.

Jin, M., Wang, H. and Walden, C. (2004) System performance measures for intermodal transportation with a case study and industrial application. National Center for Intermodal Transportation: A partnership between the University of Denver and Mississippi State University.

Juran, J.M. (1992) Juran on quality by design the new steps for planning quality into goods and services. The Free Press: New York. 1st ed. 
Kader, A. (1997) Cost modeling for inland waterway transport systems, A thesis submitted in partial fulfilment of the requirements of Liverpool John Moores University for the degree of Doctor of Philosophy. Liverpool: Liverpool John Moores University.

Katayama H, (1999),"Design of a global car production-logistics system for a future ASEAN-China region", International Journal of Operations \& Production Management, Vol. 19 Iss $5 / 6$ pp. $582-603$.

Kahneman, D. and Miller, D. T. (1986) Norm theory: Comparing reality to its alternatives. Psychological Review, Vol. 93, pp. 136-153.

Kauko, T. J. (2002), Modelling the locational determinants of house prices: neural network and value tree approaches, PhD thesis, Utrecht: Utrecht University, p. 252.

Kessides, I. (2004) Reforming infrastructure: privatization, regulation, and competition. Policy research report. Washington, DC: World Bank.

Kengpol, A., Meethom, W. and Tuominen, M. (2011) The development of a decision support system in multimodal transportation routing within Greater Mekong sub-region countries. International Journal of Production Economics.

Kelleher G, El-Rhalibi A and Arshad F, (2003),"Scheduling for intermodal transport", Logistics Information Management, Vol. 16 Iss 5 pp. 363 - 372.

Klibi, W., Martel, A. and Guitouni, A. (2010) The design of robust value-creating supply chain networks: A critical review. European Journal of Operational Research, pp.283293.

Kreutzberger, E. (2008) Distance and time in intermodal goods transport networks in Europe: A generic approach. Transport Research Part A, Vol.42, pp.973-993.

Koepp, S. (1987), Pul-eeze! Will Somebody Help Me?. Time (February 2), pp. 28-34. 
Korinek, J. (2011) To what extent are high-quality logistics services trade facilitating? OECD Trade Policy working paper, No. 11.

Kotler, P. (1992) Marketing's new paradigms: What's really happening out there, Planning Review, Vol. 20 Iss 5, pp. 50 - 52.

Kotler, P. and Keller, K. 2006 Marketing Management, 12th Edition, Upper Saddle River, New Jersey, Pearson Prentice Hall.

Kuo, R. J., Chi, S. C. and Kao, S. S. (2002) A decision support system for selecting convenience store location through integration of fuzzy AHP and artificial neural Network, Computers in Industry, in Press.

Kunz, J. (2010) The AHP: A presentation to the Eagle city hall location options task Force.

Lang, R.E. and Dhavale, D. (2005) Beyond megalopolis: exploring America's new megapolitan'geography. Metropolitan Institute Census Report Series, Metropolitan Institute at Virginia Tech, Vol. 5 No. 1.

Larsson F and Kohn C, (2012),"Modal shift for greener logistics - the shipper's perspective", International Journal of Physical Distribution \& Logistics Management, Vol. 42 Iss 1 pp. $36-59$.

Lawton, L. and Parasuraman, A. (1980) The Impact of the Marketing Concept on New Product Planning, Journal of Marketing, Vol. 44, pp. 19-25.

Lawson, C. and Strathman, J. (2002) Survey methods for assessing freight industry opinions. U.S. Department for Transportation.

Levitt, T. (1976) The Industrialization of Service, Harvard Business Review

Lieb, J. J., \& Lieb, R. C. (2010). Environmental sustainability in the third-party logis-tics (3PL) industry. International Journal of Physical Distribution \& Logistics Man-agement, 40(7), 524-533. 
Lovelock, C. H. (1992) Managing Services: Marketing, Operations and Human Resources, Prentice Hall, Englewood Cliffs, NJ.

Martin, W. B. (1986) Defining what quality service is for you. Cornell Hotel and Restaurant Administration Quarterly. February, pp. 32-38.

Martilla, J. A. and James, J. C. (1977) Importance-performance analysis. American Marketing Association, Vol 41, pp. 77-79.

Madu, CN, Kuei, C (1995) Strategic total quality management-corporate performance and product quality. Quorum, Westport.

Mesa-Arango, R., Ukkusuri, S.V., 2013. Benefits of in-vehicle consolidation in less than truckload freight transportation operations. Transport. Res. Part E: Logist. Transport. Rev. 60, 113-125.

McGee, T.G. and Ira M. Robinson (1995). The Mega-Urban Regions of Southeast Asia. Vancouver: UBC Press.

Moreno, E. (2010) World's largest cities are morphing into overcrowded 'mega regions' defined by poverty and pollution, UN report warns, Daily Mail [Online]. Available at: http://www.dailymail.co.uk/news/article-1260329/Worlds-largest-cities-morphingovercrowded-mega-regions-defined-poverty-pollution-UN-report-warns.html [Accessed 10 April 2014]

Moghadam M.K., Bonsall, S. Wang J. and Wall A. (2009) Application of multiple attribute decision-making (MADM) and analytical hierarchy process (AHP) methods in the selection decisions for a container yard operating system. Marine Technology Society Journal, Vol.23, Issue 3, pp.34-45.

Millet, I. and Schoner, B. (2005) Incorporating negative values into the Analytic Hierarchy Process, Computers and Operations Research, Vol 32, pp. 3163-3173. 
O'Neal, Charles R, and William C, Lafief, (1992), Marketing's lead role in total quality, Industrial Marketing Management Vol 21, pp. 133-143.

Oliver, R.L. (1993), A conceptual model of service quality and service satisfaction: compatible goals, different concepts, in Swartz, T.A., Bowen, D.E. and Brown, S.W. (Eds), Advances in Services Marketing and Management, Vol. 2, pp. 65-85.

Parasuraman, A., Zeithaml, V.A. and Berry, L.L. (1985) A Conceptual Model of Service Quality and Implications for Future Research, Journal of Marketing, Vol. 49, Fall, pp. 41-50.

Parasuraman, A., Zeithaml, V.A. and Berry, L.L. (1988), SERVQUAL: a multi - item scale for measuring consumer perceptions of the service quality, Journal of Retailing, Vol. 64, No. 1, pp. 12.

Parasuraman, A., Zeithaml, V.A. and Berry, L.L. (1991), Refinement and reassessment of the SERVQUAL scale|, Journal of Retailing, Vol. 67, pp. $420-450$.

Parasuraman, A., Zeithaml, V.A. and Berry, L.L. (1994), Reassessment of expectations as a comparison standard in measuring service quality: implications for future research, Journal of Marketing, Vol. 58, pp. 111- 124.

Patti A, (2006) "Economic clusters and the supply chain: a case study", Supply Chain Management: An International Journal, Vol. 11 Iss: 3, pp.266 - 270 Brunet, R. (1989) “Les villes europeénnes: Rapport pour la DATAR”, Montpellier, RECLUS.

Pain, K. (2011), 'New Worlds' for 'Old'? Twenty-First-Century Gateways and Corridors: Reflections on a European Spatial Perspective. International Journal of Urban and Regional Research, 35: 1154-1174.

Peter, J. Paul, G. Brown, J., (1993) Caution in the Use of Difference Scores in Consumer Research, Journal of Consumer Research, Vol. 19 (March), pp. 655-662. 
Perrels, A. (2004) The basic service quality level of transport infrastructure in peripheral areas VATT Discussion papers, Government institute of Economic Research, Helsinki.

Poon W and Lau K, (2000),"Value challenges in supply chain management", Logistics Information Management, Vol. 13 Iss 3 pp. 150 - 155.

Preston, J. (2001) Integrating transport with socio-economic activity - a research agenda for the new millennium. Journal of Transport Geography. Vol.9. pp.13-24.

Profir, I. (2011) Considerations on the development of intermodal transport network. Contanta Maritime University Annuals, Vol.16, pp.61-68.

Radmilovic, Z. Zobenica, R. Maras, V. (2011) River-sea shipping - competitiveness of various transport technologies" Journal of Transport Geography, Vol.19, No.6, pp.15091516.

Rees, J. (2005) Trans-European networks: EU Infrastructure proposals Research in Transportation Economics, Vol.15, pp.67-73.

Regional Plan Association (2007), Northeast Megaregion 2050: A Common Future, Regional Plan Association, New York, NY, available at: www.america2050.org

Rodrigue, J.P.(2010) Maritime Transportation: Drivers for the shipping and port industries, International Transport Forum.

Ross, C.L. (2009) Megaregions: Planning for global competitiveness. Island Press, Washington.

Levitt, T. (1976) The industrialisation of service, Harvard Business Review, (September - October), pp. 63-74.

Lovelock, C. (1983) Classifying Services to Gain Strategic Marketing Insights, Journal of Marketing, Vol. 47 No. 3, pp. 9-20. 
Liberatore, M. and R. Nydick (2008) The analytic hierarchy process in medical and health care decision making: A literature review. European Journal of Operational Research, Vol.189 No.1, pp. $194-207$.

Mihelis, G. Grigoroudis, E. and Siskos, Y. (2001) Customer satisfaction measurement in the private bank section. European Journal of Operation Research, Vol. 130, pp. $347-360$

Naumann, J., (2001), Implement a Customer Satisfaction Program. Newyork: Business Horizons.

Newman P, (2015),"Transport infrastructure and sustainability: a new planning and assessment framework", Smart and Sustainable Built Environment, Vol. 4 Iss 2 pp. 140 $-153$.

Saaty, T. (1977) A scaling method for priorities in hierarchical structures. Journal of mathematical psychology, Vol. 15 No.3, pp. 234 - 281.

Saaty, T. (1980) The Analytic Hierarchy Process. New York, McGraw - Hill.

Sasser, W.E. (1976) Match Supply and Demand in Service Industries, Harvard Business Review, Vol. 54 No. 6, November-December, pp. 133-40.

Sassen, S. (2007), "Megaregions: benefits beyond sharing trains and parking lots?", in Goldfeld, K. (Ed.), The Economic Geography of Megaregions, Policy Research Institute for the Region, Princeton, NJ.

Sasson A and Reve T, (2015),"Complementing clusters: a competitiveness rationale for infrastructure investments", Competitiveness Review, Vol. 25 Iss 3 pp. 242 - 257

Saunders, M., Lewis, P. and Thornhill, A. (2009) Research methods for business students, 5th ed., Harlow, Pearson Education. 
Scott, Allen J. Ed. (2001). Global City-regions: Trends, Theory, Policy. New York and Oxford: Oxford University Press.

Shostack, G., (1982), "How to Design a Service", European Journal of Marketing, Vol. 16 Issue 1 pp. $49-63$.

Schmitter P, (2010),"Governance arrangements for sustainability: a regional perspective", Corporate Governance: The international journal of business in society, Vol. 10 Iss $1 \mathrm{pp}$. $85-96$.

Stock, J.R. \& Lambert, D.M. (2001) Strategic Logistics Management. New York: McGraw- Hill

Storbacka, K. (1994) Managing Customer Relationships for Profit: The Dynamics of Relationship Quality, International Journal of Service Industry Management, Vol. 5 Issue 5 , pp. $21-38$

Spreng, R. A.; Olshavsky R. W. (1992), A desires-as-standard model of consumer satisfaction: implications for measuring satisfaction. Journal of Consumer Satisfaction, Dissatisfaction and Complaining Behavior, Vol. 5, pp. 45-54.

Smith, S. (1987) How to quantify quality. Management Today (U.K.), pp 86-88.

Slack, N. (1994) The Importance-Performance Matrix as a Determinant of Improvement Priority. International Journal of Operations \& Production Management, Vol. 14 No.4, pp. 59-75.

Slack, N. (2001) Exploring the trade-off concept, International Journal of Operations and Production Management, Vol. 21 Issue 7 pp. 949 - 964.

Solomon, B. (1985) An alternative to new product development - Business products for consumer markets, Journal of Consumer Marketing, Vol. 2 Issue 1 pp. 56 - 60. 
Susan, L. Donna, F. McCarthy T. (2005), A balanced approach to research in supply chain management, Research methodologies in Supply Chain Management, Springer Link, pp $15-29$.

Sureshchandar, G.S., Rajendran, C. and Ananth araman, R.N. (2002), The relationship between service quality and customer satisfaction - a factor approach, Journal of Services Marketing, Vol . 14 No. 4, pp. 363-379.

Tang, J. C. S. and Nam, I. (1993) Sector priority and technology choice in the Korean machinery industry. International Journal of Technology Management, Vol. 8, pp. 333341.

Taylor, S.A. (1993), "The roles of service quality, consumer satisfaction, and value in Quinn's (1992) paradigm of services", Journal of Marketing: Theory and Practice, Vol. 2 No. 1, pp. 14-25.

Taylor, F. (1998), The principles of scientific management, engineering and management Press, Atlanta, GA, Originally published: Harper \& Row, New York, NY.

Taylor, P. J. and K. Pain (2007) Polycentric Mega-city regions: Exploratory Research from Western Europe. In P. Todorovich (ed.), The Healdsburg Research Seminar on Megaregions, Lincoln Institute of Land Policy and Regional Plan Association, New York.

Teas, R.K. (1993) Expectations, performance evaluation and consumers' perception of quality, Journal of Marketing, Vol. 57, pp. 18-34.

Teitz, M.B. and Barbour, E. (2007), "Megaregions in California: challenges to planning and public policy", Conference Proceedings for The Healdsburg Research Center on Megaregions, Regional Plan Association and the Lincoln Institute of Land Policy, New York, NY. 
Teye, V. and Leclere, D. (2003) The white Caucasian and ethnic minority cruise markets: Some motivational perspectives. Journal of Vacation Marketing, Vol 9, pp. 227.

Tegart G and Jolley A, (2001),"Sustainable transport for Asia-pacific megacities", Foresight, Vol. 3 Iss 5 pp. $419-427$.

Todorovich P, (2009),"America's emerging megaregions and implications for a national growth strategy", International Journal of Public Sector Management, Vol. 22 Iss 3 pp. $221-234$.

Thill, J. and Lim, H. (2010) Intermodal containerised shipping in foreign trade and regional accessibility advantages Journal of Transport Geography, Vol.18, pp.530-547.

Trip, J. and Bontekoning, Y. (2002) Integration of small freight flows in the intermodal transport system. Journal of Transport Geography. Vol.10. pp.221-229.

Trochim, W. M. (2000). The research methods knowledge base. Retrieved November $13,2003$.

Tsamboulas, D. Vrenken, H. Lekka, A. (2006) Assessment of a transport policy potential for intermodal mode shift on a European scale. Transportation Research Part A, Vol.47, pp. 715-733.

United Nations World Commission on Environment and Development (1987) Our Common Future (The Brundtland Report). Oxford, Oxford University Press.

United Kingdom: Scottish Government (2008) Transport Infrastructure and Services: Industry views. Final Report for Transport Scotland, Ipsos MORI

Vaidya, O.S. and Kumar, S. (2006) Analytic hierarchy process: an overview of applications, European Journal of Operation Research, Vol. 169 No. 2006, pp. 1 - 29.

Van Klink and Van den Berg, 1998 H.A. Van Klink, G.C. Van den Berg Gateways and intermodalism Journal of Transport Geography, 6 (1) (1998), pp. 1-9. 
Velazquez L, Munguia N, Markus W, Zavala A, Patricia S, Bernd V, Delakowitz Biagio Giannetti, (2015),"Sustainable transportation strategies for decoupling road vehicle transport and carbon dioxide emissions", Management of Environmental Quality: An International Journal, Vol. 26 Iss 3 pp. 373 - 388.

Vickerman, R. (1996) Location, accessibility and regional development: the appraisal of trans-European networks, Transport Policy, Vol.2, No.4, pp.225-234.

Vreeker, R. Nijkamp, P. and Welle, C. T. (2002) A multicriteria decision support methodology for evaluating airport expansion plans, Transportation Research Part D, Vol. 7 No.1, pp. 27-47.

Voss, C.A. Armistead, C.G. Johnston, R. and Morris, B. (1985) Operations Management inService Industries and the Public Sector, Wiley, Chichester.

Wassalo, W, (2008) Co-modality, a new buzz-word in the logistics field?, KOMODA project, The Logistics 2008 Congress, Poland

Weisbrod, G. Vary, D. and Treyz, G. (2001) Economic Implications of Congestion NCHRP Report 463. Transportation Research Board, Washington, DC, USA.

Whiting, E. Walsh, M. (1986), What is quality and how much does it cost? Accountancy Vol. 97, pp. 146-149.

Wicks, A. and Freeman, E. (1998) Organization studies and the new pragmatism: Antipositivism, and the search for ethics. Organization Science, Vol 9. No. 2, pp. $123-40$.

Wichser, J. Nash, A. (2007) Strategies for increasing intermodal freight transport between Eastern and Western Europe. Association for European Transport.

Wilson, D. Purushothaman, R. (2003) Dreaming With BRICs: The Path to 2050, Global Economics Paper No. 99, Goldman Sachs, October 1. 
Woodruff, R. (2003) Alternative Paths to Marketing Knowledge, Qualitative Methods Doctoral Seminar, University of Tennessee

Wotruba, T.R., and Tyagi, P.K., (1991) Met Expectations and Turnover in Direct Selling. Journal of Marketing. 55, 24-35.

Yang Z., Wang J., Bonsall S. (2010) Facilitating uncertainty treatment in the risk assessment of container supply chains, Journal of Marine Engineering and Technology, Vol.A17, pp. 23-36.

Yavas U, and Shemwell D, (2001),"Modified importance-performance analysis: an application to hospitals", International Journal of Health Care Quality Assurance, Vol. 14 Iss 3 pp. $104-110$.

Zeithaml, Valarie A, (1990) Communicating With Customers About Service Quality, In Service Management Effectiveness. Eds, D, E, Bowen, R, B, Chase, and T, E, Cummings, San Francisco- Jossey-Bass, pp. 369-383.

Zeithaml, V.A., Berry, L.L. and Parasuraman, A. (1993) The nature and determinants of customer expectations of service, Journal of the Academy of Marketing Science, Vol. 21 No. 1, pp. 1-12.

Zeithaml, V.A. and Bitner, M.J. (1996) Services Marketing, McGraw-Hill, New York, NY.

Zhang, Q., Seto, K.C., 2011. Mapping urbanization dynamics at regional and global scales using multi-temporal DMSP/OLS night-time light data. Remote Sensing of Environment 115, 2320-2329.

Zografos, K.G.and Regan, A (2004) Current challenges for intermodal freight transport and logistics in Europe and the US. Journal of the Transportation Research Board, Vol. 1873, pp. 70-78. 
Appendix A

Research tools 


\section{$\underline{\text { Research statement }}$}

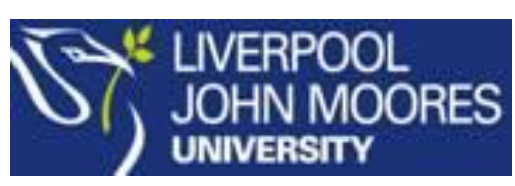

Title of Research Project: Sustainable service delivery of multimodal logistics gateway transport infrastructure in emerging mega regions of North West Europe: An operations management perspective of supply chain clusters.

\section{Name of Researcher and School/Faculty}

My name is Dimitrios Paraskevadakis, I am carrying out a research project at Liverpool Logistics, Offshore and Marine (LOOM) Research Institute. You are being selected to take part in a research study. Before you decide it is important that you understand why the research is being done and what it involves. Please take time to read the following information. Ask us if there is anything that is not clear or if you would like more information. Take time to decide if you want to take part or not.

\section{What is the purpose of the study?}

The aim of the above research topic is to investigate the service quality performance of the transport infrastructure system in the Liverpol-Manchester Gateway and also to identify critical transport priority projects that will have a significant impact (either positive or negative) in various areas of the emerging megaregion of North West Europe. This research is student led, and in order to improve the quality and relevance of the research, the researcher would greatly appreciate your views by completing the provided questionnaire.

\section{Do I have to take part?}

No. It is up to you to decide whether or not to take part. If you do you will be given this information sheet. You are still free to withdraw at any time and without giving a reason. 
A decision to withdraw will not affect your rights/any future treatment/service you receive.

\section{What will happen to me if I take part?}

The questionnaires takes a maximum of 20 minutes of your time, however it is vital to the research development. Within the next 2 months, the researcher hopes to have collected significant data. The duration of this research is 36 months, although a significant amount of time have elapsed.

\section{Are there any risks / benefits involved?}

No risks involved

\section{Will my taking part in the study be kept confidential?}

The information provided will be treated with confidentiality.

This study has received ethical approval from LJMU's Research Ethics Committee (15/ENR/006) 


\section{Contact Details of Researcher}

Dimitrios Paraskevadakis

\section{LOOM}

Tel: +44(0)1512312028

Email: d.paraskevadakis@ljmu.ac.uk

Room 121, James Parsons Building

Liverpool John Moores University, Byrom Street, Liverpool, L3 3AF, UK

\section{Contact Details of Academic Supervisor}

Dr Jun Ren

Reader in Logistics and Supply Chain Management, LJMU

School of Engineering, Technology and Maritime operations

Tel: $+44(0) 1512312236$

Email: j.ren@ljmu.ac.uk

Room 121, James Parsons Building

Liverpool John Moores University, Byrom Street, Liverpool, L3 3AF, UK 
A-1: Questionnaire for the service quality assessment of transport infrastructure systems in the Liverpool-Manchester Gateway

\begin{tabular}{|l|l|}
\hline Name of Organisation & \\
\hline Address: & \\
\hline Country: & \\
\hline & \\
\hline Type of Organisation: & \\
\hline Name of Respondent & \\
\hline Title/Position: & \\
\hline Telephone/Fax: & \\
\hline Website/Email: & \\
\hline
\end{tabular}




\section{PART A: Importance Performance Analysis (IPA)}

We would like to ask you about how your business uses different transport networks in its day to day operations of moving freight. We are thinking particularly of four transport networks:

- The trunk road network - Covering the motorways and some major 'A' roads of the Liverpool - Manchester Gateway.

- The rail network - Covering freight train routes in the Liverpool - Manchester Gateway.

- The air network - Covering freight flights to other countries from and to the Liverpool - Manchester Gateway.

- The water based transport network - Covering ports and harbours, ferry services, and inland waterways in the Liverpool - Manchester Gateway.

\begin{tabular}{|l|l|l|l|}
\hline Are you a: & & & \\
\hline $\begin{array}{l}\text { Goods Provider (i.e. } \\
\text { Manufacturing) }\end{array} \quad \square$ & $\begin{array}{l}\text { Service Provider (i.e. Distribution, } \\
\text { Warehousing) }\end{array}$ & Infrastructure Provider & Other \\
\end{tabular}

\begin{tabular}{|l|l|l|l|}
\hline Are you involved in: & & & \\
\hline Road Transport & $\square$ & Air Transport & Waterborne Transport \\
& $\square$ & $\square$ & $\square$ \\
\hline
\end{tabular}




\begin{tabular}{|c|c|c|c|c|c|c|c|c|c|c|c|}
\hline \multirow{2}{*}{$\begin{array}{l}\text { ROAD MODE } \\
\text { Indicators }\end{array}$} & \multirow[b]{2}{*}{ Sub-indicators } & \multicolumn{5}{|c|}{ Importance } & \multicolumn{5}{|c|}{ Performance } \\
\hline & & 1 & 2 & 3 & 4 & 5 & 1 & 2 & 3 & 4 & 5 \\
\hline \multirow[t]{2}{*}{ Mobility } & Accessibility to Road Network & & & & & & & & & & \\
\hline & Capacity of Road Network & & & & & & & & & & \\
\hline \multirow[t]{2}{*}{ Reliability } & Travel Time from Origin to Destination & & & & & & & & & & \\
\hline & Congestion & & & & & & & & & & \\
\hline \multirow[t]{2}{*}{ Cost Efficiency } & Operating Costs of Moving Freight & & & & & & & & & & \\
\hline & Competitiveness (How infrastructure allows me to compete) & & & & & & & & & & \\
\hline \multirow[t]{2}{*}{ Safety \& Security } & Traffic Safety & & & & & & & & & & \\
\hline & Traffic Security & & & & & & & & & & \\
\hline \multirow{2}{*}{$\begin{array}{l}\text { Infrastructure } \\
\text { Condition }\end{array}$} & Road Conditions & & & & & & & & & & \\
\hline & Intermodal Links & & & & & & & & & & \\
\hline \multirow[t]{2}{*}{ Environment } & Energy Consumption & & & & & & & & & & \\
\hline & Amount of Pollutants released & & & & & & & & & & \\
\hline & & \multicolumn{5}{|c|}{$\begin{array}{l}\text { How important is this } \\
\text { factor to you? } \\
\text { (1) Not usually important } \\
\text { (2) Only an issue if it falls } \\
\text { below a minimum standard } \\
\text { (3) It is useful but not vital } \\
\text { (4) It is very important to } \\
\text { our satisfaction } \\
\text { (5) It is crucial to our } \\
\text { satisfaction }\end{array}$} & \multicolumn{5}{|c|}{$\begin{array}{l}\text { What is the network's } \\
\text { performance at delivering } \\
\text { this factor to you? } \\
\text { (1) They fall below your } \\
\text { minimum standard } \\
\text { (2) They meet the minimum } \\
\text { standard which you could } \\
\text { tolerate } \\
\text { (3) They just meet your } \\
\text { expectations } \\
\text { (4) They meet your best } \\
\text { expectations } \\
\text { (5) They exceed your best } \\
\text { expectations }\end{array}$} \\
\hline
\end{tabular}




\begin{tabular}{|c|c|c|c|c|c|c|c|c|c|c|c|}
\hline \multirow{2}{*}{$\begin{array}{l}\text { RAIL MODE } \\
\text { Indicators }\end{array}$} & \multirow[b]{2}{*}{ Sub-indicators } & \multicolumn{5}{|c|}{ Importance } & \multicolumn{5}{|c|}{ Performance } \\
\hline & & 1 & 2 & 3 & 4 & 5 & 1 & 2 & 3 & 4 & 5 \\
\hline \multirow[t]{2}{*}{ Mobility } & Accessibility to Rail Network & & & & & & & & & & \\
\hline & Capacity of Rail Network & & & & & & & & & & \\
\hline \multirow[t]{2}{*}{ Reliability } & Travel Time from Origin to Destination & & & & & & & & & & \\
\hline & Congestion & & & & & & & & & & \\
\hline \multirow[t]{2}{*}{ Cost Efficiency } & Operating Costs of Moving Freight & & & & & & & & & & \\
\hline & Competitiveness (How infrastructure allows me to compete) & & & & & & & & & & \\
\hline \multirow[t]{2}{*}{ Safety \& Security } & Traffic Safety & & & & & & & & & & \\
\hline & Traffic Security & & & & & & & & & & \\
\hline \multirow{2}{*}{$\begin{array}{l}\text { Infrastructure } \\
\text { Condition }\end{array}$} & Road Conditions & & & & & & & & & & \\
\hline & Intermodal Links & & & & & & & & & & \\
\hline \multirow[t]{2}{*}{ Environment } & Energy Consumption & & & & & & & & & & \\
\hline & Amount of Pollutants released & & & & & & & & & & \\
\hline & & \multicolumn{5}{|c|}{$\begin{array}{l}\text { How important is this } \\
\text { factor to you? } \\
\text { (1) Not usually important } \\
\text { (2) Only an issue if it falls } \\
\text { below a minimum standard } \\
\text { (3) It is useful but not vital } \\
\text { (4) It is very important to } \\
\text { our satisfaction } \\
\text { (5) It is crucial to our } \\
\text { satisfaction }\end{array}$} & \multicolumn{5}{|c|}{$\begin{array}{l}\text { What is the network's } \\
\text { performance at delivering } \\
\text { this factor to you? } \\
\text { (1) They fall below your } \\
\text { minimum standard } \\
\text { (2) They meet the minimum } \\
\text { standard which you could } \\
\text { tolerate } \\
\text { (3) They just meet your } \\
\text { expectations } \\
\text { (4) They meet your best } \\
\text { expectations } \\
\text { (5) They exceed your best } \\
\text { expectations }\end{array}$} \\
\hline
\end{tabular}




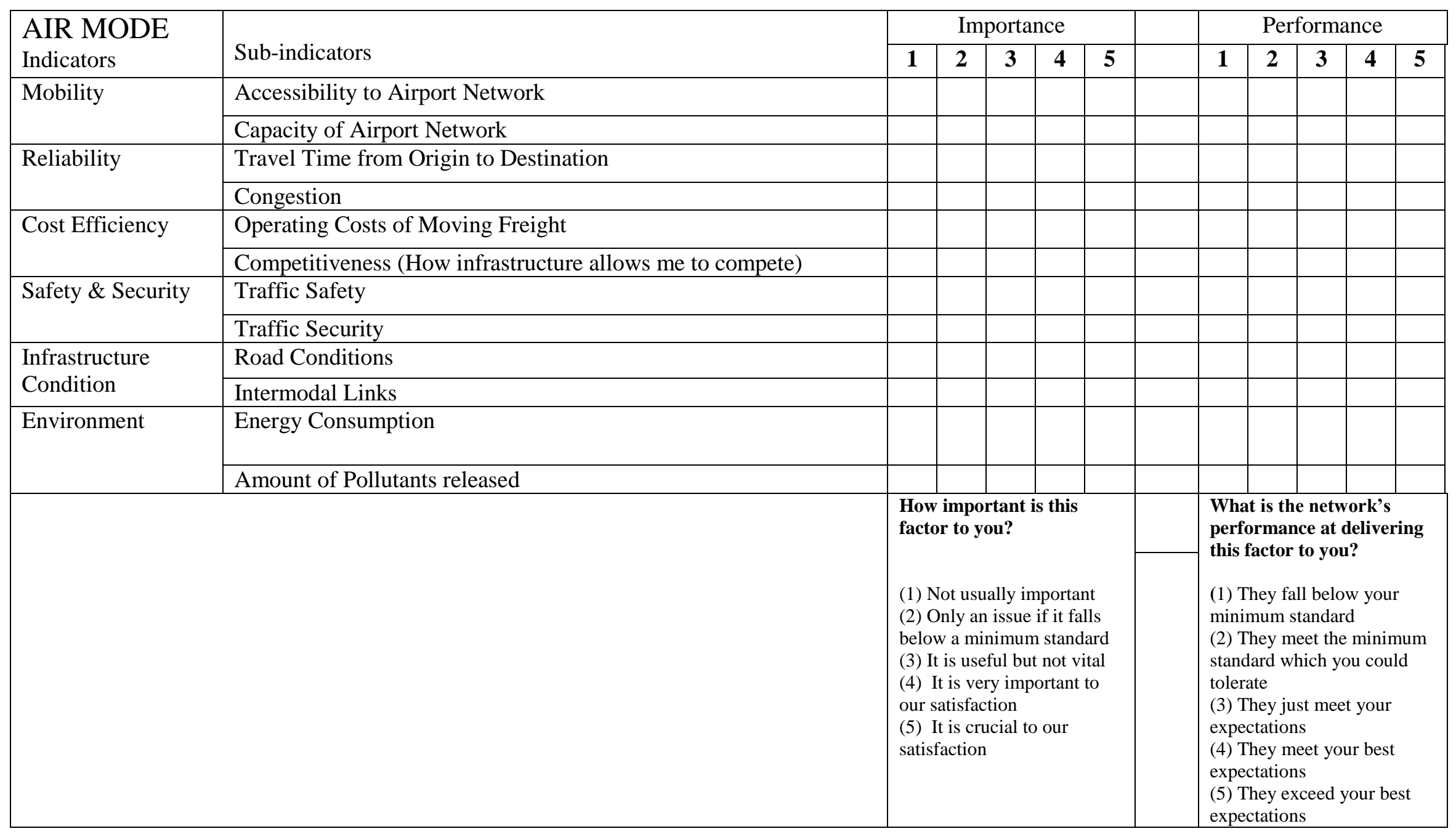




\begin{tabular}{|c|c|c|c|c|c|c|c|c|c|c|c|}
\hline \multirow{2}{*}{$\begin{array}{l}\text { WATER MODE } \\
\text { Indicators }\end{array}$} & \multirow[b]{2}{*}{ Sub-indicators } & \multicolumn{5}{|c|}{ Importance } & \multicolumn{5}{|c|}{ Performance } \\
\hline & & 1 & 2 & 3 & 4 & 5 & 1 & 2 & 3 & 4 & 5 \\
\hline \multirow[t]{2}{*}{ Mobility } & Accessibility to Waterborne Network & & & & & & & & & & \\
\hline & Capacity of Waterborne Network & & & & & & & & & & \\
\hline \multirow[t]{2}{*}{ Reliability } & Travel Time from Origin to Destination & & & & & & & & & & \\
\hline & Congestion & & & & & & & & & & \\
\hline \multirow[t]{2}{*}{ Cost Efficiency } & Operating Costs of Moving Freight & & & & & & & & & & \\
\hline & Competitiveness (How infrastructure allows me to compete) & & & & & & & & & & \\
\hline \multirow[t]{2}{*}{ Safety \& Security } & Traffic Safety & & & & & & & & & & \\
\hline & Traffic Security & & & & & & & & & & \\
\hline \multirow{2}{*}{$\begin{array}{l}\text { Infrastructure } \\
\text { Condition }\end{array}$} & Road Conditions & & & & & & & & & & \\
\hline & Intermodal Links & & & & & & & & & & \\
\hline \multirow[t]{2}{*}{ Environment } & Energy Consumption & & & & & & & & & & \\
\hline & Amount of Pollutants released & & & & & & & & & & \\
\hline & & \multicolumn{5}{|c|}{$\begin{array}{l}\text { How important is this } \\
\text { factor to you? } \\
\text { (1) Not usually important } \\
\text { (2) Only an issue if it falls } \\
\text { below a minimum standard } \\
\text { (3) It is useful but not vital } \\
\text { (4) It is very important to } \\
\text { our satisfaction } \\
\text { (5) It is crucial to our } \\
\text { satisfaction }\end{array}$} & \multicolumn{5}{|c|}{$\begin{array}{l}\text { What is the network's } \\
\text { performance at delivering } \\
\text { this factor to you? } \\
\text { (1) They fall below your } \\
\text { minimum standard } \\
\text { (2) They meet the minimum } \\
\text { standard which you could } \\
\text { tolerate } \\
\text { (3) They just meet your } \\
\text { expectations } \\
\text { (4) They meet your best } \\
\text { expectations } \\
\text { (5) They exceed your best } \\
\text { expectations }\end{array}$} \\
\hline
\end{tabular}




\section{PART B: Analytical Hierarchical Process (AHP)}

\begin{tabular}{|c|c|c|c|c|c|c|c|c|c|c|c|c|c|c|c|c|c|c|}
\hline Mode Indicators & 9 & 8 & 7 & 6 & 5 & 4 & 3 & 2 & 1 & 2 & 3 & 4 & 5 & 6 & 7 & \begin{tabular}{|l|l|}
8 & 9 \\
\end{tabular} & Mode Indicators & Important measures \\
\hline Mobility & & & & & & & & & & & & & & & & & Reliability & \\
\hline Mobility & & & & & & & & & & & & & & & & & Cost efficiency & \\
\hline Mobility & & & & & & & & & & & & & & & & & Safety and Security & \\
\hline Mobility & & & & & & & & & & & & & & & & & Infrastructure Condition & $1=$ Equal \\
\hline Mobility & & & & & & & & & & & & & & & & & Environment & $2=$ Intermediate \\
\hline Reliability & & & & & & & & & & & & & & & & & Cost efficiency & $3=$ Weak \\
\hline Reliability & & & & & & & & & & & & & & & & & Safety and Security & $4=$ Intermediate \\
\hline Reliability & & & & & & & & & & & & & & & & & Infrastructure Condition & $5=$ Fairly Strong \\
\hline Reliability & & & & & & & & & & & & & & & & & Environment & $6=$ Intermediate \\
\hline Cost efficiency & & & & & & & & & & & & & & & & & Safety and Security & $7=$ Very Strong \\
\hline Cost efficiency & & & & & & & & & & & & & & & & & Infrastructure Condition & $8=$ Intermediate \\
\hline Cost efficiency & & & & & & & & & & & & & & & & & Environment & $9=$ Absolute \\
\hline Safety and Security & & & & & & & & & & & & & & & & & Infrastructure Condition & \\
\hline Safety and Security & & & & & & & & & & & & & & & & & Environment & \\
\hline Infrastructure Condition & & & & & & & & & & & & & & & & & Environment & \\
\hline \multicolumn{19}{|l|}{ Example: } \\
\hline
\end{tabular}




\begin{tabular}{|c|c|c|c|c|c|c|c|c|c|c|c|c|c|c|c|c|c|c|c|}
\hline Category & \begin{tabular}{|l|} 
Mode Sub- \\
Indicators \\
\end{tabular} & 9 & 8 & 7 & 6 & 5 & 4 & 3 & 2 & 1 & 2 & 3 & 4 & 5 & 6 & 7 & 8 & 9 & Mode Sub-Indicators \\
\hline Mobility & $\begin{array}{l}\text { Accessibility to } \\
\text { Transport Network }\end{array}$ & & & & & & & & & & & & & & & & & & $\begin{array}{l}\text { Capacity of Transport } \\
\text { Network }\end{array}$ \\
\hline Reliability & $\begin{array}{l}\text { Travel Time from } \\
\text { Origin to Destination }\end{array}$ & & & & & & & & & & & & & & & & & & Congestion \\
\hline Cost Efficiency & $\begin{array}{l}\text { Operating Costs of } \\
\text { Moving Freight }\end{array}$ & & & & & & & & & & & & & & & & & & $\begin{array}{l}\text { Competitiveness (How } \\
\text { infrastructure allows me to } \\
\text { compete) }\end{array}$ \\
\hline Safety and Security & Traffic Safety & & & & & & & & & & & & & & & & & & Traffic Security \\
\hline $\begin{array}{l}\text { Infrastructure } \\
\text { Condition }\end{array}$ & $\begin{array}{l}\text { Infrastructure } \\
\text { Condition }\end{array}$ & & & & & & & & & & & & & & & & & & Intermodal Links \\
\hline Environment & Energy Consumption & & & & & & & & & & & & & & & & & & Amount of Pollutants released \\
\hline & \multicolumn{19}{|c|}{$\begin{array}{l}\text { Example: } \\
\text { If Accessibility is more important than Capacity and this is absolutely the case then please tick } 9 \text { on the right hand } \\
\text { side. } \\
\text { If Capacity is less important than Accessibility and this is very strongly the case then please tick } 7 \text { on the left hand } \\
\text { side. }\end{array}$} \\
\hline
\end{tabular}




\section{LIVERPOOL JOHN MOORES UNIVERSITY CONSENT FORM}

"Sustainable service delivery of multimodal logistics gateway transport infrastructure in emerging mega regions of North West Europe".

Dimitrios Paraskevadakis/School of Engineering and Maritime Operations

1. I confirm that I have read and understand the information provided for the above study. I have had the opportunity to consider the information, ask questions and have had these answered satisfactorily

2. I understand that my participation is voluntary and that I am free to withdraw at any time, without giving a reason and that this will not affect my legal rights.

3. I understand that any personal information collected during the study will be anonymised and remain confidential

4. I agree to take part in the above study (if appropriate please specify the type of study or particular intervention you are seeking consent for - eg focus group, interview, training programme)

For studies involving the use of audio / video recording of interviews, focus groups etc or where there is a possibility that verbatim quotes from participants may be used in future publications or presentations please include the following:

5. I understand that the interview/focus group will be audio / video recorded and I am happy to proceed

6. I understand that parts of our conversation may be used verbatim in future publications or presentations but that such quotes will be anonymised. 
(if different from researcher)

Note: When completed 1 copy for participant and 1 copy for researcher 
A-2: Questionnaire for identification and sustainability assessment of critical transport infrastructure projects in the emerging mega-region of North West Europe

Please provide us with the description of projects related to transport and freight logistics from your region which are expected to contribute to the creation of future significant sustainable development scenarios both regionally and at a European - Global level.

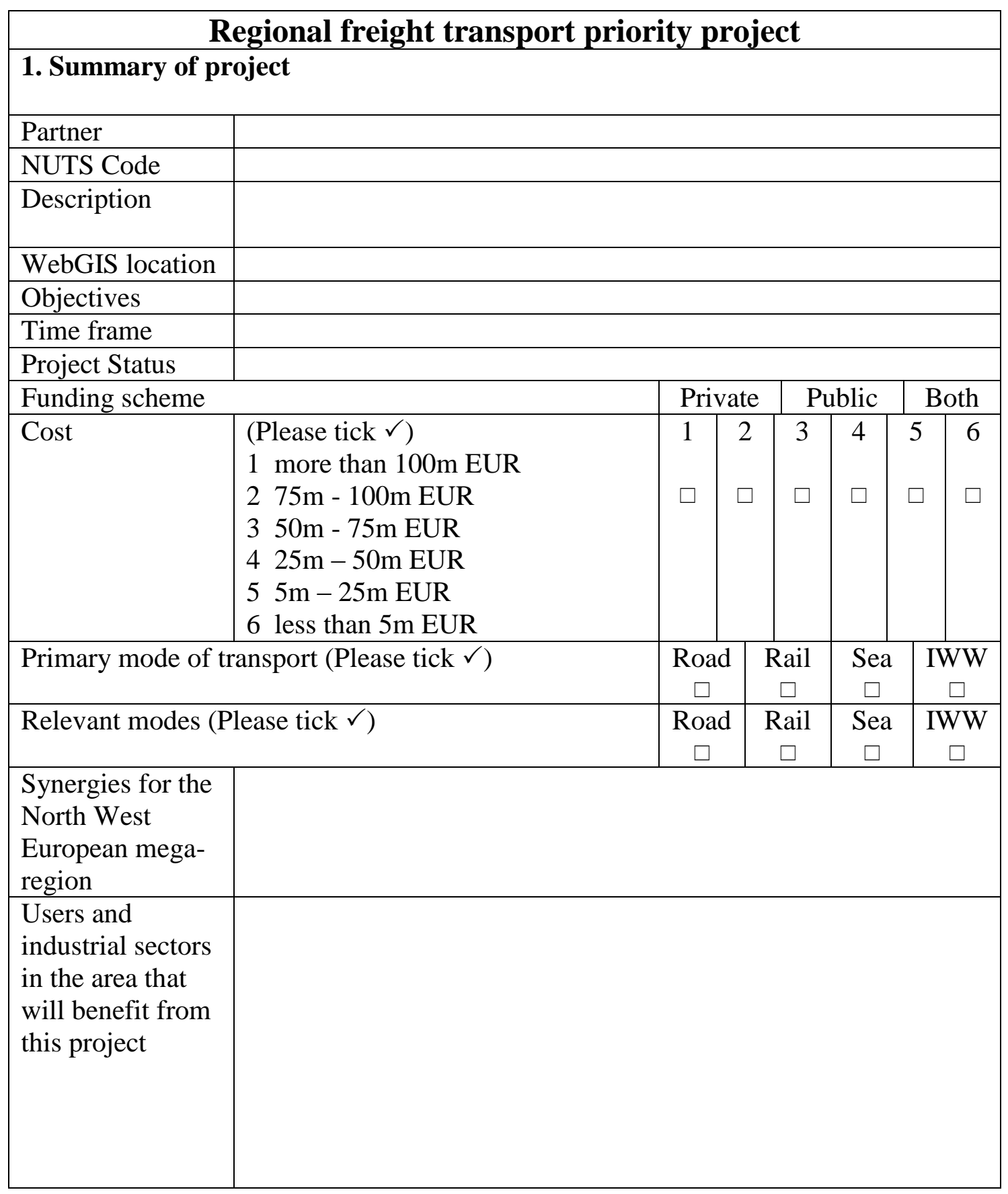




\begin{tabular}{|l|l|}
\hline $\begin{array}{l}\text { 2. SWOT Analysis (with an emphasis to tackling congestion and promoting } \\
\text { modal shift) }\end{array}$ \\
\hline Strengths & \\
\hline Weaknesses & \\
\hline Opportunities & \\
\hline Threats & \\
\hline
\end{tabular}

3. Key bottlenecks and areas of pressure that this project aims to eliminate or to reduce in the region

$$
1 .
$$

2.

3.

4.

4. Overview or co-modality scenarios for the specific priority project to 2030

\begin{tabular}{|c|c|c|c|c|}
\hline \multicolumn{2}{|c|}{ Growth scenario (Please tick $\checkmark$ ) } & Low & Medium & High \\
\hline \multirow{4}{*}{$\begin{array}{l}\text { Give reasons } \\
\text { why. }\end{array}$} & \multicolumn{4}{|l|}{1.} \\
\hline & \multicolumn{4}{|l|}{2.} \\
\hline & \multicolumn{4}{|l|}{3.} \\
\hline & \multicolumn{4}{|l|}{4.} \\
\hline
\end{tabular}

5. Transportation system's likely scenarios for 2030 based on key drivers and the mega-region's sustainability goals for future change.

\begin{tabular}{|c|c|c|c|c|c|c|}
\hline \multirow{6}{*}{$\begin{array}{l}* \text { Key drivers (Please tick } \checkmark \text { ) } \\
* * \text { Secondary drivers (Please tick } \checkmark \text { ) }\end{array}$} & \multirow{2}{*}{\multicolumn{6}{|c|}{$\begin{array}{l}1 \text { It is expected to have a negative impact } \\
2 \text { In some way is expected to have a } \\
\text { negative impact }\end{array}$}} \\
\hline & & & & & & \\
\hline & \multicolumn{6}{|c|}{$\begin{array}{l}3 \text { In some way is expected to have no } \\
\text { impact at all }\end{array}$} \\
\hline & \multicolumn{6}{|c|}{4 It is expected to have no impact at all } \\
\hline & \multicolumn{6}{|c|}{$\begin{array}{l}5 \text { In some way is expected to have a } \\
\text { positive impact }\end{array}$} \\
\hline & \multicolumn{6}{|c|}{6 It is expected to have a positive impact } \\
\hline Policy* & & 1 & \begin{tabular}{l|l}
2 & 3
\end{tabular} & 4 & 5 & 6 \\
\hline Governance** & & 1 & \begin{tabular}{|l|l|}
2 & 3
\end{tabular} & 4 & 5 & 6 \\
\hline Sustainable development** & & 1 & \begin{tabular}{l|l}
2 & 3
\end{tabular} & 4 & 5 & 6 \\
\hline Regulation/Taxation** & & 1 & 3 & 4 & 5 & 6 \\
\hline Demography \& Society* & & 1 & \begin{tabular}{|l|l|}
2 & 3
\end{tabular} & 4 & 5 & 6 \\
\hline Population growth** & & 1 & \begin{tabular}{|l|l|}
2 & 3
\end{tabular} & 4 & 5 & 6 \\
\hline Employment and retirement** & & 1 & \begin{tabular}{|l|l}
2 & 3
\end{tabular} & 4 & 5 & 6 \\
\hline
\end{tabular}




\begin{tabular}{|c|c|c|c|c|c|c|}
\hline Urbanisation** & 1 & 2 & 3 & 4 & 5 & 6 \\
\hline Changing work patterns** & 1 & 2 & 3 & 4 & 5 & 6 \\
\hline Energy \& Environment* & 1 & 2 & 3 & 4 & 5 & 6 \\
\hline Carbon emissions** & 1 & 2 & 3 & 4 & 5 & 6 \\
\hline Air quality** & 1 & 2 & 3 & 4 & 5 & 6 \\
\hline Natural environment, heritage and landscape ${ }^{* *}$ & 1 & 2 & 3 & 4 & 5 & 6 \\
\hline Noise** & 1 & 2 & 3 & 4 & 5 & 6 \\
\hline Technology and transport chain management* & 1 & 2 & 3 & 4 & 5 & 6 \\
\hline Information technologies** & 1 & 2 & 3 & 4 & 5 & 6 \\
\hline Congestion and traffic management** & 1 & 2 & 3 & 4 & 5 & 6 \\
\hline Capacity** & 1 & 2 & 3 & 4 & 5 & 6 \\
\hline Connectivity \& interoperability** & 1 & 2 & 3 & 4 & 5 & 6 \\
\hline Modal shift** & 1 & 2 & 3 & 4 & 5 & 6 \\
\hline Economics \& Finance* & 1 & 2 & 3 & 4 & 5 & 6 \\
\hline Economic growth** & 1 & 2 & 3 & 4 & 5 & 6 \\
\hline Global trade** & 1 & 2 & 3 & 4 & 5 & 6 \\
\hline Regional development** & 1 & 2 & 3 & 4 & 5 & 6 \\
\hline Transportation costs** & 1 & 2 & 3 & 4 & 5 & 6 \\
\hline Risk management* & 1 & 2 & 3 & 4 & 5 & 6 \\
\hline Reliability** & 1 & 2 & 3 & 4 & 5 & 6 \\
\hline Resilience** & 1 & 2 & 3 & 4 & 5 & 6 \\
\hline Security** & 1 & 2 & 3 & 4 & 5 & 6 \\
\hline \multicolumn{7}{|c|}{$\begin{array}{l}\text { 6. Please provide web links for any additional info related to this specific } \\
\text { regional priority project }\end{array}$} \\
\hline & & & & & & \\
\hline & & & & & & \\
\hline & & & & & & \\
\hline & & & & & & \\
\hline & & & & & & \\
\hline
\end{tabular}




\section{Appendix B}

Analysis of transport priority projects in North West Europe 


\section{B-1: Regional priority projects in Ireland}

Participants in the focus group have identified the following critical transport infrastructure projects in Ireland:

- The Air Cargo project in Shannon Airport

- The Foynes Port rail link restoration project 


\section{The Air Cargo project in Shannon Airport}

The air cargo project is a perceived to be a high priority project for Shannon airport as the stakeholders involved recognise the important role that it will play in the long term as a major international logistics hub.

\section{Location and overview of the project}

The main objective of the project is to optimise the airfreight transport potential at Shannon International Airport that started in 2014. It is an ongoing project located in the Irish mid-west region. Also it is funded both from the private and the public sector and it is expected to complete in 2016. The cost of the project is in the region of $€ 25 \mathrm{~m}$ to $€ 50 \mathrm{~m}$ and it is perceived to be of great significance for the emerging mega-region of North West Europe as it will substantially make a contribution when it will be finalised to the development of a West-East Axis. This can be justified by the fact that major industrial economic drivers for the Irish mid-West region are the pharma, bio pharma, medical advices, IT software and other products, high end food and drink industries. Also air freight from point close to manufacture is more sustainable and product friendly than a trucking and air combination.

\section{SWOT analysis with emphasis to congestion and modal shift}

The SWOT analysis by participants in the focus group revealed that the main strengths of the project are that its objectives are consistent with passenger traffic development and that the available belly hold capacity is utilised. Weaknesses of the project are considered to be the lack of long haul services. These are only seasonal at present in Shannon Airport and short haul carriers do not take cargo in the hold. However the co-operation between Shannon Airport Authority (SAA) and the Lynxs group is seen to be a good opportunity. When finalised, the cargo hub at the airport will increase its existing freight capacity and will make a significant contribution to regional economic growth. Also the reintroduction by Aer Lingus of year round long-haul services gives credibility to the project. Major threats will occur if the project will be stopped because of unforeseen reasons as a lack of appropriate services could restrict the development of high end manufacturing in the Shannon gateway area. 


\section{Bottlenecks that the projects aims to reduce in the region}

The key bottlenecks and areas of pressure that the project aims to eliminate or to reduce in the Irish mid-western region are identified mainly in the road links to Dublin and Rosslare Ports because of heavy freight tariff. Also the project is expected to reduce overall road miles without adding to air miles and the project is critical to the development of Shannon International airport and the credibility of the Limerick-Shannon region.

\section{Overview of co-modality growth and scenarios by 2030}

There is a high growth scenario as according to participants in the focus group the project is expected to make a substantial contribution to the development of the co-modal freight transportation system by the year 2030. The primary mode of transport of this project is the air mode and there are currently good links with the road network but in the long term possible new links are projected to be established with also other modes of transport such as rail and waterborne transport.

\section{Sustainable development scenarios by 2030}

The following radar chart models the scores given during the evaluation process. Moreover, it gives an overview of the significant impact scenarios that the project is likely to have on the transport system that it is a part of by the year 2030 . 


\section{The air cargo project in Shannon airport}

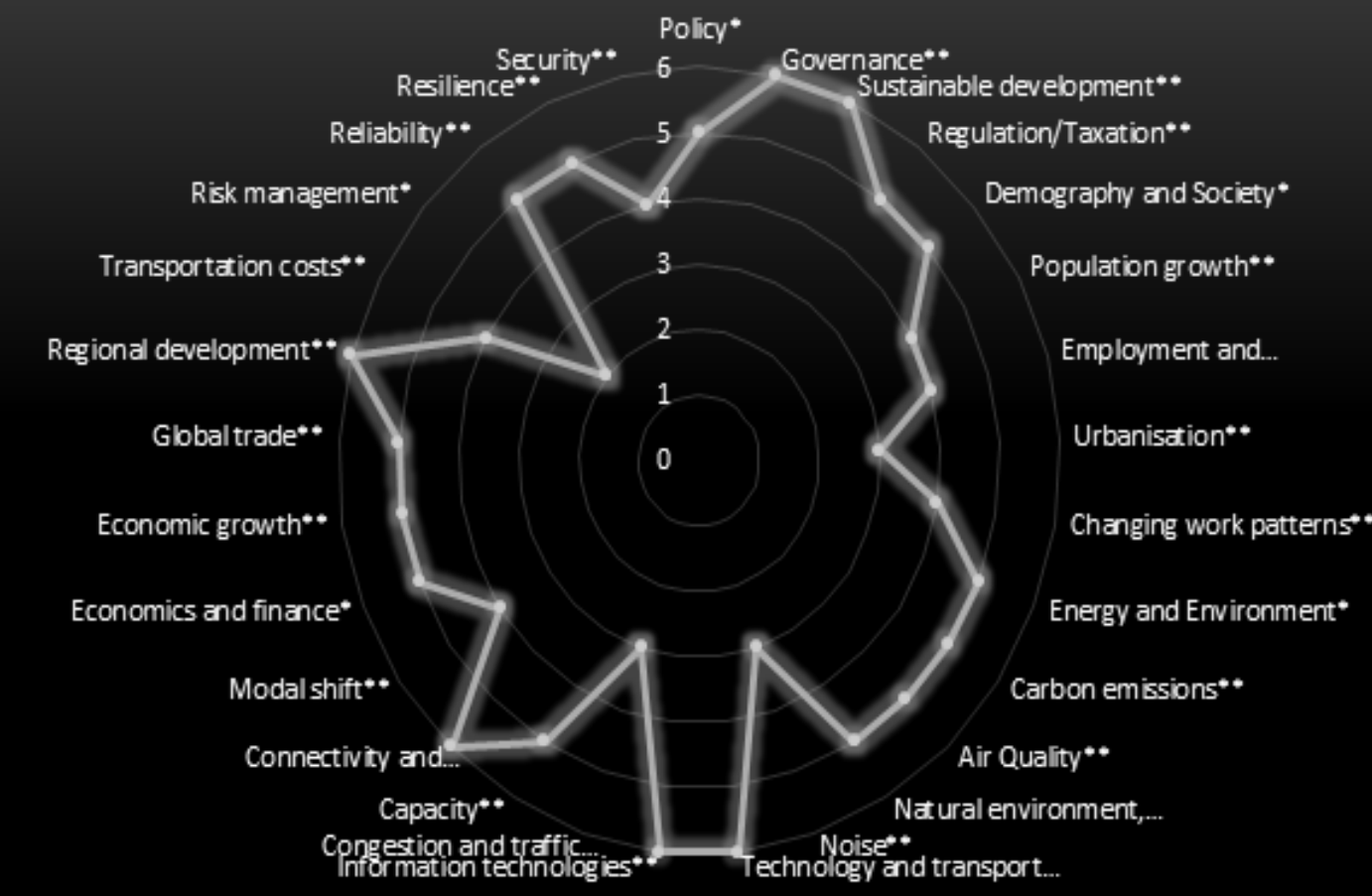

Figure B-1: Radar chart representation future growth scenario of sustainable development for the air cargo project in Shannon Airport 


\section{The Foynes Port rail link project}

The restoration or rail link for carriage of freight from Foynes Port is expected to stimulate bulk traffic through the port and reduce road miles.

\section{Location and overview of the project}

From the information provided by participants in the focus group the restoration project could last a couple of years with a time frame to 2016 if given the green light. The funding scheme is both private and public is in the region of $€ 5 \mathrm{~m}$ to $€ 25 \mathrm{~m}$. The port is located in the Irish mid-western region and synergies exist for with other parts of the megaregion as intermodal links will be developed. The combination of movement of product arriving in the only port in the Irish Republic with capability to handle Suez-max vessels to locations both with the Limerick-Shannon gateway region and nationally rather than using smaller vessels to other ports and/or use road is more sustainable. A Zinc Ore mine is to be developed within the region by 2017 that will involve shipment of up to 3000 tonnes of ore daily to the Port. A biomass fuelled power plant planned for May will require up to 4 trains daily. Also plans for oil product distribution from the Port to western coastal areas will be developed.

\section{SWOT analysis with emphasis to congestion and modal shift}

The main strength of the Foynes Port rail link restoration project is that the restoration will be of low cost and of relative technical simplicity. However, the current shortage of funding in absence of contract signing is a major weakness of the project's proposal. The opportunity of effectively linking this port with the national rail infrastructure facilitates the shifting of sea traffic from other ports in more congested areas. Unfortunately, until to this point the project proposal is threatened not to go ahead as currently financing is inadequate to complete and operate the line. 


\section{Bottlenecks that the project aims to reduce in the region}

The project's proposal for the restoration of the rail link between the Foynes port and Limerick will tackle the actual and potential congestion on the N69 route and also on routes through Limerick city. The addition of traffic in the new rail route will also ensure the viability of the rail network as congestion will be relieved on key routes.

\section{Overview of co-modality growth and scenarios by 2030}

If ever completed, the project will make a significant contribution to the development of co-modality by the year 2030 in the region since major traffic growth is expected for bulk cargo. Moreover the projected increase in agricultural output by $50 \%$ by 2020 will increase imports of fertilizers, seed, etc. Added to this the move from peat fired power generation to biomass powered will require major import volumes and therefore an intermodal distribution centre will be needed along the line.

Sustainable development scenarios by 2030 
The following radar chart models the scores given during the evaluation process for the Foynes port rail link project. Moreover, it gives an overview of the significant impact scenarios that the project is likely to have to the transport system that it is a part of by the year 2030 .

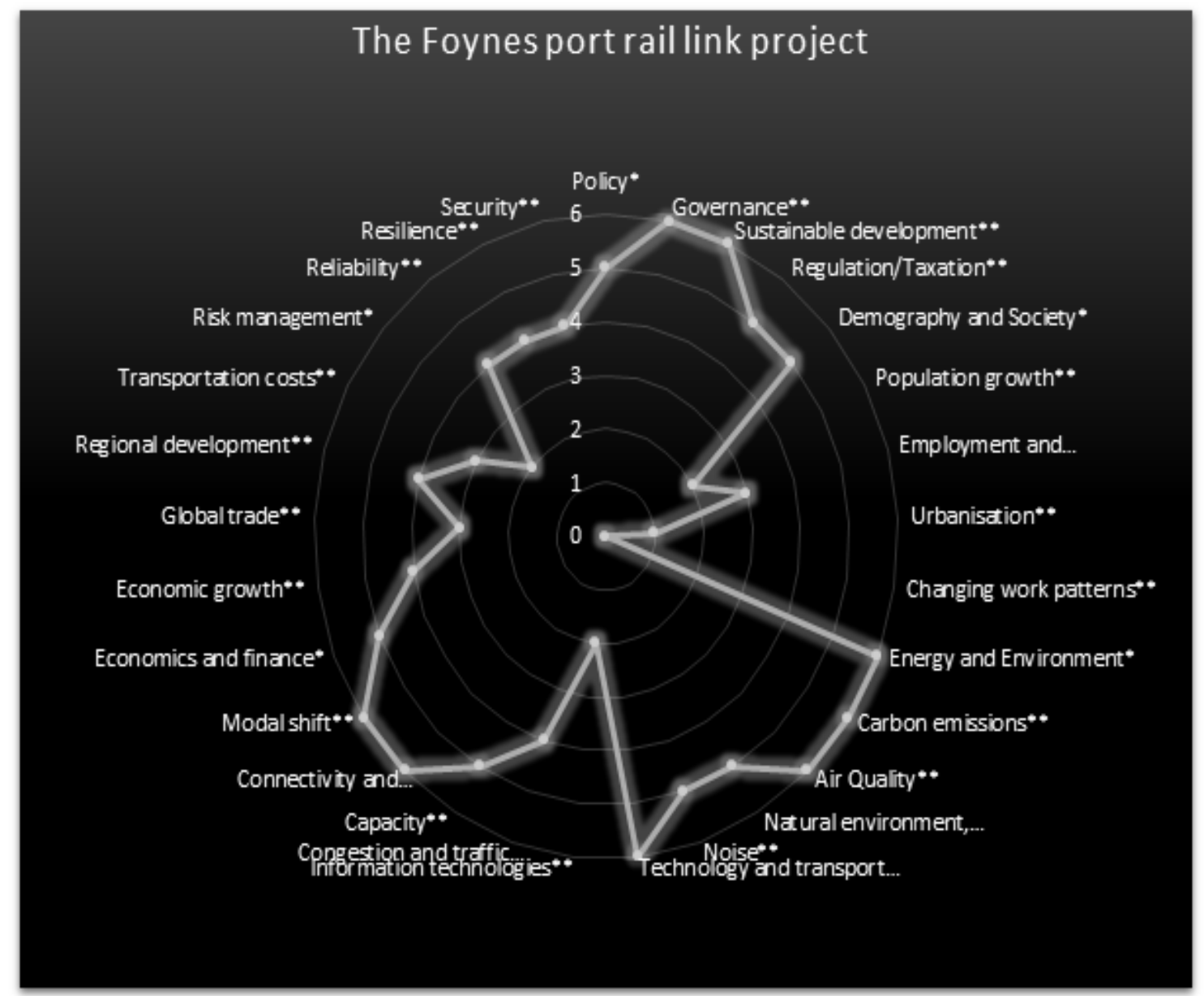

Figure B-2: Radar chart representation of future growth scenario of sustainable development for the Foynes port rail link project 


\section{B-2: Regional priority projects in the United Kingdom}

Participants in the focus group have identified the following critical transport infrastructure in the United Kingdom as part of the greater megaregion of North West Europe. These are the following:

- The Forth Replacement Crossing

- The Rosyth international container terminal

- The Aberdeen Western Bypass

- The Edinburgh Glasgow Improvement Program (EGIP)

- The Peel Ports Liverpool 2 project

- The Manchester Ship Canal

- The Mersey Gateway Bridge

- The London Gateway

- The High Speed 1 railway

- The London Thames Port

- The Daventry International Rail Freight terminal 


\section{The Forth Replacement Crossing (FRC) project}

The Forth Replacement Crossing project is a major infrastructure project for Scotland, designed to safeguard a vital connection in the region's transport network.

\section{Location and overview of the project}

The project is ongoing and it is located in South East of Scotland. It is a publicly funded project costing more than $€ 100 \mathrm{~m}$.

Its main objectives are to:

1. Relieve the congestion on the aging Forth Road Bridge; the old bridge will only have access to pedestrians, cyclists, coaches and buses in the future.

2. Provide an essential road link between central Scotland and Fife.

3. Provide an improved public transport through the existing Forth Road Bridge only being open to public transport.

The project is believed to be of great significance for the emerging megaregion of North West Europe as it will increase capacity and will facilitate freight flows. Upon completion the benefits that the project is expected to deliver are numerous from an economic, transport and social perspective.

More specifically:

\section{Economic Benefits:}

- It will provide an essential link for businesses in Fife and further north with Edinburgh.

- Support sustainable development and economic growth.

- 1,200 job opportunities and a large number of sub contract and supply order opportunities for Scottish companies. 


\section{Transport Benefits:}

- Maintain cross-Forth transport links for all modes to at least 2006 levels.

- Connect to strategic transport network to aid optimisation of the network as a whole.

- Improve reliability of journey times for all modes.

- Increase travel choices and improve integration across modes to encourage modal shift of people and goods.

- Minimise impacts of maintenance on effective operation of the transport network.

\section{Social Benefits:}

- $\quad$ Forth Road Bridge will be accessible to cyclists, buses, taxis and coaches.

- Improvements to public transport.

- Improvements to walking and cycling.

- A safer way for cyclists and pedestrians to cross the Firth of Forth.

- Improve accessibility and social inclusion.

\section{SWOT analysis with emphasis to congestion and modal shift}

An important strong point that the under construction project has is that the current driving factor for the new bridge is its potential to provide relief for the existing Forth Road Bridge which is over 50 years old, and cannot support the current level of traffic. Its major weakness is that it may have an adverse environmental impact on the local community on the mile of the Forth. However, the opportunity is given for the new bridge to provide a more reliable and sustainable link between Fife and northern Scotland, and Edinburgh. The impact on modal shift could be threatened as the project may, to a very small extent, encourage a small shift from rail to road for both passengers and freight. 


\section{Bottlenecks that the project aims to reduce in the region}

The new bridge will significantly reduce the current usage on the existing Forth Road Bridge, by directing all car and road freight to the new crossing. Also it will have a reduction in delays across the Firth of Forth, since a dual lane system on each side and an additional hard shoulder will alleviate congestion caused through breakdowns. The Forth Replacement Crossing (FRC) project will create a managed motorway by using an Intelligent Transport System to help regulate the flow of traffic approaching and crossing the Forth.

\section{Overview of co-modality growth and scenarios by 2030}

The project is expected according to participants of the focus group to realise a high growth development scenario which will enhance co-modality in the region. This is primarily because it will enhance the existing link between Fife and Edinburgh. Also because it will enhance sustainable development by allowing the Forth Road Bridge to be used for public transport, pedestrians and cyclists only. Moreover because access will be improved to Rosyth Ports.

\section{Sustainable development scenarios by 2030}

The following radar chart models the scores given during the evaluation process for the Forth Replacement Crossing project. Moreover, it gives an overview of the significant impact scenarios that the project is likely to have to the transport system that it is a part of by the year 2030 . 


\section{The Forth replacement crossing project}

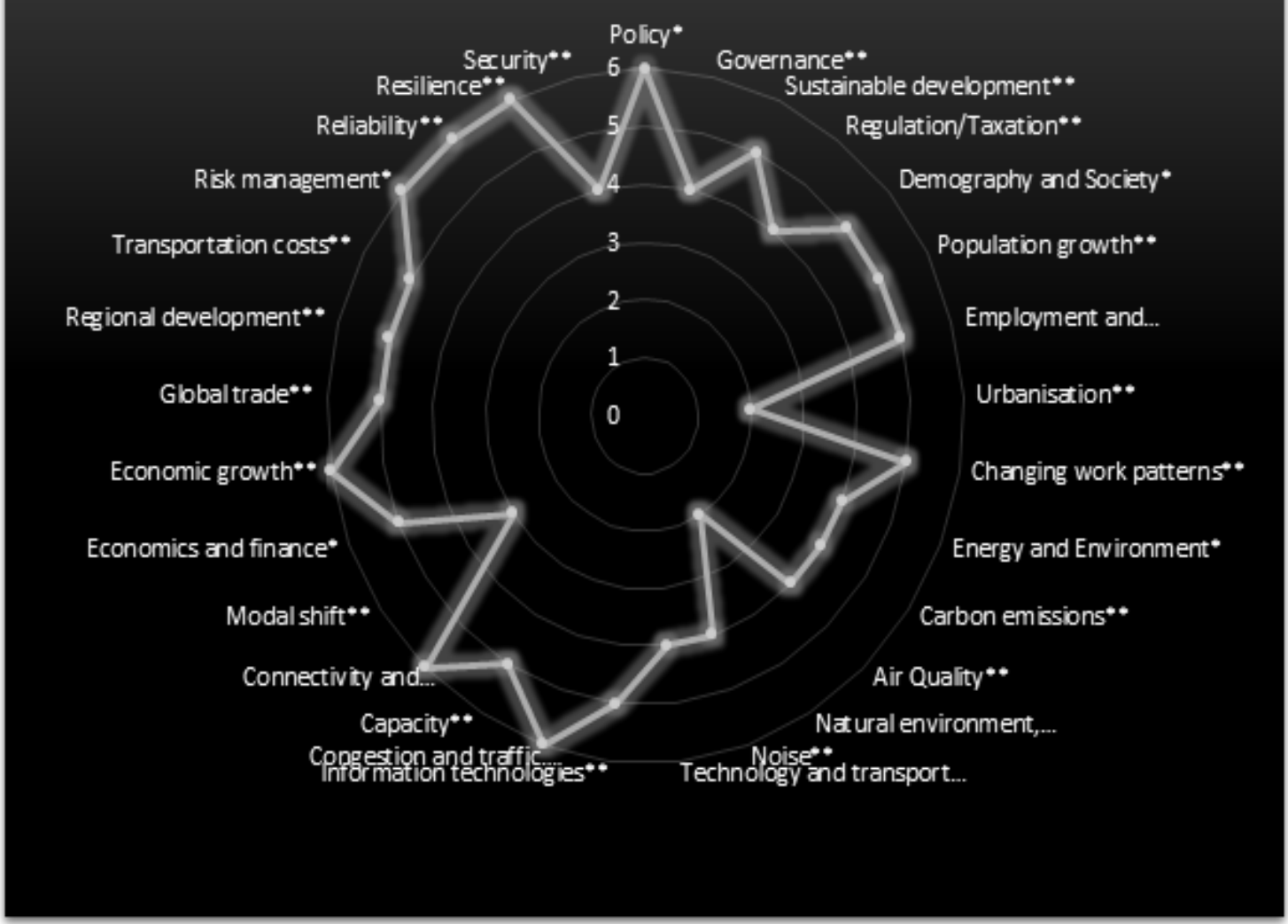

Figure B-3: Radar chart representation of future growth scenario of sustainable development for the Forth replacement crossing project 


\section{The Rosyth International Container Terminal project}

\section{Location and overview of the project}

The Rosyth international container terminal is a multimodal facility in the heart of the central belt of Scotland, adding much needed capacity and complementing existing container facilities with an estimated cost of $€ 75 \mathrm{~m}$ to $€ 100 \mathrm{~m}$ primarily funded by the private sector.

The main objectives of the project are:

- To improve the current port and efficiency of the port (Currently there are no lo-lo container facilities at Rosyth).

- To withstand the current and future demand for freight.

- To improve freight distribution at the current port.

- To build upon current rail and road links with the port, and will allow larger vessels to berth at the port.

The port has intermodal links and the project is of great significance for the sustainable development of the emerging megaregion of North West Europe as it will increase capacity and it will facilitate containerised freight flows and improve freight distribution. The benefits that the project is expected to deliver are numerous from an economic, transport and social perspective for the users. More specifically:

\section{Economic Benefits:}

- The port will be able to deal with an increase in demand and can host larger vessels, therefore reducing company costs.

- $\quad$ There is capacity for storage and warehousing on site.

- The development of the terminal will offer the opportunity to create a new logistics and distribution hub in the East of Scotland. 
- Terminal will contribute to the regeneration of the Rosyth waterfront and Fife economy as well as that for the South East of Scotland.

- It will also provide further competition in the provision of port and maritime services as there is currently only one container terminal on the East Coast of Scotland (Grangemouth).

- It will also reduce 'leakage' through English gateways, recognising lost economic opportunity in wealth creation.

\section{Transport benefits:}

- The proximity of the Rosyth International Container Terminal to the central belt and industrial hinterland will enhance the efficient and competitive movement of goods through the supply chain.

- Crucially, it will provide a long term platform to support the growth in trade with the Baltic Region, Eastern Europe and improve connectivity to other international markets.

- It will provide new container feeder services to the major European ports.

- The development can also play a part in realising Scotland's potential as a land bridge between Ireland and Europe.

- There is potential to link the terminal to the rail network by upgrading the redundant line.

\section{Social benefits:}

- Increase in employment opportunities.

\section{SWOT analysis with emphasis to congestion and modal shift}

One of the strengths of the project's proposal is the driving factor of the increase in freight movement that the Rosyth port is currently experiencing (annually by 5-8\%). The current port cannot accommodate this increase and therefore needs to be extended or renovated. 
This also offers $24 / 7$ operation and would not be dependent on ships negotiating locks to access the port.

A major weakness can be identified in the environmental side of the proposal as dredging will need to be carried of the nearby river. However, this extension of the current port will give the opportunity for larger vessels to dock at the port. The project also will create a competitive port within the UK, without the current restrictions. Yet, the project proposal is under environmental review in order to evaluate how the marine-life in the Fifth of Forth will be affected.

\section{Bottlenecks that the project aims to reduce in the region}

The newly designed port will be able to accommodate larger vessels and will be able to handle increases in freight movement. It will also reduce freight congestion as it has the potential for 24/7 operations and will not be "lock" dependent. Moreover the project proposes to reduce leakage through English waterways and thereby reduce road freight flows between Scotland and England. The development will facilitate deep sea liner companies cost reduction and service enhancement demands when serving the Scottish market. It is also expected to provide a straight forward solution to link the new port to the existing rail network and therefore it should facilitate further shift from road to rail.

\section{Overview of co-modality growth and scenarios by 2030}

The project's proposal is very promising for the long term as according to participants of the focus group it promotes modal shift in the region significantly and co-modality is expected to grow highly. This is because the new container terminal will be able to accommodate larger vessels and also because it will have the potential to operate on a 24/7 basis. As a result freight traffic is expected to grow and the proximity that the Rosyth International Container Terminal will offer to the central belt and industrial hinterland will enhance the efficient and competitive movement of goods through the supply chain. 


\section{Sustainable development scenarios by 2030}

The following radar chart models the scores given during the evaluation process for the Rosyth International Container Terminal project. Moreover, it gives an overview of the significant impact scenarios that the project is likely to have to the transport system that it is a part of by the year 2030 .

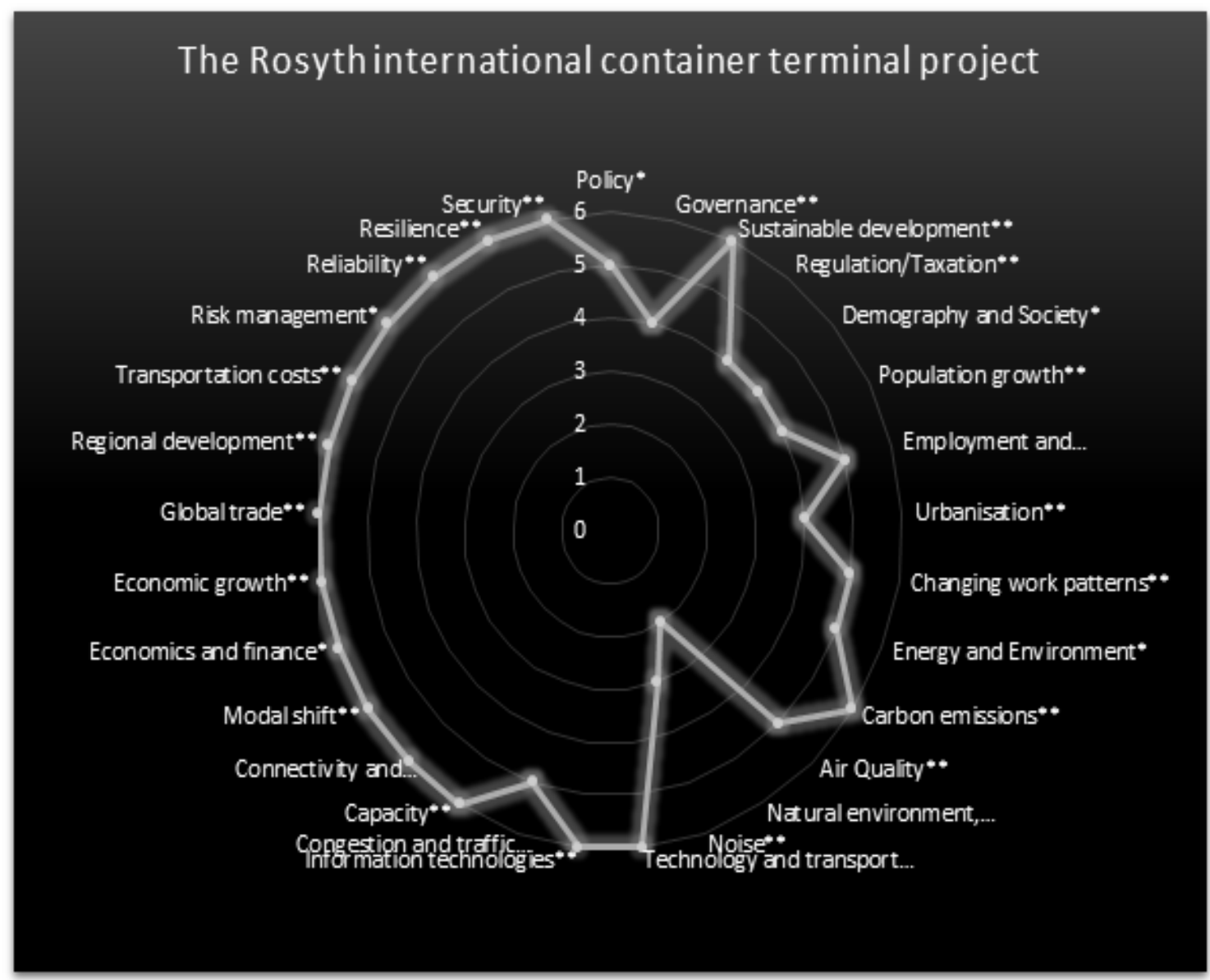

Figure B-4: Radar chart representation of future growth scenario of sustainable development for the Rosyth International container terminal project 


\section{Edinburgh - Glascow improvement programme (EGIP)}

The Edinburgh Glascow improvement programme (EGIP) is a comprehensive package of improvements to Scotland's railway infrastructure. A Scottish Government priority, the $£ 650 \mathrm{~m}$ EGIP is being delivered by Network Rail and includes modernisation and upgrades to key junctions and infrastructure as well as widespread electrification of the Scottish rail network, including the main line between Edinburgh and Glasgow.

\section{Location and overview of the project}

The current project's status is ongoing and commenced in 2012 with a total budget is over $€ 600 \mathrm{~m}$. The project has major links with other modes of transport such as rail and sea. It is believed that the project will reduce the current journey time between Edinburgh and Glasgow, increase capacity of the trains and provide a cleaner, greener and quieter railway with lower carbon emissions.

It will provide an electric railway link to Grangemouth Port and across the central belt linking the East and West Coast main lines, thereby providing greater opportunities for sustainable freight transport.

The main objectives of the project are:

- To upgrade and fully electrify the line between Edinburgh and Glasgow, including spurs and associated lines.

- To shorten journey times and provide more reliable services between our two biggest cities.

- To improve capacity and to offer more seats with less crowding at peak journey times.

- To provide passengers with a cleaner, greener and quieter railway with lower carbon emissions

- To transform the Queen Street station. 
When completed the benefits that the project is expected to deliver are numerous from an economic, transport and social perspective for the users, balancing therefore supply and demand.

More specifically:

\section{Economic benefits:}

- Faster and more frequent rail links between our towns and cities mean more job opportunities for more people.

- Rail is the lowest carbon mode of mass transport and is an essential part of a future low carbon economy.

- Benefits for the communities that the route serves while also stimulating growth and unlocking investment opportunities.

\section{Transport benefits:}

- Reduction in journey times of up to 10 minutes in peak periods.

- 7 and 8 car trains will be introduced to increase capacity.

- More reliable and frequent trains.

- Improved link between Edinburgh and Glasgow, as well as other locations along the route.

- Opportunities for more efficient freight movements for the freight industry.

\section{Social benefits:}

- Increased employment due to improved access to job markets.

- A cleaner, greener, quieter railway with lower carbon emissions.

- The increased capacity will reduce overcrowding on trains at peak periods. 


\section{SWOT analysis with emphasis to congestion and modal shift}

The main strong point of the Edinburgh Glascow improvement programme (EGIP) is its driving force to reduce the travel times between Edinburgh and Glasgow, and the increased capacity of the trains. However, during its ongoing development phase the project experienced weaknesses as the demolition of the Millenium Hotel and the works on Winchburgh Tunnel closed down the line for forty four days. Although there will be many job opportunities because of the construction works, the project was threatened in a challenging way from other parts of Scotland, as it is believed that "too much" transport investment goes to the Central Belt.

\section{Bottlenecks that the project aims to reduce in the region}

Passenger overcrowding at peak periods will be reduced with increased capacity and a reduction of current journey time will improve passenger satisfaction and will encourage switching from road to rail. Greater flexibility in the routing of freight flows should reduce congestion on the network and also switching from diesel to electric traction should help in achieving 'green targets'.

\section{Overview of co-modality growth and scenarios by 2030}

The project's proposal looks very promising for the long term as according to participants of the focus group it will promote modal shift in the region significantly and co-modality is expected to increase as a result. This is because the project is expected to improve the current rail system between Edinburgh and Glasgow by also reducing lead times. Also a cleaner, faster and more reliable service will enhance route options for freight services.

\section{Sustainable development scenarios by 2030}

The following radar chart models the scores given during the evaluation process for the Edinburgh Glasgow improvement project. Moreover, it gives an overview of the significant impact scenarios that the project is likely to have to the transport system that it is a part of by the year 2030 . 


\section{The Edinburgh Glascow Improvement Program (EGIP)}

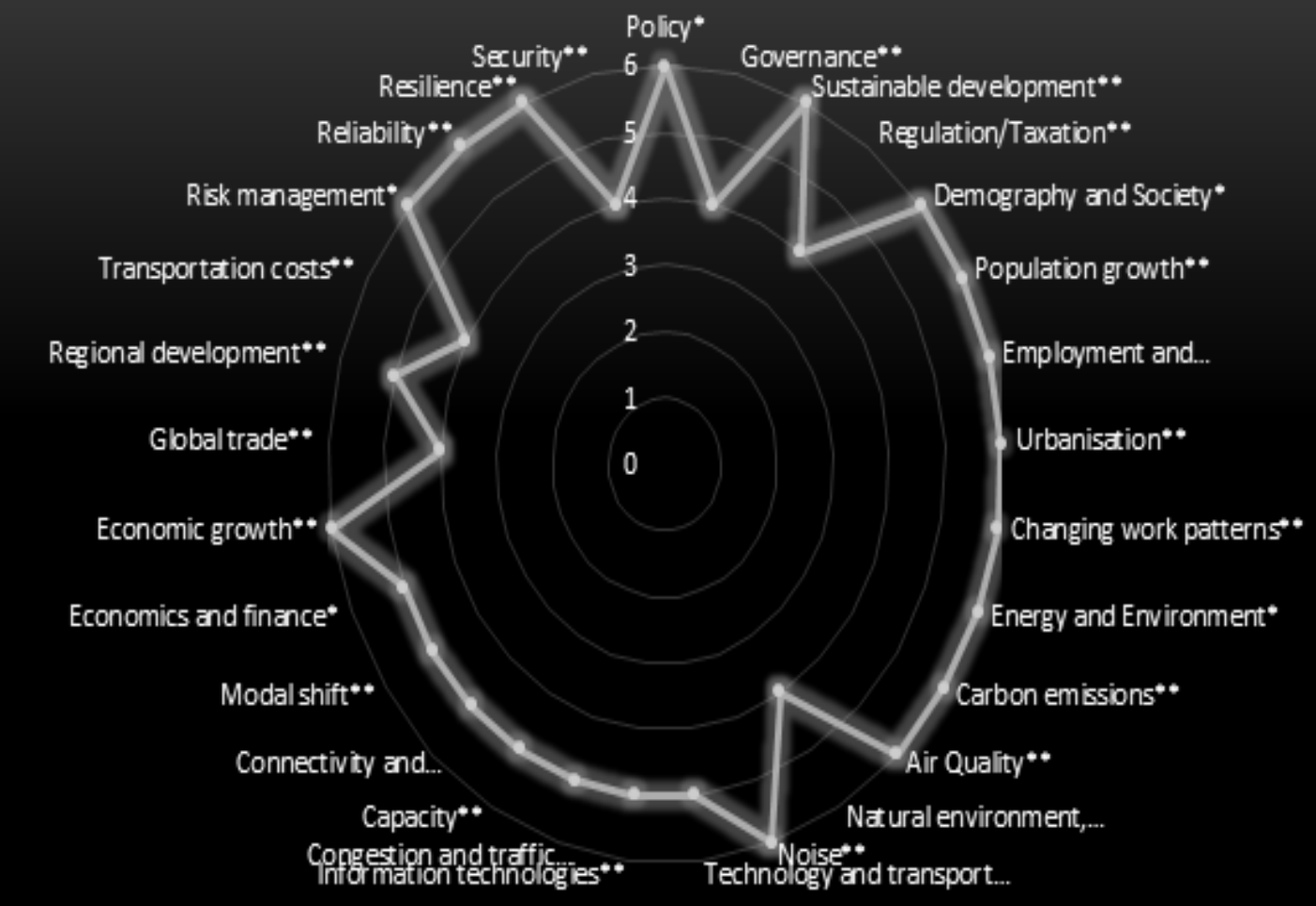

Figure B-5: Radar chart representation of future growth scenario of sustainable development for the Edinburgh - Glasgow improvement project 


\section{The Aberdeen Western Bypass project}

The Aberdeen Western Peripheral Route project is a major transport infrastructure project which will significantly improve travel in and around Aberdeen and the North East of Scotland.

\section{Location and overview of the project}

The project is located in Northern Scotland, around the city of Aberdeen which is a major driver for the Scottish economy and good transport links are vital for the UK's continued and sustainable growth. The peripheral route is currently under construction and it will be fully operational by spring 2018. It is funded both from the public and private sectors and it has a budget of over $€ 100 \mathrm{~m}$.

According to the participants of the focus group the project has synergies is of great significance for the sustainable development of the megaregion of North Wes Europe as it will increase the efficiency of road freight movement and will improve current links with the rest of Scotland and other modes of transport.

The main objectives of the project are to:

- Relieve the current congestion on existing traffic routes, especially during peak periods.

- Reduce traffic and congestion on nearby bridges into central Aberdeen.

- Reduce emissions from HGVs in Aberdeen through HGVs not entering the city itself.

- Grow the local economy by improving road accessibility, this will ensure the competitiveness of the North East.

- Improve road safety.

Upon completion the benefits that the project is expected to deliver are numerous from an economic, transport and social perspective. 
More specifically:

\section{Economic Benefits:}

- Will create around 14,000 new jobs.

- Provide an additional $£ 6$ billion to the local economy.

- It will support sustainable growth in Aberdeen and the North East of Scotland and improve business productivity.

\section{Transport Benefits:}

- Less congestion in the centre of Aberdeen.

- Less congestion results in lower carbon emissions.

- Better accessibility for Aberdeen, Aberdeen airport and the surrounding North East of Scotland.

- A major strategic transport route that will link the North East of Scotland to the rest of the country.

- Reduction in journey time during peak periods.

\section{Social Benefits:}

- Improvements to public health due to the reduction in carbon emissions.

- Improved road safety in the centre of Aberdeen due to less traffic.

- Improved integration of public transport and access to Aberdeen.

- Job creation.

\section{SWOT analysis with emphasis to congestion and modal shift}

The main strength of the Aberdeen West Peripheral Route project is that its driving factor for the new bypass is the vastly improved accessibility to Aberdeen and the North East of Scotland. This will provide a significant reduction in congestion in and around the 
Aberdeen area. The impact that the proposed route will have on residents residing nearby is considered to be one of its weaknesses. Nevertheless, the project is expected to provide good opportunities for connectivity between Aberdeen, the North East of Scotland and the rest of Scotland. Also it will provide businesses in Aberdeen with a more competitive road link. The project was threatened to be suspended in the past as local residents affected took legal action to block the construction of the new bypass.

\section{Bottlenecks that the project aims to reduce in the region}

The project aims to eliminate bottlenecks in the region by reducing congestion and emissions through the centre of Aberdeen. Accessibility to Aberdeen and the North East of Scotland will be improved and as a result HGVs will benefit from a faster and less congested route. Moreover congestion will be reduced not only in the city centre but also in the port area.

\section{Overview of co-modality growth and scenarios by 2030}

The Aberdeen West Peripheral Route project according to participants of the focus group will contribute significantly to the enhancement of co-modality by the year 2030 and therefore is expected to realise a high growth scenario. Along with its prospects of enhancing sustainable development it will also better safeguard freight access to the port and the airport. 


\section{Sustainable development scenarios by 2030}

The following radar chart models the scores given during the evaluation process for the Aberdeen Western bypass project. Moreover, it gives an overview of the significant impact scenarios that the project is likely to have to the transport system that it is a part of by the year 2030 .

\section{The Aberdeen Western Bypass project}

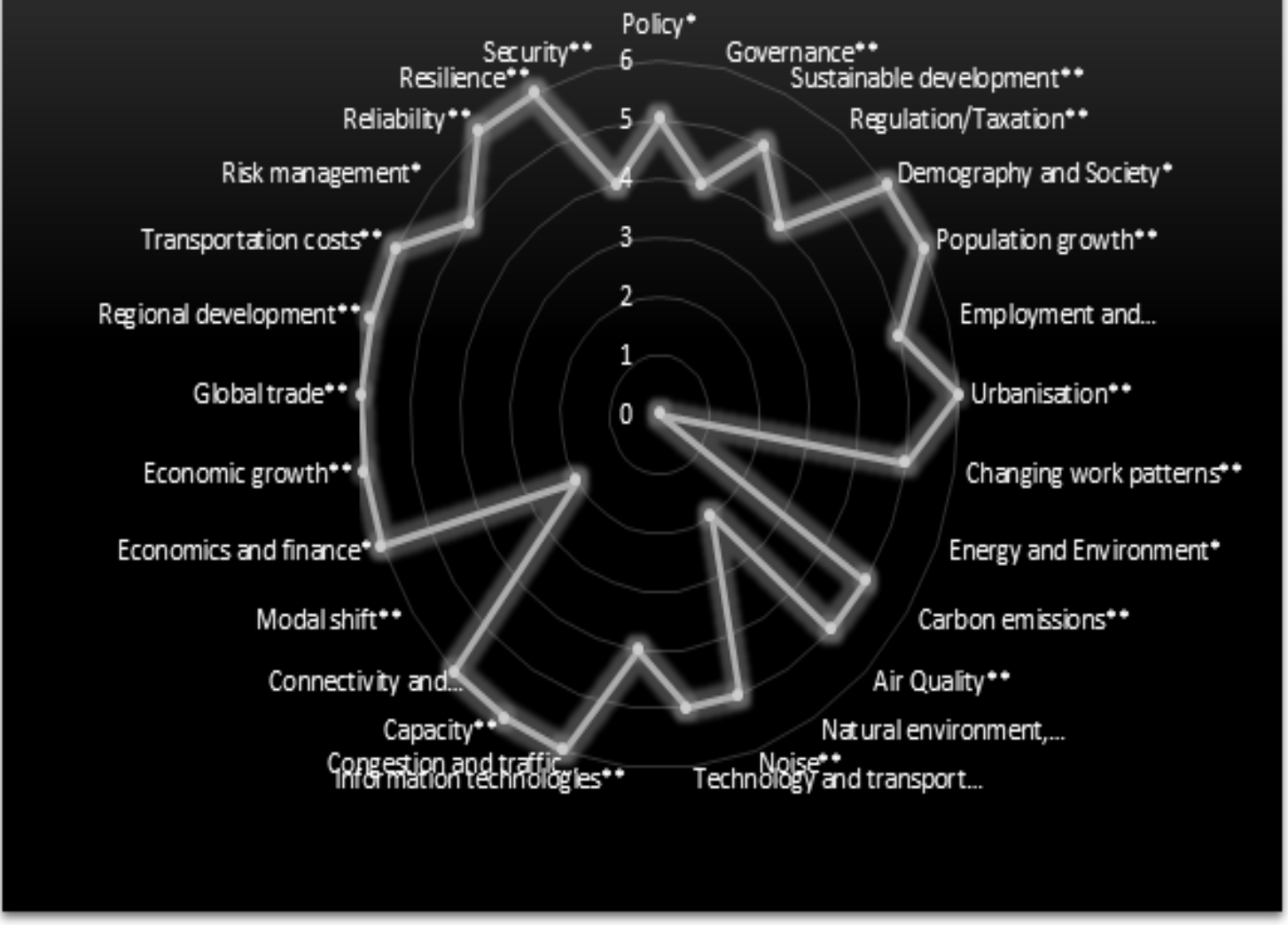

Figure B-6: Radar chart representation of future growth scenario of sustainable development for the Aberdeen Western bypass project 


\section{The Liverpool 2 container terminal project}

\section{Location and overview of the project}

The project costing $£ 300$ million, and promising 5,000 new jobs at the Port and in the supply chain, a brand new in-river container port known as Liverpool 2 with jobs coming on-stream as soon as the licenses are approved.

The new facility will add a further half-a-million containers (TEUs) annually to the Port of Liverpool, taking its capacity toward two million TEUs in all. The new terminal will allow shipping lines to connect to the UK's major trade centers in the most cost efficient manner. It will also facilitate improved trans-shipment links to Ireland and Scotland through Liverpool's existing services, allowing shipping lines to benefit from a lower cost, reduced transit time and higher frequency service whilst enabling an equalization of equipment imbalances that exist around the British Isles. Importers and exporters will also benefit as the terminal will enable a much cheaper route to market whilst simultaneously reducing the carbon footprint of the total journey. These benefits arise from the significant reduction in land-based mileage that results from the container terminal being located in the center of the British Isles.

\section{SWOT analysis with emphasis to congestion and modal shift}

The improvement in service standards for shipping lines, importers and exporters brought about by Liverpool 2 will be transformational. Forecasts for import/export use of the new deep-water terminal indicate it could remove more than 150 million miles of transport from the UK's motorway and rail freight networks. This will be a significant saving, in terms of both operational costs for customers and carbon efficiency. Residents nearby have been warned to expect noise disturbance as several hundred steel piles are driven into the river bed. 


\section{Bottlenecks that the project aims to reduce in the region}

The development consists of a new deep water container terminal in the River Mersey, removing the vessel restrictions imposed by the current in-lock container terminal. Once it's completed, Liverpool 2 will allow two vessels up to 13,500 TEU to berth at the same time - removing the need for goods to be transhipped to smaller feeder vessels from larger ports in Europe.

Overview of co-modality growth and scenarios by 2030

The Liverpool 2 container terminal project according to participants of the focus group is expected to have a high impact on the development of co-modality in the region as it will allow global services to be shipped direct to the heart of major UK conurbations. Liverpool 2 will also operate alongside the Manchester Ship Canal, now in common ownership and operation for the first time, providing a green corridor of water borne access deep inland to logistics sites and population centres. 


\section{Sustainable development scenarios by 2030}

The following radar chart models the scores given during the evaluation process for the Liverpool 2 Container Terminal project. Moreover, it gives an overview of the significant impact scenarios that the project is likely to have to the transport system that it is a part of by the year 2030 .

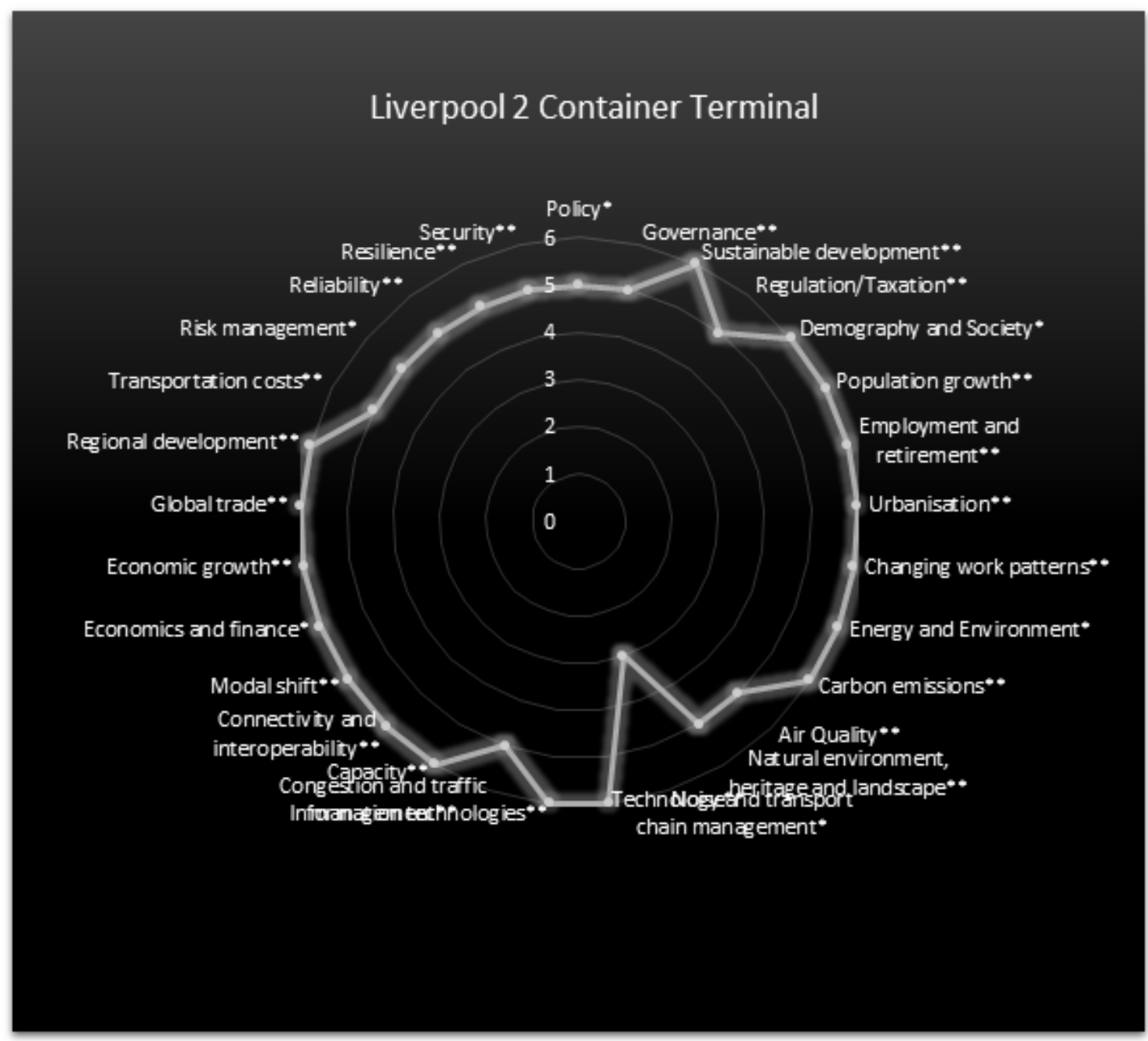

Figure B-7: Radar chart representation of future growth scenario of sustainable development for the Liverpool 2 Container Terminal project 


\section{Manchester Ship Canal}

\section{Location and overview of the project}

The Manchester Ship Canal is an inland waterway 36 miles $(58 \mathrm{~km})$ long in the North West of England. Starting at the Mersey Estuary near Liverpool, it generally follows the original routes of the rivers Mersey and Irwell through the historic counties of Cheshire and Lancashire.

The project's strategy is to create a fully integrated logistics platform by combining the Port of Liverpool and Manchester Ship Canal, stretching from Liverpool 2, the new deepwater container terminal on the River Mersey, into the heart of Manchester along the Manchester Ship Canal. Additionally, a number of logistics hubs will be developed, including Port Bridgewater (near Ellesmere Port) Port Warrington and Port Salford. Currently the project is ongoing and is funded both from the private and the public sector in excess of $€ 100 \mathrm{~m}$.

\section{SWOT analysis with emphasis to congestion and modal shift}

One of the main advantages of the Manchester Ship Canal is that it links deep water services at Liverpool 2 to inland distribution and manufacturing facilities. Also it offers many opportunities as a cheaper option to the inland road haulage by reducing carbon emissions.

\section{Bottlenecks that the project aims to reduce in the region}

With ten motorways within ten miles of this integrated waterway, each terminal raillinked with up to nine services a day between the Port of Liverpool and Ireland, the project will upon completion be able to offer a green alternative to the motorway network. 


\section{Overview of co-modality growth and scenarios by 2030}

According to participants of the focus group the project has the potential to achieve upon completion as it is expected to have a high impact on the development of co-modality in the region. This will be achieved through the promotion of green shipping, modal shift and connectivity to intermodal facilities across the UK.

\section{Sustainable development scenarios by 2030}

The following radar chart models the scores given during the evaluation process for the Manchester Ship Canal project. Moreover, it gives an overview of the significant impact scenarios that the project is likely to have to the transport system that it is a part of by the year 2030.

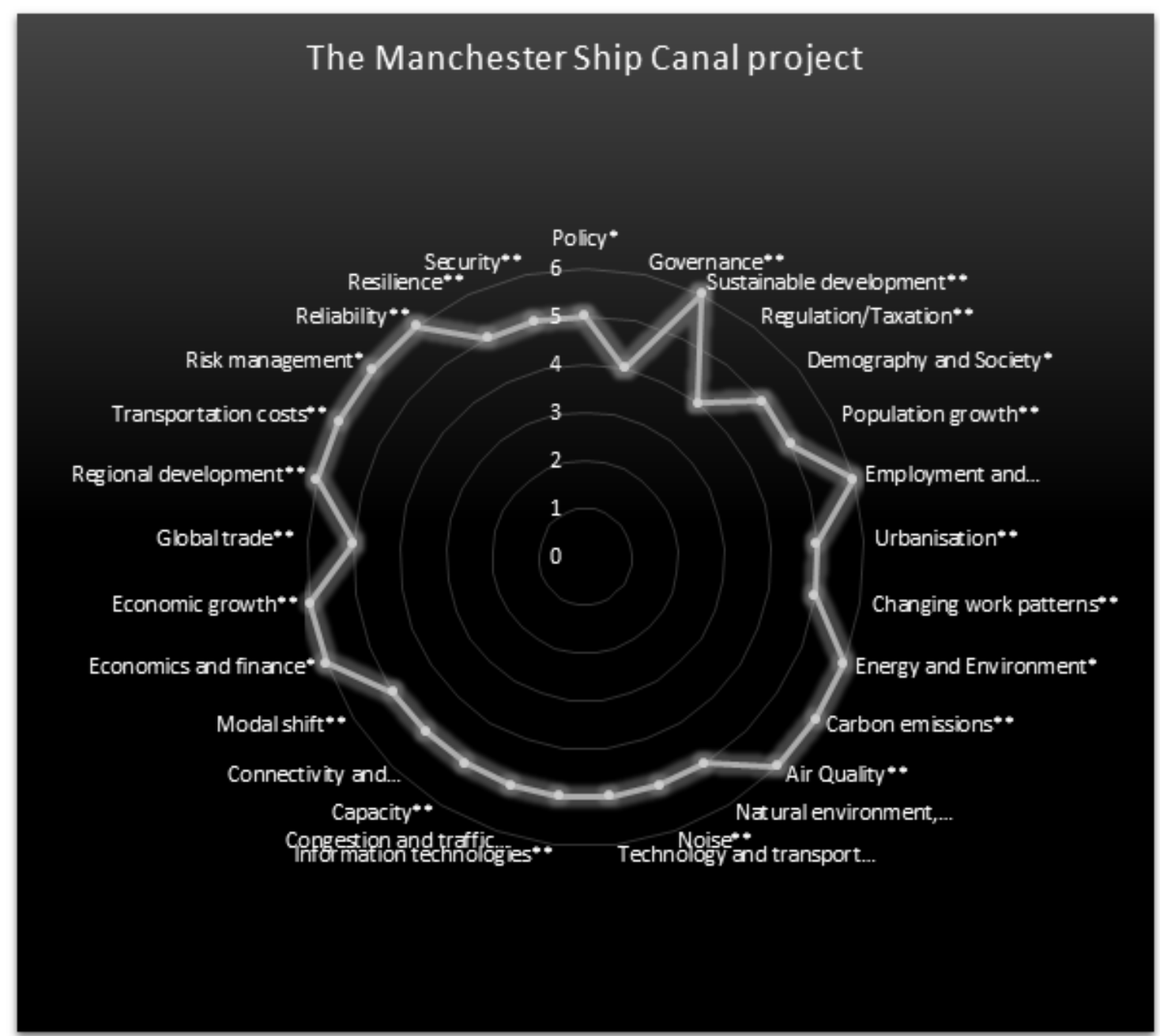

Figure B-8: Radar chart representation of future growth scenario of sustainable development of the Manchester Ship Canal project 


\section{The Mersey Gateway bridge project}

The Mersey Gateway is a new road bridge across the River Mersey and the Manchester Ship Canal in north-west England. The bridge will be located approximately $1.5 \mathrm{~km}$ to the east of the existing Silver Jubilee Bridge that connects the towns of Widnes and Runcorn. It will connect the Central Expressway in Runcorn with the Eastern Bypass and Speke Road in Widnes.

\section{Location and overview of the project}

Work started on the Mersey Gateway Project on 7 May 2014. In autumn 2017 a new six lane toll bridge over the Mersey between the towns of Runcorn and Widnes will open to relieve the congested and ageing Silver Jubilee Bridge. Both the new Mersey Gateway Bridge and the Silver Jubilee Bridge will be tolled. The project will be funded both from the public and the private sector is expected to cost around $£ 589 \mathrm{~m}$.

The main objectives of the project are to:

1) To relieve the congested Silver Jubilee Bridge, thereby removing the constraint on local and regional development and better providing for local transport needs.

2) To apply minimum toll and road user charges to both the Mersey Gateway Bridge consistent with the level required to satisfy the affordability constraints.

3) To improve accessibility in order to maximise local development and regional economic growth opportunities.

4) To improve local air quality and enhance the general urban environment.

5) To improve public transport links across the river Mersey.

6) To encourage the increased use of cycling and walking.

7) To restore effective network resilience for road transport across the river Mersey.

The project is expected to establish intermodal links with other modes of transport and also it will increase capacity and will facilitate freight flows. Upon completion the benefits that the project is expected to deliver are numerous from an economic, transport and social perspective. 
More specifically:

\section{Economic benefits:}

- 470 permanent full-time equivalent jobs on site during the construction phase

- 4,640 permanent new jobs as a result of the operation of the Mersey Gateway, regeneration activity and inward investment

- $\quad £ 61.9$ million a year in Gross Value Added from the new jobs by 2030, and

- It will also support sustained growth at Liverpool Ports and Liverpool John Lennon Airport and improve business productivity throughout the Mersey corridor (known as agglomeration impacts).

\section{Transport benefits:}

- Reductions in journey times of up to 10 minutes in peak periods

- Increase in journey time reliability

- Less congestion resulting in lower carbon emissions

- Reductions in the cost of accidents of up to $£ 39$ million

- $80 \%$ less traffic using the Silver Jubilee Bridge, freeing it up for use as a local bridge

- Increased network resilience and civil contingencies

- Reductions in maintenance delays as a result of reduced congestion, and

- A major strategic new transport route linking the Liverpool city-region and the North West to the rest of the country.

\section{Social benefits:}

- Improvements to public transport facilities

- Improvements to walking and cycling facilities

- Improved health as a result of reduced air pollution 
- Safer, new routes for cyclists and pedestrians across and around the river, more reliable access to emergency services and more robust emergency civil contingency planning.

\section{SWOT analysis with emphasis to congestion and modal shift}

One of the strengths of the project is the driving factor for the new bridge to provide relief for the existing Silver Jubiliee Bridge which is operating at or close to capacity and experiences significant congestion at peak times. The implementation of tolls is posing both a threat and weakness for the project as the proposed tolls might encourage traffic to divert east. However, the government may decide to block the tolls free routes at Warrington and the M6 Thelwood Viaduct.

As well as providing a new link between the towns of Runcorn and Widnes the bridge is considered an important strategic route linking the Liverpool city region, north Cheshire and the North West to the rest of the country.

\section{Bottlenecks that the project aims to reduce in the region}

The new bridge will eliminate bottlenecks by acting as a new and improve route which will run from Junction 12 of the M56 in the south to the A562 Speke road in Widnes in the North. It will also reduce the volume of traffic crossing the Silver Jubilee Bridge by directing the natural movement of through traffic over the new crossing, a process known as 'delinking'. This will free up the Silver Jubilee Bridge so it can provide a local link across the river between Widnes and Runcorn.

The northern end of the Mersey Gateway road system starts to the north west of Widnes, along the existing A562 Speke Road to and from Liverpool. The route then heads eastwards towards a new junction called the Ditton Junction, which will replace Ditton roundabout. 


\section{Overview of co-modality growth and scenarios by 2030}

The Mersey Gateway bridge is projected to increase co-modality in the region by 2030 as the new bridge will facilitate seamless access to the Port of Liverpool which is only a few miles away. It will also provide a great link to the existing network and it will enhance sustainable development. Moreover it will give greater access to nearby multimodal terminals like the $3 \mathrm{MG}$ logistics park.

\section{Sustainable development scenarios by 2030}

The following radar chart models the scores given during the evaluation process for the Liverpool 2 Container Terminal project. Moreover, it gives an overview of the significant impact scenarios that the project is likely to have to the transport system that it is a part of by the year 2030 . 


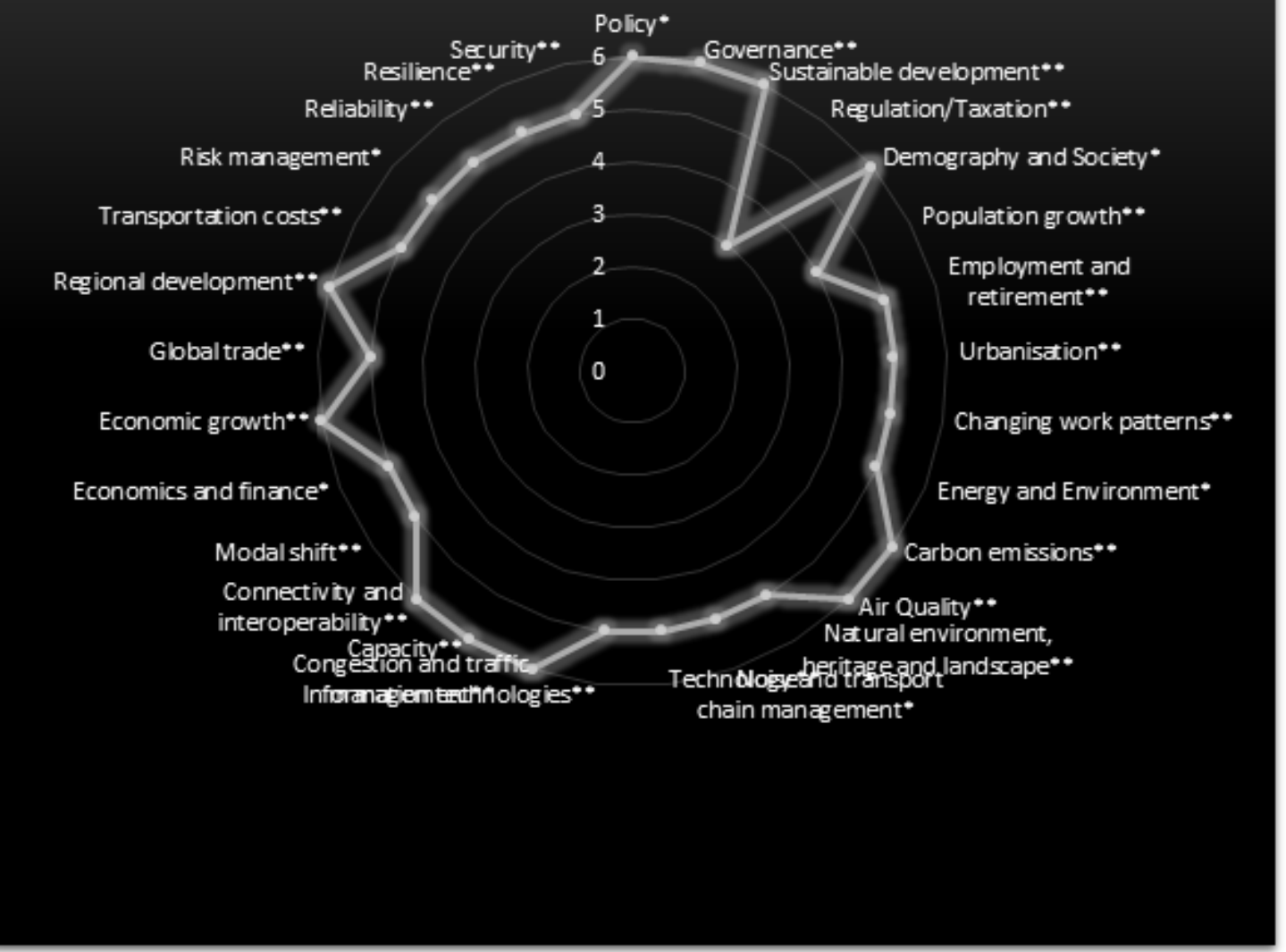

Figure B-9: Radar chart representation of future growth scenario of sustainable development for the Mersey Gateway Bridge project 


\section{The London Gateway project}

London Gateway is a development on the north bank of the River Thames in Thurrock, Essex. It comprises a new deep-water port, which is able to handle the biggest container ships in the world, as well as one of Europe's largest logistics parks, providing access by road and railways to London and the rest of Great Britain.

\section{Location and overview of the project}

According to participants of the focus group the London Gateway will be the UK's first 21st Century major deep-sea container port and Europe's largest logistics park. Owned and operated by DP World and situated on the north bank of the River Thames, London Gateway will provide unrivalled deep-sea shipping access to the largest consumer markets in the UK. The port's location, with its superior operational systems and service, will ensure ships load and unload as fast as possible, making London Gateway a world class asset for the UK.

London Gateway Logistics Park offers importers the opportunity to tighten up their supply chain solutions, cutting costs, time and carbon by locating closer to major population centres. The project is currently under development and it is privately funded with an excess of $£ 1.5 \mathrm{bn}$. The project's status is currently ongoing and partially completed. The project is also truly multimodal as all transport modes are combined.

The London Gateway will enable shippers from across the UK to make substantial savings by reducing delivery times, haulage costs, consumption and carbon emissions. This project has strong emphasis on sustainable logistics operations. The users and industrial sectors that will benefit when the project will be completed are shippers, hauliers, port users and local employment markets. 


\section{SWOT analysis with emphasis to congestion and modal shift}

One of the main strengths of the London Gateway project is that it provides excellent accessibility, with the UK's best tidal access; road connections to the North, South, East and West via an eight-lane highway. Also more than $30 \%$ of London Gateway port traffic is expected to go by rail. Although no major weaknesses could be identified it is believed that the London Gateway could pose a threat for the A13 road as it is likely to increase freight traffic and to impact negatively on the structural condition of this carriage way.

\section{Bottlenecks that the project aims to reduce in the region}

DP World (the managers of London Gateway) are delivering major capacity improvements at the A13/ A1014 Stanford Interchange which is a key pinch point, and new access arrangements from the A1014 Sorrells roundabout to the LG development site. However, the port and logistics park related traffic, especially freight traffic, is forecast to increase significantly and as a result is likely to dramatically worsen the structural condition of the carriageway in between the A13 and the Sorrells junctions with the A1014, which is already in a poor structural condition. Thurrock Council has applied to DfT to help mitigate this through funding to help improve the condition of this carriage way.

\section{Overview of co-modality growth and scenarios by 2030}

The London Gateway project according to participants of the focus group is projected to increase co-modality in the region by 2030 as the new multimodal infrastructure will provide seamless transport of freight from sea to other modes including rail.

\section{Sustainable development scenarios by 2030}

The following radar chart models the scores given during the evaluation process for the London Gateway project. Moreover, it gives an overview of the significant impact scenarios that the project is likely to have to the transport system that it is a part of by the year 2030 . 


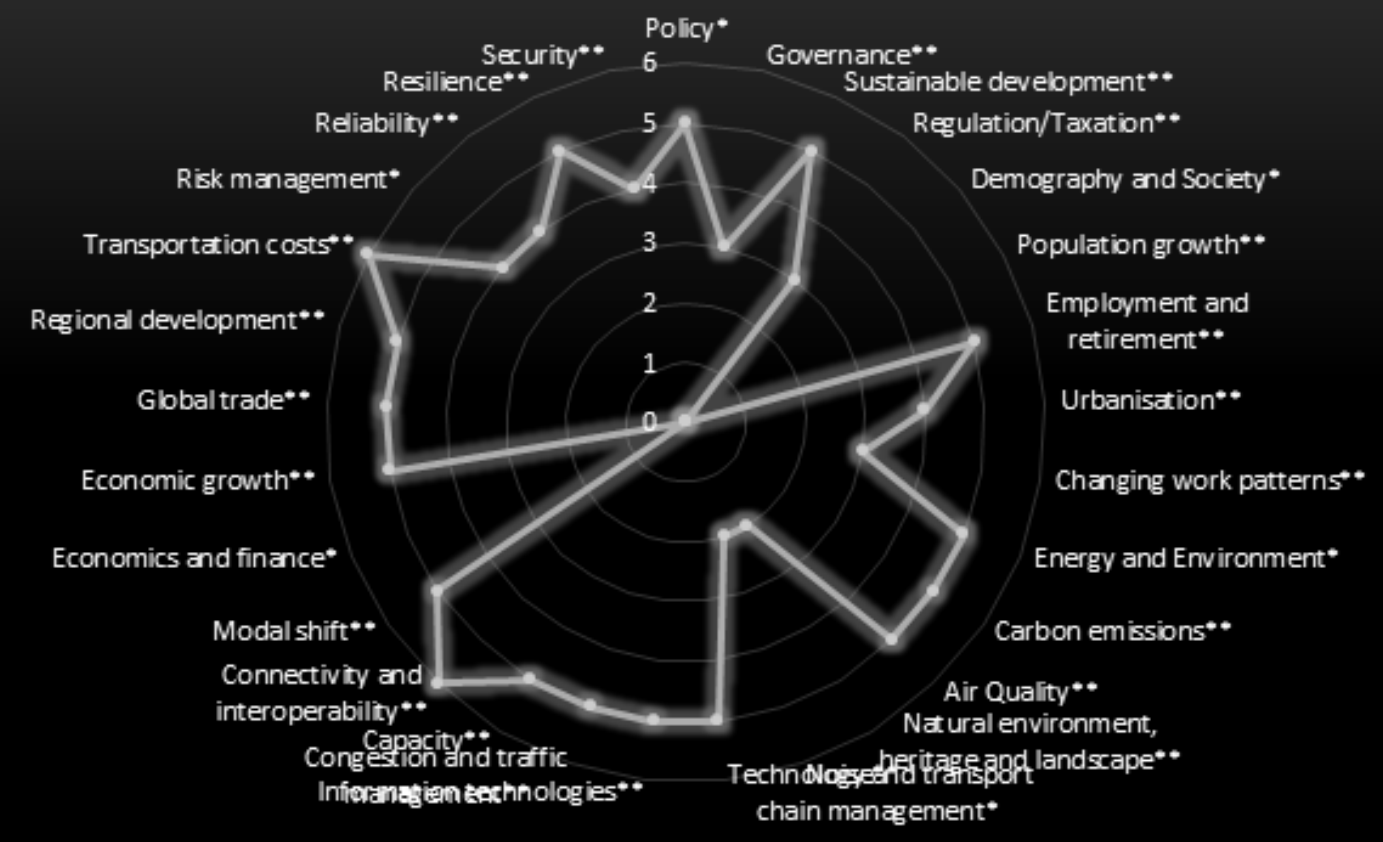

Figure B-10: Radar chart representation of future growth scenario of sustainable development for the London Gateway project 


\section{The High Speed One (HS1) rail project}

High Speed 1 (HS1), officially known as the Channel Tunnel Rail Link (CTRL) and originally as the Union Railway or Continental Main Line (CML), is a 108-kilometre (67 mi) high-speed railway between London and the United Kingdom end of the Channel Tunnel, through Kent.

\section{Location and overview of the project}

High Speed 1 is the railway between St Pancras in London and the Channel Tunnel and connects with the international high speed routes between London and Paris, and London and Brussels. High speed domestic trains also use the railway, providing a much improved commuter service between London and Kent.

The railway is also capable of carrying freight traffic. HS1 Ltd holds the concession from government to operate, manage and maintain the high-speed railway infrastructure until December 2040.

There is a future opportunity to link rail freight services on the high speed line to the continent. Already, from 11 November 2011 a weekly service using European-sized swap body containers has run between London and Poland using High Speed 1. Upon completion the benefits that the project is expected to deliver are numerous from an economic, transport and social perspective. More specifically the following groups are enjoying the benefits of the project:

- Passengers.

- Freight operators e.g. DB Schencker.

- Potential for local companies to benefit from Northfleet hub link to HS 1 e.g. Recresco who are a glass recycling company who are looking to use the development to transport their goods to the north of England and also to the continent. 


\section{SWOT analysis with emphasis to congestion and modal shift}

The main strength of the HS1 project is that it supports reliable and safe train operations. It also offers time saving in passenger and increasingly freight operations that can run on HS1. A major weakness of the project is that frequent maintenance is required to ensure the expected level of performance. While the trains have a high standard of built-in safety, their design slows down both boarding and alighting, and thus results in slower turnaround times and longer "dwells" at stations. Many opportunities for commercial use exist as it could be possible to build on the DB Schencker's current service running from London to Poland.

\section{Bottlenecks that the project aims to reduce in the region}

The project has delivered new mobility by relieving congestion on highways and runaways especially from London to Dover.

\section{Overview of co-modality growth and scenarios by 2030}

The project is expected to make a significant contribution to the development of comodality in the region in the long term. Also a high speed 2 project is being discussed on how it could benefit other parts of the UK and expand the European high speed network.

\section{Sustainable development scenarios by 2030}

The following radar chart models the scores given during the evaluation process for the High Speed Rail 1 project. Moreover, it gives an overview of the significant impact scenarios that the project is likely to have to the transport system that it is a part of by the year 2030 . 


\section{The High Speed 1 project}

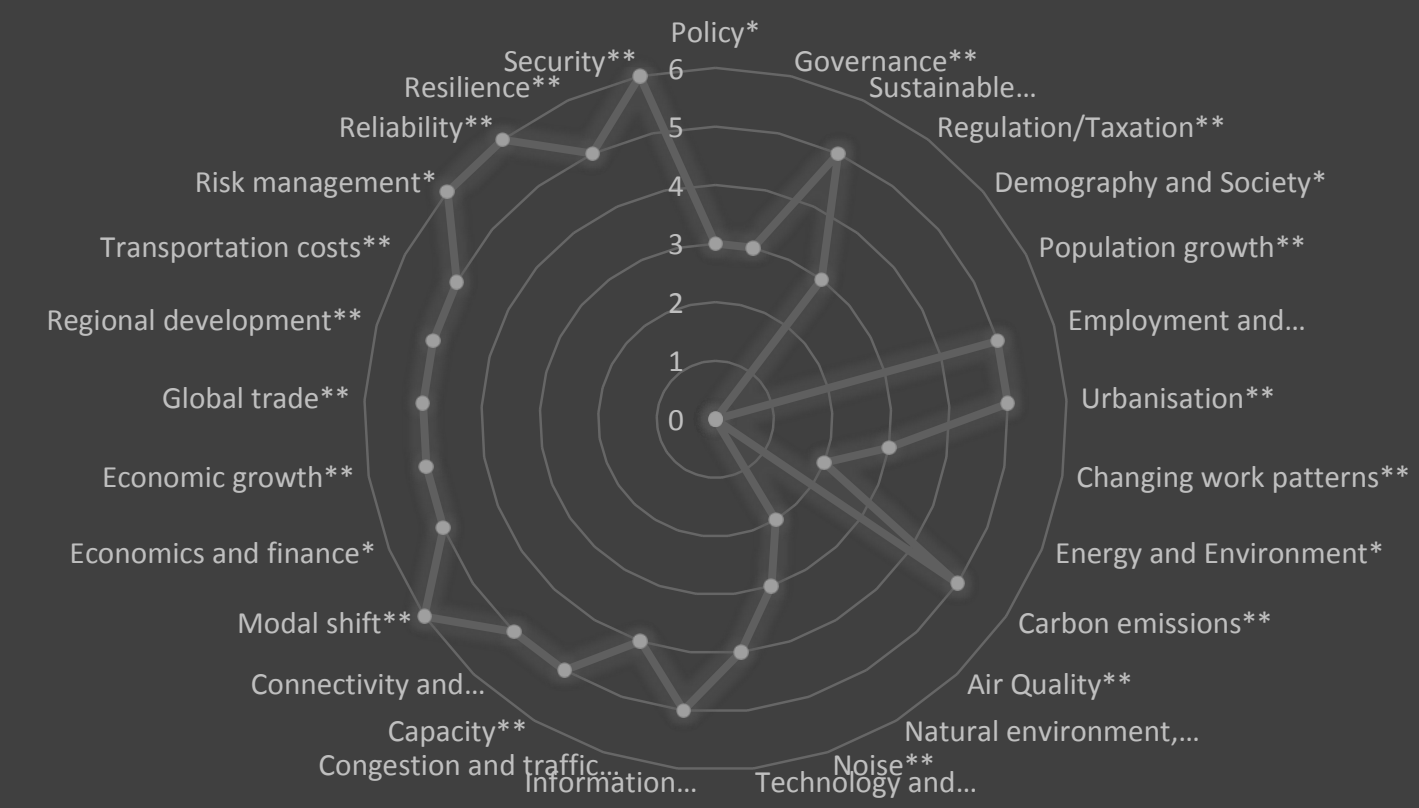

Figure B-11: Radar chart representation of future growth scenario of sustainable development for the High Speed One rail project 


\section{The London Thames Port project}

\section{Location and overview of the project}

London Thames Port is a container seaport on the River Medway, serving the North Sea. It is located on the Isle of Grain, in the Medway unitary authority district of the English county of Kent. It is one of the UK's busiest container ports. Situated only 35 miles from the City of London and 55 miles from the Channel Tunnel, the port is accessed via the excellent M2 motorway. London Thamesport is one of only three UK deep-water ports capable of handling super post-panamax container vessels. London Thamesport has a depth of 15 metres of water alongside, and the quay of 655 metres of quay provides 2 operational berths equipped with 8 ship-to-shore gantry cranes, allowing high intensity operations and excellent operational performance is the UK's first automated container terminal.

London Thamesport's on-site, multi-user rail terminal offers a range of reliable and environmentally friendly rail solutions. Daily rail services connect the port to key regional hubs in the North West, the Midlands, and Yorkshire. According to participants of the focus group the project's status is operational with good intermodal links. Also it is believed that the London Thames Port is of great significance for the emerging megaregion of North West Europe as it is one of only three UK deep-water ports capable of handling super post-panamax container vessels, this example offers a good reference point in terms of the intermodal transport of freight and a comparator with other similar container ports on mainland Europe. The users that benefit from the project are shippers, rail freight operators and their customers.

\section{SWOT analysis with emphasis to congestion and modal shift}

The SWOT analysis carried out by participants of the focus group revealed that London Thamesport is one of only three UK deep-water ports capable of handling super postpanamax container vessels making it a very competent transport infrastructure. Also London Thames Port has its own Customs Freight Station, with 14 loading bays only 800 
metres from the quay, and adjacent to the main storage areas. London Thames Port also remains at the forefront of the port industry with its application of information technology. State-of-the-art software allows staff to monitor each container's progress through the port, from ship's rail to gate departure or vice versa. However the port's potential lack of profile and visibility could be one of its weaknesses. The development of new ports in the UK could have a negative impact on the role and performance of London Thamesport in the future.

\section{Bottlenecks that the project aims to reduce in the region}

Thamesport is connected to national road network by the A228. This leads Stoke and Hoo to Strood, where it feeds into A2 towards London and the M2 motorway over the Medway Viaducts to Faversham where it rejoins the A2 which leads to Dover.

\section{Overview of co-modality growth and scenarios by 2030}

The project is expected to make a significant contribution to the development of comodality in the region in the long term by offering accessibility and connectivity to transport infrastructure. 
The following radar chart models the scores given during the evaluation process for the London Thames Port project. Moreover, it gives an overview of the significant impact scenarios that the project is likely to have to the transport system that it is a part of by the year 2030 .

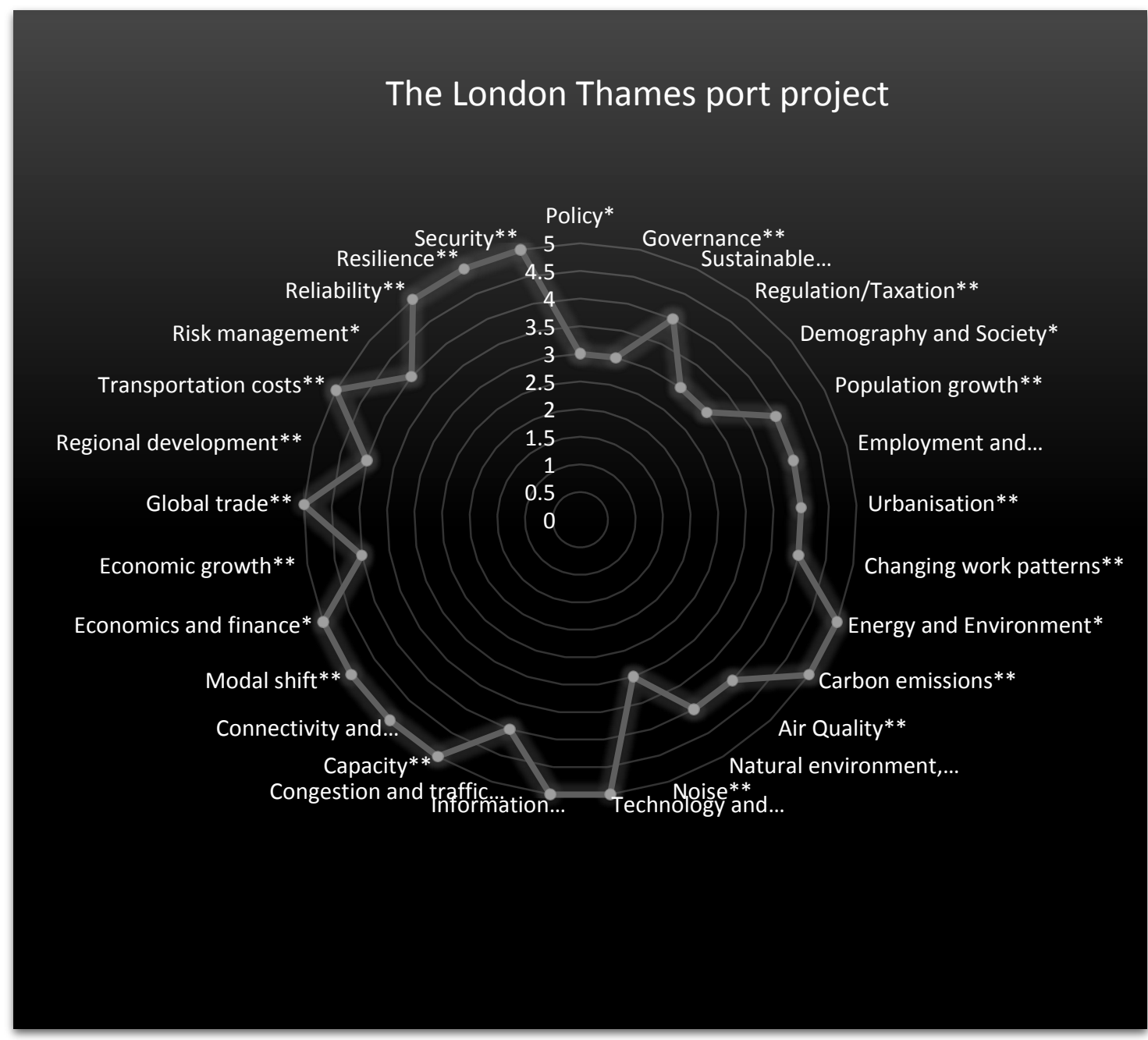

Figure B-12: Radar chart representation of future growth scenario of sustainable development for the London - Thames port project 


\section{The Daventry International Rail Freight project (DIRFT)}

\section{Location and overview of the project}

Daventry International Rail Freight Terminal (DIRFT) is a rail-linked logistics park with a Rail Port (the 'intermodal area') where goods can arrive or be dispatched by either road or rail. The facility is located at the junctions between the M1 Motorway, A5 and A428 roads with a rail connection from the Northampton loop of the West Coast Main Line. The site currently employs around 4,000 people with a further 2,000 people anticipated at DIRFT II. Logistics buildings at DIRFT (warehouses for storage and distribution) are either owned or operated by individual occupiers. Many of these are high street retailers and some of these buildings are also directly rail-connected, so goods from trains can be loaded and unloaded directly from rail.

Depending on the nature of their business, occupiers will often receive goods from suppliers to this central location and then redistribute them across their own network of regional warehouses or direct to shops

\section{SWOT analysis with emphasis to congestion and modal shift}

The SWOT analysis carried out by participants of the focus group revealed that the project has unrivalled attributes in terms of its location. It sits at the heart of the country with convenient connections to the UK's strategic transport network, including motorways such as the M1 and M6 and also trunk roads like the A14 and the A5. However one of its major weaknesses is that the A5 corridor includes a number of congestion points where long distance and local traffic interacts (for example in Tamworth and Cannock). Also some high levels of reported injury accidents exist along the corridor and some which are related to vulnerable road users. Many opportunities exist in various sources of funding such as the Regional Growth Fund and the Local Sustainable Transport Fund which offer opportunities to delivery improvements to the A5 corridor. It should be noted though that central and local government over the next 5 years are likely to be limited. This is likely to restrict the level of public investment for the development and surrounding road corridors. 
Bottlenecks that the project aims to reduce in the region

DIRFT enables the utilisation of rail to convey freight which in turn can save costs, reduce carbon emissions and help to remove HGVs from congested highways including on the M1, M6, A14 and A5.

Overview of co-modality growth and scenarios by 2030

The Daventry International Rail Freight (DIRFT) project according to IFS is projected to increase co-modality in the region by 2030 as it offers a very good opportunity to shift goods by rail from road.

Sustainable development scenarios by 2030 
The following radar chart models the scores given during the evaluation process for the Daventy International rail freight project. Moreover, it gives an overview of the significant impact scenarios that the project is likely to have to the transport system that it is a part of by the year 2030 .

\section{The Daventry International Rail Freight project}

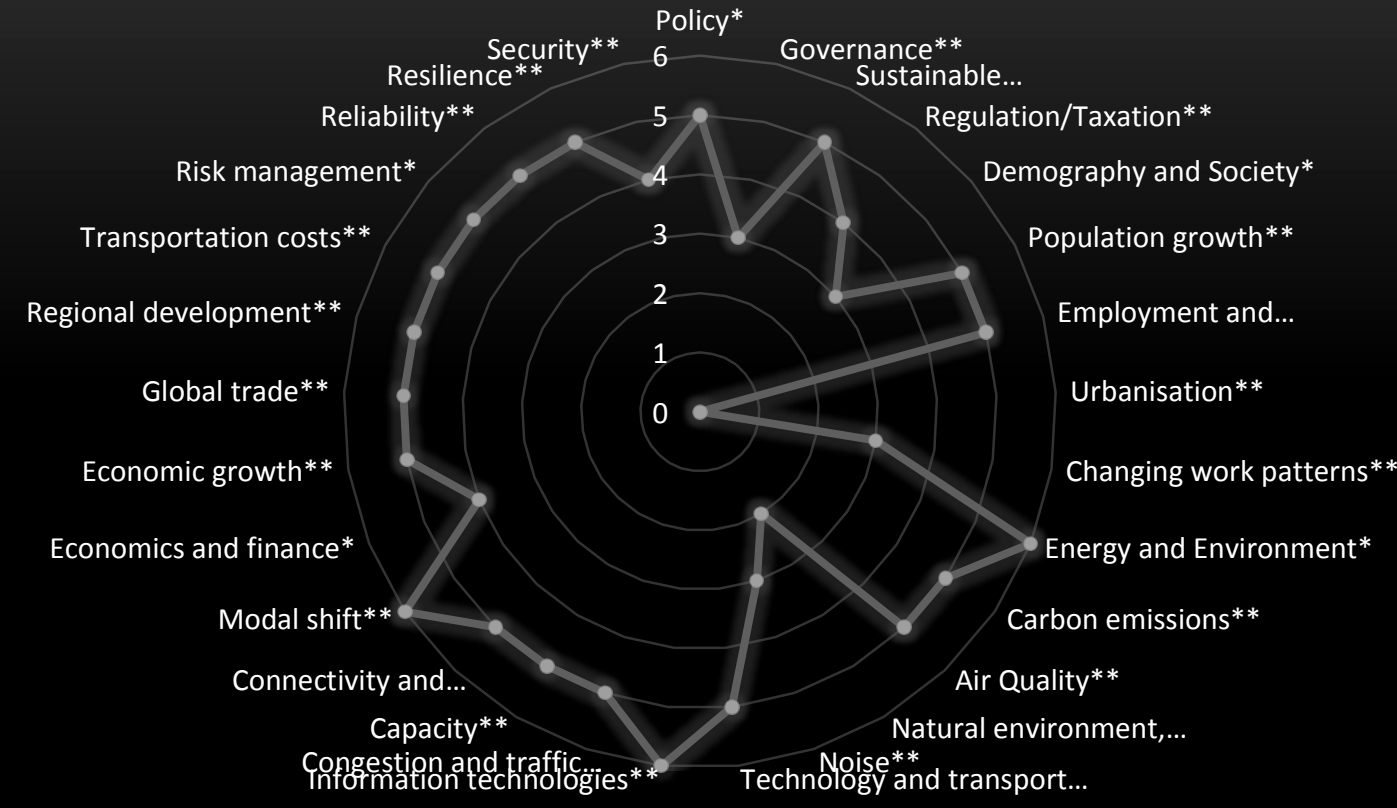

Figure B-13: Radar chart representation of future growth scenario of sustainable development for the Daventry Rail Freight Project 


\section{B-3: Regional priority projects in France}

\section{The maritime container shuttle project between Le Havre and Caen}

This project is a partnership agreement between the Ports of Normandy (PNA) and the Port of Le Havre with a view to setting up a maritime container shuttle service.

\section{Location and overview of the project}

The project's proposal will pave the way for a strengthening the co-operation in the Baie de Seine between the two entities, covering Caen-Ouistreham and Cherbourg on the one hand, and Le Havre on the other. According to participants of the focus group, the project's proposal will pave the way for a strengthening the co-operation in the Baie de Seine between the two entities, covering Caen-Ouistreham and Cherbourg on the one hand, and Le Havre on the other. It is still unclear what is the time frame and total budget of the project as the technical feasibility study is on-going.

More specifically the proposal's objectives are to:

- Reduce road transport to release congestion and pollution.

- Reduce carbon emissions.

- Reinforce the competitiveness of the regions.

- Develop freight multimodal transport.

The project's proposal is of great significance for the megaregion of North West Europe as it will establish intermodal links with other modes of transport and also it will help to reduce congestion on the road network between Le Havre and Caen. It will also help to reduce carbon emission by transporting by sea 15000 TEU per year currently transported by road (10 000 trucks), 50000 TEU could be considered in the long term. If the project's proposal is approved and gets funding there will be several benefits to the users and industrial sectors in the area that will benefit from the project. 
More specifically this project will benefit to:

- Ports Normands Associés by increasing its container traffic.

- $\quad$ Le Havre Port and HAROPA.

- Carriers and end users by reducing the waiting time.

\section{SWOT analysis with emphasis to congestion and modal shift}

The project's proposal has a strong point as it proposes to develop a maritime traffic link between Le Havre and Caen. This will result in the reduction of trucks on the region's road network. However the proposal's weak point is that the cost comparison to the use of road is not in favour of the proposed maritime link although there are opportunities for a $15 \%$ increase in container traffic by 2030 .

\section{Bottlenecks that the project aims to reduce in the region}

There are two key areas of pressure that the proposed infrastructure development project aims to deliver significant improvements for. The first one is the congestion that exists on the A13 motorway between Le Havre and Caen as the new motorway of the sea will attract more freight flows off the road. Also the project will reduce the waiting times in the ports that will be involved in the project.

\section{Overview of co-modality growth and scenarios by 2030}

Respondents in the focus group has given a high growth scenario label for the development of co-modality by 2030 to the specific project proposal. This is because the partnership agreement between the different stakeholders will create additional freight traffic for the region and consequently will increase the capacity in the available infrastructure to handle such volumes. 


\section{Sustainable development scenarios by 2030}

The following radar chart models the scores given during the evaluation process for the maritime container shuttle project between Le Havre and Caen. Moreover, it gives an overview of the significant impact scenarios that the project is likely to have to the transport system that it is a part of by the year 2030 .

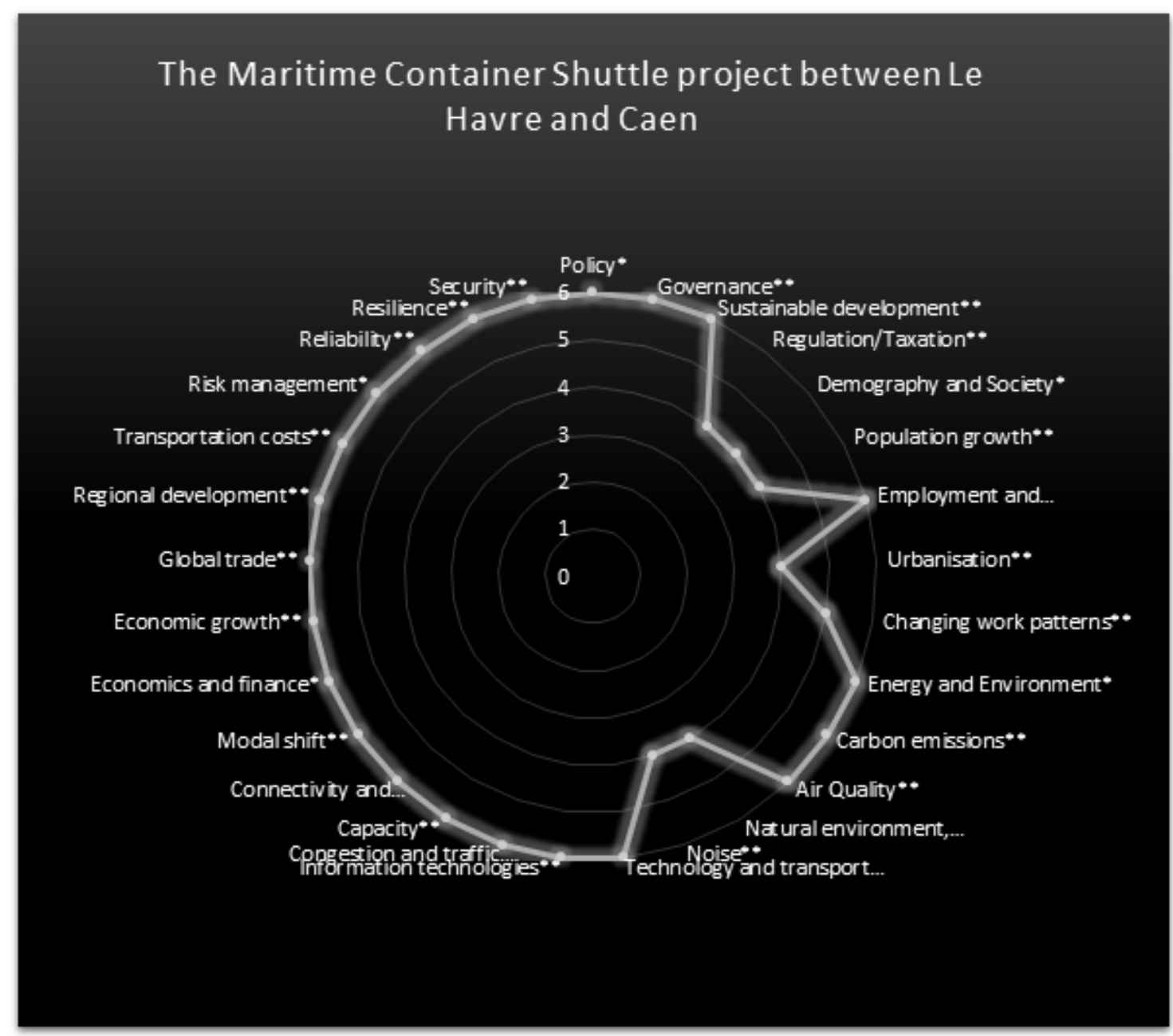

Figure B-14: Radar chart representation of future growth scenario of sustainable development for the Maritime Container Shuttle project between Le Havre and Caen 


\section{The new railway line project between Paris and Le Havre}

The proposed new line Paris-Normandie is designed to improve the movement of passengers and freight between Le Havre and Paris.

\section{Location and overview of the project}

The project is planned into two construction phases with the first starting in 2020 and the second in 2030 and is expected to cost over $€ 100 \mathrm{~m}$.

The specific objectives of the proposed new railway line are the following:

- To remove bottleneck and congested areas.

- To develop the transport of freight by rail.

- To increase rail capacity.

- To reduce road transport and release congestion.

- To reduce carbon emissions.

- To reinforce the competitiveness of the regions and the Ports.

- To develop freight multimodal transport.

- To help to face the competition of the Northern ports.

- To develop the hinterland of Le Havre Port and HAROPA.

The project is expected to contribute to the sustainable development of the emerging megaregion of North West Europe in the long term as the project will help to release congestion on the rail network and to offer more multimodal capacity for freight. It is linked with the project of modernization of the rail network from Gisors to Serqueux. There is a significant demand from carriers for freight transport massification from Le Havre, with an objective of 2025 to increase the modal share of rail from $15 \%$ to $25 \%$. By increasing the level of service of the railway network, the project will go with the port development and will benefit all the companies involved in freight transportation. It will support economic national growth. 


\section{SWOT analysis with emphasis to congestion and modal shift}

The SWOT analysis provided by participants of the focus group revealed that one of the core competencies of the project's proposal is that the construction of a new railway line will increase the level of services of the railway network for freight transportation and reduce congestion. However, a long term project regarding Le Havre port development is the entry into service of the multimodal platform of Le Havre Port. The project does not treat the bottleneck in Paris where the traffic is very important. The opportunities for the logistics sector are great as the existing railway line will be used for freight movement only and the new one will service passenger transport. Funding uncertainties nevertheless could pose a threat for the future development of the project.

\section{Bottlenecks that the project aims to reduce in the region}

The proposed project is expected to have an impact in the areas of Rouen and the congested area of Mantes (just before Paris) where the traffic is very important.

\section{Overview of co-modality growth and scenarios by 2030}

The new railway line between Le Havre and Paris is expected to achieve high growth comodality development as there will be increased port traffics in Le Havre.

\section{Sustainable development scenarios by 2030}

The following radar chart models the scores given during the evaluation process for the new railway line project between Paris and Le Havre. Moreover, it gives an overview of the significant impact scenarios that the project is likely to have to the transport system that it is a part of by the year 2030 . 


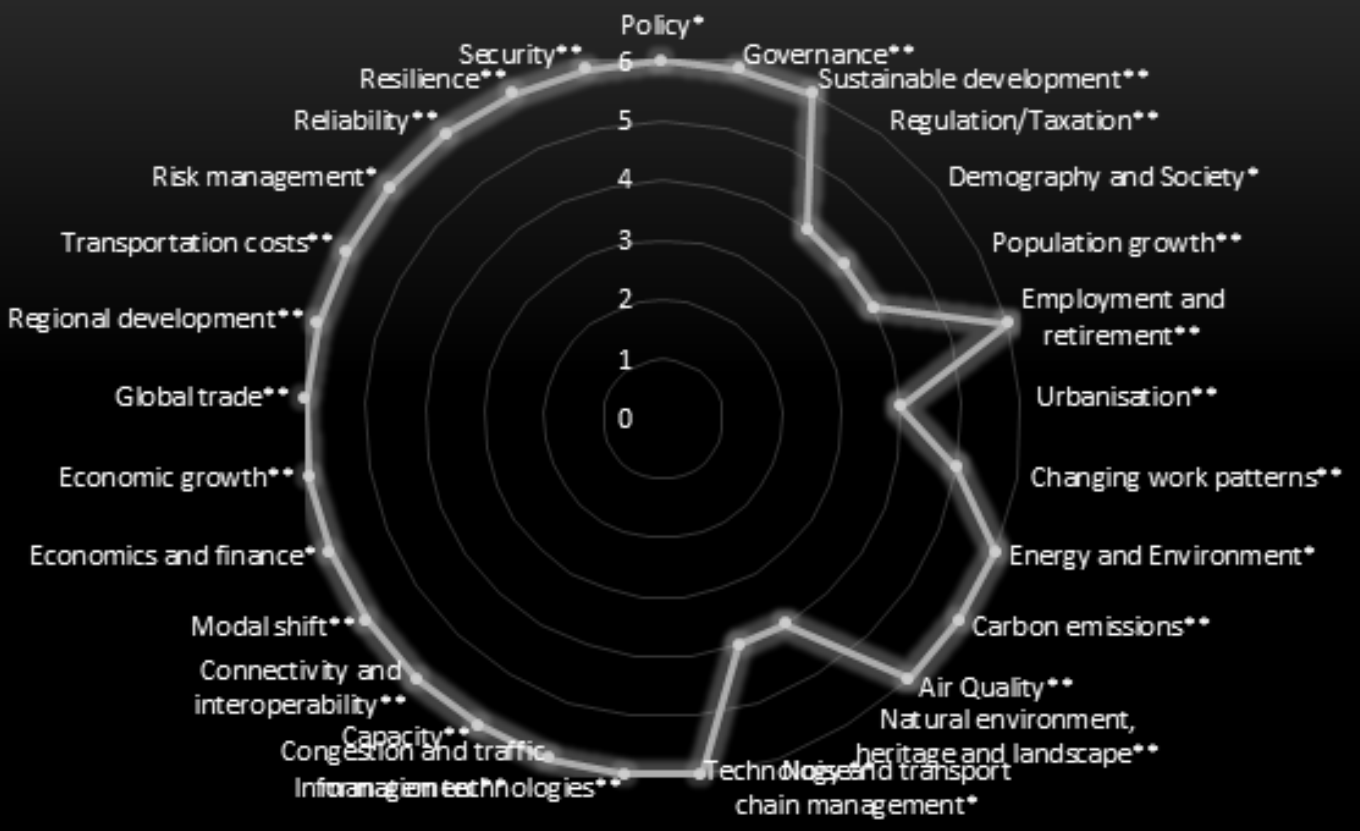

Figure B-15: Radar chart representation of future growth scenario of sustainable development for the new railway line project between Paris and Le Havre 


\section{The multimodal terminal project in the Port of Le Havre}

The Port of Le Havre plans to build a new multimodal terminal that will act as a transfer platform for the transshipment of containers and trailers between rail and barge.

\section{Location and overview of the project}

According to participants of the focus group the project is funded from the public sector and has a budget of over $€ 100 \mathrm{~m}$.

The project's specific objectives are the following:

- To facilitate the transport of goods in the port area.

- To develop rail and river transport.

Upon completion the project is expected to contribute to the sustainable development of the megaregion of North West Europe as the multimodal terminal will facilitate freight flows, relieve congestion in port areas and enhance intermodal freight transport. The users and industrial sectors in the area will enjoy also the following benefits:

\section{Environmental benefits:}

- Less congestion resulting in less carbon emissions (500 000 tons of CO2 saved each year) through the reduction of the number of trucks on the road.

- Development of multimodal solutions (15\% to $25 \%$ increase of modal transport share before 2020).

\section{Economic benefits:}

- Cost reduction thanks to the massification of goods 


\section{Transport benefits:}

- Time-saving through the reduction of time transfer and direct access to the port terminal.

- Increased storing capacity.

- New rail terminal with eight tracks with direct access.

- Increased possibilities to pool goods and provide cost reduction for the customer.

- New logistics services.

- Facilitate access to the Ile-de-France region and Paris.

\section{SWOT analysis with emphasis to congestion and modal shift}

The SWOT analysis carried out by participants of the focus group revealed that the Le Havre port's multimodal terminal key strength will be its ability to provide multimodal transport solutions to lower $\mathrm{CO} 2$ emissions, reduce costs by pooling goods and release congestion in specific areas. Also the opportunity will be given to increase the port's handling capacity. However, its major weakness is the current impact of the construction works to the environment. The terminal which is built next to a natural bird reserve could threaten to have major environmental consequences if the on-going progress is not carefully planned.

\section{Bottlenecks that the project aims to reduce in the region}

The new multimodal terminal is expected to release congestion in the Port of Le Havre as less trucks on the road will help release congestion when exiting Le Havre and when accessing the A13 motorway to Rouen/Paris and the A29 to Caen. Also it will release congestion on the bridges of Normandy and Tancarville.

\section{Overview of co-modality growth and scenarios by 2030}

For this given project respondents assigned a high co-modality development growth scenario by 2030 as the new multimodal terminal in Le Havre will allow dealing with more containers at a faster pace with a proposed maximum handling capacity of 500,000 
TEU annually. Access will also be improved to the port's terminals and multimodal and sustainable transport will be enhanced.

\section{Sustainable development scenarios by 2030}

The following radar chart models the scores given during the evaluation process for the multimodal terminal in the Port of Le Havre project. Moreover, it gives an overview of the significant impact scenarios that the project is likely to have on the transport system that it is a part of by the year 2030 .

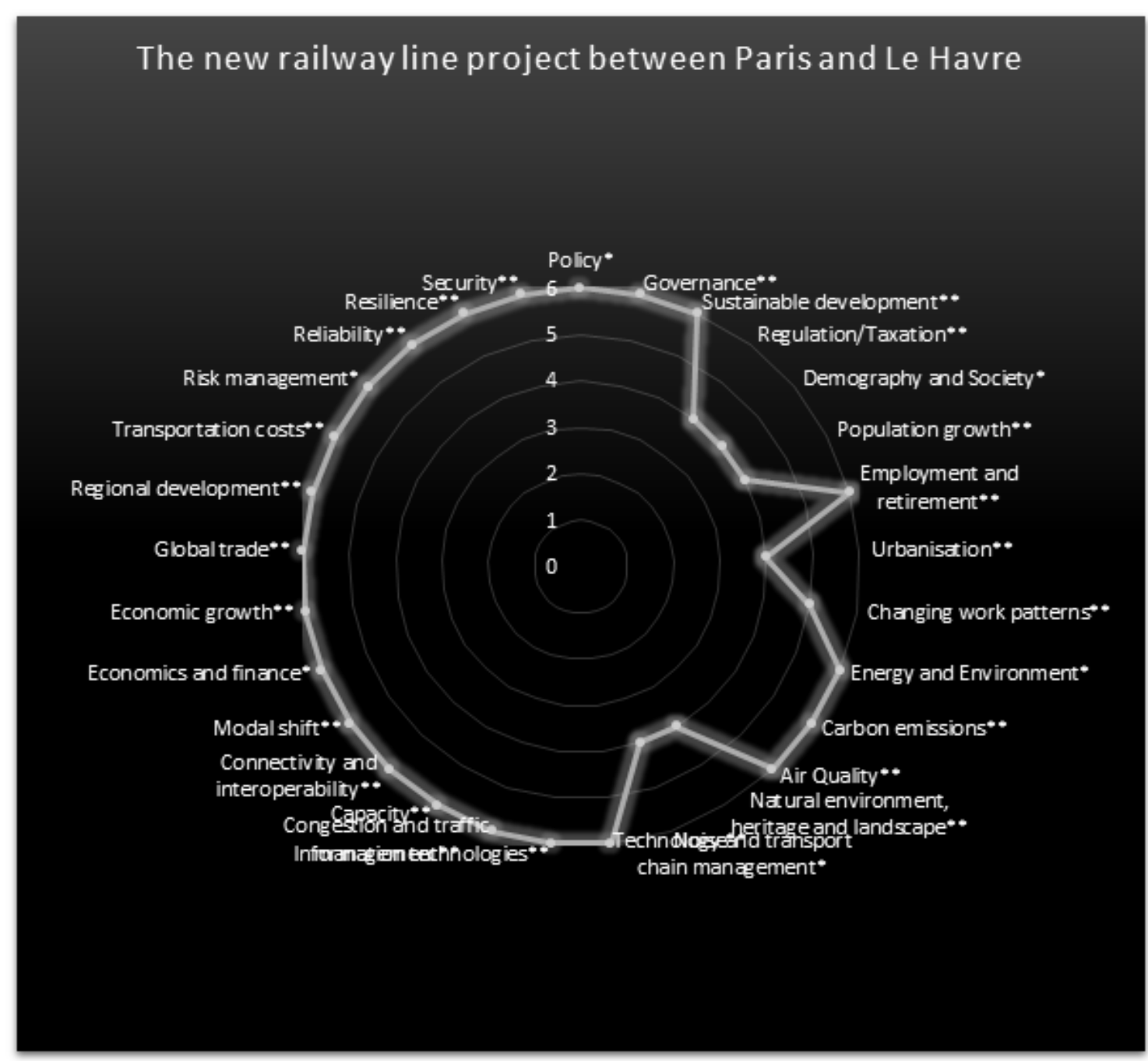

Figure B-16: Radar chart representation of future growth scenario of sustainable development for the multimodal terminal project in the port of Le Havre 


\section{The extension and renovation project of the Tancarville bridge}

The Tancarville Bridge (Pont de Tancarville in French) is a suspension bridge that crosses the Seine River and connects Tancarville (Seine-Maritime) and Marais-Vernier (Eure), near Le Havre.

\section{Location and overview of the project}

The extension and renovation of the Tancarville bridge is an on-going project which started in April 2014 and it is expected to be completed by the end of 2016. The project is funded by the public sector with a total budget in the region of $€ 75 \mathrm{~m}$ to $€ 100 \mathrm{~m}$.

The project's specific objectives are to:

- To release congestion on the bridge.

- To facilitate circulation of trucks and cars.

Upon completion the expanded and renovated bridge will facilitate access and circulation on the bridge and allow dealing with the increasing number of trucks. It will relieve congestion and allow saving time and reduce $\mathrm{CO} 2$ emissions.. Also the many users and industrial sectors in the area will benefit from the project in the long term. Some of the benefits provided by participants of the focus group are the following:

\section{Environmental benefits:}

- The new facilities will be built according to environmental standards

- Special car parks dedicated to carsharing will be built

- Less congestion will allow a reduction of $\mathrm{CO} 2$ emissions

\section{Transport benefits:}

- Circulation will be facilitated which will reduce waiting times for trucks

- Less accidents by securing lanes and traffic 
- Decongestion of the bridge which is a major axis to Paris and to the Port-Jerome industrial zone

\section{SWOT analysis with emphasis to congestion and modal shift}

It is forecasted that by 2030, around 22,500 vehicles on daily basis will cross the bridge. Almost $25 \%$ of the total number of vehicles is expected to be HGVs and the expansion of the bridge will give a strong competitive advantage to this critical transport infrastructure project as accessibility will be improved and so will the flows of vehicles. Regrettably, one the project's weaknesses is that toll fees will be increased as a result of the improvements that will be made. Also the impact of the construction work could threaten the natural environment in the area which is very sensitive as there is a natural bird reserve. On the other hand however, the bridge will have the opportunity to serve as a major axis to Paris via the A131 motorway and also as an access point to the important industrial plant of Port Jerome.

\section{Bottlenecks that the project aims to reduce in the region}

The Tancarville bridge renovation project according the respodents will increase capacity from 18,000 vehicles per day to 22,500 vehicles per day in the long term.

\section{Overview of co-modality growth and scenarios by 2030}

Upon completion the renovated bridge is expected to realise a high growth co-modality development scenario as it will facilitate circulation on the bridge and will ease access to the road network. Moreover it will allow reducing waiting time and therefore $\mathrm{CO} 2$ reductions.

\section{Sustainable development scenarios by 2030}

The following radar chart models the scores given during the evaluation process for the Tancarville bridge renovation project. Moreover, it gives an overview of the significant impact scenarios that the project is likely to have on the transport system that it is a part of by the year 2030 . 


\section{Extension and renovation of the Tancarville Bridge}

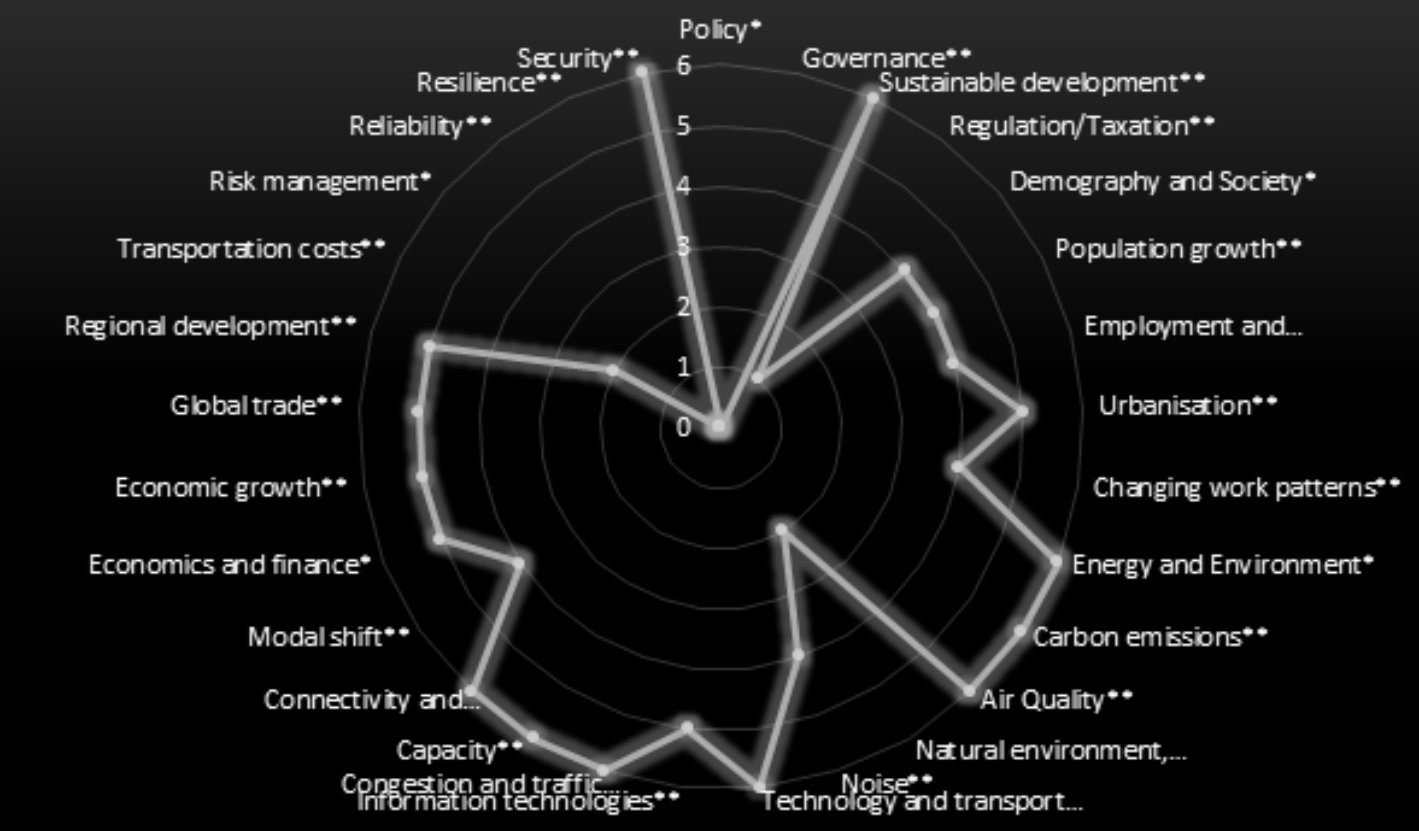

Figure B17: Radar chart representation of future growth scenario of sustainable development for the Tancarville bridge renovation project 


\section{The modernisation of the rail network project from Gisors to Serqueux}

\section{Location and overview of the project}

The modernisation of the rail network from Gisors to Serqueux project according to participants of the focus group is funded from the public sector.

The total budget of the project will be in excess of $€ 100 \mathrm{~m}$ and the objectives set to achieve will be:

- To release some traffic from the congested Paris-Rouen-Le Havre network.

- To create a new route to reinforce the rail servicing of Port of Le Havre.

- To increase rail capacity.

- To reduce road transport to release congestion.

- To reduce carbon emissions.

- To reinforce the competitiveness of the regions.

- To develop freight multimodal transport.

- To help to face the competition of the Northern ports.

The project will make a significant contribution to the sustainable development of the megaregion of North West Europe as it will help to release congestion on the rail network and to offer more multimodal capacity. Upon completion some of the benefits that the users and industrial sectors in the area will enjoy are the following:

\section{Environmental benefits:}

- Reduction of CO2 emissions.

- Preservation of the natural and living environment.

- Noise protection with new equipment (walls, soundproofing homes...).

- Vibration protection : reduce the risk for houses and buildings. 


\section{Social benefits:}

- Improvement of accessibility of rail stations for disabled people.

- Suppression of level crossings to reinforce security.

- Reintroduction of passenger traffic on this line.

- Addition of more transport capacity.

\section{Economic benefits:}

- Support sustainable growth of Port of Le Havre.

- Support economic regional growth.

- Reinforce local competitiveness.

- Development of freight transport.

\section{Transport benefits:}

- $\quad$ Reinforcement of rail capacity.

- Decongestion of roads and congested rail network.

- Development of massified rail transport.

- Development of freight capacity.

- Less congestion resulting in lower carbon emissions.

\section{SWOT analysis with emphasis to congestion and modal shift}

The new line will provide relief to the heavily congested line from Rouen-Rouen-le Havre. However, due to a number of constraints, the number of trains that can be additionally serviced on this line is 25 trains maximum per day. Also another weakness is that this line is going through an area with limited population and potential shippers. The opportunities that can be utilised are many starting by the fact that the new line will also be able to release congestion when needed on the Rouen - Mantes axis often overloaded. Also this new line will also allow bypassing the city of Paris which is always congested and link other rail networks to the East and the North of France. According to 
the participants of the focus group the project might not get additional funding for the second phase and also it may not attract enough customers both from the passenger and the freight sector as in the region the population is low and there are not many industrial users.

\section{Bottlenecks that the project aims to reduce in the region}

The main rail network going from Paris-Rouen-Le Havre and servicing the Port of Le Havre which is heavily congested. This new project will help release congestion on this overloaded line. This new line will also, if needed, be used to release congestion on the Rouen-Mantes line which is often congested.

\section{Overview of co-modality growth and scenarios by 2030}

Upon completion the modernised rail line is expected to realise a high growth co-modality development scenario based on the following reasons provided by the respondents:

- This new line will ease access to the Port of Le Havre.

- It will enhance sustainable development and multimodal transport.

- It will enhance regional development and especially the hinterland.

\section{Sustainable development scenarios by 2030}

The following radar chart models the scores given during the evaluation process for the Gisors to Serqueux rail link project. Moreover, it gives an overview of the significant impact scenarios that the project is likely to have to the transport system that it is a part of by the year 2030 . 


\section{Modernisation of the rail network from Gisors to Serqueux}

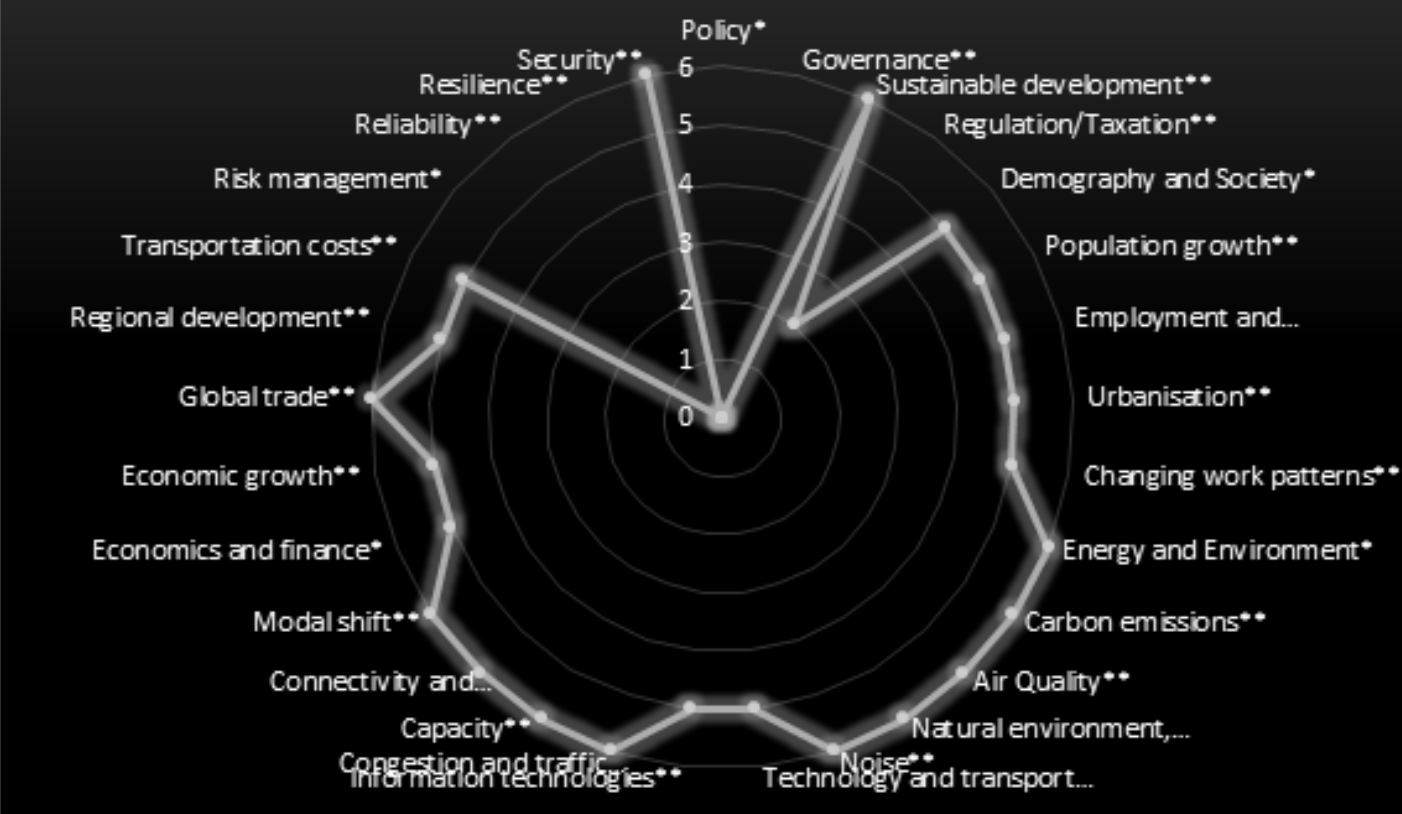

Figure B-18: Radar chart representation of future growth scenario of sustainable development for the modernisation of the rail network from Gisors to Serqueux project 


\section{Bypass Rouen}

By creating a direct link between the A28, north-east of Rouen and the A13, south-west of Rouen, the project aims to divert part of the transit traffic, including lorries, and keep on a motorway infrastructure.

\section{Location and overview of the project}

According to participants of the focus group the project has been taken both from the private and public sectors. The best case scenario projects that construction works will begin in 2020 and the total budget will be over $€ 1 \mathrm{bn}$.

The main objectives of the project are to:

- At a European scale link North / South from Calais to Spain.

- At a national level, ensure a continuous bypass to Paris area via highways.

- At a regional level, improve access to Rouen port's terminals, enhance links between the Port of Le Havre and the Port of Rouen, and encourage economic growth of Rouen's agglomeration.

- Link between two motorways A28 and A13.

- At local scale, ensuring a better fluidity in transport in order to:

- Relieve congestion in the city center.

- Improve public transport in the agglomeration as a whole.

- Restore links between opposite hills.

The project proposal has the potential to integrate intermodal connectivity and therefore. The project will also facilitate freight flows between North and West Europe (UK via Euro Tunnel) to Normandy, and then to the South of Paris area. Upon completion some of the benefits that the users and industrial sectors in the area will enjoy are the following: 


\section{Economic benefits:}

- Creation of full-time jobs during the construction phase.

- Support economic growth of the two ports and the Normandy Region.

\section{Transport benefits:}

- Reductions in journey times in peak periods.

- Increase in journey time reliability.

- Less congestion resulting in less air pollution (-17\%).

- Reduction in accidents.

- Less traffic using this new road. Today, it is 36,000 trucks/day, including $20 \%$ transit, $20 \%$ trading and $20 \%$ internal moves.

- A major strategic new transport road linking the North city-region and the South and west to Paris area.

\section{Social benefits:}

- Improvements to public transport facilities and urban economic development of Rouen.

- Improved quality of life and health as a result of reduced air pollution.

- Better safety because of this new road.

\section{SWOT analysis with emphasis to congestion and modal shift}

The SWOT analysis carried out by participants of the focus group revealed that the bypass project will give solutions to problems that have existed in the area for more than 40 years now. However, the environmental constraints make the project more and more expensive to start. Although it could provide a strategic link between the North and the South East of agglomeration and also a metropolitan link which will facilitate the access to South of 
Paris and underneath, still the project has to deal with uncertainty until the construction phase commences.

\section{Bottlenecks that the project aims to reduce in the region}

Connecting the main clusters of Rouen and northern Eure, the project will contribute to the economic attractiveness of the Haute-Normandie. It will benefit the Seine-Nord business park, shifted to industries and multimodal logistics activities. In addition, areas of the industrial port of Port of Rouen, points of departure or arrival of most of the urban traffic exchange activities will benefit from the infrastructure with travel time by road reduced and secured.

\section{Overview of co-modality growth and scenarios by 2030}

The project should enable the business areas of Louviers Val-de-Reuil to retain their attractiveness and the inhabitants of these towns to reach easily the Rouen area. The exchanger Alizay is projected to strengthen the momentum of this business and open up new economic opportunities for the entire valley Andelle. Connecting the project with the A13 and the A154 in the south end should also enhance the attractiveness of the economic center of Louviers, Val-de-Reuil. 


\section{Sustainable development scenarios by 2030}

The following radar chart models the scores given during the evaluation process for the east bypass in the Rouen area project. Moreover, it gives an overview of the significant impact scenarios that the project is likely to have to the transport system that it is a part of by the year 2030 .

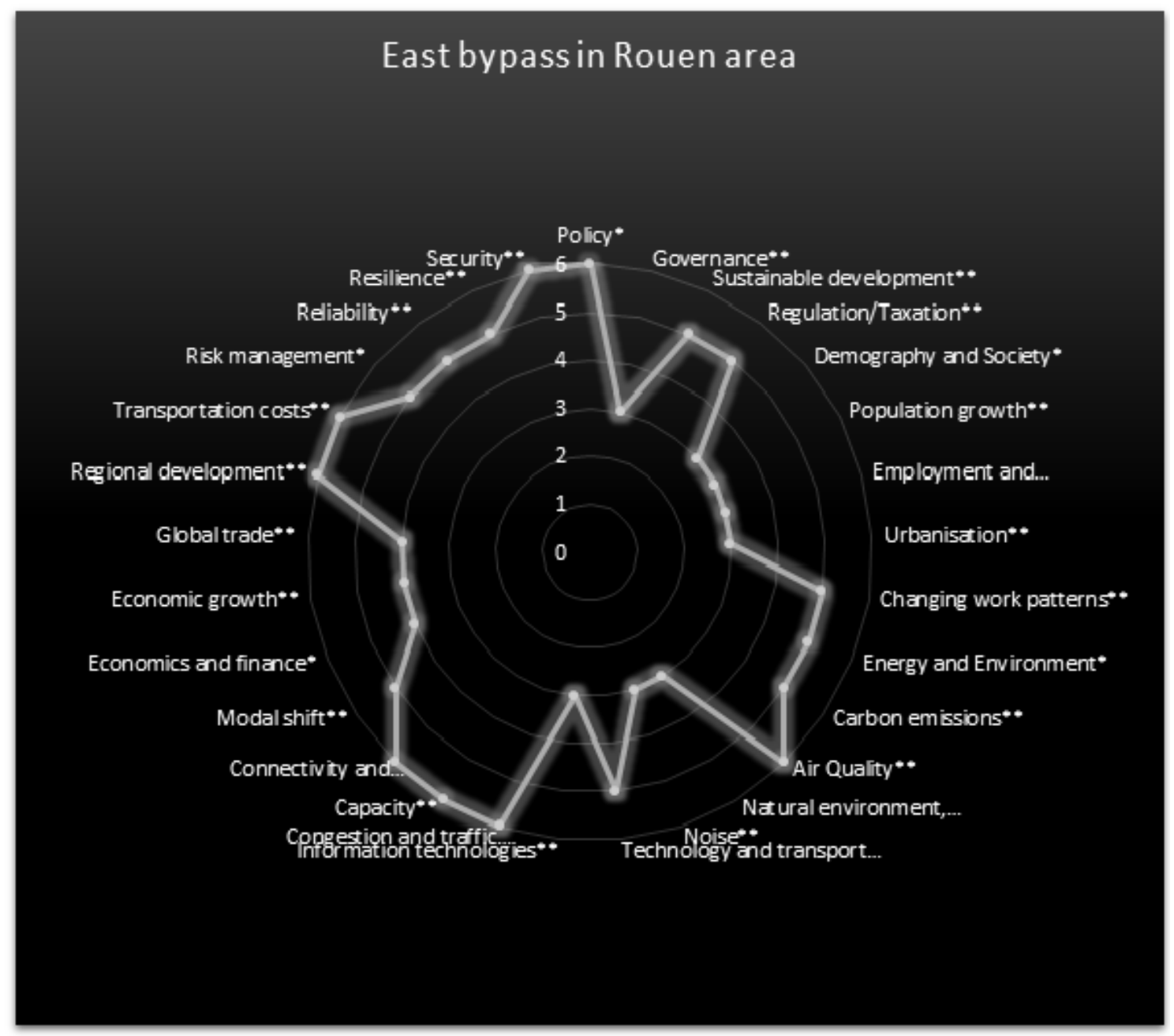

Figure B-19: Radar chart representation of future growth scenario of sustainable development for the Rouen bypass project 


\section{The Laoutebourg platform extension project}

\section{Location and overview of the project}

Within the Upper Rhine, the extension of the Port of Lauterbourg is one of the last opportunities for land development along the banks of the Rhine. Set in the heart of a dynamic and fully recognised economic area, at the crossroads of important European transport routes, it benefits from an exceptional location.

The main objectives of the project are to:

- Provide a dedicated area to host logistic added-added value operations.

- Develop container operations by setting up a new container terminal.

- Enhance interconnectivity between inland waterways, roads and railways alongside the French Rhine region.

The Port of Strasbourg has chosen the Lauterbourg site to meet the growing needs of container traffic by setting up a new container terminal by 2014. The project has good synergies as it will help to increase the modal share of IWW and shift traffic from roads.

Upon completion some of the benefits that the users and industrial sectors in the area will enjoy are the following:

\section{Economic benefits:}

- Equipped site of 48 ha to host logistic related activities.

- The project will generate 1000 permanent jobs.

\section{Transport benefits:}

- The Lauterbourg platform will enhance the connection between inland waterways, road, and railways. 
- The project will improve access to Rhine River for local enterprises.

\section{SWOT analysis with emphasis to congestion and modal shift\#}

One of the strong points of the Port of Lauterbourg is its location on the border between France and Germany, close to Port of Strasbourg and linked to inland waterways, roads and railways. The Port also takes advantage of its direct connection to the major maritime ports (Antwerp, Rotterdam and Amsterdam), with no locks between the Port of Lauterbourg and the maritime ports.

\section{Bottlenecks that the project aims to reduce in the region}

The project will help to shift road traffic from the Upper Rhine region towards major ports of the North Sea. Although industries located in the Port of Lauterbourg already benefit from the advantage of multi-modal transport, the port services will be reinforced by the construction of a new container terminal.

\section{Overview of co-modality growth and scenarios by 2030}

Upon completion the project is expected to realise a high growth co-modality development scenario based on the following reasons provided by participants of the focus group:

- The platform will enhance access to inland waterways from roads and railways.

- It will increase containerised transport capacity alongside the Rhine River.

\section{Sustainable development scenarios by 2030}

The following radar chart models the scores given during the evaluation process for the Lauterbourg platform extension project. Moreover, it gives an overview of the significant impact scenarios that the project is likely to have to the transport system that it is a part of by the year 2030 . 


\section{The Lauterbourg platform extension project}

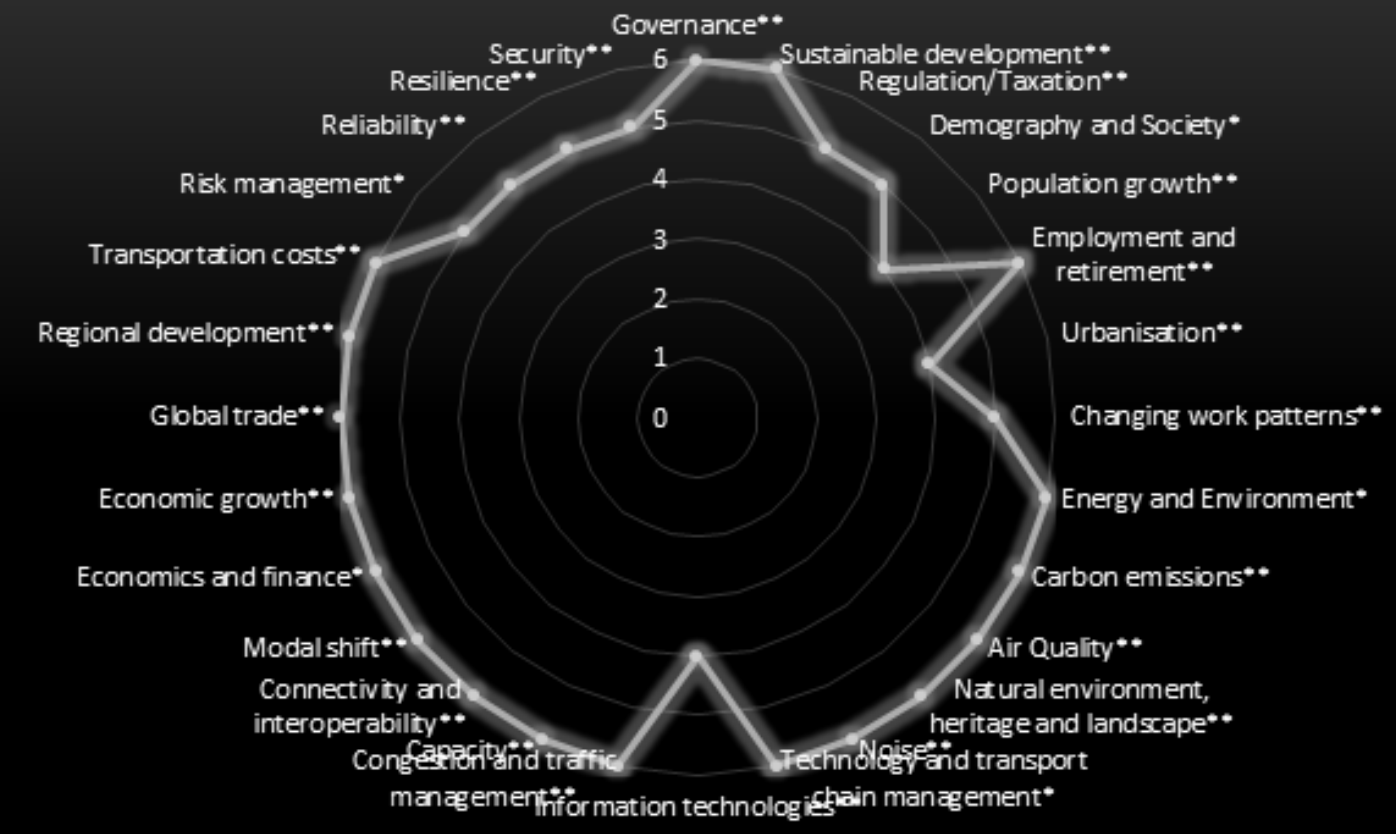

Figure B-20: Radar chart representation of future growth scenario of sustainable development for the Laouterbourg platform extension project 


\section{B-4: Regional priority projects in Belgium}

Participants of the focus group identified six critical infrastructure projects in their region of interest. These are the following:

- The Luxembourg Freeport.

- The new Luxembourg - Bettembourg rail link.

- Zeebrugge Open.

- The A11 motorway.

- The Liege Trilogiport.

- The Iron Phine. 


\section{The Luxembourg Freeport project}

The Luxembourg Freeport - a high-end and contemporary facility for storage, handling and trading of valuable goods such as works of art, precious metals, wine, jewellery... will change the landscape of the Luxembourg airport for the better. The four storey $21,000 \mathrm{~m} 2$ facility is being constructed on a prime location at the Luxembourg airport next to the Air Cargo Terminal, which is the 5th largest air cargo hub in Europe.

\section{Location and overview of the project}

This is a privately funded project in the region of $€ 50 \mathrm{~m}$ to $€ 75 \mathrm{~m}$ which is expected to be completed by the end of September 2014. The main objectives of the project are to:

- Provide warehousing facilities of various sizes for the storage of high value goods including works of art, precious metals, wines, antiques, vintage cars, jewellery, antiques, watches, gems, carpets and archives.

- Offer show spaces for the display and photography of stored goods.

- Provide workshops for handling, packaging, and restoration of stored goods.

- Offer in situ shipping, insurance, handling, clearance formalities.

- Connect directly the Luxembourg Airport tarmac to road.

The project is expected to offer additional warehousing facilities in the region and according to participants there are very good synergies. Upon completion the users and industrial sectors in the region will enjoy the benefits that the project will offer.

More specifically:

\section{Economic benefits:}

- Value added services (packaging, framing, restoration, photographing etc.) performed in the Freeport on the stored goods and are VAT exempt.

- The Freeport acts as a free trade zone, benefiting from suspended VAT or customs duties. 
- Banks based in Luxembourg can also benefit from the new warehouse, with a possibility to outsource storage of valuable goods.

\section{Transport benefits:}

- Increase storage capacity within the Luxembourg Airport area.

- 24-hour security and the latest safety technology.

- A one-stop-shop directly connected to the airport tarmac offering services ranging from shipping and packaging to custom clearing and restoration of stored goods.

\section{Social benefits:}

- 250 jobs on site during the construction phase.

- Generating 50 to 100 jobs for both qualified and unqualified people.

\section{SWOT analysis with emphasis to congestion and modal shift}

According to the SWOT analysis provided by participants of the focus group the project is not expected to deliver any significant intermodal core competencies. The lack of connectivity with other modes of transport such as inland waterways and rail is one of its major weaknesses but the proximity with Luxembourg Airport $\left(5^{\text {th }}\right.$ busiest cargo airport in Europe) and the Luxembourgish VAT exempt legislation provides the opportunity to capture more logistic flows. This could also be a threat as the Freeport will generate more road freight flows.

\section{Bottlenecks that the project aims to reduce in the region}

The project is expected to add a new link between the air and the road mode and it will be located very close to the existing cargo centre. 


\section{Overview of co-modality growth and scenarios by 2030}

Upon completion the new facility is expected to realise a high growth co-modality development scenario based on the following reasons:

- The Freeport is unique of its kind in the European Union. The other similar existing facilities are located in Geneva and Singapore.

- The project will benefit from the Luxembourgish know-how in air freight transport.

\section{Sustainable development scenarios by 2030}

The following radar chart models the scores given during the evaluation process for the Luxemburg Freeport project. Moreover, it gives an overview of the significant impact scenarios that the project is likely to have on the transport system that it is a part of by the year 2030 . 


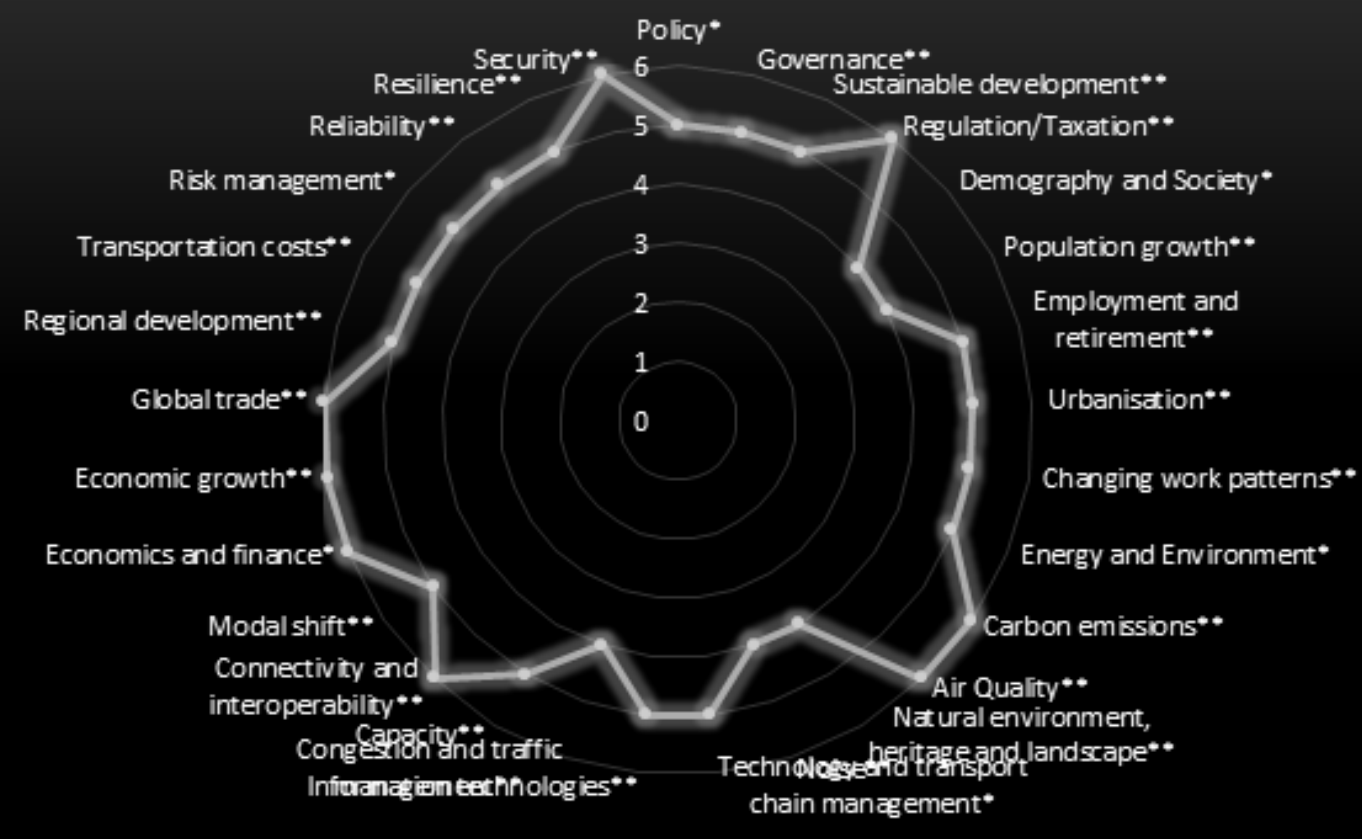

Figure B-21: Radar chart representation of future growth scenario of sustainable development for the Luxembourg Freeport project 


\section{The new Luxembourg - Bettembourg rail link project}

The project of the new railway line from Luxembourg to Bettembourg aims to put a double track of approximately $7 \mathrm{~km}$ in place from Luxembourg to Bettembourg, without stops.

\section{Location and overview of the project}

This will be a project funded from the public sector and its construction phase is expected to last five years from 2015 to 2020 .

According to participants of the focus group the main objectives of the project are to:

- Relieve the existing railway between Luxembourg and Bettembourg from traffic.

- Support efforts toward intermodal transport between Luxembourg-city, Southern regions and the Lorraine.

- Create new railway nodes in Luxembourg city suburban area.

The new railway line from Luxembourg to Bettembourg project it expected to contribute significantly to the sustainable development of the emerging megaregion of North West Europe as it will help increase the modal share of rail transport, and shift traffic from congested existing rail and road infrastructure. Upon completion the users and industrial sectors in the region will enjoy the benefits that the project will offer.

More specifically:

\section{Economic benefits:}

- Develop both passenger and freight services between Luxembourg-city and the Bettembourg and Lorrain region

- The project will generate on site jobs during construction 


\section{Transport benefits:}

- Enhance connectivity between Luxembourg-city and Bettembourg

- Develop cross border rail transport between Luxembourg and France

- Support shifting traffic from road to rail for both passenger and freight flows

\section{Social benefits:}

- Bring the rail infrastructure close to the road in order to minimise the impact on the landscape

\section{SWOT analysis with emphasis to congestion and modal shift}

One of the main strengths of the project is that the railway will link Luxembourg-city with the southern demographic area and France, where many frontier workers live. The Bettembourg region also hosts an important rail-road freight platform.

According to participants of the focus group the main weakness and threats that the project is facing is that it could be difficult to acquire enough land that is required for the construction phase. However, as well as providing a new link between Luxembourg-city and Bettembourg, the railway will enhance rail connectivity between the city, the suburban areas and Lorrain region.

\section{Bottlenecks that the project aims to reduce in the region}

The project will help in the shifting of traffic from the A31 road and the new line will increase the capacity of the rail corridor between Luxembourg and Bettembourg. Moreover, the new link will allow enhancing rail connectivity between downtown Luxembourg-city and suburban areas. 


\section{Overview of co-modality growth and scenarios by 2030}

Upon completion the new railway link is expected to realise a high growth co-modality development scenario based on the following reasons provided by participants of the focus group:

- The railway will facilitate seamless connection between Luxembourg city and the Bettembourg areas.

- It will enhance sustainable development.

- It will add a new link to the nearby multimodal terminals of Bettembourg. 


\section{Sustainable development scenarios by 2030}

The following radar chart models the scores given during the evaluation process for the new Luxemburg - Bettembourg rail link project. Moreover, it gives an overview of the significant impact scenarios that the project is likely to have on the transport system that it is a part of by the year 2030 .

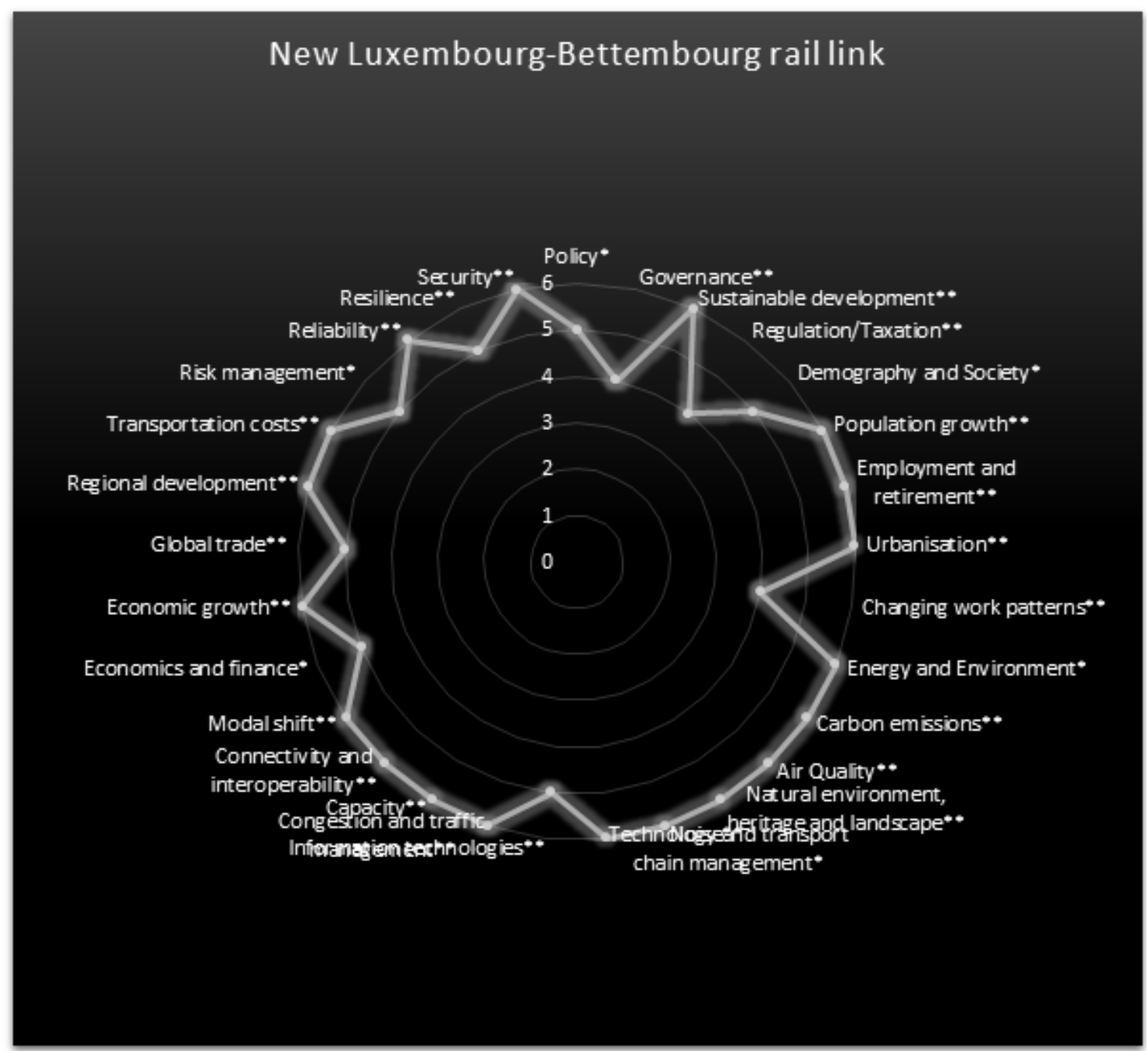

Figure B-22: Radar chart representation of future growth scenario of sustainable development for the Luxembourg - Bettembourg rail link project 


\section{The Zeebrugge open project}

\section{Location and overview of the project}

The main objectives of the project are to:

- Improve the port of Zeebrugge's maritime access.

- Upgrade the existing marshalling yards.

- Enhance the connectivity between maritime facilities and other transport modes: roads, railways and inland waterways.

- Strengthen the landscape preservation and access to riparian residents.

According to participants of the focus group this is an on-going project funded from both the private and the public sectors with a total budget of over $€ 100 \mathrm{~m}$. Although, the timeframe of this project is somehow unclear it is believed that the project will have a positive impact on sustainable development as the project will enhance the maritime access and connectivity between four different modes in the Zeebrugge port area.

Upon completion the users and industrial sectors in the region will enjoy the benefits that the project will offer. More specifically:

\section{Economic benefits:}

- The project will strengthen the port of Zeebrugge's important role in generating jobs in the West-Flanders region.

- It will improve the attractiveness of the port vis-à-vis companies relying on maritime transport. 


\section{Transport benefits:}

- The Zeebrugge Open project aims to upgrade maritime access to the port of Zeebrugge

- It will improve intermodal connections in the port area.

- It will increase transport capacities by upgrading rail infrastructure and the existing marshalling yard.

\section{Social benefits:}

- The project includes the creation of green spaces and new safe cycling roads linking the port to the adjacent villages.

\section{SWOT analysis with emphasis to congestion and modal shift}

The SWOT analysis carried out by participants of the focus group revealed that the project is supported by the steady growth of economic activity in the port of Zeebrugge and that the new "Seine-Scheldt - West" canal will create opportunities for more freight flows to Belgian ports. However, one of its major weaknesses is that the new A11 will lead to additional roads flows.

\section{Bottlenecks that the project aims to reduce in the region}

The bridge will facilitate seamless maritime access to the port of Zeebrugge and overall the project will improve railway and inland waterways connection in the port. It will also help to reduce the levels of congestion on the road network by building additional capacity.

\section{Overview of co-modality growth and scenarios by 2030}

Upon completion the Zeebrugge open project is expected to realise a high growth comodality development scenario based on the following reasons provided by participants of the focus group: 
- It will improve connection between the sea, roads, inland waterways and railways.

- It will enhance sustainable development.

\section{Sustainable development scenarios by 2030}

The following radar chart models the scores given during the evaluation process for the Zeebrugge Open project. Moreover, it gives an overview of the significant impact scenarios that the project is likely to have on the transport system that it is a part of by the year 2030 .

\section{Zeebrugge Open}

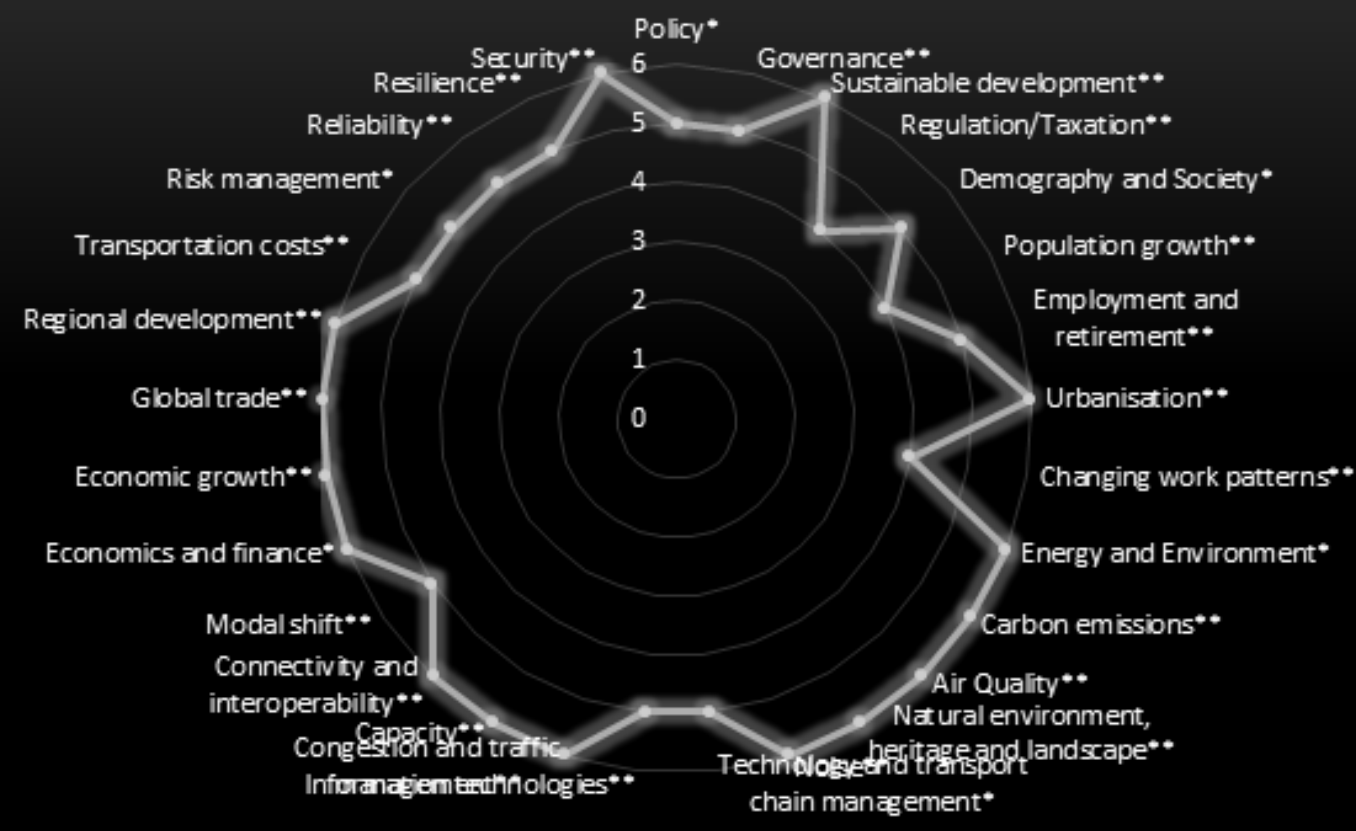

Figure B-23: Radar chart representation of future growth scenario of sustainable development for the Zeebrugge open project 


\section{The A11 motorway project}

\section{Location and overview of the project}

The A11 is a new motorway between the "Blauwe Toren" in Bruges and Knokke-Heist over a distance of $12 \mathrm{~km}$. The new motorway will ensure a better connection between the port of Zeebrugge and the hinterland. Also road safety and the quality of life in the region will be increased, by separating port traffic from local traffic. The A11 will also contribute towards the improved accessibility of the east coast of Flanders.

With a total budget in excess of $100 \mathrm{~m}$ Euros the project is funded both from the private and the public sector.

The main objectives of the project are to:

- Build a missing road section linking the port of Zeebrugge to the European roads E40 and E34.

- Increase road capacity in Flanders region.

- Improve accessibility to the port of Zeebrugge.

The synergies that this priority infrastructure project will have a positive impact on the sustainable development of the emerging megaregion of North West Europe are quite good as it will decongest the road infrastructure surrounding the port of Zeebrugge and enhance its accessibility. Upon completion the users and industrial sectors in the region will enjoy the benefits that the project will offer.

More specifically:

\section{Economic benefits:}

- The project will support sustained growth of the economic activity in the port of Zeebrugge

- It will also support the tourist economy of the Belgian coast 


\section{Transport benefits:}

- Enhance accessibility of the port of Zeebrugge

- Increase road capacity in the provinces of West-Flanders and East-Flanders

\section{Social benefits:}

- Relieve local traffic

\section{SWOT analysis with emphasis to congestion and modal shift}

The key strength of this project is its driving factor to provide relief for the existing road infrastructure around the port of Zeebrugge and complete the construction of the road link between Antwerp and Belgian coast. It also is a part of the TEN-T network. It also creates opportunities for new motorway connections for the port of Zeebrugge to its hinterland. However the project may lead to increasing the share of road transport in the region and could possibly pose a threat for an important Natura 2000 "Poldercomplex" area.

\section{Bottlenecks that the project aims to reduce in the region}

The new road section will decongest the road infrastructure surrounding the port of Zeebrugge and it will increase road capacity in the West-Flanders and East-Flanders provinces.

\section{Overview of co-modality growth and scenarios by 2030}

Upon completion the new A11 motorway is expected to realise a high growth co-modality development scenario based on the following reasons:

- The A11 is a new link between East and West Flanders 
- It will help to relief flows from existing sections of E40 and E34

- It will enhance the accessibility of the port of Zeebrugge

\subsubsection{Sustainable development scenarios by 2030}

The following radar chart models the scores given during the evaluation process for the new A11 motorway project. Moreover, it gives an overview of the significant impact scenarios that the project is likely to have on the transport system that it is a part of by the year 2030.

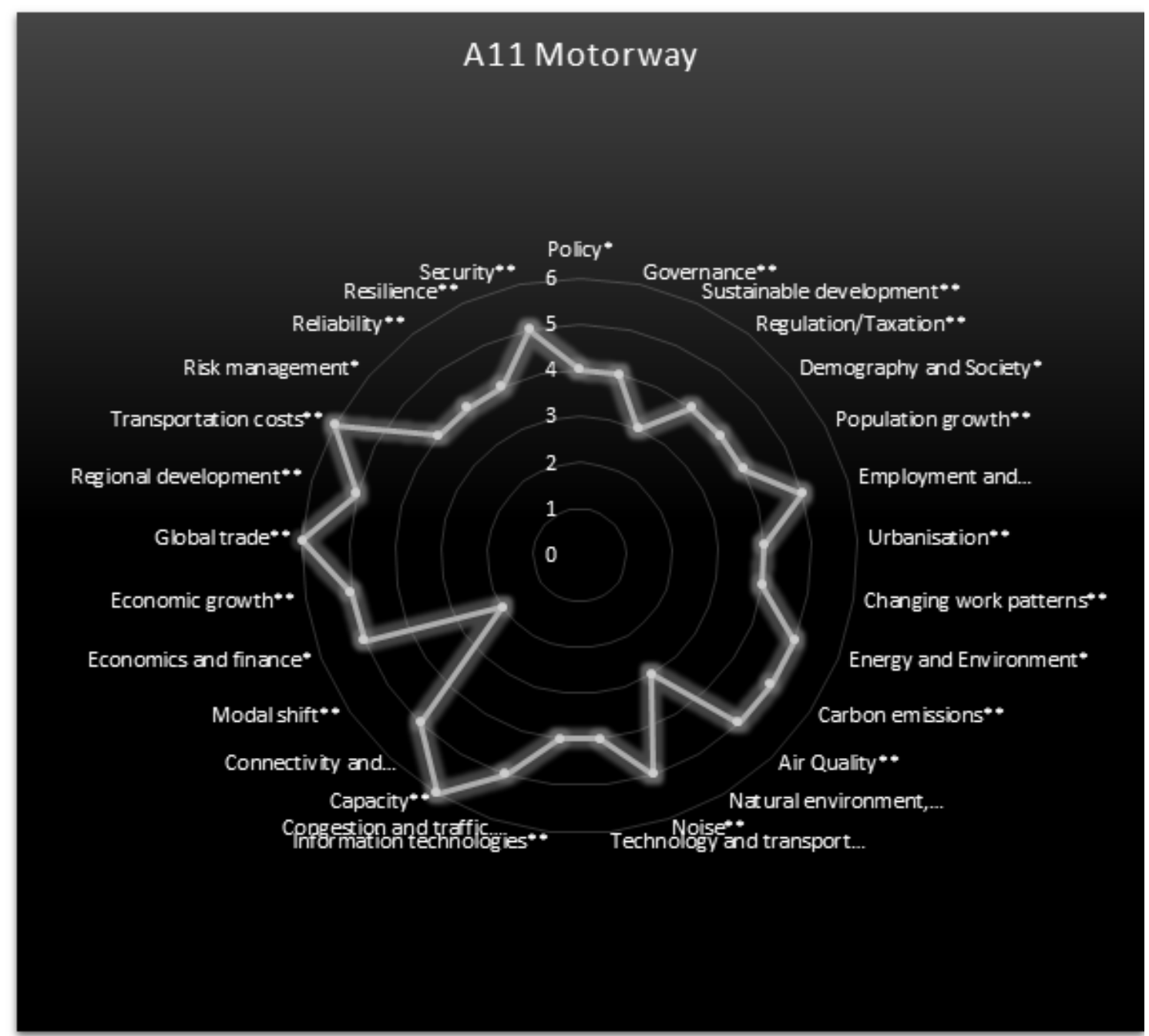

Figure B-24: Radar chart representation of future growth scenario of sustainable development for the A11 motorway project 


\section{The Liege Trilogiport project}

\section{Location and overview of the project}

As Belgium's foremost and Europe's third largest inland port (19 million tonnes in 2012), Liège Port Authority is presently developing a multimodal platform called "Liège Trilogiport" located alongside the Albert canal in Hermalle-sous-Argenteau. This future multimodal platform is soon to become a real "logistical village" in the heart of Europe.

As Belgium's foremost and Europe's third largest inland port (19 million tonnes in 2012), Liège Port Authority is presently developing a multimodal platform called "Liège Trilogiport" located alongside the Albert canal in Hermalle-sous-Argenteau. This future multimodal platform is soon to become a real "logistical village" in the heart of Europe.

The main objectives of the project are to:

- Create a trimodal logistic platform alongside the "Canal Albert".

- Offer home to European distribution centres directly connected to the container terminal.

- Improve intermodal capacity in the Liege area.

- Enhance connections with Dutch and Belgian maritime ports (Antwerp, Rotterdam).

- Support inland waterborne containerised transport in the region.

The project is currently on-going and it is expected to be finalised in October 2015. According to participants project provides excellent intermodal links and it has been funded in excess of $100 \mathrm{~m}$ Euros from both the private and the public sector. The synergies that this prioritised infrastructure project has are quite good as it will offer a seamless connection between inland waterways, road and rail in an important logistics area connecting three countries (Belgium, Netherlands and Germany).

Upon completion the users and industrial sectors in the region will enjoy the benefits that the project will offer. 
More specifically:

\section{Economic benefits:}

- The Liege Trilogiport will offer a tertiary service area of 1.8ha.

- It will generate 2000 permanent new jobs.

- It will act as a magnet for companies relying on IWW transport.

\section{Transport benefits:}

- The project will connect three modes on a same site: IWW, road and rail.

- It will improve container transport capacity on the Canal Albert.

- It will enhance the connection between Liege port and Rotterdam and Antwerp ports.

- It will develop cooperation between the three ports (Port of Antwerp joined the Economic Interest Grouping monitoring the project).

\section{Social benefits:}

- The project was arranged so as to protect riparian zones from noise.

- The project scheme includes 25 ha of green spaces and aquatic preserved areas.

- It includes the creation of an orchard, historic feature of the neighbouring villages. and the opportunity to develop a project of community gardens.

- It will offer facilities for local fishery activities.

\section{SWOT analysis with emphasis to congestion and modal shift}

The SWOT analysis carried out by participants of the focus group revealed that the Trilogiport project's key strength is its location and good connection with inland waterways, roads and railways. Also a great opportunity is provided by the project to work as a hinterland trimodal facility relieving flows from ports of the North Sea. However, one of the weaknesses identified is that the project might generate more road 
traffic in neighbouring infrastructure. Also the development project might face stiff competition from other inland container terminals well connected to Dutch ports.

\section{Bottlenecks that the project aims to reduce in the region}

The cooperation with Antwerp port will help to shift some traffic and port activities to Liege Trilogiport. The port will also help to increase the inland waterways modal share and shift traffic from roads in the region and other neighbouring regions.

\section{Overview of co-modality growth and scenarios by 2030}

Upon completion the Liege Trilogiport is expected to realise a high growth co-modality development scenario based on the following reasons provided by the paricipants in the focus group:

- The Liege Trilogiport will facilitate seamless connection between inland waterways, rail and road infrastructure.

- The project scheme includes many dispositions regarding landscape preservation and sustainable development.

- The Trilogiport is close to Liege cargo airport.

\section{Sustainable development scenarios by 2030}

The following radar chart models the scores given during the evaluation process for the Liege Trilogiport project. Moreover, it gives an overview of the significant impact scenarios that the project is likely to have on the transport system that it is a part of by the year 2030 . 


\section{Liege Trilogiport}

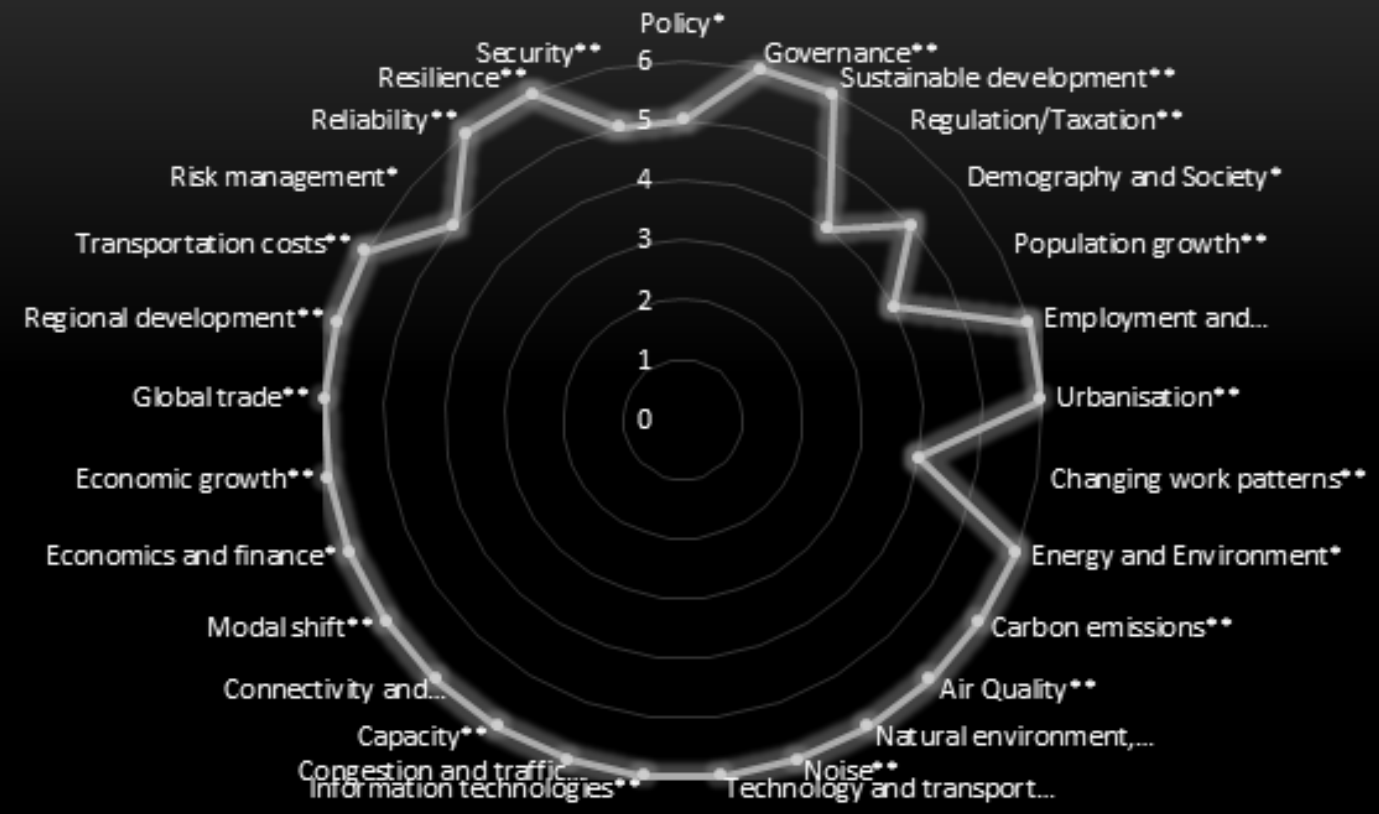

Figure B-25: Radar chart representation of future growth scenario of sustainable development for the Liege Trilogiport project 


\section{The Iron Rhine railway project}

\section{Location and overview of the project}

The Iron Rhine or Steel Rhine railway is a partially nonoperational freight railway connecting the port of Antwerp (Belgium) and Mönchengladbach (Germany) by way of Neerpelt and the Dutch towns of Weert and Roermond.

The main objectives of the project are to:

- Reactivate the shortest railway link between the port of Antwerp and Ruhr region in Germany.

- Relive freight flows from the Montzen axis.

- Modernise the existing infrastructure.

Currently the project's status is ongoing and it will be ready in 2015. The new railway link is funded only from the public sector with a total budget in excess of $€ 100 \mathrm{~m}$. It will provide excellent links with other modes of transport and therefore will have a positive impact on the sustainable development of North West Europe. The project is also a major link between the port of Antwerp and the industrialised region of the Ruhr that will help to increase rail modal share and shift traffic from roads within the NW European region. Upon completion the users and industrial sectors in the region will enjoy the benefits that the project will offer.

More specifically:

\section{Economic benefits:}

- Reduction in transportation costs between Antwerp and the Ruhr.

- The Iron Rhine will help to increase the total tonnage of freight carried between Antwerp and the Ruhr to $15 \mathrm{~m}$ tonnes. 


\section{Transport benefits:}

- Reduction in journey times between Antwerp and the Ruhr region.

- Relieving traffic from the existing Montzen route.

- Shift transport flows from road to rail.

\section{Social benefits:}

- Enhancing security since the project includes replacing level crossings by grade separated junctions.

- Sanitisation of the soil alongside the Iron Rhine.

\section{SWOT analysis with emphasis to congestion and modal shift}

One of the key strengths of this priority project is that it will provide the shortest link between the port of Antwerp and Ruhr region. This will also help to reduce traffic flows around the port. More opportunities will also be created as the project will act as a crossborder corridor linking three countries in NW Europe. However, environmental issues need to be rectified and also the Montzen rail route which runs in parallel to the Iron Rhine, has not yet reached its capacity.

\section{Bottlenecks that the project aims to reduce in the region}

The project will help to shift traffic from roads linking the port of Antwerp to Germany through the Limburg region, crossing the E313, E314 and E34. This should help to reduce traffic congestion around the port of Antwerp.

\section{Overview of co-modality growth and scenarios by 2030}

Upon completion the Iron Rhine railway link is expected to realise a high growth comodality development scenario based on the following reasons provided by participants in the focus group:

- The new road will reduce the distance between the port of Antwerp and Ruhr region by $48 \mathrm{~km}$. 
- It will increase the capacity and the flexibility of the network.

- It will shift flows from road to rail.

\subsubsection{Sustainable development scenarios by 2030}

The following radar chart models the scores given during the evaluation process for the Iron Rhine railway project. Moreover, it gives an overview of the significant impact scenarios that the project is likely to have on the transport system that it is a part of by the year 2030.

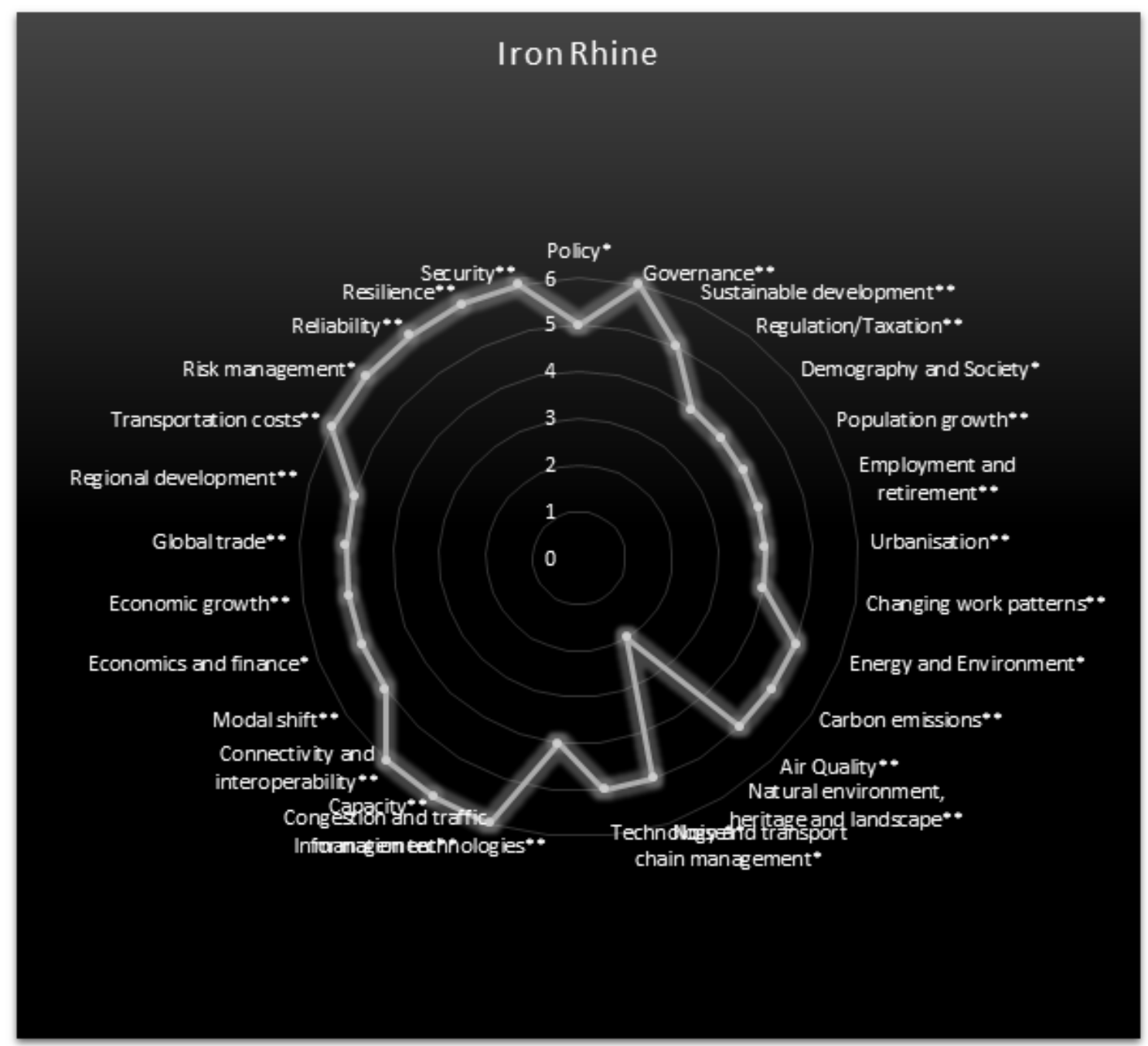

Figure B-26: Radar chart representation of future growth scenario of sustainable development for the Iron Rhine railway project 


\section{The Moselle-Saône-Rhône inland water link project}

\section{Location and overview of the project}

It would produce a European large-vessel waterway between the Saône large-vessel waterway (to the east of Dijon) and the Moselle large-vessel waterway (to the south of Nancy).

The main objectives of the project are to:

- Create an inland water link between the Moselle and Saône on the one hand, and between Saône and Rhône on the other.

- $\quad$ Link NWE inland waterways network to the Mediterranean Sea.

- Open up the Rhone inland waterways network.

Funding comes from the public sector in excess of $€ 100 \mathrm{~m}$. According to participants of the focus group the project will have a positive impact at the megaregion of North West Europe as it will increase IWW modal share and lead to a shift of traffic from the roads. Upon completion the users and industrial sectors in the region will enjoy the benefits that the project will offer. More specifically:

\section{Economic benefits:}

- Opening the Rhone region and French Mediterranean coast economy to NWE Europe and vice-versa.

\section{Transport benefits:}

- The project will create a direct IWW link between NWE inland waterways and the Mediterranean Sea.

- The canal will open up the Rhone inland waterways network and link it to the European network.

- The project will add a new, shorter and sustainable corridor between the major ports of the North Sea and the Mediterranean basin. 
- The project will connect numerous multimodal inland ports linking the inland waterway to other modes.

- Opportunities for the Mediterranean ports (Marseille) to extend their hinterland.

\section{Social benefits:}

- The project will boost economic activity alongside the corridor and thus, generate jobs.

\section{SWOT analysis with emphasis to congestion and modal shift}

The SWOT analysis carried out by participants of the focus group revealed that the project's main strong point is that it is linking two major economic activity areas in Europe (NWE and Rhone region). However, the air-draft which is limited to 3 containers layer (and only 2 while crossing Lyon) is proving to be a major weakness. Nevertheless, there are many opportunities as the inland waterways in the region are increasingly used thanks to its competitiveness, unused and affordable capacity, and soaring oil prices. Threats are identified from the rail transport competition and more specifically the European Rail Freight Corridor C2.

\section{Bottlenecks that the project aims to reduce in the region}

The project will help to shift traffic flows, crossing Benelux and the Lorraine to Rhone region and the Mediterranean coast, from roads to inland waterways. Also, it will decongest the A7 and A9 motorways in France, which are expected to reach their capacity by 2025 .

\section{Overview of co-modality growth and scenarios by 2030}

Upon completion the Moselle-Saône-Rhône inland water link project is expected to realise a high growth co-modality development scenario based on the following reasons provided by participnats of the focus group: 
- The project will create a network of interlinked inland multimodal ports in NWE and the Rhone region.

- It will attract flows from other Mediterranean countries (Spain, Italy) toward Benelux and North Sea major ports.

- It will enhance sustainable development.

\section{Sustainable development scenarios by 2030}

The following radar chart models the scores given during the evaluation process for the Moselle-Saône-Rhône inland water link project. Moreover, it gives an overview of the significant impact scenarios that the project is likely to have to the transport system that it is a part of by the year 2030 .

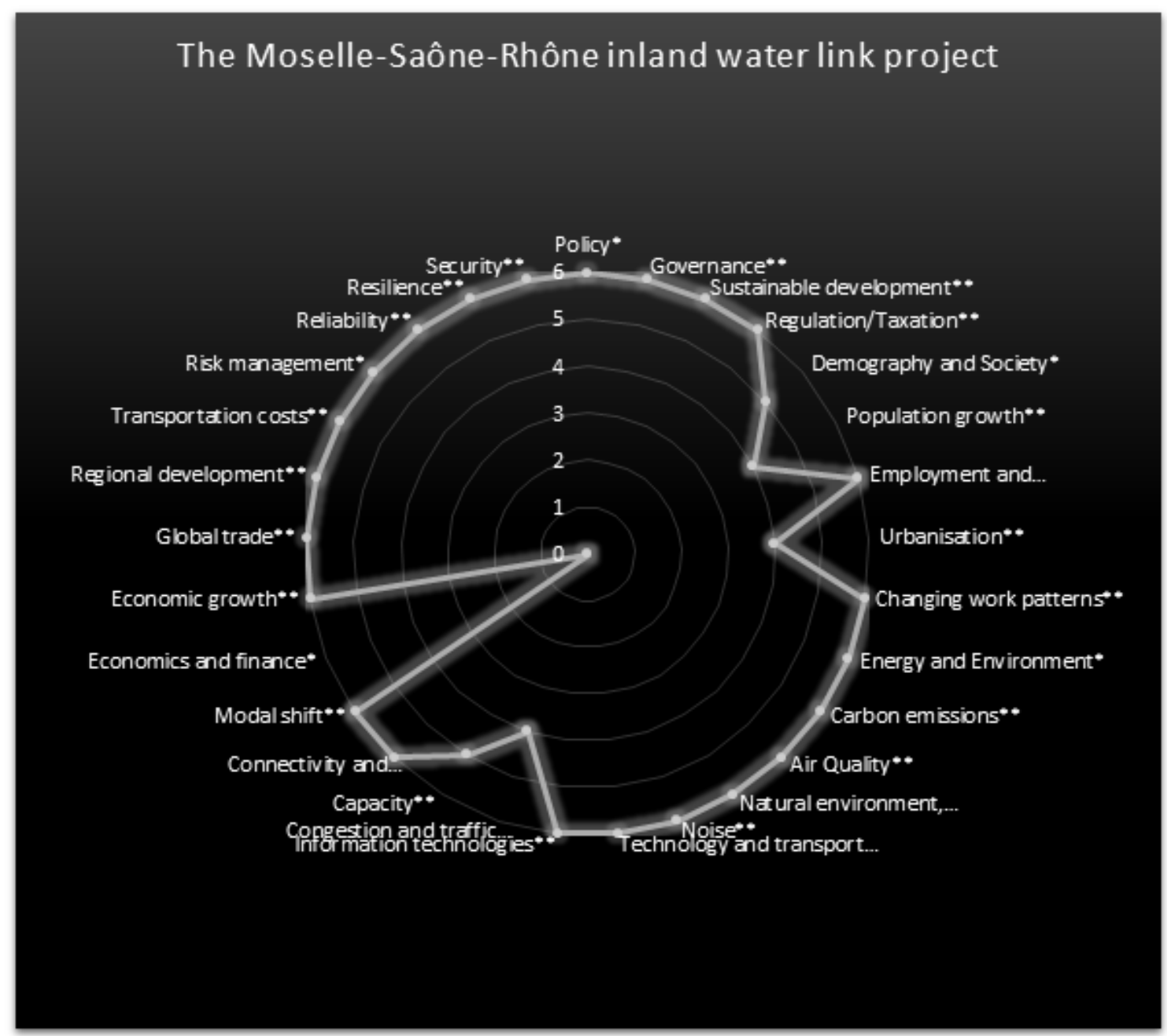

Figure B-27: Radar chart representation of future growth scenario of sustainable development for the Moselle - Saone - Rhone inland water link project 


\section{B-5: Regional priority projects in Germany}

\section{The Logistik Ruhr project}

With 5.2 million inhabitants, the Ruhr metropolis is, after Paris and London, the third largest metropolitan area in the European Union. The direct access to the European market within this area.

\section{Location and overview of the project}

The Ruhr metropolis is one of the largest and economically most important centers in Europe. It is the headquarters of 16 of the 100 and 43 of the 500 largest companies in Germany.

World-renowned companies such as RWE, ThyssenKrupp, Evonik Industries, Klöckner, Karstadt, Aldi and Hochtief are hallmarks of the region. Based on a still strong industrial core and a broad base medium, the Ruhr metropolis has developed into a leading technology and service location. In the area of logistics the Ruhr area has the largest transport hub in Europe - an excellent position: 33 of the top 100 logistics companies have their headquarters here; 160,000 employees work in logistics or logistics related industries. Add to this, there is a prime market access to the densest rail networks of roads, waterways and railways in Europe. This project enhances logistics competencies in the Ruhr metropolis. Therefore the project will increase capacity and will facilitate freight flows. The project also works on a concept for greener logistics and its current status is ongoing.

\section{SWOT analysis with emphasis to congestion and modal shift}

The SWOT analysis carried out by participants of the focus group revealed that the Ruhr regional logistics project benefits the region of Duisburg Lower Rhine as it has been established the Europe's largest inland port in Duisburg in particular as a logistics hub, of the northern ports. Due to the convenient location on the central trans-European transport axes and the supply of space, among other things "logport" has grown from a national hub to an internationally important site for systemic logistics services. However, the 
success of the project depends on the cooperation between the companies within this area. So there's a high level of communication and cooperation, which has to get reduced to certain main objectives and actions. Moreover, the main results of this project are also available for other projects that want to improve logistics in the field of the Ruhr metropolis.

\section{Bottlenecks that the project aims to reduce in the region}

The existing transport infrastructure in the region such as the port of Duisburg, the airport of Dortmund and other intermodal terminals like the port of Dortmund are expected to promote modal shift and to decongest the main road networks.

\section{Overview of co-modality growth and scenarios by 2030}

Upon completion the Logistik Ruhr project is expected to realise a moderate growth comodality development scenario based on the following reasons provided by participants of the focus group:

- Other projects have to implement the results successfully.

- The results of the project aim to improve the intermodal hub in the Ruhr Metropolis. 


\section{Sustainable development scenarios by 2030}

The following radar chart models the scores given during the evaluation process for the Logistik Ruhr project. Moreover, it gives an overview of the significant impact scenarios that the project is likely to have on the transport system that it is a part of by the year 2030

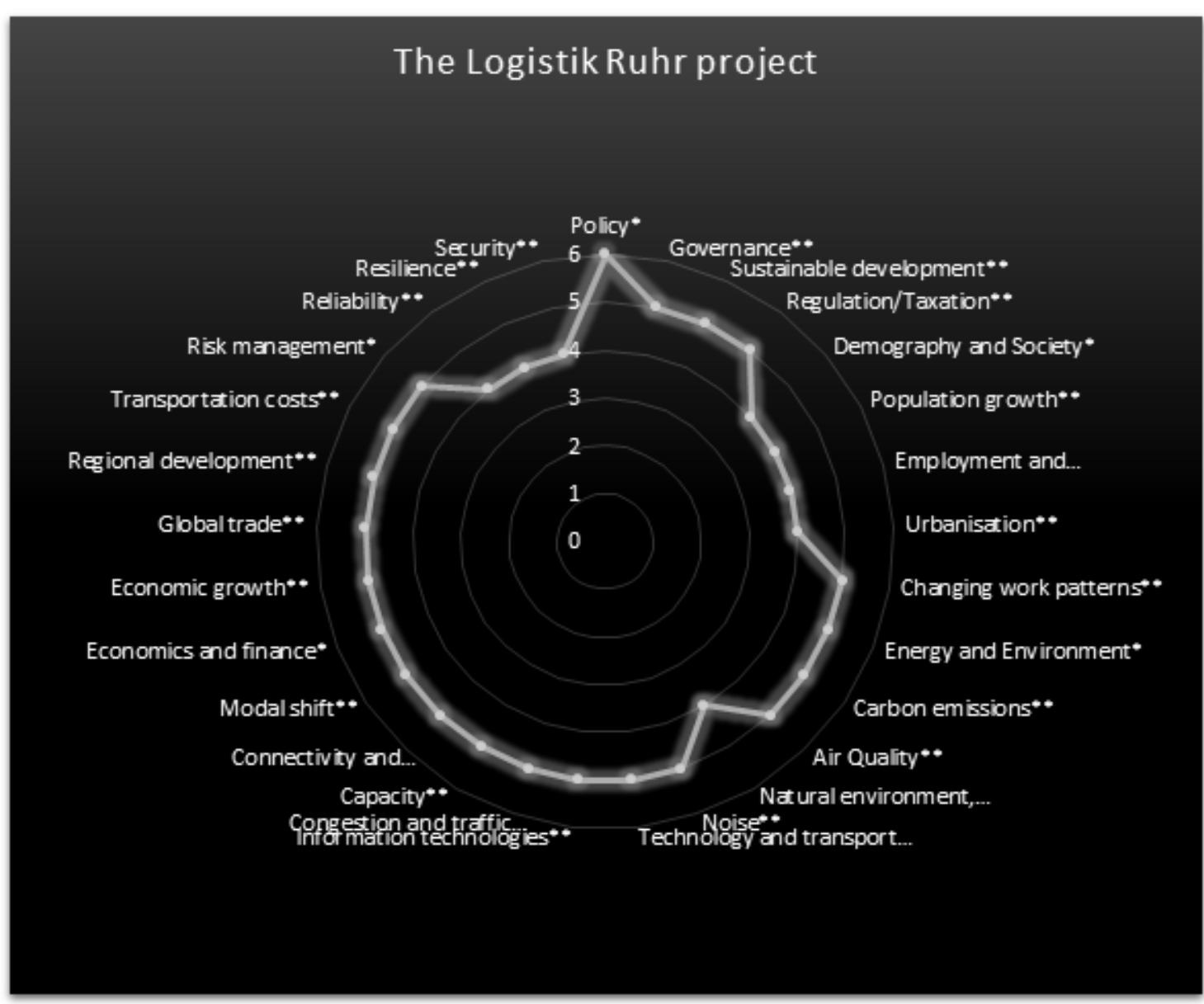

Figure B-28: Radar chart representation of future growth scenario of sustainable development for the Logistik Ruhr project 


\section{B-6: Regional priority projects in Holland}

\section{$\underline{\text { Zuid }}$}

\section{Location and overview of the project}

The overall objective of the project is to improve accessibility to the South East Brabant region by water and stimulate intermodal freight transport over water.

The project consists of several subprojects like adjusting the location/route of the ZuidWillemsvaart around the city of 's-Hertogenbosch, widening the canal at Den Dungen and Veghel and building new locks. In 2005 the national government together with the region developed a vision on making the region of southeast Brabant accessible for class IV ships. A three-layer container ship can potentially replace 100 freight trucks on the road. This is a substantial contribution to sustainable transport.

By the end of 2014 the last big projects (adjusting the route of the Zuid-Willemsvaart nearby 's-Hertogenbosch and widening the canal between Den Dungen and Veghel) will be finished and the canal will be accessible by class IV ships. The project is funded both from the private and the public sector in excess of $100 \mathrm{~m}$ Euros. The project is expected to have a positive impact on the sustainable development of the emerging megaregion of North West Europe as it will increase the accessibility of a canal in the heart of Northwest Europe for larger ships. This stimulates more green forms of freight transport, increases capacity and will facilitate freight flows between the Rotterdam port and the Dutch/German hinterland (East- west).

Upon completion the users and industrial sectors in the region will enjoy the benefits that the project will offer. More specifically:

\section{Economic benefits:}

- The project will provide a substantial boost to the economy of Brabant. 
- Many companies in Southeast Brabant are increasingly making use of the Brabant channel system for the supply and delivery of goods.

- Transport costs will be lower for (transport) companies.

\section{Transport benefits:}

- Fewer trucks on the road (reduction of 460 trucks).

- Less congestion (a study showed a potential of 1.2 million tonnes of bulk and 50,000 TEU that could be replaced by waterborne transport (reduction of 150.000 truck movements a year).

\section{Social/Ecological benefits:}

- Fewer CO2 emissions

- New urban developments possible in the city of "s-Hertogenbosch because of the adjustment of the canal route out of the inner-city of 's-Hertogenbosch.

\section{SWOT analysis with emphasis to congestion and modal shift}

The SWOT analysis carried out revealed that the Zuid-Willemsvaart project will improve the intermodal transport options for companies in South-East Brabant and thereby potentially reduce road transport on heavily used (and during peak hours congested) highways like the A2, A58 and A67. The improvements on the Zuid-Willemsvaart are done on the northern part of the canal which results in a canal that is only accessible for class IV ships from the northern side. The Zuid-Willemsvaart has a connection with the river Maas on the southern side. By improving also the southern part of the canal the south East part of the Netherlands gets a better connection with the European hinterland. By investing and expanding terminal facilities along the Zuid-Willemsvaart the possibilities of the expanded canal can utilized more. There are plans for expanding the highways A58 and A67, which creates a solution to the congestion and makes the option for road transport cheaper and more reliable. 


\section{Bottlenecks that the project aims to reduce in the region}

Upon completion the project will resolve the following bottlenecks:

- The narrow canal through the city of 's-Hertogenbosch is a key bottleneck for the inland shipping.

- The capacity of the necessary locks in the canal was a bottleneck.

- The lack of wideness and depth of the canal between Veghel and Den Dungen was a bottleneck for bigger ships.

\section{Overview of co-modality growth and scenarios by 2030}

Upon completion the Zuid-Willemsvaart project is expected to realise a moderate growth co-modality development scenario based on the following reasons provided by the respodent:

- The canal provides new intermodal transport possibilities for an economic important region.

- Inland shipping always has to compete with road transport as the region has very good road accessibility towards all directions.

\section{Sustainable development scenarios by 2030}

The following radar chart models the scores given during the evaluation process for the Zuid-Willemsvaart project. Moreover, it gives an overview of the significant impact scenarios that the project is likely to have to the transport system that it is a part of by the year 2030 . 


\section{Zuid-Willemsvaart}

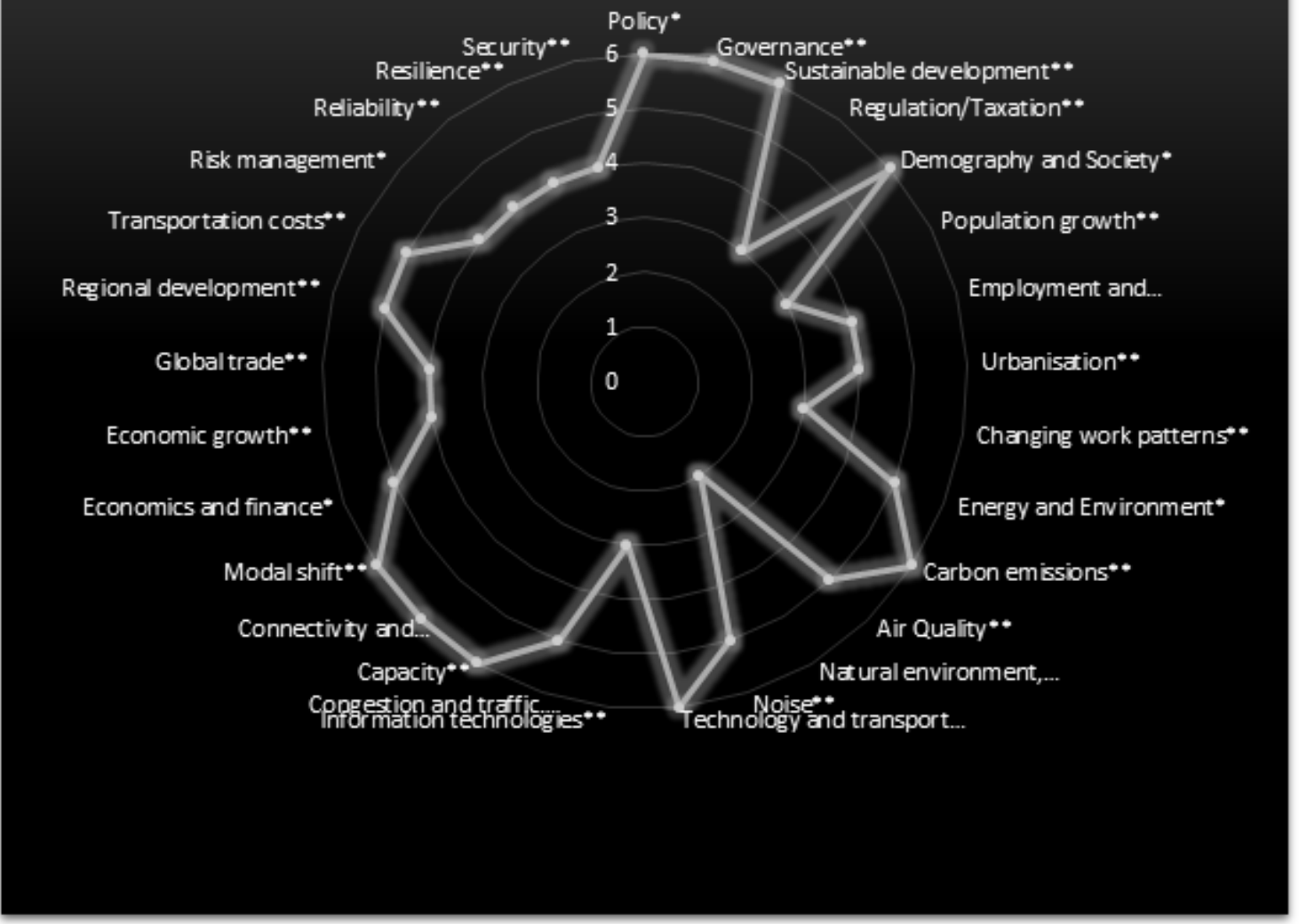

Figure B-29: Radar chart representation of future growth scenario of sustainable development for the Zuid project 